\title{
An investigation of supports and barriers experienced by students with learning disabilities as they transition to and persist in the postsecondary setting
}

\author{
Shawn Mahoney Kuba
}

West Virginia University

Follow this and additional works at: https://researchrepository.wvu.edu/etd

\section{Recommended Citation}

Kuba, Shawn Mahoney, "An investigation of supports and barriers experienced by students with learning disabilities as they transition to and persist in the postsecondary setting" (2006). Graduate Theses, Dissertations, and Problem Reports. 4243.

https://researchrepository.wvu.edu/etd/4243

This Dissertation is protected by copyright and/or related rights. It has been brought to you by the The Research Repository @ WVU with permission from the rights-holder(s). You are free to use this Dissertation in any way that is permitted by the copyright and related rights legislation that applies to your use. For other uses you must obtain permission from the rights-holder(s) directly, unless additional rights are indicated by a Creative Commons license in the record and/ or on the work itself. This Dissertation has been accepted for inclusion in WVU Graduate Theses, Dissertations, and Problem Reports collection by an authorized administrator of The Research Repository @ WVU.

For more information, please contact researchrepository@mail.wvu.edu. 
An Investigation of Supports and Barriers Experienced by Students With Learning Disabilities as They Transition to and Persist in the Postsecondary Setting

Shawn Mahoney Kuba

Dissertation submitted to the

College of Human Resources and Education at

West Virginia University

in partial fulfillment of the requirements for the degree of

Doctor of Education

in

Educational Psychology

\author{
Neal Shambaugh, Ph.D., Chair \\ Daniel Hursh, Ph.D. \\ Katherine Glenney, Ed.D. \\ Richard T. Walls, Ph.D. \\ Jaci L. Webb-Dempsey, Ph.D. \\ Department of Advanced Educational Studies \\ Morgantown, West Virginia \\ 2006
}

Keywords: postsecondary students, learning disabilities, postsecondary transition, postsecondary persistence, higher education, accommodations, college transition, college retention, strategies for postsecondary success, barriers to postsecondary success, postsecondary programming for students with learning disabilities 


\begin{abstract}
An Investigation of Supports and Barriers Experienced by Students with Learning Disabilities as They Transition to and Persist in the Postsecondary Setting
\end{abstract}

\title{
Shawn Mahoney Kuba
}

This inquiry investigated supports and barriers experienced by students with learning disabilities as they transitioned to, and persisted in, a four-year liberal arts college setting. The goal of the inquiry was twofold: first, to understand from the perspective of the students themselves, the experience of being in and working through the postsecondary environment, especially what facilitates and what obstructs continued participation; and second, to extrapolate from these data, recommendations to inform postsecondary programming for students with learning disabilities.

Over a 3 year period, two cohorts of students with learning disabilities, transition and persistence phase students, volunteered to participate in semi-structured face-to-face individual interviews for this collective case study. Strategies from the qualitative methodologies of phenomenology and grounded theory were used to analyze, interpret, and synt hesize the data from 33 verbatim transcripts.

Two groupings emerged as a result of the analysis of the transition cohort. Divergent patterns of performance outcomes, behavior, and outlook were revealed even though the average of the number of disabling conditions and the average of the full-scale intelligence quotients were similar for both the ineffective and the effective transition groupings. The students in the ineffective performance grouping revealed the following nonadaptive patterns during the transition to college: inadequate self-understanding and self-management, complicated relationships with authority structures, a reluctance to accept their disabling condition, unconstructive patterns of social functioning, problems adapting to the academic environment, and an inability to manage developing life circumstances. The students in the effective performance grouping revealed the following adaptive patterns during the transition to college: they recognized, appreciated, and followed through on preparative experiences, they integrated socially into the campus community, they were proactive in managing their learning disability, they sought constructive help, they recognized and managed problematic issues, they took a strategy based approach to the transition, and they acknowledged the primacy of learning and graduating. In addition, the students from the persistence cohort described internal and external factors they perceived to facilitate and/or bar postsecondary functioning and uncovered a prototype of internal facilitation for successful postsecondary performance. The knowledge of personal goals and strivings, limitations, strengths, and a mindset supported by self-awareness formed the stage for individual and interactive practice to promote academic, social, and emotional well-being.

These findings are significant because the results imply that identifiable patterns of outlook and behavior make a marked difference in the postsecondary persistence of students with learning disabilities. Instructing students on how they can develop internal frameworks to promote their success is recommended. The findings of this study may be utilized to respond to the problem of lower than normal postsecondary persistence outcomes for this emergent postsecondary population. 


\section{Acknowledgements}

I gratefully acknowledge. . .

My parents, Helen and Joseph Mahoney. . . you probably won't remember this, but when I was a little girl, you knew just the right time to remind me of The Little Engine that Could.

Mike Kuba, thank you for many years of love and support, and for listening to all the major turning points and "aha" moments in this analysis.

Katie Kuba. . . you had confidence I could finish up, you gave me permission to be consumed by the research when I needed to be. . . and for being all I could ever hope for in a daughter.

The students who volunteered to interview. . you were willing to talk with me about the good and the bad. . .your honesty made this project possible.

Robin Belknap. . your help and cheerful disposition kept me going on some really bad days. 


\section{Table of Content s}

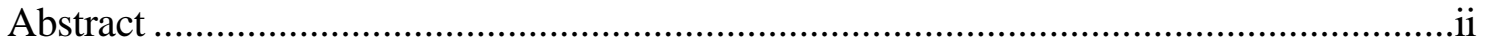

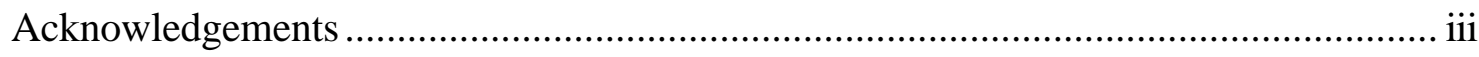

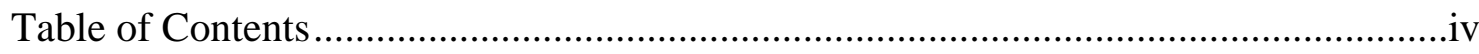

List of Tables ..................................................................................................

Chapter 1: Introduction and Statement of the Problem ..............................................

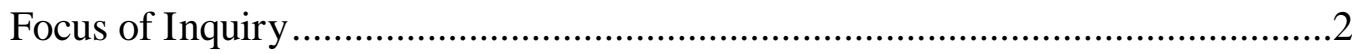

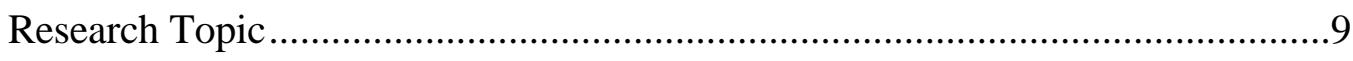

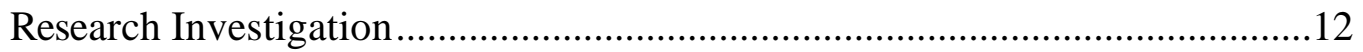

Researcher Assumptions ........................................................................... 14

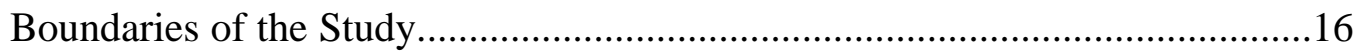

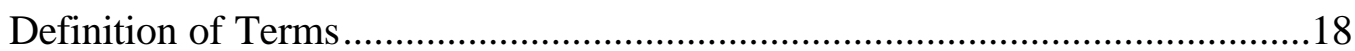

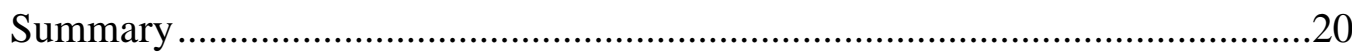

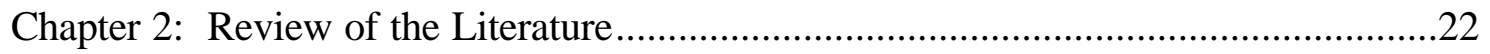

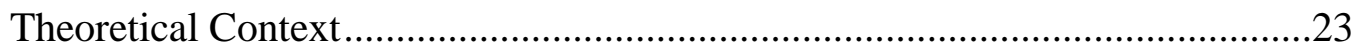

Research Finding on Individuals with Learning Disabilities...........................38

Psychosocial Vulnerabilities of Individuals with Learning Disabilities .............43

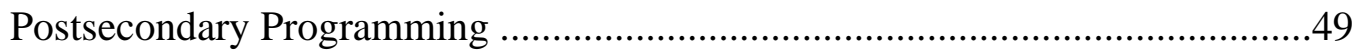

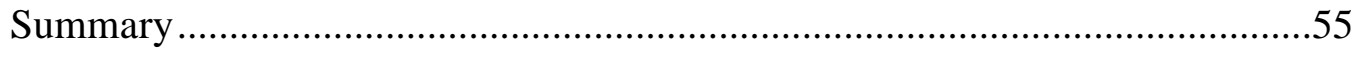

Chapter 3: Research Design and Methodology .....................................................57

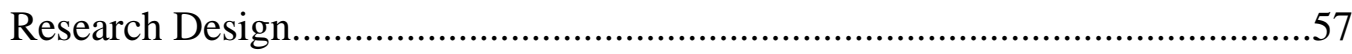

The Qualitative Genre ...............................................................58

The Case Study Approach.............................................................60 
The Phenomenological Approach...........................................................62

The Grounded Theory Approach..........................................................63

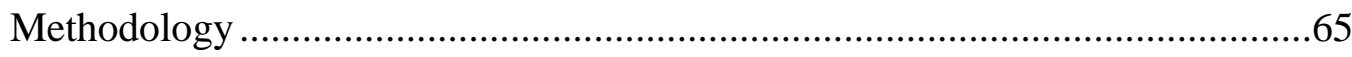

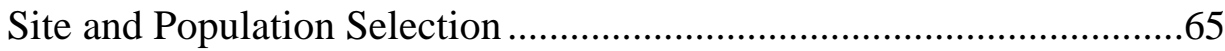

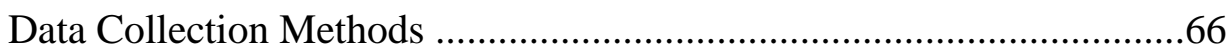

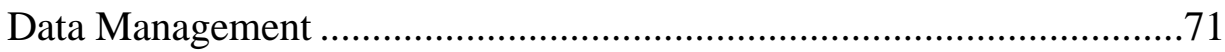

The Role of the Researcher .................................................................

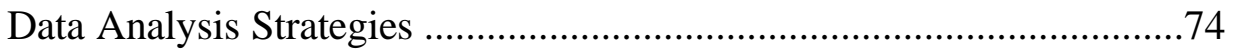

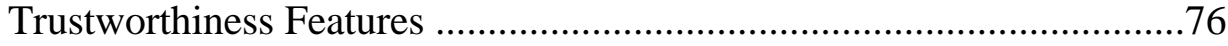

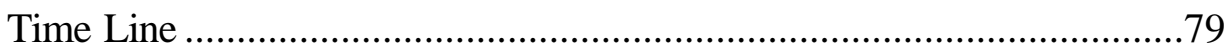

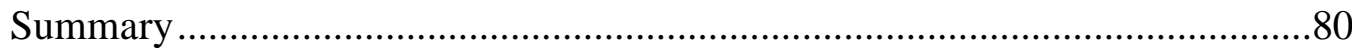

Chapter 4: Transcript Analysis and Presentation of Findings ......................................81

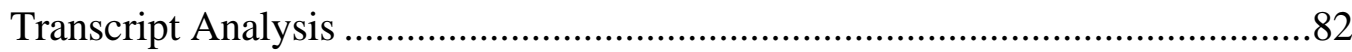

Transcript Cohort Transcript Analysis...................................................82

Persistence Cohort Transcript Analysis ....................................................92

Presentation of the Findings............................................................................99

Negative Collective Case ......................................................................99

Problems with Self-Understanding and Self-Management ........100

Trouble Establishing a Routine.......................................100

The Absence of Follow-Through....................................102

Difficulty Sustaining Effort ...........................................104

Difficulty Organizing Multiple Tasks.............................105

Unclear Personal Goals .................................................107 
Complicated Relationships with Authority Structures 108

Current Intervention of Authority Figures 109

Felt Absence of Past Structures 110

Complex Connection and Separation from Parents ......112

Wishing for External Structure ..................................116

Negative Reaction to the Structure of the Mentor ........118

Problems Related to Disability Acceptance.............................120

Embarrassment over Disability-Related Problems .......121

Conflict and Denial over Acknowledging Needs .........125

Problems Related to Social Functioning .................................129

Constricted Social Interaction.....................................129

Deficient Social Assertiveness.....................................132

Thoughts of Inferiority..............................................134

Difficulty Adapting to the Academic Environment ..................134

Prior Inappropriate Help and Low Expectations ..........135

Insufficie nt Readiness and Preparation........................137

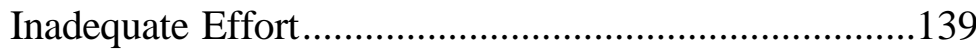

Losing Purpose for Being in College ..........................141

Inability to Manage Life Circumstances ..................................143

Inability to Cope with Everyday Problems ...................143

Denial of Academic Reality.......................................145

Lessons Learned from Failure: Denouement ...............................147

Summary of Negative Collective Case ........................................153 
Recognition of Preparative Experiences .....................................164

Experiences that Promote Effective Functioning .........165

Significant Figures that Made a Positive Difference ....167

Intentional Programs Designed to Develop Students ...171

Social Integration in the Campus Community ............................174

Sense of Community ........................................................

Proactive Integration..................................................... 180

Proactive Management of the Disability .....................................182

Support Program and Small Community Setting...........183

Important Role of Personal Educational History ...........185

Awareness of Limitations and Compensation ...............189

Active Use of Accommodations and Services ...............195

Benefits and Conflicts of Reasoned Disclosure .............200

Positive Use of Constructive Help ............................................212

A Posture of Active Help-Seeking...................................213

Evaluating the Right Kind of Help .................................216

Utilizing the Special Support Mentor ............................219

Suggestions for Program Improvements.........................224

Acknowledging and Managing Problems ..................................226

Psychological Impact of Disability-Related Problems...227

Problems Adjusting to the College Environment .........237

The Ability to Acknowledge and Correct Mistakes .....244 
Dealing with Problematic Circumstances 250

A Strategy Based Approach to the Transition.

.254

General Strategies for Adjusting to College ................254

Manage Thinking to Adapt .......................................259

Self-Control Strategies ...........................................263

Intra-Cognitive and Social Academic Strategies ..........267

The Primacy of Learning and Graduating ...............................2275

Valuing the Educational Process...............................2275

Prioritizing Academic Work and Effort......................279

Taking Initiative and Personal Responsibility .............283

Establishing Goals and Staying Goal-Directed............287

Inappropriate High School Educational Experiences ................293

Summary of the Positive Collective Case ....................................297

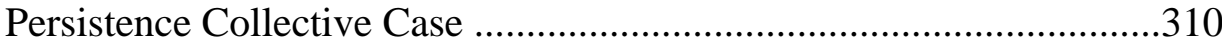

Internal Facilitators for Successful Performance ......................311

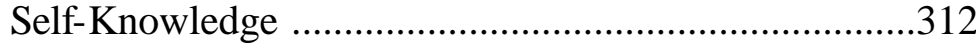

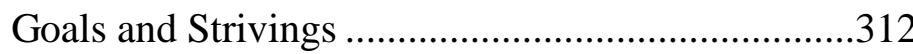

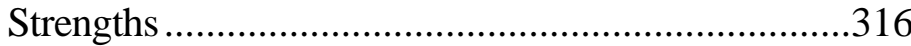

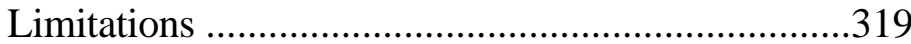

Awareness-Based Outlook .....................................323

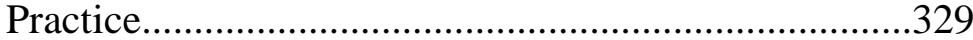

Individual Practice/Academic Well-Being .............329

Interactive Practice/Academic Well-Being.............332 
Individual Practice for Social and Emotional

Well-Being.

Interactive Practice for Social and Emotional

Well-Being

External Facilitators of Successful Performance

344

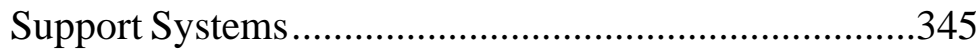

Faculty and Departmental Support ..................345

Special Support Services.................................351

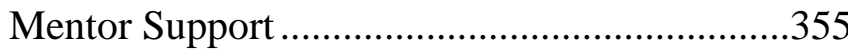

Family Support.............................................358

Peer Support .............................................. 361

Qualitative Factors Supporting Success .......................365

Systemic Qualities of the College .....................365

Individual Qualities of Exemplary Helpers ......367

Internal Barriers to Successful Performance ...........................372

Limitations Imposed by the Disabling Condition..........373

Limitations Grounded in Self-Understanding and

Self-Management

External Barriers to Successful Performance ............................383

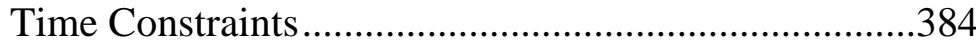

Limitations in Faculty Understanding of Student

Needs

Limitations Related to the Requirements of the

Academic Curriculum .488

Social, Emo tional, and Familial Factors ......................491

Summary of the Collective Persistence Case

.494 


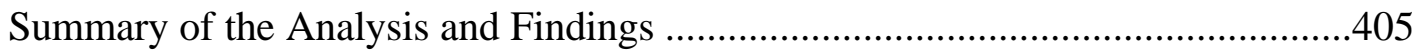

Chapter 5: Summary, Conclusions, and Recommendations .........................................411

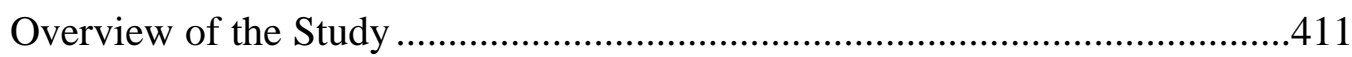

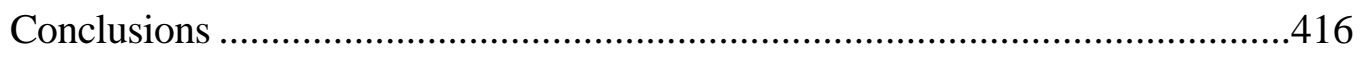

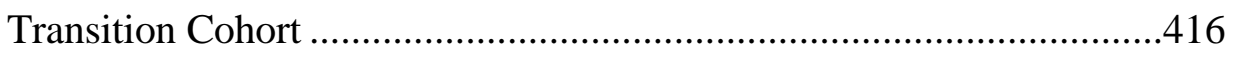

Effective and Ineffective Transitional Approach Compared ....417

Disability-Related Problems ...................................................421

Inappropriate Prior Educational Experiences Disclosed............422

External Facilitators of an Effective Transition.........................423

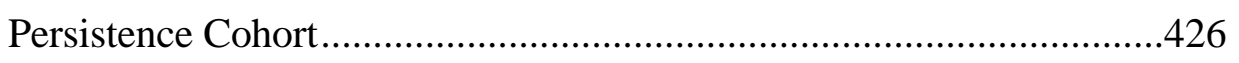

Process of Internal Facilitation for Successful Performance ....427

External Facilitators of Successful Performance …………........432

Internal Barriers to Successful Performance..............................438

External Barriers to Successful Performance..............................441

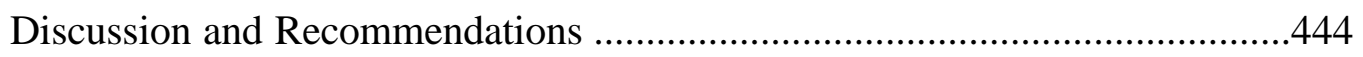

Practical Frameworks for Effective Postsecondary Functioning ...........448

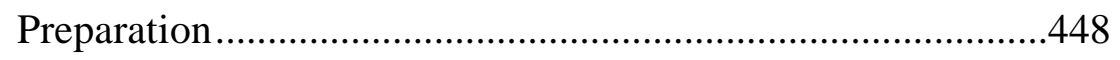

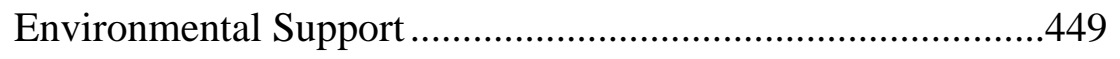

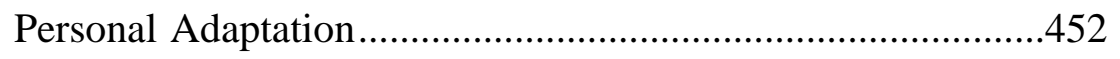

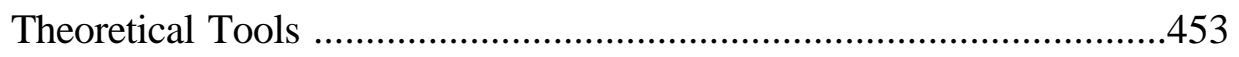

Psychosocial Perspective …………………………………......455

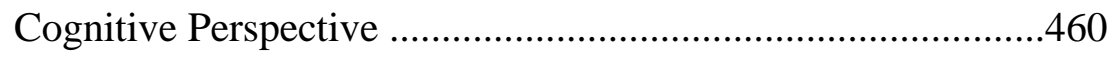

Self-Determination and Self-Regulated Learning......................463 


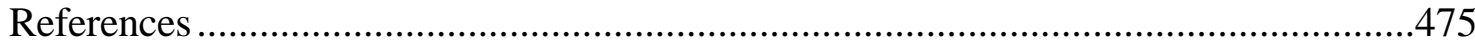

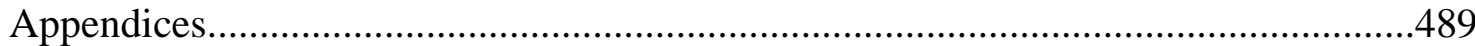

A. Persistence Interview Protocol.........................................489

B. Transition Interview Protocol...........................................492

C. Letter to Potential Persistence Participants ..........................495

D. Letter to Transition Participants........................................497

E. Research Site Approval for Persistence Study ....................499

F. Academic Site Approval Transition Study Extension.........501

G. Research Site Approval for Transition Study Extension ....503

H. Academic Site Approval for Exploratory Study .................505

I. Research Site Approval for Exploratory Study ..................507

J. Academic Site Approval for Dissertation Study .................509

K. Sample Coding Process for Initial Transitional Themes ....511

L. Sample of Coding Process for Persistence Themes ............518

M. Sample of Audit Trail ..........................................................528 


\section{List of Tables}

Table 1: A Comparison of Self-Determination and Self-Regulation Models ................36

Table 2: Transition and Persistence Study Data Collection Table .............................69

Table 3: Transition and Persistence Study: Research Topic by Question .....................70

Table 4: Numeric Background Information on Transition Cohort ..............................89

Table 5: Numeric Background Information on Persistence Cohort............................98

Table 6: Negative Collective Case Findings ........................................................161

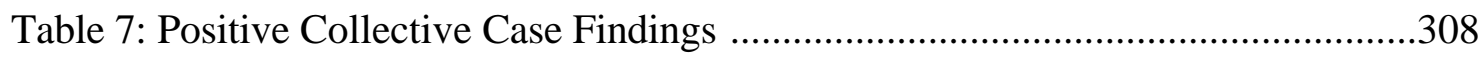

Table 8: Persistence Collective Case Findings ...................................................403

Table 9: Effective and Ineffective Postsecondary Transitional Management ............419

Table 10: Process of Internal Facilitation for Successful College Performance .........430

Table 11: External Facilitation of Successful Postsecondary Performance................435

Table 12: Internal Barriers to Successful Postsecondary Performance .......................440

Table 13: External Barriers to Successful Postsecondary Performance .....................443 


\section{Chapter 1: Introduction and Statement of the Problem}

"Nationwide, students with learning disabilities are the fastest-growing segment of disabled students in college and are part of what some say is the newest wave of campus diversity. Just as laws brought more working-class students, racial minorities and women onto campuses, disabled students are gaining access they were once denied" (Schackner, 2004, p. A16). The American legal system has begun to ensure protection of the civil rights of students who have been diagnosed with learning disabilities within the environment of higher education. However, outcomes for the post-secondary success of these students are weak compared to those of students enrolled in higher education who do not disclose learning disabilities (Wolanin \& Steele, 2004).

This inquiry seeks to investigate supports and barriers experienced by students with learning disabilities as they transition to, and persist in, the college setting. The findings will contribute to a knowledge base, grounded in the reality of the student voice, from which environments of support for this "newest wave of campus diversity" can be thoughtfully constructed. Improved understanding of the barriers and supports experienced by postsecondary students with learning disabilities may translate into higher rates of postsecondary success for this population. The results of the inquiry will be of interest to postsecondary professionals who provide direct service to this population, to those who deliver transition services in the K-12 setting, to college administrators who seek to manage enrollments, to parents of students making the transition to college, and to the students experiencing within the postsecondary setting.

Qualitative methodology is particularly suited to answer the research question because though open-ended inquiry, we can learn about student experience: what the student does, knows, thinks, and feels (Marshall \& Rossman, 1999; Patton, 1990; Strauss \& Corbin, 1998). To 
learn about the experience of transition and persistence in the college setting for the student with learning disabilities, it is appropriate to talk with the student, an insider, going through the process. A semi-structured interview format aims to uncover student perception of the postsecondary experience, determine significant themes of transition and persistence, and reveal strategies and attitudes that promote or inhibit success for this population: phenomena that are not easily observed. The student voice will express major themes that will be used to inform program development.

Entrance into higher education is a relatively new phenomenon for individuals with learning disabilities. A discussion of the legal foundation which has supported the entrance of this population into the postsecondary arena and how these laws have translated into programming follows. For the most part, a literature search on postsecondary programming for students with learning disabilities turned up position papers on best practice. Although valuable to practitioners in the field during its early stages, the professional papers lack academic rigor. Appropriately, there has been a recent call in the literature for data-based field study exploring the experience of this population within the postsecondary setting.

\section{FOCUS OF INQUIRY}

The number of students with learning disabilities attending postsecondary institutions has increased significantly in the last fifteen years. In 1998, 58,000 college freshmen reported having learning disabilities compared to the 18,000 who reported them in 1988 (Heath Resource Center, 1999). The professional field of learning disabilities is young; between 1960 and 1980, learning disabilities became an established discipline in schools throughout the United States (Lerner, 2000). Federal regulations have set the stage for the free appropriate education of children with 
disabilities, and in turn, growing numbers of students with learning disabilities are entering higher education.

Renowned experts in the field of postsecondary service delivery for students with learning disabilities, Brinckerhoff, McGuire, and Shaw, list additional factors that account for the increase in the number of students with learning disabilities entering higher education(2002). Many of these stem from the federal regulations put into place during the last few decades. Increasing numbers of students follow a college preparatory curriculum and have been included in "mainstream" academic environments. Students are taught social and academic compensatory strategies within the public school system. Because students learn advocacy skills as they actively plan for their transition out of high school, they are better prepared to independently navigate the postsecondary environment. Transition and college planning guides specifically geared toward the student with learning disabilities and disability advocacy networks have increased the awareness of the types of college programs and services provided to individuals with learning disabilities. Finally, continued development of assistive technology eases access to college level work for students who have difficulty processing information.

\section{Legislative Background}

Two important laws lay the foundation for educating individuals with learning disabilities during the K through 12 years, The Education for All Handicapped Children Act (Public Law 94-142) and Section 504 of the Rehabilitation Act. Both laws protect the civil rights and prohibit discriminatory and substandard treatment of individuals with disabilities. The Education for All Handicapped Children Act (Public Law 94-142) was established as federal law in 1975. This piece of legislation has been updated, revised, and renamed the Individuals with Disabilities Education Act (IDEA). This legal mandate ensures all children with disabilities, ages 3 to 21, 
have the right to a "free and appropriate public education" specifically designed to meet the unique needs of the child with a disability, regardless of the nature or severity of the disability (Henderson, 2001; Learning Disabilities Association [LDA], 1997).

Additionally, there are some students with learning disabilities in the K-12 setting who do not meet the requirements of coverage under IDEA. The civil rights of these individuals are protected through another law, Section 504 of the Rehabilitation Act of 1973. Section 504 mandates accommodations for "otherwise qualified individuals" with disabilities attending institutions that receive federal funding (Lerner, 2000). Individuals within the sphere of influence of the public school system who have other health related impairments including physical and/or psychiatric diagnoses that are not covered under IDEA are usually protected under Section 504.

Stemming from IDEA and Section 504 are the Individualized Education Program (IEP) and the 504 Learning Plan: a prescription for services, accommodations, and modifications tailored to educate each protected individual with the ultimate objective of preparation for independent living. Parents, teachers, resource room professionals, guidance counselors, and the student (after the age of fourteen) make decisions about educational programming: explicit goals and objectives and appropriate accommodations and modifications are put in place to guarantee equal access to education in the least restrictive setting for each protected individual during the K-12 years (Brinckerhoff, McGuire, \& Shaw, 2002; Learning Disabilities Association [LDA], 1997; Lerner, 2000).

In part, different laws guide the provision of accommodation and service for students with learning disabilities in higher education. Although Section 504 of the Rehabilitation Act of 1973 applies to individuals in the college setting, IDEA does not. IDEA applies to the pub lic school setting and is specifically worded in a way that guarantees initiation and delivery of 
special education services to protected individuals. This is not the case in the college setting (Latham, 1996; U.S. Department of Education Office for Civil Rights, 2002). Institutions of higher education are not required by law to identify and proactively program for students with learning disabilities. Responsibility for identification rests with the student. There is no mandated IEP in college. This shift in initiation of services requires a different outlook and set of operating behaviors for the student with learning disabilities who is enrolled in higher education.

Two pieces of legislation guide the provision and delivery of services to students with LD at the postsecondary level: Section 504 of the Rehabilitation Act of 1973 and the Americans with Disabilities Act (ADA), signed into law in 1990. Both the ADA and Section 504 "cover the vast majority of colleges and universities" (Heyward, 1998, p. 2:1) and make illegal the exclusion of qualified students with disabilities on the basis of their disability. Both laws state that provision of services to students with disabilities must be equal to those provided to non-disabled peers. Protected individuals are those with a physical or mental impairment that substantially limits one or more major life activities (such as caring for oneself, performing manual tasks, walking, seeing, hearing, breathing, learning, or working), have a history of such impairment, or who could be regarded as having such impairment (Kincaid, 1994; Latham \& Latham, 1997).

The rights given to individuals with disabilities by the ADA are similar to those specified under Section 504 of the Rehabilitation Act. The ADA, however, expands protections to individuals with disabilities while they are using privately owned businesses and services, public transportation, and communication (Council for Disability Rights, 1990; Kincaid, 1994). It is important to note that services, auxiliary aids, and academic adjustments provided at the postsecondary level may not fundamentally alter an institutional course, program of study, or curriculum. The postsecondary institution is not required to lower its standards and it can judge 
whether or not an accommodation, service, or auxiliary aid would be an "undue" financial or administrative burden (Heyward, 1998). Students with learning disabilities are protected under both laws; learning is considered a major life activity.

\section{The Postsecondary Setting}

The postsecondary milieu is considerably different than the K-12 public school environment for the student with learning disabilities. The legal system that protects the rights of individuals with disabilities in higher education requires the student to play a different role. In higher education, there is not only the responsibility to identify oneself as having a learning disability, but also to provide documentation of the disability and to actively work with the disability service provider to determine appropriate academic accommodations and services which allow equal access to the educational experience (Brinckerhoff, Shaw, \& McGuire, 1993). Students who are coming into higher education are used to receiving support and resources that parents and educational professionals have initiated since diagnosis. Brinkerhoff, McGuire and Shaw describe the inconsistency between the two environments: "Students with learning disabilities in elementary and secondary schools are often surrounded by a team of special educators, speech and language therapists, counselors, and teachers. Institutions of higher education are not required to provide special programs, and few higher education settings have the luxury of providing comprehensive support services to students with learning disabilities" (2002, pp. 87-88).

The problem of transitioning out of the K-12 education system was addressed by the 1997 reauthorization of the Individuals with Disabilities Act (IDEA). The legislation required intentional programming, beginning at age 14, to facilitate the student's proactive shift to independent living. The regulations mandated that the annual IEP include objectives focusing on 
student aspirations following high school (Learning Disabilities Association [LDA], 1997). It is within this context that the student with learning disabilities has the opportunity to become skilled at the initiation and decision making processes needed to navigate the environment of higher education. Unfortunately, this growing marginal population exhibits a marked deficiency in self-determination skills in the opinion of many postsecondary service providers (Janiga \& Costebader, 2002).

What kinds of post-secondary educational environments are students with learning disabilities going into? How do the laws that protect students in higher education translate to a setting in which the student with a learning disability functions? What do these regulations mean in terms of actual assistance for the student with information processing problems? How do the students who enter postsecondary education fare once they enroll? Beirne-Smith and Deck (1989) found that there was an inconsistent institutional response in program design for students with learning disabilities. Postsecondary institutional reaction to the law and to the increased matriculation of students with learning disabilities progresses from the "bare bones" provision of legally required adjustments to the other end of the continuum: the incorporation of whole programs whose objective is the fostering of academic success for students with learning disabilities (Mangrum \& Strichart, 1997). Guides to colleges for students with learning disabilities have been published over recent years and include descriptions of hundreds of colleges and universities which provide either support services or comprehensive programs serving students with LD (Mangrum \& Strichart, 1997; Wax \& Kravets, 2003).

Each individual with learning disabilities possesses unique processing difficulties. The $\mathrm{ADA}$ and Section 504 require postsecondary institutions to make academic adjustments to provide equal access to the educational environment; however, as stated previously, an 
institution is not mandated to change essential elements in its standards or curriculum (National Joint Committee on Learning Disabilities [NJCLD], 1999). The examination of educational evaluations completed by stipulated licensed professionals guide a case-by-case determination of the most appropriate method of accommodation.

Extra time, a reduced-distraction environment, readers, scribes, and other alternate text formats are common adjustments that allow students with learning disabilities equal opportunity to complete testing for their academic courses. Note takers and/or the ability to tape classes are a necessity for the student who cannot fully participate in the lecture or discussion while simultaneously writing notes. Assistive technology provides alternate text format and a variety of media that aid in information processing. The preceding list enumerates the bare le gal essentials of accommodation. Brinckerhoff, et al. note that "central to the provision of services for students with learning disabilities is the understanding that nondiscrimination comprises more than a menu of services [italics added]. It is a dynamic process of actively considering varying individuals' disability-related needs within the context of the specific post-secondary setting" (2002, p. 296).

The civil rights of the student with learning disabilities have been addressed; entry into and basic accommodation in higher education for the otherwise qualified student is a reality. Even with this legal basis established, more is needed for the individuals in this grouping to persist in the postsecondary environment; what more is the focus of this inquiry.

\section{Transition and Persistence}

Although all students entering college have to navigate the differences between high school and higher education, the difficulty of the transition is magnified for the student with learning disabilities (Adelizzi, 1995; Fisher, 1985; Hicks-Coolick \& Kurtz, 1996). Many leaders 
in the field have written about the complexity of the transition to college for this population (Adelizzi, 1995; Dalke \& Schmitt, 1987; Eaton,1996; McGuire, Hall, \& Litt, 1991; Wren \& Segal, 1985). In addition to experiencing problems with "rapid storage and retrieval of information ... because they experience no outward manifestation of handicaps, they experience credibility problems when seeking assistance ...”(Fisher, 1985, p. 2). In 1989, the National Center for Education Statistics surveyed undergraduates who enrolled in postsecondary institutions. When surveyed again in 1994, 53\% of students with disabilities had acquired a degree or were still enrolled compared to $64 \%$ of their non-disabled counterparts (Horn \& Berktold, 1999). According to the latest figures published by the Institute for Higher Education Policy, the discrepancy still exists: The drop-out rate by 2001 for students with learning disabilities who began college during the 1995 to 1996 school year was $46 \%$ compared to the $33 \%$ attrition experienced by those who had no disability diagnosis (Wolanin \& Steele, 2004).

\section{RESARCH TOPIC}

The following considerations form the foundation of this study. Once a student enters college, how does he or she navigate the transition from a system that is obliged to actively identify, remediate, support, and accommodate to a setting that requires the individual to proactively set up these accommodations and services? How does the student with a learning disability establish academic, social, and emotional supports that create a foundation for success in the environment of higher education? What internal dynamics play a role in the student's transition and persistence? What environmental or external dynamics play a role in the student's transition and persistence?

Experience and intuition inform practitioners about matters with which our students struggle. When postsecondary service providers were asked to describe research topics of 
interest related to the provision of services to students with learning disabilities, the second most frequently asked question related to student perception of support services that facilitated their success (Vogel, Leonard, Scales, Hayeslip, Hermansen, \& Donnells, 1998). The National Joint Committee on Learning Disabilities communicated this multi-contextual challenge several years ago: "Building an academic community responsive to diverse student populations, including students with learning disabilities, benefits the college community as well as society" (NJCLD, 1999, p. 266).

Even though postsecondary programming for students with learning disabilities has burgeoned over the past several years, the educational community continues to build practices on the basis of experience. We have much to learn from the voice of the students who are making the transition and staying in higher education. We who are involved with students at this level keep in touch with our colleagues in similar settings, stay current with research in the field, and work as we practice to identify the supports that create secure learning environments for the student with learning disabilities.

There is no legal mandate that requires supports in addition to the accommodations mentioned earlier in this paper, however, we have witnessed the positive difference that supplementary assistance makes for the student with learning disabilities. Systematic inquiry focused on understanding this growing marginal population may validate our experience and intuition, lead to improvements in our practice, and in turn, support postsecondary student persistence.

What does the existing literature tell us about the needs of students with learning disabilities once they enter the postsecondary setting? There is a marked absence of data driven studies suggesting appropriate programming for this population in the professional literature. 
Several opinion papers offer guidance on the topics of self-advocacy, characteristics of successful students, strategies for determining accommodations, the educational evaluation, appropriate college and course choice, and social adjustment are found in the Educational Resources Information Clearinghouse [ERIC] (Dexter, 1982; Harris \& Robertson, 2001; Hildreth, Candler-Lotven, \& Macke, 1994; Lock \& Layton, 2001; Navicky, 1998; Pagels, 1998; Satcher, 1989). Descriptions of services, appearing in peer-reviewed journals, have provided the basis for program development (Dalke \& Schmitt, 1987; Vogel, 1982). Rath and Royer (2002) conducted a review of the literature to investigate the nature and effectiveness of learning disability services for college students. One of the major conclusions drawn from their findings is the absence of data-based studies exploring the value of these services. The authors found "many descriptions of programs in the literature but relatively little empirical documentation of program effectiveness" (Rath \& Royer, 2002, p. 377).

In recent years there has been a move to consider a framework of risk and resilience when considering "high risk" individuals such as the student with learning disabilities (Cosden, 2001). The "risk" of having a learning disability may be mediated by protective factors within "broader personal, social, familial, and societal contexts" (p. 353). This perspective impels us to focus on building "protective" environments of support that facilitate the self-regulatory, academic, social, and emotional potential of the student with learning disabilities at the postsecondary level. The authors of the second edition of Postsecondary Education and Transition for Students with Learning Disabilities, Brinckerhoff, McGuire and Shaw (2002), call for continued work in fostering the success of students with learning disabilities in higher education and indicate there is a "widespread need for field-based research on effective interventions and services" for this population (2002, p. 487). 


\section{THE RESEARCH INVESTIGATION}

This inquiry investigated supports and barriers experienced by students with learning disabilities as they transitioned to, and persisted in, the college setting. The findings will contribute to a knowledge base, grounded in the reality of the student voice, from which environments of support for this "newest wave of campus diversity" can be thoughtfully constructed. Improved understanding of the barriers and supports experienced by the student with learning disabilities may translate into higher rates of postsecondary success for this population. The results of the inquiry will be of interest to postsecondary professionals who provide direct service to this grouping, to those who deliver transition services in the K-12 setting, to college administrators who seek to manage and retain enrollments, to parents of students making the transition to college, and to the students under study.

An exploratory study was conducted by the researcher to gain more information about the transition experience of students with learning disabilities. Analysis of 7 semi-structured one-onone interviews revealed the following themes of significance for the first-time, full-time college student with learning disabilities:

1. establishing academic competence and confidence;

2. acknowledging the need for a responsive support system;

3. recognizing the impact of adequate or inadequate academic preparation;

4. appreciating the link with family support and nurturing social connections;

5. navigating the differences between high school and college;

6. establishing internal disciplinary structures;

7. affirming the importance of a strong work ethic and the will to persist;

8. seeking compatibility with the campus milieu; and, 
9. acknowledging concerns over being accepted as normal.

In addition, the exploratory findings suggested that supportive conditions facilitating postsecondary adjustment focused not only on the practical aspects of access to accommodations and services; specific attitudinal attributes of parents, faculty, and support service providers were significant for the students. Transparent investment in student success, empathy, and confidence in the student's ability on the part of these significant players was considered by the interviewees to be instrumental in achieving transition to the postsecondary environment. Noteworthy was the student response to the assistance provided by a professional mentor. One person to link the student to accommodations and services, to help with academic scheduling, to troubleshoot, and to be a sounding board for psychosocial transitional concerns, was repeatedly acknowledged as advancing the transition process. The students in the study recognized the use of scaffolding techniques by parents, teachers, and support service providers as a method of helping that encouraged independence and confidence (Kuba, 2003).

The current study sought to validate the exploratory findings by interviewing more students as they made the postsecondary transition as well as to supplement these findings by exploring supports and barriers encountered by students with learning disabilities who had progressed at least halfway toward a bachelor degree. The inquiry addressed the following areas of preliminary interest, reflected in the semi-structured interview protocols, which are sub-topics of the primary research objective: the investigation of supports and barriers experienced by students with learning disabilities as they transitioned to, and persisted in, the college setting:

- What characteristics of support does the student with learning disabilities find beneficial? 
- From the student's retrospective point of view, what happened in high school and what has happened in the postsecondary environment to facilitate the process of transition and persistence?

- What internal and external challenges does the student with learning disabilities face in the postsecondary environment?

- What qualities are evident in the student with learning disabilities who succeeds in "taking on" the environment of higher education?

- What environmental factors go into making a successful transition to, and ultimately, persistence in, college for the student with learning disabilities?

- What are the common themes of concern for the student with learning disabilities?

Since the qualitative approach inherently permits the emergence of new deliberation as the researcher explores the research topic with the participants and analyzes and interprets the data, the findings of this study have come to reflect information supplementary to the specific answers to the questions listed above, nevertheless, important to the research context. The unit of analysis was the student undergoing the college experience and the center of the investigation was the student perspective and experience once he or she entered the college setting.

\section{RESEARCH ASSUMPTIONS}

Qualitative methodology was particularly suited to answer the research investigation because though open-ended inquiry, the researcher learned about student experience (what the student does, knows, thinks, and feels). To find out about a particular phenomenon, "understanding emerges most meaningfully from an inductive analysis of open-ended, detailed, descriptive, and quotational data gathered through direct contact..." (Patton, 1990, p. 119). 
Qualitative methodology has been used by experts in the field as a means to understand the population under study. "A qualitative approach to research ... can provide a richer understanding of the characteristics, attributes, qualities, and environmental factors that affect the life outcomes of persons with LD” (Goldberg, Higgins, Raskind, \& Herman, 2003, p. 222). The approach differs from the traditional deductive approach in which the researcher decides about major variables before data collection and then tests hypotheses about the variables to confirm them or not (Patton, 1990). Qualitative methods allowed the researcher to penetrate specific issues "without being constrained by predetermined categories..." (Patton, 1990, p.13). To learn about the experience of transition to and persistence in the college setting for the student with learning disabilities, it was appropriate to talk with the student, an insider, going through the process.

Student perception of supports and barriers to transition and persistence in the postsecondary setting were analyzed from verbatim interview narrative. It was the opinion of the researcher that qualitative methodology was the best process for uncovering the phenomenon under study. The researcher held the following assumptions about the strategy used for this inquiry: First, the use of the qualitative interviewing approach expressed confidence that student perspective is meaningful; it clarified the kinds of support needed to assist this growing population in higher education. Second, it was assumed that student s interviewed for the study would be forthcoming in their descriptions. Third, in-depth discussion with a small number of students with the diagnosis of learning disabilities would represent the salient issues for the grouping. Fourth, the researcher believed that analysis, synthesis, and interpretative reconstruction of the interview data would contribute to a broader, deeper, and meaningful understanding of student experience. And finally, the researcher believed that educational 
practitioners and administrators would consider researcher-based findings exploring the characteristics and programming needs of this population to be a viable avenue of improving the outcomes of this unique grouping in the higher educational setting.

\section{BOUNDARIES OF THE STUDY}

As stated earlier, this study was an attempt to gain more information about the experience of students with learning disabilities as they navigated the transition to and persisted in higher education. From this knowledge base, environments of support can be evaluated and further constructed. A phenomenological collective case study approach was used to examine student perception of transition to and persistence in the postsecondary environment. Phenomenological study focuses on the descriptions of personal experience and allows the use of interviewing as a tool for inquiry (Patton, 1990).

The semi-structured interview format uncovered the student perception of the postsecondary experience, determined significant themes of transition and persistence, and revealed strategies and attitudes that promoted or inhibited success in the postsecondary environment for this population: phenomena that were not easily observed. The student voice expressed major themes that were coded, analyzed, and synthesized into meaningful findings. Hopefully, these understanding will be used to inform future program development.

A purposive criterion sampling strategy was employed. All of the participants were students enrolled in a mid-size (1400) four-year liberal arts college who submitted documentation disclosing a learning disability to the disability support program at the research site. Two subsets of students who have been diagnosed with learning disabilities were sent invitations to participate in the study over a period of 3 years: The first grouping was composed of second semester first year full-time students; the second grouping was made up of students 
who earned at least 60 credit hours toward graduation. Existing records accessible to the researcher who is also the director of the disability support program at the research site institution were checked to confirm disability status, academic progress toward graduation, grade point averages, and other pertinent background information. Permission from both the research and academic site institutional review boards was granted to carry out the inquiry (documents included in the Appendix).

The interviews followed the same basic format to obtain data that were "systematic and thorough" (Patton, 1990, p. 281). However, the researcher had the flexibility to use follow-up questioning, when appropriate, to understand student perspective and experience. Interview formats are included in the Appendix. The content of all the interviews was read for broad themes linked with transition and persistence in the postsecondary environment. The data was read several times to confirm theme categories, label sub-themes, and to re-label categories as needed. Subtopics were blended into larger categories. Transcripts were selected and submitted to an expert colleague in the delivery of postsecondary disability services as one method of checking the dependability of the analysis.

The researcher, who is also the director of the disability program at the research site, conducted the interviews and analyzed and synthesized the data for presentation. Generally, the director is not a direct service provider to the students in the program unless a student, a faculty member, or a direct service provider requests consultation. If consultative service was requested from the researcher regarding a student who volunteered to participate in the study, the student's interview transcript would have been omitted from the findings. 


\section{DEFINITION OF TERMS}

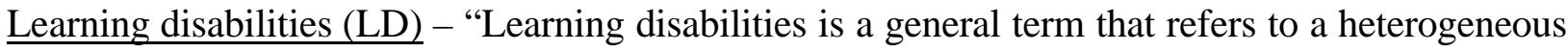
group of disorders manifested by significant difficulties in the acquisition and use of listening, speaking, reading, writing, reasoning, or mathematical abilities. These disorders are intrinsic to the individual, presumed to be due to central nervous system dysfunction, and may occur across the life span. Problems in self-regulatory behaviors, social perception, and social interaction may exist with learning disabilities but do not by themselves constitute a learning disability. Although learning disabilities may occur concomitantly with other handicapping conditions (for example, sensory impairment...) or with extrinsic influences (cultural differences...), they are not the result of those conditions or influences" (National Joint Committee on Learning Disabilities in LD OnLine, 1995, p. 2).

The Individuals with Disabilities Education Act (IDEA) - IDEA is a federal law that protects the civil rights of American individuals with disabilities; it ensures that all children with disabilities, ages 3 to 21, have the right to a "free and appropriate public education" (Learning Disabilities Association [LDA], 1997; Henderson, 2001).

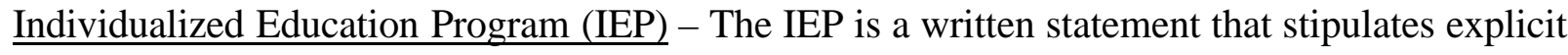
educational objectives and placement of children and youth with disabilities. It is the overall plan to support the student who has been diagnosed with a learning disability during the $\mathrm{K}$ through 12 years (Lerner, 2000).

Section 504 of the Rehabilitation Act of 1973 - Section 504 of the Rehabilitation Act of 1973 is a federal law that protects the civil rights of all Americans with disabilities; the scope of the law reaches beyond the K through 12 setting (Learning Disabilities Association [LDA], 1997). 
504 Learning Plan - The 504 Plan is much like the IEP but not as detailed. It is a general prescription for services, accommodations, and modifications tailored to educate each protected individual with the ultimate objective of preparation for independent living (Lerner, 2000). Americans with Disabilities Act of 1990 (ADA) - The ADA was signed into law in 1990. Both the ADA and Section 504 of the Rehabilitation Act of 1973 "cover the vast majority of colleges and universities" (Heyward, 1998, p. 2:1) and make illegal the exclusion of qualified students with disabilities on the basis of their disability. Both laws state that provision of services to students with disabilities must be equal to those provided to non-disabled peers. Protected individuals are those with a physical or mental impairment that substantially limits one or more major life activities (such as caring for oneself, performing manual tasks, walking, seeing, hearing, breathing, learning, or working), have a history of such impairment, or who could be regarded as having such impairment (Kincaid, 1994; Latham \& Latham, 1997).

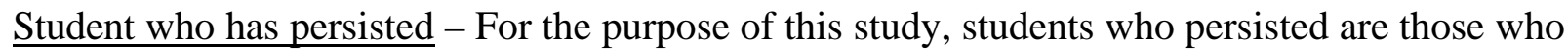
have completed at least 60 credit hours toward a bachelor's degree.

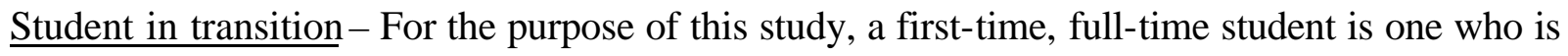
currently enrolled in at least 9 credit hours and who has completed fewer than 30 hours counting toward a baccalaureate degree.

Post-secondary environment/college/higher education-For the purpose of this study, a postsecondary environment is a 4 year accredited institution that grants a baccalaureate degree to students who successfully complete an approved program of study.

Accommodations and services - Accommodations and services are academic adjustments made to provide equal access to the educational environment for a student with a disability; however, an institution of higher education is not mandated to change essential elements in its standards or 
curriculum (National Joint Committee on Learning Disabilities [NJCLD], 1999). Examples of such are extra time, a quiet environment, readers, scribes, and alternate text formats to complete testing, note takers and/or the ability to tape classes.

\section{ORGANIZATION OF REMAINING CHAPTERS}

The remainder of this document is organized into 5 chapters. Professional literature relevant to the post-secondary programming needs of individuals with learning disabilities is reviewed in Chapter 2. Methodological decisions made by the researcher and the processes of this qualitative inquiry are detailed in Chapter 3 . Chapter 4 portrays and illustrates salient themes expressed by the population under study. Chapter 5 summarizes the findings, draws conclusions from the inquiry, connects the findings with current issues revealed in the professional literature, and recommends postsecondary program development grounded in the substance of what has been learned from the student participants.

\section{SUMMARY}

Increasing numbers of students with learning disabilities are entering higher education. Although the issue of civil rights has been addressed, postsecondary outcomes of this population are poorer than that of their non-disabled peers. The complexity of the college environment requires a new level of personal and academic regulation that is challenging for all students. Rates of persistence have shown that the student with learning disabilities has magnified difficulty adjusting and building resources within the context of higher education. In general, postsecondary programming design for the student with learning disabilities is focused on legal accommodation. There are some programs that provide comprehensive services; however, they are mostly fee-based and available to a privileged few. 
Although the number of data driven studies appearing in the professional literature is increasing, for the most part, a search on postsecondary programming for students with learning disabilities turned up position papers on best practice. Appropriately, there has been a recent call in the literature for field study exploring the experience of this population within the postsecondary setting. Since entrance into higher education is a relatively new phenomenon for individuals with diagnosed learning disabilities, exploratory study was appropriate to understand the needs of the population. Investigation of supports and barriers experienced by students with learning disabilities as they transition to and persist in the college setting will add to the knowledge base upon which to structure programming for this growing population. From these findings, stronger educational communities of support can be developed. Stronger support may transfer into higher rates of success for this emergent marginal postsecondary population. 


\section{Chapter Two: Review of the Literature}

All students entering college have to endure the challenge of navigating differences between the environments of high school and higher education; however, the difficulty of managing the college experience is magnified for the student with a disability (Adelizzi, 1995; Fisher, 1985; Hicks-Coolick \& Kurtz, 1996). Many leaders in the field have written about the complexity of the college environment for the student with a learning disability (Adelizzi, 1995; Dalke \& Schmitt, 1987; Eaton, 1996; McGuire, Hall, \& Litt, 1991; Wren \& Segal, 1985). In addition to experiencing problems with "rapid storage and retrieval of information...because they experience no outward manifestation of handicaps, they experience credibility problems when seeking assistance..." (Fisher,1985, p. 2).

Entrance into higher education is a relatively new phenomenon for individuals with learning disabilities. The civil rights of students with learning disabilities have been addressed through the ADA and the Rehabilitation Act of 1973; entry into and basic accommodation in higher education for the otherwise qualified student is a reality. Although programs and services vary in the amount and type of support provision, all postsecondary environments are required to provide some kind of assistance for students with learning disabilities (Brinckerhoff, McGuire, \& Shaw, 2002). Recent discussions in the postsecondary disability literature focus on the general shaping of environments of support and success for students with learning disabilities (Field, Sarver, \& Shaw, 2003; Price, 2002; Skinner, 2004).

Drawing upon the fields of college student development, learning disabilities, and educational psychology, this literature review addresses two objectives: to explore existing knowledge that may be applied to the experience of individuals with learning disabilities in higher education and to provide foundational theoretical constructs which may function as an 
interpretive and synthesizing lattice for the patterns that emerge in the findings of this inquiry (Marshall \& Rossman, 1999). In particular, the review tracks four themes that form the framework of the study: selected theoretical structures that provide the context for encouraging healthy development within the postsecondary setting, empirical knowledge that may facilitate our understanding of college students who have been diagnosed with learning disabilities, an overview of the psychosocial vulnerabilities of the population, and descriptions of empirically based explorations of the postsecondary programming needs of students who have been diagnosed with learning disabilities.

\section{THEORETICAL CONTEXT}

College students move from simple, less formed adolescents to more complex and effective functioning young adults by the time of graduation. Theories of college student development provide descriptions and explanations of how students grow during and because of their exposure to institutions of higher education (Evans, Forney \& DiBrito, 1998). Particularly useful for understanding traditionally aged college students are William Perry's (1981) description of cognitive structural positions and Arthur Chickering and Linda Reisser's (1993) revised theory of identity development. In addition, lesser known theoretical constructs that may apply to building environments of support for students with learning disabilities are reviewed: including Nevitt Sanford's contribution of challenge and support (1966; 1967), Field and Hoffman's model of self-determination (1994), and Barry Zimmerman's model of self-regulated learning (2002).

\section{Identity Development}

Chickering (1969) and Chickering and Reisser (1993) developed a theory of college student development describing psychosocial growth that characterizes traditionally aged college 
students as they move through the postsecondary experience. The theory encompasses intrapersonal, emotional, interpersonal, intellectual, and moral dimensions of college student development. Drawing on Erik Erikson's theory of life span development $(1968 ; 1982)$, Chickering (1969) and Chickering and Reisser (1993) expanded upon the tasks laid out for adolescents and young adults to include the establishment of identity and intimacy. The seven areas of development are called vectors because they "indicate direction and magnitude" (Reisser, 1995). Although the authors state the areas of development build toward and support one another, the vectors do not have to be experienced in sequence. Movement through each phase of development varies in terms of timing and pace because of individual differences. “Chickering's theory provides a comprehensive picture of the developmental tasks college students face. His work not only helps explain the issues and concerns with which students are dealing but also suggests steps that student development educators can take to foster student growth....his theory is easy to understand and use" (Evans et al., 1998, pp. 51-52).

Psychosocial theories help describe developmental concerns individuals face at various points in their lives (Evans et al., 1998). Chickering (1969) and Chickering \& Reisser's (1993) Theory of Identity Development is based on Erik Erikson's $(1968 ; 1982)$ psychosocial view of the developing person (Chickering \& Reisser, 1993). According to psychosocial theorists, development occurs throughout the lifespan in a series of stages that are connected to the age of the individual. Each stage presents with a new "developmental task" as physical and emotional changes intersect with social expectations to create a developmental crisis or turning point. This crisis places the individual off balance and creates the need for the person to do something to adjust to the new life demands. At each juncture the person moves forward or regresses developmentally (Erikson, 1982). Going to college represents a turning point linked with the 
stages of adolescence and early adulthood. According to Erikson(1982), a person's life, in large part, is a result of the choices made at each stage.

A psychosocial theoretical perspective is particularly helpful as a context for understanding postsecondary students with learning disabilities. Many are at risk for developing psychosocial vulnerabilities, especially as they transition away from familiar supports and resources and into the environment of higher education. Individuals with learning disabilities often experience the psychosocial challenges of healthy self-concept and social skill development, dependency issues, and managing emotions related to stress and anxiety (Price, 2002). Another leader in the field, Dr. Sam Goldstein, describes problems that can emerge as a result of living with a learning disability: adolescents and adults experience "stress and anxiety resulting from struggles to meet life's demands, low self-esteem and feelings of incompetence, [and] grief over lack of accomplishments, and helplessness" (1997, p. 236).

The following points of development are described by Chickering and Reisser (1993). The vector developing competence includes movement toward "greater confidence and acceptance of the self as a respectable work in progress" (Reisser, 1995, p. 507) in the areas of intellectual, physical, and interpersonal development. Visual, auditory or kinesthetic processing deficits inherent in learning disabilities often undermine the development of self-confidence. An understanding of how the individual views personal abilities/disabilities will be a valuable asset in exploring the development of competence and the student's adjustment to the college environment.

The vector managing emotions involves the ability to label a range of positive and negative feelings, to recognize their differential intensity, and to make reasoned decisions about their communication. It also incorporates the task of "increasing awareness and acceptance of 
negative emotions as vital sources of information [and] more flexible control of impulses" (Reisser, 1993, p. 507). This is an important area to monitor if the student with learning disabilities is more prone to experience feelings of stress, anxiety and depression than other students (Goldstein, 1997; Price, 2002; Silver, 1984, 1997).

The vector moving through autonomy toward interdependence describes developing "freedom from continual and pressing needs for reassurance, affection, or approval from others" (Chickering \& Reisser, 1993). The individual with learning disabilities is at risk for becoming dependent on parents and teachers (Price, 2002; Spekman, Goldberg, \& Herman, 1992). The student ideally develops self-direction and a healthy need for others; interdependence is a key objective. If the student is to become an autonomous individual, the advocacy and support of significant others must be assumed internally.

The vector developing mature interpersonal relationships involves developing partnerships and friendships "that are consistently rewarding and that last through time, despite crises, distance, or separation" (Reisser, 1995, p. 509) and the ability to acknowledge and accept personal differences. History of educational difficulty may cause the student to over focus on the academic aspects of college at the expense of developing social connections (Kuba, 2003).

The vector establishing identity entails learning and affirming who we are at the foundation. "Any experience that helps students define "who I am" and "who I am not" can help solidify a sense of self" (Reisser, 1993, p. 509). Ideally, an understanding of personal strengths and weaknesses contributes to a healthy sense of personal awareness, which in turn, contributes to optimal everyday functioning. The student should be helped toward acknowledging strengths and weaknesses and to gain an understanding of how these interface with academic, social, and emotional management in the college environment. Higgins, Raskind, Goldberg and Herman 
(2002) discovered five common stages of coming to terms with the disability diagnosis. One of the last two stages, compartmentalization, involves putting the disability into perspective..." the task of this stage is to minimize weaknesses and maximize strengths, both inside and outside the classroom" (p.12). The individual sees his or her learning disability as one aspect of the self, "rather than being defined entirely by it" (p. 6).

The vector developing purpose involves making and staying with intrapersonal, interpersonal, and vocational commitments, in spite of obstacles. Developing purpose can be examined in light of Gerber and Ginsberg's (1990) findings linking the quality of persistence to successful adults who have learning disabilities. Persistence is defined as doing whatever is necessary to accomplish or achieve a goal; this may mean working harder than others. Seeking environments that have a goodness of fit and nurturing social ecologies involves situating oneself to adapt and set up responsive structures for further personal development. Making and staying with commitments involves continual academic, social, and emotional learning; developing a personal system of learning based on knowledge of strengths and weaknesses or learned creativity should facilitate the student's ability to develop purpose (Gerber \& Ginsberg, 1990).

The vector developing integrity includes descriptions of processes similar to the latter stages of college student cognitive development discussed by William Perry (1981), commitment in relativism. Students develop "humanizing values" when they move away from a dualistic (black-or-white/all-or-nothing) cognitive position toward a more relativistic form of thinking that takes the other and many points of view into account. The student is able to simultaneously affirm personal core values while showing consideration for alternate perspectives. "Students develop congruence by aligning their behavior with those personal values in socially responsible ways" (Reisser, 1995, p. 510). In addition, moving from away from a dualistic perspective can 
help repair one's view of self. Just as the student can affirm differences in others, he or she is ready to accept the learning disability as an individual difference that is okay. The student has moved past the "all or nothing" thinking that erodes self-acceptance and no longer believes "I am wrong" because of the learning disability. In this stage, the student can transform her disability into a positive force (Higgins et al., 2002). In addition to developing psychosocial skills, traditionally aged college students' cognitive structures change while they are enrolled in higher education (Perry, 1981). The next section reviews how this happens according to the theory of William Perry.

\section{Cognitive Development}

William Perry is a cognitive-structural theorist (Evans, 2003) who wrote about the intellectual development of young adults (Perry, 1981). Cognitive theories help explain transformations in the way a person thinks. Rooted in the work of Jean Piaget (Chickering \& Reisser, 1993; Evans, 2003), cognitive-structural theorists believe the mind has structures that Piaget labeled "schemas" (Walls, 1999) and Perry called "positions" (Perry, 1981). These structures are sets of assumptions by which persons "adapt to and organize the environment" (Walls, 1999, p. 285). The positions in Perry's theory act as formative lenses for the perception and evaluation of experiences and events (Evans et al., 1998). These structures gradually change, become larger and more complex as the person develops. When conflict is experienced, new information cannot be taken in by the cognitive structure as it exists; this disequilibrium forces the assimilation of the new information into the existing structure or the development of a new structure, accommodation (Chickering \& Reisser, 1993; Walls, 1999). Personal readiness as well as environmental stimulation cause cognitive growth (Chickering \& Reisser, 1993). 
The cognitive theory developed by William Perry describes changes in how college aged students think. "Perry's scheme still has saliency today because the basic underlying structure movement from right-wrong mentality, to one in which multiple viewpoints are experienced as valid, and finally to one in which evaluations of evidence are made in a relativistic world remains viable" (Love \& Guthrie, 1999, p. 13). Although Perry (1981) observed students at nine levels of cognitive growth, four basic concepts are named in his theory: dualism, multiplicity, relativism, and commitment in relativism. Movement along each of the nine positions represents the development of more complicated thought processes; the positions are viewed as "resting points" along a continuum of cognitive growth, culminating in a place of personal affirmation and commitment to an intentional life path, commitment in relativism. This final position is similar to the description of Chickering and Reisser's (1993) latter two vectors, developing purpose and developing integrity. Perry's theory enables us to look at variations in the way college students make sense of the events in their world (Evans et al.,1998) and are instructive in helping us know the type of support we offer to students.

The following description of the four basic concepts in Perry's scheme is developed from the work of Perry (1981), Evans et al. (1998), Chickering and Reisser (1993), and Love and Guthrie (1999). When a student is thinking from the position of dualism, he or she believes an authority (parent, teacher or book) holds the right answer for everything. There is an all or nothing, right or wrong, good or bad (dichotomous) view of the world. Learning, from this position, involves taking in the right answers. Since the world is viewed from this dualistic or dichotomous perspective, the student who has a learning disability may be thinking, not always consciously, that her processing abilities are wrong since she has a disabling condition. Disequilibrium or cognitive conflict occurs when the expectation or the student's previous way 
of thinking is challenged by experience. When a student is exposed to multiple points of view and is able to see that the experts often disagree, a space for transition to the next position, multiplicity, can take place.

In the stage of multiplicity, students are able to accept diverse viewpoints when the right answers are not yet known. "As individuals move through multiplicity, they tend to shift their conception of the role of student from that of one who learns how to learn and works hard to one who learns to think more independently" (Evans et al., 1998, p. 131). The student with a learning disability begins to understand that there is not one right way to process information, that there are multiple ways of learning and understanding. "Rightness vanishes as a standard of evaluation" (Love \& Guthrie, 1999, p. 9) in this stage and all opinions are thought to have equal merit. The transition to relativism can be seen when students understand there is a need to support a point of view.

When a student is thinking from the position of relativism, he or she is able to discern the difference between a well thought out, substantiated opinion and one that is not and is able to critically analyze information to draw her own conclusions. All knowledge has a contextual backdrop. Love and Guthrie (1999) describe the transition to this position as a "radical reperception of all knowledge and values as contextual and relativistic" (p. 12). Mental processing from the position of relativism also requires "the capacity to think about one's own thinking" (Love \& Guthrie, p. 12). At this stage the student with a learning disability is able to reevaluate his or her perception of personal abilities and disabilities. The next stage of student development discussed by Perry, commitment in relativism, "does not become different in terms of cognitive complexity" (Evans et al., 1998 p. 133). 
Commitment in Relativism involves knowing that personal choices need to be made in order to find one's "bearings in a relativistic world" (Love \& Guthrie, 1999, p. 12). An individual makes life-forming decisions regarding vocation, relationships, political beliefs, religious commitments, and life style from a contextual and relativistic framework. If knowledge is relativistic and contextual, then there is not one right way of knowing, not one right way of learning. Having a learning disability is not flawed or wrong, it is a variance. Once a student has reached this position on Perry's scheme, having a learning disability "involves appreciating that the key problem is not the disability itself, but rather the capacity (and commitment) to confront the various challenges one faces in living with it and overcoming it" (Gerber \& Ginsberg, 1990, p. 8) just as one commits to other life tasks.

To this point, major theories of identity and cognitive development have been presented as a background for the understanding traditionally aged individuals enrolled in higher education. In addition, less known theoretical constructs relevant to encouraging healthy development for students with learning disabilities will be reviewed: these include the concepts of Challenge and Support (Sanford, 1966), Self-Determination (Field \& Hoffman, 1994) and Self-Regulation (Zimmerman, 2002).

\section{Challenge and Support}

Considering the right combination of readiness, challenge and support ideally promotes the development of college aged students (Sandford, 1967). The idea of optimal environmental challenge is important because students tend to get overwhelmed and regress if they are presented with situations or tasks that are too far above their current capacities. On the other hand, if there is no stress, there is little or no development. The scaffolding principle provides a meaningful framework as we examine the kind of support that is ideal for growth and 
development in the college setting. Scaffolding "involves a teaching/learning relationship that uses the expert or tutor who intervenes as required and gradually withdraws as assistance becomes unnecessary" (Bukatko \& Daehler, 1995, p. 212). Initially, strong support is given in an individualized manner whe re needed; however, guidance gradually tapers. This approach is compatible with the methodology of the Individualized Educational Plan required in special education. The learner ideally operates within his or her "zone of proximal development" (Vygotsky, 1978), an area in which the student is capable of task participation and, at the same time, stretched to expand competence (Bukatko \& Daehler, 1995). "The most effective assistance from the expert is that just slightly beyond or ahead of [student] capacitie s" (Bukatko \& Daehler, p. 212).

\section{Self-Determination}

In response to disability legislation emphasis on adolescent participation and choice in planning for transition to and within the "next" setting, Field and Hoffman (1994) developed an educational model describing the construct that has come to be known in the disability literature as self-determination (Brinckerhoff, McGuire \& Shaw, 2002; Field \& Hoffman, 1994; Field, Sarver \& Shawn, 2003; Ryan \& Deci, 2000). The authors of the model described selfdetermination as "the ability to define and achieve goals based on a foundation of knowing and valuing oneself. It is promoted, or discouraged, by factors within the individual's control (e.g., values, knowledge, skills) and variables that are environmental in nature (e.g., opportunities for choice making, attitudes of others)" (Field \& Hoffman, 1994, p. 164).

Although the model of self-determination considers "factors which can be mediated by the individual" which "compromise and promote" self-determined behavior, the authors do not describe specific features that impact self-determination, "such as opportunities and supports 
available in the environment" (p. 164). However, Field and Hoffman do not overlook the importance of the setting: "this model is concerned with the way individuals can achieve and maintain self-determination in environments of varying levels of receptivity and support" (p. 164).

Field and Hoffman (1994) hypothesized five basic steps that describe the path to increased levels of self-determination. Based on a foundation of knowing and valuing oneself, persons with disabilities can then plan and act to experience outcomes and learn. The last phase described in the cyclical process leads back to the developing foundation of knowing and valuing oneself. The model is "reciprocally causal" in that it assumes actions that generate "selfdetermination are also expressions of self-determination" (p. 164).

The model of self-determination promotes healthy decision-making, is compatible with psychosocial theory, and provides a framework for moving individuals with disabilities toward healthy and autonomous functioning. Field, Sarver, and Shaw (2003) promote the use of this model with individuals who have been diagnosed with learning disabilities in the postsecondary environment :

Self-determination is an emerging concept in postsecondary services that holds tremendous promise for increased success for students with learning disabilities in postsecondary settings. With further research and broader implementation of selfdetermination practices, this promising concept could become a key program feature that promotes success for students with learning disabilities in postsecondary educational settings (p. 348).

Although the "fleshing out" of the model and the development of supporting curricula have primarily focused on preparing students to transition out of the public school system, it is 
reasonable to extend the construct to guide post-secondary service provision. Once more, Field, Sarver and Shaw (2003) comment on the value of using the model as a resource for improving the outcomes of college students with learning disabilities:

To be successful, college students with learning disabilities need to have a sense of themselves as individuals who make decisions about important matters in their lives. They need to understand and value themselves, and they need to take actions according to responsible plans in order to achieve their academic goals. Finally, they need to exhibit behaviors indicative of reflective thinking and self-awareness consistent with an accurate evaluation of outcomes (p. 343).

\section{Self-Regulated Learning}

Another construct useful in facilitating the understanding and success of college students with learning disabilities is Zimmerman's model of self-regulated learning (2002). Although the model is cumbersome, Zimmerman and his colleagues have been researching various motivational, affective, and behavioral subprocesses and outcomes related to self-regulated learning since 1986 (Zimmerman, 1989, 1998, 2002; Zimmerman, Bandura \& Martinez-Pons, 1992; Zimmerman, Bonner \& Kovach, 1996; Zimmerman \& Martinez-Pons, 1986, 1988, 1990; Zimmermnan \& Schunk, 1989, 2001).

In its simplest form, the self-regulatory process can be described as a three phase cyclical progression including forethought which consists of the mental processing that paves the way for action; performance which involves action to secure intended outcomes; and, self-reflection which refers to the analysis of and personal reaction to the results of the action phase. The selfreflection phase influences subsequent forethought. 
The benefit of including self-regulated learning theory in the discussion of service provision for postsecondary students with learning disabilities lays in the definition of many elusive motivational, affective, and behavioral subprocesses. Zimmerman's model helps to clarify numerous components that play a part in academic performance issues. Zimmerman's most current description of self-regulated learning (2002) categorizes and defines several of these nebulous motivational, affective, and behavioral concepts and positions them in the appropriate phase of the self-regulation cycle. Self-determination (Field \& Hoffman, 1994) and self-regulation (Zimmermann, 2002) may be thought of as complementary constructs; both could be used together to promote effective functioning of college students with learning disabilities. Table 1 summarizes and compares phases and subprocesses of the models of self-determination and self-regulation. 
Table 1

A Comparison of Self-Determination and Self-Regulation Models

Self-determination

Self-regulation

Know yourself

Forethought [stage 1]

Dream

Self- motivation beliefs

Know strengths, needs, preferences

Self-efficacy

Know options

Outcome expectations

Decide what is important to you

Intrinsic interest/value

Learning goal orientation

Value yourself

Accept and value yourself

Admire strengths coming from weaknesses

Recognize rights and responsibilities

Take care of yourself

Plan

Forethought [stage 2]

Set goals

Task analysis

Plan actions to meet goals

Goal setting

Anticipate results

Strategic planning

Be creative

Visually rehearse 
Performance

Take risks

Self-control

Communicate

Imagery

Access resources and support

Self-instruction

Negotiate

Attention focusing

Deal with conflict and criticism

Task strategies

Be persistent

Self-observation

Self-recording

Self-experimentation

Experience outcomes and learn

Real to expected outcome

Self-reflection

Self-judgment

Real to expected performance

Self-evaluation

Realize success

Causal attribution

Make adjustments

Self-reaction

Self-satisfaction/affect

Adaptive defensive response

Note. Adapted from Field \& Hoffman(1994) and Zimmerman (2002). 
The next section of this review will cover empirical studies germane to the experience of the individual who has been diagnosed with a learning disability, another important contextual consideration for this study.

\section{RESEARCH FINDINGS ON INDIVIDUALS}

\section{WITH LEARNING DISABILITIES}

Recent qualitative research that focused on understanding the experience of individuals with learning disabilities contributes to a contextual reference for facilitating the potential of this population in higher education. These works highlight various aspects of what it is like to go through life with a learning disability: stages of disability acceptance, elements that support to resilient functioning, and understandings of attributes that contribute to successful adult functioning.

\section{Stages of Disability Acceptance}

The individual's reconciliation with the learning disability is a factor that may influence the student's success or failure in the college environment. This gradual acceptance is described in the research of Higgins, Raskind, Goldberg and Herman (2002). In a qualitative longitudinal project tracking the lives of 41 individuals with learning disabilities, the researchers discovered five common stages of "coming to terms" with the disability diagnosis. Analysis of interview data uncovered "a shared set of understandings concerning distinct stages" (p. 3) of accepting the diagnostic label.

In the first stage, awareness of a difference, the student observes a personal difference from others in the academic, social, emotional, behavioral, and physical arena even before the diagnosis is made. In addition to this pre-diagnostic awareness, the individual describes a negative self-judgment in relation to others. The labeling event includes all of the events leading 
to the diagnosis or the labeling event. It is a "process whereby parents, doctors, teachers, and other adults were attempting to identify what is wrong Participants at this stage begin to accept the labels that reflect their difficulties, and to reject those that do not. The next stage, understanding/negotiating the label involves making sense out of the label by determining how the label will impact school/life functioning for both the student and significant others. In the compartmentalization phase, the individual puts the limiting conditions into perspective..."the task of this stage is to minimize weaknesses and maximize strengths, both inside and outside the classroom, and contain the disability to classroom situations" (p.12) if possible. The individual sees her learning disability as one aspect of the self, "rather than being defined entirely by it" (p. 6). During the compartmentalization stage, individuals begin to discover or realize strengths and talents and to actively participate in remedial opportunities.

In the final stage of disability acceptance, transformation, the individual is able to view his or her disability in a positive light. Because the person is able to see the disability is "as a positive force" (p. 13) in his or her life, the researchers labeled this stage transformation. This phase is related to what Gerber and Ginsberg (1990) call a reframing of the learning disability: "appreciating that the key problem is not the disability itself, but rather the capacity to confront the various challenges one faces in living with it and overcoming it" (Gerber \& Ginsberg, 1990, p. 8).

\section{Resilience}

The student's history of resilience may come into play as he or she navigates the postsecondary college environment. Maurice Miller (2002) interviewed ten college students who have learning disabilities to try to retrospectively understand the development of resilience in children who have the diagnosis. Although there are several ways of looking at resilience, for the 
purpose of his study, Miller defined the resilient student as one who fit the disability diagnosis and achieved a B+ or better average in his or her major. Six of the students met Millers's definition of resilient; four were diagnosed with learning disabilities but not considered resilient because they did not achieve a $\mathrm{B}+$ or better average in their major. Using data from open-ended interviews, Miller discovered thematic differences between the resilient and nonresilient college student with learning disabilities. Themes in how resilient "individuals saw, in their own histories, the elements which led to their resilience" (p. 293) were:

1. identifiable success experiences,

2. acknowledgement of particular areas of strength,

3. self-determination,

4. distinctive turning points,

5. special friendships,

6. encouraging teachers, and

7. acknowledgement of the learning disability.

Successful Adults

We can learn about strategies students with disabilities may employ to move toward success in higher education from the research of Reiff, Ginsberg and Gerber (1995) and Goldberg, Higgins, Raskind and Herman (2003). Reiff et al. conducted interviews with 71 highly successful adults who have been diagnosed with learning disabilities to discover commonalities in their experience; the following characteristics these individuals shared "represent skills and processes that can be taught and learned" (Reiff et al., p. 29).

The characteristic of taking control was viewed by the participants as the foundation for success. Interviewees believed that gaining or regaining a sense of personal management was 
fundamental to their achievements. "The need for control is the driving force underlying both the internal and external behaviors that are correlated with success" (Reiff et al., 1995, p. 32).

The authors classified the characteristics expressed by the participants as internal and external components of success. The common internal decisions or attitudes that emerged as the participants reviewed their experiences follow: The interviewees had the desire to excel in order to do well. They maintained a goal orientation toward explicit targets that were realistic and focused. Achieving even minimal goals helped interviewees move forward and set more challenging goals. Finally, they were able to reframe their learning disability. This involved "appreciating that the key problem is not the disability itself, but rather the capacity to confront the various challenges one faces in living with it and overcoming it" (Gerber \& Ginsberg, 1990, p. 8). According to the participants interviewed, reframing the learning disability included the following sub steps: recognition of the disabling condition, accepting both the negative and positive aspects of the learning disability, acknowledging and understanding both personal strengths and weaknesses, and acting or making the choice to do something about the “circumstances" of having a disability (Gerber \& Ginsberg, 1990, p. 8).

The following factors are labeled external manifestations of successful adults who have learning disabilities. These features focus on the individual's ability to adapt to the environment. "All the successful adults with learning disabilities adapted so they could excel in a world biased in favor of non-learning disabled persons" (Gerber \& Ginsberg, 1990, p. 10). External components of success were categorized into the following constructs by the researchers: persistence, goodness of fit, learned creativity and the development of social ecologies.

Participants described a sense of persistence in doing whatever was necessary to accomplish a goal; this often meant working harder than others. Goodness of fit meant being 
strategic about vocational decisions. Successful adults pursued careers that "maximized their strengths and minimized their weaknesses" (Reiff et al., 1995, p. 34). In addition, "They chose work environments wisely and created a balance between their ability to adapt to the environment and the responsiveness of the environment to adapt to their needs" (Reiff, et al., 1995, p. 34). Like the students in the study conducted by Reis, McGuire and Neu (2000), the successful adults developed their own way of doing things based on personal strengths and needs. This compensation approach was termed learned creativity and described as "specialized and individual methods for coping and succeeding with the very circumstances previously deemed overtaxing" (Reiff et al., 1995, p. 34). The successful adults in the Gerber and Ginsberg study reported something akin to Chickering and Reisser's (1993) description of interdependent behavior as they established their social ecologies. The participants described surrounding themselves with supportive and helpful people; they were careful to find mentors but resisted becoming overly dependent upon them: “...they often developed interdependent relationships where they returned support by offering their own unique talents" (Reiff et al., 1995, p. 36).

In a 20-year longitudinal study, Goldberg et al. (2003) qualitatively explored the success attributes of individuals with learning disabilities though the analysis of in-depth interviews of 41 informants. The findings of the study support and supplement the work of Reiff et al. (1995). In the eyes of the informants, their successful functioning was attributed to the following characteristics: self-awareness, proactivity, perseverance, appropriate goal setting, effective use of social support systems and emotional stability/emotional coping strategies. The authors of the study note that these factors are "more predictive of success than are academic skills" (Goldberg, et al.). The findings also discredit the notion that individuals grow out of learning disabilities. Learning disabilities exist across the life span and influence multiple aspects of the individual's 
life. Building environments to help students with learning disabilities develop the characteristics found to be "predictive of success" is strongly suggested in the implications section of the study. “Traditionally, the field of LD has focused the majority of its intervention strategies on improving academic skills. . . . individuals with LD need to learn to develop "strategies of success" across the life span, and in multiple contexts" (Goldberg, et al., p. 234).

In addition to learning about the experience of individuals with learning disabilities through the empirical studies that have been summarized, it is appropriate to review the work of medical, educational, and psychological experts who have studied the psychosocial vulnerabilities of this population.

\section{PSYCHOSOCIAL VULNERABILITIES OF INDIVIDUALS}

\section{WITH LEARNING DISABILITIES}

The literature is replete with descriptions of the psychosocial vulnerabilities experienced by individuals with learning disabilities (Fisher, 1985; Goldstein, 1997; Gregg \& Ferri, 1998; Price, 2002; Silver, 1984, 1997, 1999). Beirne-Smith and Deck (1989) surveyed disability service providers at four-year colleges; the concern the professionals expressed for the nonacademic needs of their students was significant. "The same problems that interfere with reading, writing, and arithmetic also interfere with emotional and social development or can cause emotional and social problems" (Silver, 1984, p. 55). In a recent discussion of the topic, Lynda Price (2002) summarized five categories of psychosocial concerns that have been revealed in the professional literature; they are self-concept development, social skills deficits, dependency issues, stress and anxiety, and negative feelings and behaviors. The names of the categories and their descriptions have been reworked to facilitate a practical understanding of how these difficulties develop. 


\section{Critical Self-Concept}

One can imagine how a critical view of the self might develop in the individual who has experienced the sense that something about me is not right over a lifetime. Dr. Larry Silver (1984) explained the development of the critical self in the child with a learning disability as a multiplication of negative social and academic experiences:

They try just as hard [as other children] to learn. Why don't they succeed? Their experiences confuse and frustrate them (p. 58)...Their failures, their inadequacies, and their poor interactions with peers and significant adults leave the child feeling angry and devalued (p. 61)...No one can talk these children out of their selfassessments because the self-image results from a collection of real experiences ( $\mathrm{p}$. 62).

Craig Michaels (1997) observed a similar phenomenon for the individual with a learning disability and suggests that this accumulation of negative learning experience turns in against the self. Any success is experienced as pure chance. The individual has learned to attribute negative experiences to oneself and positive experiences to something out there.

Faulty self-beliefs often contribute to a critical self-concept. Ramsay and Rostain (2004) discuss two examples of incorrect automatic thought patterns that often plague young adults with disabilities. It can be argued these beliefs are applicable to students with learning disabilities given what is known about the psychosocial vulnerabilities of individuals with learning disabilities (Cohn, 1998; Price, 2002; Silver 1997). The first is the tendency to take setbacks personally; the second is to base one's self-worth on the standard of others.

Neilson (2001) conducted a qualitative investigation of eight university students' retrospective perceptions of how their learning disabilities have influenced their lives in general. 
Commonalities found among the participants were "problems in academic skills...needing more time than others, forgetting and misunderstanding, and continued self-doubt" (Neilson, 2001, p. 39). Findings indicate all eight students believe that early diagnosis and awareness on the part of professionals in childhood instructional settings contribute to success.

\section{Social Skills Awareness}

Learning disabilities often impact the individual's social development. Shumaker and Deshler (1995) discovered through their research with adolescents and young adults at the University of Kansas that individuals with learning disabilities are "less socially skilled than same aged peers" and have "difficulty generalizing social skills and social skills strategies" (p. 12-13). Betty Osman (1996) described the phenomenon of social difficulties in her work, No One to Play With. Osman wrote that it is a mistake to attribute social problems simply to classroom or playground disappointments students with learning disabilities experience while they are growing up. She explained that the social problems many experience "are an intrinsic part of the learning disability itself..." (Osman, 1986, p. 1). Information processing deficits can slow down the development of important social skills: inability to quickly discriminate or read the finer points of communication such as voice tone, facial expressions, body posture, and humor impede social competence, and in turn, acceptance by peers and significant others in the student's environment. In addition, Osman highlighted the expressive problems that can interfere with nonverbal communication: an individual can be adept at interpreting incoming verbal and nonverbal elements of communication but fail to self- monitor other nuances of communication such as voice volume and appropriate conversational distance. Osman quotes one of her students in a speech she delivered at the Hill Top conference (1986) to summarize the communication 
paradox of the student with $\mathrm{LD}$ : "Some of us have little to say and say a lot, while others have a lot to say and can't say it (p. 7)."

The Struggle to Become Independent

The student with a history of learning disabilities can become overly dependent on parents for support (Spekman, Goldberg, \& Herman, 1992). College students with learning disabilities often have difficulty trusting their own judgment to make the everyday decisions that are part of independent functioning (Cohn, 1998). "Becoming independent, or moving from being a child toward becoming an adult, means going out from the family and realizing successes and positive experiences on one's own. If the adolescent is insecure, has a poor self-image, and relates poorly with his or her peers, he or she will have difficulty moving away from family and being more independent" (Silver, 1999, p. 117). Individuals manifest their struggle with independence by exhibiting a range of behaviors. On one end of the continuum, a student may show excessive dependence, on the other, a student may fight dependent feelings and cover them up by strongly resisting parental or societal norms. Both reactions show difficulty in establishing independence (Silver, 1999).

The Build-Up of Stress and Anxiety

"Low self-esteem, inadequate social skills and dependency issues usually result in a great deal of ongoing stress and anxiety for adults with learning disabilities" (Price, 2002, p. 143). College students with learning disabilities experienced anxiety as a significant problem in comparison to their nondisabled peers, as measured on scales of current and generalized anxiety (Hoy, Greg, Wisenbaker, Manglitz, King \& Moreland, 1997). An extreme form of stress, hypervigilance, can be the result of natural compensatory strategies gone extreme. Phillip Cohn (1998) composed a compelling description of the stress and anxiety he experienced as a college 
student at Brandeis University. Greg and Ferri (1998) analyze his description. "The author of the narrative 'Why does my Stomach Hurt?' acutely describes his hypervigilence toward his social and academic environments and provides many examples from both worlds whereby he internalized anxiety by obsessing over his perceived failures" (p. 517).

\section{More Extreme Psychological Problems}

Because of their life long vulnerability, persons with learning disabilities are at risk for the development of more complex emotional challenges as well (Rourke \& Fuerst, 1991). Feelings of isolation resulting from poor social interactions and a sense of inadequacy and frustration may lead to the more extreme behaviors of "acting in" or "acting out" (Ostrander, Goldstein, \& Griffin, 1998; Silver, 1984, 1997, 1999). When an individual "acts in" he or she internalizes negative feelings which may surface in the following ways: unhealthy eating or sleeping patterns, psychosomatic illness, or by becoming withdrawn, depressed or even suicidal (Goldstein, 1997, 1999; Ostrander et al., 1998; Silver, 1984, 1997). The individual who "acts out" personal feelings externalizes anxiety and depression by blaming others. This results in the shirking of responsibility for personal actions or in the individual's defiance of authority. A student may "act out" in an effort to numb the pain of the anxiety or depression. Feelings of isolation and the longing for connection can lead to chemical dependency or engagement in high risk sexual behaviors as well (Ostrander et al., 1998; Silver, 1999).

Jane Adelizzi (1995) unraveled the distress of three academically "dysfunctional" postsecondary students by viewing the ir difficulties in the light of Posttraumatic Stress Disorder (PTSD). Aldelizzi presents Posttraumatic Stress Disorder as a "degradation or humiliation that unseats us from our daily routine" (p. 85). In nontechnical language, PTSD is the result of realizing that we cannot trust what we thought we could. Many children start school trusting 
caregivers in their environment. Unfortunately, some come to understand they never should have. Adelizzi (1995) recounts how this could happen:

[When a child is] called upon to deliver answers which are incorrect or inadequate and consequently made to feel 'less than,' and inevitably 'stupid'.... Onlookers observe while this person experiences deep humiliation, degradation and a general sense of disorientation in combination with a variety of physiological symptoms such as sweating, stuttering and a 'sick' feeling. Ultimately, the 'victim' may be rendered silent by his/her sense of helplessness (p. 88).

Aldellizi continues to explain the early experiences that contribute to dysfunctional behaviors: College students who are learning disabled encounter a special kind of struggle in order to survive the abuse that has been dealt them both in and out of the classroom environment. Their coping and adaptive skills are finely tuned; their mental scanning for potentially dangerous and threatening situations is acute....There is no rest. When a child or adult must invest that much energy into surviving from day to day, always on guard for trouble, then it becomes not only physiologically and emotionally wearing, but it often becomes too taxing to concentrate in the classroom (p. 95). The "psychological bruise" with which the child is branded is "uniquely different according to the individual affected" (p. 85) and depends on the person's cognitive perception of the event(s), social and emotional resilience and development, cultural background, and neurobiological makeup. Adelizzi points out that it may be useful to examine the anxiety response on a continuum which begins with the stress phenomenon that interferes with learning or other life functioning and then ranges to the severe anxiety reaction that renders the person helpless. It is common for students with learning problems to feel some stress or anxiety as they struggle to 
process information; however, there are students' whose experiences reach the extreme end of the anxiety continuum. In this case, acknowledgement and exploration with a trained professional can be the key ingredients in healing.

In summary, medical, educational, and psychological experts have observed psychosocial vulnerabilities in individuals with learning disabilities, placing the population at risk for developing specific problems in the following areas: inadequate self-concept and social skills development, increased levels of stress and anxiety, and problems with individuation. These conditions may lead to more severe psychological difficulties and must be considered in a proactive way when planning for this population at any level. The final section of this review will focus on what the literature reveals about postsecondary service provision for students with learning disabilities.

\section{POSTSECONDARY PROGRAMMING FOR INDIVIDUALS}

\section{WITH LEARNING DISABILITIES}

Citing a lack of sufficient knowledge on which postsecondary service providers can plan and implement programming, Mull, Sitlington, and Alper (2001) examined eleven program factors in a meta-analysis of peer-reviewed literature on postsecondary educational services for students with learning disabilities. One important implication drawn from the findings was the call for research based evaluation of "the effectiveness of specific support services" for this population. (Mull, et al., p. 107). In addition, Rath and Royer (2002) conducted a review of the literature to investigate the nature and effectiveness of learning disability services for college students. One of the major conclusions drawn from their findings is the absence of data based studies exploring the value of these services. The authors found "many descriptions of programs 
in the literature but relatively little empirical documentation of program effectiveness" (Rath \& Royer, 2002, p. 377).

\section{Student Preparedness}

The following data based studies explore the issue of postsecondary preparation of students with learning disabilities. Vogel, Hruby and Adelman (1993) investigated the differences between graduated and dismissed undergraduate groupings. Significant findings revealed that the dismissed grouping received more assistance prior to attending college through extended individual tutoring and self-contained classroom placement during elementary, middle and high school. In addition, the findings indicated that the students who were graduated from college enrolled in almost twice as many high school English classes compared to the college students who were dismissed.

Supporting the findings of Vogel, Hruby and Adelman (1993), Strasburger, Turner and Walls (1998) found that students with learning disabilities who had less structure and support within the high school setting had higher postsecondary graduation rates than those who had more structure and support at the high school level. Students from self-contained public and private LD high school settings showed significantly lower college graduation rates than those who were enrolled in public and private schools with no LD services, or than those enrolled in public school with resource room assistance. The authors of this study believe their results support the notion that students perform better in the college setting if they are both supported and guided toward independence while they are still in the high school setting.

The idea of supporting the development of student independence and transition to facilitate postsecondary success was corroborated by the opinions of disability service coordinators surveyed in a study carried out by Janiga and Costenbader (2002). The researchers 
surveyed disability service coordinators to find out about their perceptions of the student preparedness at 74 colleges and universities in New York State. Findings indicated that the coordinators perceived students to be lacking in self-advocacy preparation. In addition, the coordinators had little overall satisfaction with the transition preparation of their students. Openended questioning to uncover the coordinators' suggestions for improving college preparedness for the student with a learning disability included improving students' self-advocacy skills (66.7\%), increasing students' understanding of their disability and specific needs (38.9\%), improving students' study skills (31.9\%), developing student independence from both teachers and parents (24.3\%), ensuring adequate reading and writing skills (18.1\%), and understanding the difference between the laws which govern high school (IDEA) and college (ADA) (18.1\%) before college entrance.

\section{Student Characteristics and Programming Needs}

Forty-nine adults with LD who were graduated from a large university were administered a structured interview by phone for the purpose of understanding the college experience of the student with learning disabilities. According to the participants, personal knowledge about the learning disability, the qualities of determination and perseverance, and emotional support from the family unit, a friend or mentor facilitated success. Lack of understanding and resistance to accommodate the learning disability on the part of faculty and administration represented external obstacles to successful functioning. The informants also reported that internal barriers of low motivation and over-socializing hindered their successful functioning in the college environment (Greenbaum, Graham \& Scales, 1995).

Finn (1999) found that students perceived the disability support service provider as a major influence in their postsecondary experience. The researcher qualitatively investigated 
through focus groups the differences between programs for students with learning disabilities at community colleges, four-year private, and four-year public institutions and student levels of satisfaction with programming. The study was conducted to explore institutional type differences; however there was one finding that related to programming needs of the population under study. It was evident from the focus group response that direct service providers had an “extraordinary impact on the students' perceptions, attitudes, and successes" (Finn, 1999, p. 6).

Compensation of the learning disability, attitudes of help seeking, and strategies used by students with learning disabilities have been as addressed by Reis, McGuire, and Neu (2000). The investigators conducted a qualitative study on twelve high-ability students who were diagnosed with learning disabilities to discover examples of typical problems faced by this subgroup as well as to uncover compensation strategies used by them while enrolled in the postsecondary environment. Among the findings, three important themes became apparent in the data analysis. Each student interviewed had developed a method of compensation that evolved from "the nature of his or her disability [and] his or her personal learning styles and preferences" (p. 130). In addition, the students spent an inordinate amount of "time, effort, and energy" (p. 130) to do well on their schoolwork. Finally, the students in this study expressed a range of comfort/discomfort with respect to use of external types of compensation strategies; examples mentioned in the findings were extended time and the use of a word processor for testing and seeking help.

Hall, Spruill, and Webster (2002) quantitatively compared seventeen college students with learning disabilities and seventeen of their nondisabled counterparts on scores of intelligence, resiliency, stress, locus of control, and the need for achievement scales. The groups did not significantly differ on intelligence or locus of control. Participants with learning 
disabilities scored higher on initiative (one of the resiliency measures) and the need for achievement measures. Surprisingly, non-disabled peers "reported experiencing significantly greater feelings of stress" (Hall, et al., 2002, p. 83) than those with learning disabilities. Noted in the conclusion section of the study are possible explanations for this finding: certain resilience factors protect the college student with learning disabilities against stress, facing more challenges earlier in life has an inoculation effect, and/or the perception and interpretation of stress by the student with learning disabilities is inaccurate. The authors conclude that initiative and the need for achievement may mitigate the risk of having a learning disability.

To gain information about the postsecondary transition experience of students who have been diagnosed with learning disabilities, the researcher of the current study conducted an exploratory qualitative study and formative program evaluation. Analysis of 7 semi-structured one-on-one interviews revealed the following themes of significance for first-time, full-time college students who have been diagnosed with learning disabilities:

1. establishing academic competence and confidence,

2. acknowledging the need for a responsive support system,

3. recognizing the impact of adequate or inadequate academic preparation,

4. appreciating the link with family support and nurturing social connections,

5. navigating the differences between high school and college,

6. establishing internal disciplinary structures,

7. affirming the importance of a strong work ethic and the will to persist,

8. seeking compatibility with the campus milieu, and,

9. acknowledging concerns over being accepted as normal. 
In addition, the exploratory findings suggest that supportive conditions facilitating postsecondary adjustment focused not only on the practical aspects of access to accommodations and services; specific attitudinal attrib utes of parents, faculty, and support service providers were significant for the students. Transparent investment in student success, empathy, and confidence in the student's ability on the part of these significant players was considered by the interviewees to be instrumental in achieving transition to the post-secondary environment. Noteworthy was student response to the assistance provided by a professional mentor. One person to link the student to accommodations and services, to help with academic scheduling, to troubleshoot, and to be a sounding board for psychosocial transitional concerns, was repeatedly acknowledged as advancing the transition process. The students in the study recognized the use of scaffolding techniques by parents, teachers, and support service providers as a method of helping that encouraged independence and confidence (Kuba, 2003).

A qualitative study recently published in the Journal of Postsecondary Education and Disability (Skinner, 2004) revealed factors that impacted the academic success of college students who have been diagnosed with learning disabilities. The researcher used a semistructured interview format to explore the retrospective insights of 20 recent graduates. Eight thematic commonalities were presented by Skinner:

1. "the importance of knowledge of one's disability and concomitant accommodations,"

2. "limited explanation of results of psychoeducational evaluations,"

3. "a dearth of information relating to disability law,"

4. "the importance of self-advocacy,"

5. "the significance of accommodations and course alternatives,"

6. "the importance of support systems," 
7. "the recognition of the need to persevere under challenging circumstances," and

8. "the positive effects of goalsetting"(p. 91).

Skinner concludes his study by calling for more investigation into the phenomenon of success for students who have been diagnosed with learning disabilities in the postsecondary setting: "We are just now uncovering the correlates of success in postsecondary setting for students with LD. Additional studies, both quantitative and qualitative, are required to more fully understand the characteristics of this unique group of learners and to delineate procedures likely to facilitate their positive academic outcomes" (Skinner, 2004, p. 102).

\section{SUMMARY}

A statement made by Elissa Fisher (1985), the founder of a pioneer college preparatory school for student with learning disabilities, calls attention to the compelling issues that continue to surface for this population in the postsecondary environment fifteen years after the passage of the ADA:

Because they exhibit no outward manifestation of handicaps, they experience credibility problems when seeking assistance and find themselves in awkward situations accordingly. As a result, they are emotionally bruised because of the wounds experienced along the way. Their trust level is not high, particularly where educators are concerned. While their self-confidence has been sufficient to get them to college, it is easily eroded" (p. 2).

The current study seeks to understand the nature of internal and external supports and barriers encountered by the postsecondary student with learning disabilities as the college experience is navigated. A review of the literature shows that we are "missing the mark" by focusing merely on the academic remediation and civil rights of these students. The condition of 
learning disabilities is wrought with psychosocial considerations that need attention, at any level, if this specialized grouping is to reach its true potential. In addition, postsecondary outcomes for the student with learning disabilities, compared to the nondisabled student, are low. Empirical knowledge of the student experience will build a foundation for postsecondary program design to promote the wellbeing and healthy functioning of this emergent marginal population. 


\section{Chapter 3: Research Design and Methodology}

This chapter contains justification for the use of qualitative design, in general, and the methodologies used, in particular, to address the topic of inquiry: the investigation of supports and barriers experienced by students with learning disabilities as they transition to, and persist in, the college setting.

\section{RESEARCH DESIGN}

"Purpose is the controlling force in research. Decisions about design, measurement, analysis, and reporting all flow from purpose" (Patton, 1990, p. 150). Gay and Airasian (2003) conceptualized basic and applied research on a single continuum and discussed the classification of any given study by the degree to which the findings are applicable (applied) or generalizable (basic). Patton (1990) characterized basic research as "knowledge for the sake of knowledge" (p. 152) and described applied research as inquiry focused on "human problems" (p. 153). Applied research has as its source "problems and concerns experienced by people" and, as its goal, the generation of "potential solutions" to these problems (Patton, 1990, p. 154).

The topic of this study, discovering and understanding the supports and barriers students with learning disabilities experience as they navigate the postsecondary environment falls within the boundaries of applied research. The findings of this study may be utilized to respond to the problem of lower than normal postsecondary persistence of these students. The goal of the inquiry is twofold: first, to understand from the perspective of the students themselves, the insiders, the experience of being in and working through the postsecondary environment, especially what facilitates and what obstructs continued participation; and second, to extrapolate from these data, recommendations to inform programming. 
Gay and Airasian (2003) endorse the use of qualitative methodology as a viable tool of inquiry designed for certain types of research problems. Maintaining that differences in research objectives should generate the use of diverse methodologies, Gay and Airasian discuss the importance of considering purpose as the foundation of methodological decision: “. . . some [research] questions require a large sample of people to provide data. ... Others focus in-depth on the performance or activities of a small number of people to provide data. ..." (p. 6). The qualitative genre is the design that flows from the research problem framed here because it "attempts to understand the meaning or nature of experience of persons with problems [and] lends itself to getting out into the field and finding out what people are doing and thinking" (Strauss \& Corbin, 1998). More specifically, the inquiry draws upon the qua litative typologies of case study, phenomenology, and grounded theory to form the design, analysis, and reporting for the study.

This chapter is concerned with the discussion of design methodology decisions made by the researcher. It will begin by describing the qualitative genre and the specific typologies used to form the study. Then, the chapter will delineate specific processes that were used, based on the typologies described, to carry out the study.

\section{The Qualitative Genre}

"[The] essence of qualitative inquiry is paying attention, being open to what the world has to show us, and thinking about what it means" (Patton, 1990, p. 140). Qualitative research provides "in-depth descriptions of unique settings and people" (Gay \& Airasian, 2003, p. 21). Gay and Airasion (2003) explained that qualitative research as a genre rejects the view that reality reflects a "stable, coherent, uniform world" (p. 9). Instead, the meaning of reality, for the qualitative researcher, is situated in context or is socially constructed (Merriam, 2001; Patton, 
1990). It is this philosophical perspective that influenced the qualitative response to research inquiry. Strauss and Corbin (1998) defined the methodology as a "nonmathematical process of interpretation, carried out for the purpose of discovering concepts and relationships in raw data and then organizing these into a theoretical explanatory scheme" (p. 11). Rather than beginning with a preconceived paradigm, the qualitative researcher starts with an area of study and lets emerging data that "is more likely to resemble the reality. . . offer insight, enhance understanding, and provide a meaningful guide to action" (p. 12).

"Qualitative researchers are interested in understanding the meaning people have constructed, that is, how they make sense of their world and the experiences they have in the world" (Merriam, 2001, p.6). Patton (1990) emphasizes that "understanding" is the end goal of qualitative research. Qualitative methodology is particularly suited to answer the research question posed in this study because though open-ended inquiry, we can learn about student experience (what the student does, knows, thinks, and feels). To find out about a particular phenomenon, "understanding emerges most meaningfully from an inductive analysis of openended, detailed, descriptive, and quotational data gathered through direct contact ..." (Patton, 1990, p. 119). This methodology differs from the deductive approach in which the researcher decides about major variables before data collection and then tests hypotheses to verify or discount them.

Merriam (2001) summarized the salient features of qualitative research. First, qualitative methodology focuses on understanding the "phenomenon of interest from the participants' perspectives" (p. 6). Second, "the researcher is the primary instrument for data collection and analysis. Data are mediated through this human instrument..." (p. 7). Third, the research process involves going into the field to understand the phenomenon under study in its natural setting. 
Fourth, qualitative researchers use an inductive approach: this means that the details in the data are extracted, classified, synthesized, and interpreted for the purpose of abstracting meaningful concepts or theories. "Qualitative researchers build toward theory from observations and intuitive understandings gained in the field" (p. 7). And finally, "words and pictures rather than numbers are used to convey what the researcher has learned about a phenomenon" (p. 8). Direct quotations capture the personal experience of the participants (Patton, 1990). The findings in a qualitative study include rich, thick description (Merriam, 2001; Patton, 1990).

Patton (1990) discussed the role of the qualitative researcher and explained how it involves direct contact with the participants or phenomenon under study. The researcher's personal insights are valuable to the inquiry and essential to understanding the phenomenon. Merriam (2001) referred to this when she described the researcher as the primary instrument for data collection and analysis. The researcher's position within the inquiry should be one of "empathic neutrality" (Patton, 1990, p. 41): a balance between subjectivity and objectivity. Advancing the researcher's personal agenda undermines the credibility of the interpretation (Patton, 1990). "Empathic insight" (p. 41) helps the researcher understand and interpret the data. Patton (1990) contended that the researcher should communicate nonjudgmental understanding toward the content emerging from the participants. In addition, the qualitative researcher must be willing to adapt and respond as understanding about the research phenomenon deepens (Patton, 1990).

\section{The Case Study Approach}

Three types of qualitative methodologies are used to conceptualize and construct this study. The first is the case study approach. Miles and Huberman (1994) defined the case as "a phenomenon of some sort occurring in a bounded context" (p. 25). Merriam (2001) explained 
that the single most important defining feature of the case study is its boundedness; it must be able to be "fenced in" (p. 27).

Stake (2000) defined the case as a "specific One" (p. 436). As a form of research, the case is defined by interest in individual cases, not by methods of inquiry used: Case study is a . . . "choice of what is to be studied" (p. 435). The phrase case study "draws attention to the question of "what can be specially learned from the single case" (p. 435). The postsecondary participation of students with learning disabilities served as the binding function for this study. Information about the student experience of transition and persistence taken from the interviews of multiple student informants from three subsequent academic years were analyzed to describe the population.

Stake (2000) identified three types of case studies: intrinsic, instrumental, and collective. The intrinsic case study is conducted because the researcher's purpose is to know about a particular case, not to understand what that case can reflect about other cases. Instrumental case study is undertaken to explore knowledge that can be learned about a particular phenomenon through an individual situation or context. The collective case study has the same purpose as the instrumental case study but involves several cases or cohorts. Merriam (2001) called this a multiple case study. Stake would define the current inquiry as a collective case study because the researcher selected several cases to be instrumental in discovering and understanding "a phenomenon, population, or general condition" (p. 437).

Merriam (2001) described the case study approach as particularistic, descriptive, and heuristic. This research is particularistic in that it explored interview data from multiple cases of students with the learning disability diagnosis who were transitioning to and persisting in higher education; it contained a "specificity of focus" (p. 29) appropriate for informing everyday 
practice. The researcher believed that specific instances within the data would illuminate common issues for the population under study. The end product of this study is descriptive (Merriam, 2001); the findings demonstrated the complexity of the transition and persistence experience for this type of postsecondary student, not easily observed phenomena. The presentation of participant quotations in the research findings were used to illustrate the complexities of the student experience. This inquiry was heuristic in that it intended to "to illuminate the reader's understanding of the phenomenon under study" (Merriam, 2001). The goal of the inquiry is to inform practitioners of the experience of a population about which little is known. The development of innovative programming for this emergent group of college students is the intended outcome of this research.

The Phenomenological Approach

Phenomenological study examines human experience "through the detailed descriptions of the people being studied" (Creswell, 1994, p. 12). This inquiry involved in-depth engagement with a small number of participants. It is defined by understanding the subjective experience of the individual to determine the meaning or essence of the phenomenon under study (Creswell, 1994; Merriam, 2002; Patton, 1990). Phenomenological inquiry focuses on the question: "What is the structure and essence of experience of this phenomenon for these people" (Patton, 1990. p. 69).

The exploration of supports and barriers experienced by students with learning disabilities in the postsecondary environment was studied through a phenomenological perspective: "a focus on what people experience and how they interpret their world" (Patton, 1990, p. 70). According to Patton (1990) and Merriam (2002), this perspective allows for the use of interviewing as a tool for inquiry. “... [The] phenomenological interview is the primary 
method of data collection [for this type of research] wherein one attempts to uncover the ... meaning of the experience" (Merriam, 2002, p. 93).

Issues that are of "contemporary interest" and experiences believed to be "typical of a group of people" are areas of inquiry that are commonly addressed by phenomenological research strategies (Merriam, 2002, p. 91). The perception of students with learning disabilities as they experienced supports and barriers in the postsecondary environment was the contemporary educational phenomenon of interest under study; the researcher had the goal of learning the essence or what it was like for this particular group of students to navigate higher education.

\section{The Grounded Theory Approach}

The grounded theory research strategy is utilized to "derive inductively from data a theory that is "grounded" in the data - hence, grounded theory" (Merriam, 2002, p. 7). Merriam (2001, 2002) contrasted substantive and formal theory to describe grounded theory and maintained that grounded theory building usually shapes substantive theory. The difference between the two is much like the difference between applied and basic research. Substantive theory building is founded upon the practical, everyday, locally situated concern of professional practice (Meriam, 2002), concern similar to that of this study: discovering and understanding supports and barriers experienced by students with learning disabilities in the environment of higher education. The development of grand or formal theory is concerned with more global or generalizable concepts such as the human processes of learning, motivation, or self-regulation.

The goal of this project was to contribute to substantive educational theory via conceptual ordering and high-level description. Strauss and Corbin (1998) maintained that high-level description and conceptual ordering are "important to the generation of knowledge and can make 
a valuable contribution to a discipline" (p. x). This methodology provided a "sense of vision" to the data analysis: the use of grounded theory as an analytic tool allowed the researcher to "move from what [she] see[s] and hear[s] and to raise that to the level of the abstract, and then to turn around again and move back to the data level" (p. 8). In addition, a grounded theory approach to analysis structured the process of thinking comparatively about the categories of data; it helped the researcher make sense of the mass amount of raw information inherent in qualitative procedures (Strauss \& Corbin, 1998).

Strauss and Corbin (1998) described the analytic process as the “... the interplay between researchers and data. It is both science and art. ... Creativity manifests itself in the ability [to] aptly name categories, ask stimulating questions, make comparisons, and extract an innovative, integrated, realistic scheme from masses of unorganized raw data" (p. 13). A scientific rigor was maintained by staying with the data and following consistent procedures while coding the information in the transcripts. The constant comparative method was the primary grounded theory analytic tool used in this analysis. Merriam (2002) summarizes the process:

Units of data deemed meaningful by the researcher are compared with each other in order to generate tentative categories and properties, the basic elements of a grounded theory. Through constantly comparing incident with incident, comparing incidents with emerging conceptual categories, and reducing similar categories into a smaller number of highly conceptual categories, an overall framework or substantive theory develops. This process is facilitated by coding... and the continual writing of memos regarding any insights that arise in the course of data analysis and, in particular, connections that are seen between and among categories and properties (p. 143). 


\section{METHODOLOGY}

This section contains the specific procedures used to develop the study. It includes site and population selection, data collection methods and management, the role of the researche $\mathrm{r}$ in the inquiry process, methodology for data analysis, and trustworthiness features.

\section{Site and Population Selection}

The study was conducted on the site of a four-year liberal arts college campus of approximately 1400 students located in the Appalachian Region of the United States. Enrolled students who disclosed a learning disability to the disability support service were sent an invitation to interview with the researcher. Since this collective case study focused on in-depth description of supports and barriers experienced by postsecondary students with learning disabilities, a purposeful, not random, sampling strategy was used (Merriam, 2002). In particular, a purposive criterion sampling strategy was used to "select information-rich cases...from which one can learn a great deal about issues of central importance to the purpose of the research ..." (Patton, 1990, p. 169).

Existing records, which were accessible to the researcher as a function of her position at the research site institution, were checked to confirm disability status, academic progress toward graduation, student grade point averages, and other pertinent background information. A letter of invitation was sent to all students at the research site who disclosed a learning disability, have registered with the disability support office, and who fit the definition of full-time first year or persisting student. Students who were willing to interview contacted the researcher. All volunteers were interviewed. 


\section{Data Collection Methods}

A pheno menological case study approach was used to examine student perception of transition to, and persistence in, the postsecondary environment. Phenomenological study focuses on the descriptions of what people experience. This perspective allowed the use of interviewing as a tool for inquiry (Patton, 1990). Underlying the qualitative interviewing approach is the belief that student perspective will be meaningful and informative in the development of program design.

The semi-structured interview format uncovered student perception of the postsecondary experience, determined significant themes of transition and persistence, and revealed strategies and attitudes that promote or inhibit success in the postsecondary environment for this population - phenomena that are not easily observed. The interview format for the transition and persistence groupings followed the same format, respectively, to obtain data that are "systematic and thorough" (Patton, 1990, p. 281). In addition, the semi-structured interview format provided the researcher flexibility to ask follow-up questions to clarify and uncover critical features of the student experience within the context of the topic under study. Student voices expressed major themes that were labeled and used to inform program development.

Two cohorts of students were interviewed beginning autumn 2001 through spring, 2005 for this collective case study. Data collection for the research project began in autumn of 2001 with permission from both academic and research site research review boards. At that time, a pilot study was conducted by the researcher for the following reasons: to gain experience conducting qualitative research, to carry out a formative program evaluation, and to understand supports that facilitate the transition of first year full-time college students who have been diagnosed with learning disabilities. One limitation of the pilot study observed by the researcher 
was that no poorly performing students volunteered to interview; all 7 pilot volunteers earned a GPA of 2.5 or better during the semester in which they were interviewed. As a result of this occurrence, the wording of the letters of invitation for the study was changed to invite both positively and negatively performing students to interview. The researcher believed that learning about the experience of adjustment from the negative as well as the positive performing student perspective would broaden the findings of the study by providing knowledge of both the constitution of the successful experience as well as an understanding of common pitfalls this population faced during the transition to college.

Both academic and research site research review boards granted the researcher permission to continue interviewing first-year full-time students during the spring 2003 and 2004. Continued collection of data enabled the researcher to interview individuals from new cohorts of first year students in the time frame of the second rather than first semester of college study. Minor revisions were made to the letter of invitation to participate and to the interview protocol employed in the pilot study; they were submitted to both research review boards for approval. Twenty-four first-year student transition interviews conducted during the spring of 2003 and 2004 were transcribed and analyzed. One interview from the first year cohort could not be used in the analysis as the interviewee did not meet the qualifications of enrollment in the study, to carry at least 9 credits hours counting toward graduation each semester. The student withdrew from several classes during the semester in which he was interviewed. Therefore the analysis on the transitional cohort was conducted on 23 , not 24 verbatim transcriptions.

In order to gain more knowledge about the question under study, the researcher interviewed an additional cohort of 10 students, a set of students who successfully transitioned to the postsecondary environment and were allowed to continue toward graduation. The new cohort 
invited to interview had completed 60 or more credit hours toward a baccalaureate degree. Altogether, 23 transition interviews and 10 persistence interviews were analyzed for the current study.

Each student interviewed individually with the researcher for approximately one hour. Approval to conduct the persistence phase of interviewing was granted by the research site RRB during August of 2004 and the academic site IRB in November of 2004. After approval was granted by the academic IRB, a new set of interviews was held with students who completed at least 60 hours toward a baccalaureate degree, the persistence cohort. RRB and IRB documents designed for the pilot study, RRB and IRB permission to extend the first year student interviews, RRB and IRB permission to conduct the current study, interview formats, and letters of invitation to interview the transition and persistence cohorts are included in Appendices A through J. Tables 2 and 3 chart the data collection. 
Table 2

Transition and Persistence Study Data Collection Table

\begin{tabular}{|c|c|c|c|c|}
\hline Year & Cohort & No. interviews & Purpose & Analysis \\
\hline \multirow[t]{5}{*}{ Autumn 2001} & Transition & 7 & Pilot - to gain & Formative \\
\hline & $1^{\text {st }}$ semester & & experience & program \\
\hline & students & & conducting & evaluation \\
\hline & & & qualitative & Autumn 2001 \\
\hline & & & research & \\
\hline Spring & Transition & 24 & The discovery & Phenomenological \\
\hline \multirow[t]{4}{*}{$2003 / 2004$} & $2^{\text {nd }}$ semester & & of supports for & approach/ \\
\hline & students & & and barriers to & collective case/ \\
\hline & & & postsecondary & grounded theory \\
\hline & & & transition & \\
\hline \multirow[t]{6}{*}{ Winter 2005} & Persistence & 10 & The discovery & Phenomenological \\
\hline & students & & of supports for & approach/ \\
\hline & & & and barriers to & collective case/ \\
\hline & & & postsecondary & grounded theory \\
\hline & & & transition and & \\
\hline & & & persistence & \\
\hline
\end{tabular}


Table 3

Transition and Persistence Study: Research Topic by Question

Transition script

Topic Question

Decision to attend college

1

High school v. college

2

Preparation for college

3-4

Evaluation of supports

$1,5,7,8,9$

Current transition experience

$6(a-b)$

Disability disclosure

10

Learning strategies

11

Other needs

12

Persistence script

Topic

Individual goals

Expectations/satisfaction with the college experience

Frustrations with the college experience

Strategies for success

Internal supports and barriers

External supports and barriers

Turning point

Other needs
Question

\section{$1-2$}

3-4

5

6

7-8

$9,10,11$

12

13 


\section{Data Management}

With permission of the participants, interviews were taped and transcribed verbatim. All tapes and transcripts associated with the inquiry will be destroyed after completion of the study. Participants were read statements regarding the storage and destruction of audiotapes.

Affirmation of confidentiality, anonymity, and the ability to withdraw from the study at any time was reinforced before each interview began. Students were reminded that the decision to participate or withdraw from the study would not affect program enrollment and athletic participation. Participants were informed that pseudonyms would be used in the discussion of the findings to protect their privacy.

\section{The Role of the Researcher}

"The human factor is the great strength and the fundamental weakness of qualitative inquiry and analysis" (Patton, 1990, p. 372). Because of this, the researcher was responsible to examine personal biases and reactions throughout the inquiry process (Patton, 1990). Merriam (2002) advised the qualitative researcher to identify and monitor personal biases rather than to try to eliminate them. Gay and Airasian (2003) noted that qualitative researchers are by definition, personally engaged with the research environment and participants.

Merriam (2002) identified the researcher as the "primary instrument" (p. 5) of data collection and analysis and commented on the value of this in the inquiry process. The researcher is in a position to adapt and respond to incoming information in several ways: to confirm personal understanding, to be attuned to the nuance of non verbal communication, and to check for accuracy of interpretation during the observation or interview process. Marshall and Rossman (1999) emphasized the notion of the investigator as primary research instrument: Penetrating 
ideas "incubate" as the human mind has the unique capacity to "reorganize and reconstruct" (p. 32) during the building, analysis, interpretation and reporting phase of the research project.

Patton (1990) cautions the researcher to stay on track during the interview and to focus on collecting high-quality data. His caution focused on guarding against jumping into a problem uncovered during the interview and maintaining empathic rapport with the participant. "Interviews are interventions. They affect people. A good interview lays open thoughts, feelings, knowledge, and experience .... [and] leaves [participants] knowing things about themselves that they didn't know - or least were not aware of - before the interview" (Patton, 353-354).

Strauss and Corbin (1998) noted that qualitative researchers are "unafraid to draw on their own experiences when analyzing materials because they realize that these experiences become the foundations for making comparisons and discovering properties and dimensions" ( $\mathrm{p}$. 5). The researcher for this inquiry is knowledgeable about the experience of the participants, as she has worked with students who have been diagnosed with learning disabilities for over twenty-five years as a teacher, counselor, and administrator, in the elementary through postsecondary educational settings. The researcher who is also the director of the disability service at the research site conducted, analyzed, and coded the interviews in a neutral manner. Generally, the director is not a direct service provider unless a student, a faculty member, or a direct service provider requests consultation. If consultative service was requested with regard to a student who volunteered to participate in the study, the student's interview transcript would have been omitted from the findings.

The results of the exploratory study (Kuba, 2003) confirmed the fact that the educational background and professional experience of the researcher would inform and strengthen the foundation of this inquiry. The researcher's expertise in the construction and delivery of the 
interview protocol facilitated authentic student response. In addition, the researcher's professional training in interviewing procedures, boundary setting, reflection of verbal and nonverbal communication, and accurate empathic response facilitated the interview and supported the discovery of the core issues under study. Finally, the researcher's established relationship with the participants through their engagement with the office of disability support was a positive factor in influencing the number of students who volunteered to interview for the study.

Below is a list of researcher biases related to best practice in the delivery of services to postsecondary students who have been diagnosed with learning disabilities:

1. Students experience both supports and barriers as they transition to and persist in the postsecondary environment;

2. Both internal and external factors influence student transition and persistence in the postsecondary environment;

3. Student outlook with respect to the disability acceptance - denial continuum influences the individual's use of support in the postsecondary setting;

4. Students vary in the level of need for support as they transition and persist in the postsecondary environment;

5. Students benefit from the support of a professional mentor during the transition to the postsecondary setting;

6. Postsecondary service provision should focus on the academic, social, and emotional support of the student with learning disabilities; and,

7. To learn about the salient issues of transition and persistence in the postsecondary setting, we should ask the student undergoing the experience. 


\section{Data Analysis Strategies}

Analytic procedures from the phenomenological and grounded theory methodologies were used to interpret the interview data. Although the procedures are described in sequence, the analytic process is recursive: many of the steps described were revisited to clarify, integrate, and synthesize the data. Before analyzing the interviews for this study, the researcher reflected upon personal biases concerning the field of postsecondary service delivery to students with learning disabilities. This phenomenological strategy known as Epochè, was used to clarify and maintain an awareness the researcher's personal agenda, since the goal of the research was to formulate program design though understanding the student experience, not the researcher's ideas of best practice (Creswell, 1994; Merriam, 2002; Patton, 1990). In addition, the researcher annotated insights into the student experience as it related to the research investigation throughout the interview, analysis, and reconstruction process. Notes were taken during and after the interviews, during the multiple readings of the interview transcripts, and throughout the interpretation and synthesis of the data (Merriam, 2002).

The grounded theory approach of constant comparison was used as a strategy to understand the similarities and differences of the individual cases. The researcher reflected upon the cases in sequence, comparing question to question, recognizing likenesses and differences in the examples provided by each case within the constructed categories of the interview script and in the cases (Strauss \& Corbin, 1998). The categories were confirmed or altered by "constantly comparing" the cases in sequence. Each case was analyzed for its own merit, to understand what could be learned about cases that were read after it, and to help reflect on cases previously read and analyzed. The first case was read to open up the researcher's mind "to the range of possible meanings, properties, dimensions and relationships" (Strauss \& Corbin, 1998, p. 88) in the data. 
This analysis generated meaningful concepts from patterns of the concrete examples offered by the participants.

In addition, the researcher used the strategy of "bracketing the data" throughout the case comparison of the interview transcripts. The participant's experience was "bracketed" by taking it out of that person's world and treating it as an example of the research topic (Patton, 1990). Then the bracketed data was grouped into "meaningful clusters" (Patton, 1990, p. 408). During this reconstruction process, data unconnected to the research context were eliminated. This process also involved "coding" the data. Once the data were broken down into segments or instances, those segments were named or "coded" because of their meaning when examined relative to other instances in the data and to the overall topic being studied. The "code" or name is the "logical descriptor of what is going on" within the context of the research topic (Strauss \& Corbin, 1998, p. 114).

In summary, four general steps of analysis were each taken in several iterations: first, the data were conceptualized as described above and reduced into categories; second, the categories were filled with meaningful data or "elaborated"; third, the categories were related and combined as appropriate; and fourth, the categories were integrated, synthesized, and described as they reflected significant patterns of meaning for the research investigation, the experience of the postsecondary student with learning disabilities (Gay \& Airasian, 2003; Merriam, 2002; Patton, 1990; Strauss \& Corbin, 1998). For specific discussion of the transcript analysis for both the transition and persistence cohort, see the Analysis of the Findings in Chapter 4. Examples of the coding process are located in Appendices K-L. 


\section{Trustworthiness Features}

Systematic inquiry must address issues of trustworthiness (Marshall \& Rossman, 1999; Merriam, 2001). Marshall and Rossman identify the following "cannons of quality" for the qualitative genre: credibility, transferability, dependability and confirmability (1999, p. 191).

\section{Credibility}

Accurate identification and description of the phenomenon under study and authentic communication of the findings to interested others is the basis for establishing credibility in qualitative research (Gay \& Airasian, 2003; Marshall \& Rossman, 1999; Patton, 1990). The exploratory (Kuba, 2003) findings for this project indicated that the semi-structured in-depth interview was an appropriate method for learning about the complex experience of transitioning to and persisting in higher education. Quotational data taken from verbatim transcription of the informant voice illustrated the researcher's analysis and interpretation. Student descriptions were a true reflection of their experience (Marshall \& Rossman, 1999).

In addition, the credibility of this study was enhanced by using the following strategies: record checking; data source triangulation through the use of multiple informants, time frames, and cohorts; and, acknowledgement and ongoing clarification of researcher assumptions.

Records were checked to ensure disability status, progress toward graduation, student grade point averages, and other background information meaningful to the research.

"Triangulation is a process by which the researcher can guard against the accusation that a study's findings are simply an artifact of a single method, a single source, or a single investigator's biases" (Patton, 1990, p. 470). The credibility of this study was enhanced by the fact that multiple informants, who progressed to different postsecondary levels over three successive years, produced numerous perspectives for analysis (Patton, 1990; Stake, 2000). 
The main challenge to establishing credibility in qualitative research is addressing researcher bias (Gay \& Airasian, 2003; Marshall \& Rossman, 1999; Merriam, 2001; Patton, 1990). Using the interview as the sole method of data collection necessitated reporting the phenomenon under study as the "participant views it, not as the researcher views it" (Marshall \& Rossman, 1999, p. 108). The researcher communicated the importance of the student perspective to the participants in the letter of invitation to join the study as well as within the context of the interview process. The researcher has examined, clarified, and acknowledged her preconceptions related to the research topic and has used the journaling process to continue to self-reflect during the interview, interpretation, and reporting phases of the study (Gay \& Airasian, 2003; Marshall \& Rossman, 1999; Merriam, 2001; Patton, 1990).

\section{Transferability}

Transferability implies that the findings of the study will be useful to others who have like "questions of practice" (Marshall \& Rossman, 1999, p. 193). The boundaries of this inquiry are clear; administrators and practitioners interested in understanding the experience of transition and persistence of the postsecondary student with learning disabilities will draw on the descriptions provided by the student participants. The researcher intended to strengthen the study's usefulness by completing and analyzing multiple (33) interviews during both the transition and persistence phase of the student's college experience. (Marshall \& Rossman, 1999; Patton, 1990; Stake, 2000). An interview protocol was utilized to ensure that similar information was sought from each respondent. (See Appendices A-B).

Qualitative methodology is used to understand a specific phenomenon in depth (Merriam, 2001). The practitioner or reader will decide whether the researcher's findings are fitting. Stake (1981, 2000) explained that generalizabilty takes place for the reader as the vivid description of 
case illustration is experienced: Case study knowledge underscores the "clear and important role for the reader in the making of that knowledge" (Stake, 1981, p. 38). What we learn from particular or multiple cases and cohorts can be transferred to similar situations (Merriam, 2002). According to Stake, the reader constructs the knowledge of the case in ways that are "likely to be personally useful" (Stake, 2000, p. 443). "The purpose of a case report is not to represent the world, but to represent the case. .. . The utility of case research to practitioners and policy makers is in its extension of experience" (Stake, 2000, p. 449).

\section{Dependability and Confirmability}

"Qualitative research does not claim to be replicable" (Marshall \& Rossman, 1999, p. 195); in fact, the philosophical assumption underlying qualitative research, that reality is continually socially constructed, precludes the use of replication as a measure of trustworthiness

(Marshall \& Rossman, 1999). Even if a qualitative study were to be replicated, the results would be different because there could be "numerous interpretations of the same data" (Meriam, 2002, p. 27). Instead, Marshall and Rossman (1999) suggest evaluating if the results make sense, given the data collected in the study.

The utilization of the audit trail (Merriam, 2002) and peer examination (Stake, 1995) helped confirm that the core findings came from the data collected and not the researcher's agenda (Marshall \& Rossman, 1999). The audit trail detailed "how the data were collected, how the categories were derived, and how decisions were made throughout the inquiry" (Merriam, 2002, p. 27) to explain the process of coming to the results.

After the researcher completed the analysis and interpretation of the data, one transcript from each final collective case, the negative transition, the positive transition, and the persistence case, was independently evaluated by both the researcher and a colleague expert in the delivery 
of postsecondary services to students with learning disabilities. The expert was given each grouping's major final themes and their associated descriptions. A percentage of agreement between the raters was calculated for each transcript. Ratios of agreement were $.65, .82$, and .76 for the negative transition, positive transition, and persistence cases, respectively. The average ratio of agreement for the raters was .74 . The negative case inter-rater agreement of .65 points to the difficulty of interpreting the interview data of the negative grouping without the exposure to the students' nonverbal communication afforded the researcher during the interview process. The negative performing students were difficult to "read" from the verbatim transcript. The average cumulative student grade point average, taken after each student's most recent semester of enrollment, of 1.86, the fact that each student had been placed on academic probation or warning at least one time during matriculation at the research site institution, and the persistence rate of $28 \%$ for this grouping clearly substantiates the ineffective functioning of these students. Examples from the transcript coding process and the audit trail are included in the Appendices K-M.

Time Line

The researcher completed online certification for Human Participant Protections Education for Research Teams and the HIPPA Research Requirements Training during the summer of 2004. Approval for Human Subjects Exemption was granted by the research and academic sites in August and November of 2004, respectively. Students experiencing the transition to college during their second semester of enrollment interviewed during the spring of 2003 and 2004. Participants who persisted beyond 60 earned credit hours interviewed during the autumn and winter 2004-2005. Transcripts of both the transition and persistence cohorts were 
analyzed during the winter, spring, and summer of 2005. Transcript analysis, findings, conclusions, and recommendations were developed during the autumn of 2005.

\section{SUMMARY}

Investigation of supports and barriers experienced by students with learning disabilities as they transitioned to and persisted in the college setting was undertaken to support the knowledge base upon which to structure programming for this growing postsecondary population. Student perception of the research phenomenon was analyzed from verbatim interview narrative. Qualitative methodology was justified as open-ended interview and followup questioning provided an appropriate design to penetrate the depth and detail of student experience (Gay \& Airasian, 2000; Patton, 1990).

The content of each interview was read to discover and code broad themes linked with transitioning to, and persisting in, the post-secondary environment. The coding helped connect fragments in the data with common elements of the postsecondary transition and persistence experience for the students (Coffey \& Atkinson, 1996). The data were read several times by the researcher who has expertise in the area of learning disabilities to confirm theme categories, integrate categories, to label subcategories, and to interpret and synthesize core categories to describe the experience from the perspective of the student (Gay \& Airasian, 2003; Merriam, 2002; Patton, 1990; Strauss \& Corbin, 1998).

The researcher employed the strategies of data source triangulation, record checking, peer examination, and the audit trail to strengthen the quality and trustworthiness of the study. Data collection began with an exploratory study in the autumn of 2001 and continued through the winter of 2005, with ongoing permission from both the research site and academic site research review boards. Project findings will be delivered in February, 2006. 
Chapter 4: Transcript Analysis and Presentation of the Findings

A summary description of the progression of the interview transcript analysis and the presentation of the findings are included in this chapter. The transcript analysis contains a description of the fundamental decisions made by the researcher during the analytic process for both the transition and persistence cohorts.

Thirty-three students attending a small liberal arts college located in the Appalachian Region of the United States volunteered to interview for the study over a three year period. All of the participants were enrolled in a special services program for students with learning disabilities. Thirty-three verbatim student transcripts were deconstructed for case presentation. The transition cohort was initially composed of 24 students: 16 made up the positive collective case and seven formed the negative collective case. One transition student did not meet the qualifications for the study so his transcript was not used in the analysis. The persistence cohort was composed of 10 students. One of the students who interviewed as a member of the transition cohort also interviewed as a student who had persisted toward graduation 3 semesters later. The number of interviews transcribed and fully analyzed was 33. The number of students whose transcripts were analyzed for case presentation was 32. Altogether, transcripts from sixteen males and sixteen females were analyzed for the study. Thirty were of Caucasian and two were of African-American ethnicity. All of the students intervie wed came from middle to upper middle socioeconomic backgrounds.

The presentation of the findings contains three sections. First, there is a detailed description of the major themes, including supporting narrative, which represent the outlook and ineffective actions taken by the negative performing students from the transitional cohort as they entered and attempted to transition to the college environment. Next, there is a detailed 
description of the major themes, including supporting narrative, which represent the approach and effective actions taken by the positive performing students from the transitional cohort as they navigated the transition to the college environment. Finally, a detailed description, containing supporting narrative, of internal and external facilitators of and barriers to transition and persistence in the college environment from the point of view of students from the persistence cohort is presented.

\section{TRANSCRIPT ANALYSIS}

A summary description of the analytic procedures utilized to interpret the 33 transcribed interviews of the transition and persistence cohorts follows. Basic steps taken and significant decisions made by the researcher in developing the thematic analysis are laid out. Numeric background information supporting the splitting of the transition cohort into the negative and positive collective case example is included in Table 4 . Table 5 provides numeric background information on the persistence cohort.

\section{Transition Cohort Transcript Analysis}

Twenty-four interviews, ranging in length from 60 to 75 minutes, were transcribed verbatim and read thoroughly several times. Although 24 transition students were interviewed, it was discovered that one student did not meet the criteria of full-time status after the close of his first year. His interview was extracted from the coding procedures before the negative and positive case analysis. The researcher completed analysis on 23 transition student transcripts.

Themes of transition surfaced as a result of analyzing the transcripts in the following way. After reading each transcript, notes were made on the researcher's impression of the student's experience. This included making comments about the student's general outlook or approach, major events, and important details that interfaced with the student's transition to 
college. Then, each transcript was reread in light of this gestalt and as it connected with the student's description of his or her experience of transition. After this procedure, more notes were made to build themes that characterized each student's story as it unfolded throughout the interview. Then, segments of the narrative were highlighted, for they illustrated important themes emerging from the previously described processes, reading for the gestalt and reading for detail to support the gestalt. Following the format of the interview protocol, some narrative related to the transition in general in which there was no mention of the disability. Other description reflected the interface of the student's experience of the college transition and the disabling condition. Many of the protocol questions that pulled for general information about the student's transition were answered through the lens of the student as an individual with a learning disability. For example, when asked why the student came to this particular College, all but one of the twenty-three students answered that he or she had come, in part, because of the strong support program for students with diagnosed learning disabilities.

Twenty-five major categories surfaced as a result of the initial analysis. The dimensional nature of several constructs from the initial classification allowed for the student experience to be viewed along the concept's continuum. Examples included perceived preparation for college, depiction of social isolation or integration, handling the freedom of the unstructured setting, managing the learning disability, academic proactivity or inactivity, positive or negative events occurring during the transition, use of accommodations and services, utilization of the mentoring relationship, proactivity or inactivity in the self-disclosure process, strategies utilized for the transition, parental involvement, self-discipline, resilience, etc. . . Each interview was reviewed in light of the 25 classifications; the categories were tightened as a result of this process. Then, all twenty-three of the transcripts were deconstructed according to these classifications, i.e., each 
student's narrative was organized into the twenty-five original themes. During this deconstruction, the interviewer's questions and minimal encouragers were extracted from the narrative. As each of the students' narrative was placed into the 25 categories, subheadings were given to each sample of narrative for the possibility of future reorganization if needed. Examples from the initial coding process are included in Appendix K.

Many of the topics covered in the interview questions were among the 25 original themes. For instance, the students were asked how they went about procuring accommodations and services, about the disability disclosure process, and the students' view of the quality of their transition. In addition, many of the themes developed from elements of answers to the interview questions and became categories of their own. For example, when asked about the help the students received during the transition, there were multiple references to the student working with the mentor from the LD support program; this description took on a life of its own. The role of parental involvement grew into its own theme as a result of student description within and among multiple question contexts: preparation for college, negative and positive aspects of transition, and how the student viewed his or her postsecondary adjustment.

During the process of transcript analysis, dissimilarity in the approach the students took to manage the transition to the college environment and its relationship to academic performance was observed. The act of placing the student narrative along the continuums of the originally perceived themes and the researcher's general background knowledge of the students' academic performance facilitated awareness of this split. In view of this observation, after all the relevant narrative had been categorized according to the 25 themes, the researcher reviewed patterns of performance by recording student grade point averages for progressive semesters of enrollment. 
Initially, three groupings emerged from this academic performance analysis: ineffective performance, middle effective performance, and high effective performance. It was decided to label the groupings according to academic performance given that academic performance is the benchmark for successful transition and eventual persistence in the college setting. The low or ineffective performance grouping in the transition cohort consisted of 7 students who made a grade point average below 2.0, the GPA required for good academic standing, for at least one semester. Two students were enrolled for 2 consecutive semesters, 2 students were enrolled for 4 consecutive semesters and 3 students were enrolled for 6 consecutive semesters. The seven ineffective performance students earned a collective cumulative grade point average of 1.86 , which was taken from each, after the student's most recent semester of enrollment. All of the students within this grouping were placed on academic probationary status during at least one semester of their matriculation at the research site institution. Four of the students in the grouping were dismissed for academic reasons, 1 left to attend a local community college, and 2 have continued matriculation at the research site institution.

The middle effective performance grouping consisted of 8 students who earned a cumulative GPA of between 2.5 and 2.99 which was calculated after each student's most recent semester of enrollment. The average GPA of the 8 members of the middle effective functioning grouping, calculated after each student's most recent semester of enrollment, was 2.82. The high effective performance grouping consisted of 8 students who earned a cumulative GPA of over 3.0 which was calculated after each student's most recent semester of enrollment. The average GPA of the 8 members of the high effective functioning grouping calculated after each student's most recent semester of enrollment was 3.19 
After the groupings were labeled according to academic performance, the researcher reread the original case notations, the notes on the gestalt of the interviews, and the reconstruction of the narratives according to the 25 original themes for commonalities and dissimilarities among the three groupings: low or ineffective performance, middle effective performance, and high effective performance. The low or ineffective performance narratives were reviewed first.

A new thematic analysis was completed on the 7 ineffective performance student narratives. Several distinctive conceptual commonalities clustered the students by patterns of outlook and behavior as well as by the negative performance outcome, a cumulative GPA of 1.86. The grouping developed into a negative collective case example representing ineffective performance during the college transition. The narrative of the ineffective performance grouping was integrated into unique thematic findings for presentation and illustration. The students in the negative collective transitional case grouping revealed the following general patterns of outlook and behavior which interfered with their successful functioning in the college environment: inadequate self-understanding and self-management, complex relationships with authority structures and helpers, a reluctance to accept their disabling condition, unconstructive patterns of social functioning, and problems adapting to the academic environment and to developing life circumstances.

In order to unlock the contrast among the performance groupings, after the completion of the analysis of the ineffective performance grouping, the researcher reviewed the original case notations, the notes on the gestalt of the interviews, and the reconstruction of the narratives according to the 25 original themes of the high effective performance students. It was hoped that reviewing contrasting postures of the students in the low and high groupings would clarify the 
differences. Multiple thematic commonalities clustered the students by outlook and behavior in addition to the academic performance outcome, a cumulative GPA of over 3.0. The grouping developed into a positive collective case example representing high effective functioning during the college transition. The narrative of the high effective performance grouping was integrated into unique thematic commonalities for presentation and illustration. The students in the positive collective transitional case grouping revealed the following general patterns of outlook and behavior which promoted their successful functioning in the college environment: recognizing, appreciating, and carrying through on preparative experiences for the college transition, integrating socially into the campus community, proactively managing the learning disability, utilization of constructive help, accepting and dealing with problematic issues, taking a strategy based approach to the transition, acknowledging the primacy of learning and graduating, and identifying prior inappropriate special education experiences.

After the thematic analysis was completed on the high effective performance grouping, the researcher reviewed the original case notations, the notes on the gestalt of the interviews and the reconstruction of the narratives according to the 25 original themes of the middle effective performance students to observe the qualitative patterns of this grouping. The middle effective performance student narrative blended within the constructs revealed by the high effective performance student narrative. Therefore, the middle effective performance students added variation to the positive collective case illustration, but not additional substantive findings. The decision was made to integrate the middle and high effective performance students into the positive collective case example. The average GPA of the 16 members of the positive collective case, calculated after each student's most recent semester of enrollment, was 3.0. 
Once the negative and positive collective case examples were built, the researcher decided to track additional background information, which already existed in the record of the student, to try to determine additional reasons for differences in student performance. To that end, a measure of aptitude or general intelligence, taken from the Wechsler Adult Intelligence Full-Scale IQ score, was recorded for each student.

Several of the students interviewed for the study were diagnosed with more than one disabling condition impacting cognitive processing and social and executive functioning. To try to determine additional reasons for differences in student performance, the number of disabling conditions included in the documentation submitted to the program by the student's evaluating psychologist or psychiatrist was recorded by the researcher. Disabling conditions which impacted the cognitive processing of the students in addition to a Learning Disorder were included in the evaluation and based on criteria set forth by the DSM-IV classification of mental disorders. The following other disabling conditions in addition to the diagnosis of Specific Learning Disability or Learning Disorder were present in the student evaluations: AttentionDeficit/Hyperactivity Disorder, Asberger's Disorder, Tourette's Disorder, Oppositional Defiant Disorder, Obsessive-Compulsive Disorder, Bipolar I Disorder, Generalized Anxiety Disorder, Depressive Disorder Not Otherwise Specified.

SAT results and final high school grade point averages were examined as well. The number of disabling conditions for the effective and ineffective grouping was 2.00 and 2.14 respectively. The average Full Scale IQ score for both groupings was 105. Table 4 summarizes the background information on both transition performance groupings. 
Table 4

Numeric Background Information on Transition Cohort

\begin{tabular}{lcc}
\multicolumn{1}{c}{ Type of data } & Positive performance & Negative performance \\
\hline No. of students & 16 & 7 \\
Average No. of disabling conditions & 2.00 & 2.14 \\
Full-scale IQ & 105 & 105 \\
SAT score & 1019 & 955 \\
Final high school GPA & 3.12 & 2.50 \\
Cumulative college GPA & 3.00 & 1.86
\end{tabular}

Note. Figures are averaged student totals from each performing group. The Wechsler Adult Intelligence Scale was used for all IQ testing and submitted prior to program enrollment. 
Category unity and differentiation posed a challenge for the researcher. The student narrative was only deconstructed to a certain point so that it could retain its context and meaning. Therefore, in some cases, the illustrations chosen to represent the thematic classifications that emerged from the analysis of the effective performance grouping overlap the chosen categories. For instance, there are examples of a strategic based approach to the transition within the social integration into the campus community conceptual segment and examples of proactive management of the learning disability within the positive use of constructive help and within the acknowledgement and engagement of problematic issues conceptual segments. Each category held its integrity in that it, conceptually, represented an important approach the individual case members used to interact with the environment, and, in that it represented a divergence from the ways of interacting found to be the case for the individual members of the ineffective performance grouping. Although some segments of narrative would have fit into more than one section, the positioning of student description into the conceptual category was based on the researcher's judgment of the major thrust of a particular piece of narrative. For example, one student talked about reworking her own class notes with the notes of the note taker. The researcher chose to place this narrative in the strategy based approach to the transition category instead of the proactive management of the disability category because the whole description within which it was embedded involved a strategic process.

Another illustration of the researcher's challenge in deciding about category unity and differentiation involved separating out the primacy of learning and graduating with the strategy based approach to the transition classifications. The primacy of learning and graduating category reflected the clear priorities of the students and the important value they placed on learning, growing, and changing as a result of their participation in a college education. 
Segments of the narrative placed in this category included strategic like thinking. However, the mindset represented in the narrative illustrations of the primacy of learning and graduating was fundamental to its category. Many of the student efforts to be successful probably emanated from this mindset of commitment, including strategic efforts at making a successful transition. The essential element in the strategy based approach to the transition category was the process the students employed to succeed.

Determining salient examples to illustrate the significant themes related to the overall research topic created another challenge for the researcher. There is variation in the number of examples presented from each theme and its subcomponents. For example, most of the students discussed a combination of a small school community, simplified access to accommodations, and the offering of excellent services as reasons for enrolling in the research site institution, subtopics within the theme proactive management of the learning disability. Representative examples of these elements were included in the presentation of the findings because nothing would be gained by incorporating repetitive responses into the presentation of the findings. In contrast, several examples of student discussion of limitations and compensation techniques were included in the findings because there is variation in the type of difficulty experienced by the students and their method of coping with the problems they encountered. All of these examples are significant because the overall goal of this research project is increased understanding of this population as a foundation for planning effective programming.

The final concern related to the presentation of the analysis. After the construction of the negative and positive collective examples for case presentation, the researcher recognized several thematically connected distinctions from the 2 contrasting collective cases. These differences were inherent in the approach the students used to manage the ir transition to the college 
environment. The researcher deliberated whether to present the findings of the positive and negative groupings by contrast. However, it was decided to present both collective cases in their entirety because there was additional significant material within each collective case that did not fit within such parallel framework. The decision was made to present the contrasting thematic connections in the discussion and conclusion section of this document, Chapter 5.

In summary, after several iterations of thematic analysis were completed, the researcher tracked aptitude testing scores, the number of disabling conditions, and the postsecondary performance outcomes of the transition cohort participants. Analysis of the student GPAs revealed a split in the academic performance of the participants. Two distinct transition cohort performance groupings emerged. The negative performance grouping consisted of 7 students whose average cumulative GPA was 1.86. The positive performance grouping consisted of 16 students whose average cumulative GPA was 3.0. Although the average of the number of disabling conditions and the average of the full-scale intelligence quotients were similar for both the negative and the positive groupings, in addition to the obvious grade point average difference, a marked divergence in qualitative patterns of student outlook and behavior manifest for the negative and positive transition performance groupings. The outlook and behavior patterns of the negative grouping illustrate ineffective student operation. The outlook and behavior patterns of the positive performance grouping illustrate effective student operation.

\section{Persistence Cohort Transcript Analysis}

The original research topic, the broad quest to understand the experience of students with diagnosed learning disabilities from their own perspective as they made the transition to the college environment, took on an additional focus as the interview and research process progressed; the decision was made to explore facilitators and barriers to managing the college 
environment from the point of view of students who had persisted in the postsecondary setting. The focus of the persistence interview protocol was narrowed to reflect this specific topic, understanding the facilitators and barriers faced by this population. The questions from the transition interview protocol focused on both positive and negative aspects of the students' experience of transition, general supports, and special service program elements that impacted the student's transition experience. The questions from the persistence interview protocol focused on student perception of internal and external facilitators and barriers experienced while managing the college environment. With this addition, the study grew to encompass both the broad experience of transition to college and a more detailed perception of facilitators and barriers to achieving success at the postsecondary level. The researcher tracked the full scale IQ scores and the number and type of disabling conditions included in the documentation submitted by the student to the support program. College grade point averages were examined as well. The number of disabling conditions for the persistence grouping was 2.4. The average Full Scale IQ score for the grouping was 108 . The students in the persistence grouping earned a cumulative average GPA of 2.95, which was calculated after each student's most recent semester of enrollment. See table 5 for additional background information on the persistence grouping.

To gain additional perspective on how students with diagnosed learning disabilities come through the transition to college and persist toward graduation, 10 additional student volunteers were interviewed who had earned at least 60 credit hours toward a bachelor's degree, half of the credit hours necessary for completion of the degree at the research site institution. The transcripts of the persistence cohort were analyzed after completion of the analysis of the transition cohort. The 10 interviews, ranging in length from 50 to 75 minutes, were transcribed verbatim and read thoroughly several times. 
At the close of each persistence interview, notes were made on the interviewer's general impression of the student's experience as it related to the individual's success in the environment and on the student's description of the disabling condition as it interfaced with his or her everyday functioning. When all of the interviews were completed, each transcript was read and reviewed; notes on the gestalt of the student experience were made in order to annotate the researcher's characterization of the student experience more fully. The major the mes were expected to closely follow the interview format since all of the questions were constructed to pull for the student's perceived supports for and barriers to functioning in the college environment. Next, the transcripts were annotated for additional themes and subthemes reflecting the student experience as he or she persisted in the college environment. Two categories, unexpected emergent findings and reinforcement of the transitional findings were integrated into the initial coding processes. The first set of themes, closely following the interview format, consisted of goals, strategies, turning points, reinforcement of the transitional findings, unexpected emergent findings, rewarding experiences, frustrating experiences, internal facilitators, external facilitators, internal barriers, and external barriers. Even though internal and external facilitators of and barriers to transition and persistence in the college setting were the key issues to be explored, the students were asked about goals, strategies, turning points, rewarding experiences, and frustrating experiences as an alternate means to bring out the focal issue of the study: supports and barriers to transition and persistence in the college setting.

Each of the 10 persistence interviews was reviewed in light of the aforementioned constructions and categorized accordingly. The 10 transcripts were deconstructed according to these classifications, i.e., each student's narrative was organized into the 11 themes. During this deconstruction, the interviewer's questions and minimal encouragers were extracted from the 
interview narrative. As the narrative was placed into the 11 major categories, subheadings were given to each piece of narrative for the possibility of future reflection and reorganization. Then, a listing was made of the subheadings of each segment of narrative organized within the 11 major categories to allow for the manipulation and reorganization of ideas as they related to the overall goal of understanding supports and barriers to transition and persistence in the college setting.

After several readings and conceptual manipulations of the subheadings and corresponding narrative organized according to the 11 themes, the decision was made to reorganize the narrative into an overall thematic pattern: internal and external facilitators of and barriers to transition and persistence in the college setting. This decision necessitated the deconstruction of the categories goals, strategies, turning points, and rewarding and frustrating experiences and the and the 2 added categories, unexpected emergent findings and reinforcement of the transitional findings as the narrative within these could be placed within the main framework.

Along with the narrative that had been placed there previously, the narrative from the deconstructed categories was placed within the main framework: internal and external facilitators of and internal and external barriers to transition and persistence in the college setting. Next, the narrative within the categories of the newly organized main framework was reviewed and organized to capture the essence of student processes and descriptions of transitioning and persisting in the college setting. Internal facilitation to successful performance encompassed student descrip tion of self-knowledge and practice to promote academic, social, and emotional well-being. External facilitation to successful performance involved a description of the utilization of a myriad of support systems and qualitative aspects of the general campus environment and exemplary helpers. Internal barriers to successful performance were 
experienced as difficulties related to the disabling condition and limitations grounded in selfview, self-understanding, and self-management. External barriers to successful performance enumerated were time constraints, limitations in faculty understanding of student needs, limitations related to the requirements of the academic curriculum, and social, emotional, and familial factors. This final analytic process is represented in detail in the presentation of the findings of the persistence collective case.

A few pieces of student narrative from the persistence cohort illustrated the use of internal knowledge and competencies or external supports to navigate internal or external barriers. In cases such as this, the narrative was not deconstructed to separate out the episode. For the purpose of category organization, the "facilitator" took precedence over the "barrier" as it was overcome. For example, one student faced the barriers of poor teaching and inadequate preparation for progress in the calculus sequence required for his major. He navigated the situation with a sound knowledge of his strengths and limitations based on his prior learning history and personal determination; he eventually succeeded through the demanding sequence. This example is placed in the segment illustrating the internal facilitation process, even though internal and external barriers are present in the description.

In summary, the persistence grouping consisted of 10 students. All but one of the students earned a cumulative GPA that ranged from 2.5 to 3.85, which was calculated after each student's most recent semester of enrollment. One student earned a GPA of 2.28, which was calculated after his most recent semester of enrollment. Taken all together, the average GPA of the 10 members of the persistence grouping, calculated after each student's most recent semester of enrollment, was 2.95. After several stages of thematic analysis, the persistence narrative was organized into an overall thematic pattern: internal and external facilitators of and barriers to 
transition and persistence in the college setting. See Table 5 for additional background information on the persistence grouping. 
Table 5

Numeric Background Information on Persistence Cohort

Type of data $\quad$ Persistence collective case

No. of students

10

Average No. of disabling conditions

2.4

Full-scale IQ

108

SAT score

1003

Final high school GPA

3.3

Cumulative college GPA

2.95

Note. Figures are averaged student totals. The Wechsler Adult Intelligence Scale was used for all IQ testing and submitted prior to program enrollment. 


\section{PRESENTATION OF THE FINDINGS}

This section contains the themes and supporting narrative of the three collective case presentations: the negative transition, the positive transition, and the persistence cohorts.

\section{Negative Collective Transition Case Findings}

I knew that I didn't know the answer to everything. . . and I would see these other kids [in class]. . I would hear these other kids, and they were getting it, they were smart and they were on it, they knew all of the stuff. . . and I had a learning disability, I wasn't learning like these kids were learning, and it really bothered me. . I felt very unintelligent, I felt that I couldn't connect with them because I didn't have that same level of learning as they did. ... I guess it bothered me and I blamed it on my learning disability. I blamed it on that. . . I wasn't as smart as these kids. . . that's always the mentality, if something goes wrong. . . It's always: "Oh gosh, I have this learning disability, I can't do it. I can't do it because I'm not as smart as those kids.” (student number XXVI, p. 9-10 of transcript)

Seven of the 23 students from the transition cohort whose one-on-one interviews were analyzed to completion earned a grade point average of less than 2.0 for at least one semester. All 7 of the students were placed on one of the following types of academic notice by the research site institution: academic warning, probation, or dismissal. Several conceptual commonalities clustered the students by patterns of outlook and behavior as well as by the negative performance outcome, an average cumulative GPA of 1.86, taken after each student's most recent semester of enrollment. The students developed into a negative collective case example representing ineffective performance during the college transition. At the time of this 
writing, 4 of the students in this grouping have been dismissed for academic reasons. One student left to attend a community college near his home and 2 remain.

The narrative of the ineffective performance grouping was integrated into unique thematic findings for present ation and illustration. Key patterns of the negative collective case included the following: problems with self-understanding and self-management, complex relationships with authority structures, hesitancy to acknowledge the learning disability, and related to this, misguided independence, unconstructive patterns of social functioning, difficulty adapting to the academic environment, and problems related to managing difficult life circumstances that occurred during the transition. The thematic elements uncovered within the negative collective case example are illustrated by the following student narrative.

\section{Problems with Self-Understanding and Self-Management}

Students in this grouping did not proactively structure their daily functioning. They reported difficulty in establishing a routine and following through with the decisions, plans, and strategies they knew would help them navigate the college environment. If they were able to start a task or begin with a plan, they could not sustain the effort to stay with it. It was perplexing that many times the students did not appear to know the reasons for their difficulty in following through with self-set plans. They described being overwhelmed by having to manage multiple tasks. In addition, they were unclear about their goals or purpose for attending college, almost as if they were in school by default.

\section{Trouble Establishing a Routine}

Matthew was unable to establish a routine in the midst of the newly found freedoms of the college environment. For most of his high school experience, he boarded at a college 
preparatory school. He was unable to internalize the structure that had been imposed by his prior environment:

It's not as easy as I thought it would be. Like, getting to class is tough and studying with out being told to study. But here, I have a lot more free time, and a lot more to do. I really haven't been studying as much as I should have. It's tough, freedom is tough. (IX, p. 2)

When it became apparent that Matthew was not attending classes, I asked him about his activities in lieu of going to class and studying. He talked about a life absent of academics, but full in many other ways: 'I mean a lot of it's talking to people and hanging out, playing video games I guess, watching TV, and stuff like that. I lift [weights] a lot too, and I run a lot, and oh, play basketball." (IX, p. 24) Matthew described that everything was going well in the transition except for his poor test grades and the fact that he couldn't establish a study routine:

I'd say that the tests are hard. I'd say mostly tests, yea...I definitely think [my grades] could change, if my study habits were routine, a lot more routine than they are now, I think that I could get a lot better grades on everything. I think routine is probably what lacks the most. (IX, p.11-13)

Collin played more than worked during the first semester; he, like Matthew, did not manage the freedom of the unstructured environment. However, he worried more than Matthew about performance outcomes. He admitted to receiving too much help in high school and worked hard to establish a network of supporters who would take him by the hand to navigate the new set of demands. When asked about problems encountered in his transition to college, his first response pointed to general problems with organization and self-management. He then talked of how he was attempting to correct: 
I wasn't organized at all in high school...looking back on it now, I got As and Bs, but I could have been a lot more organized. I didn't do the planner or anything [in high school]. I was the person that kind of always stumbled into class a couple minutes late....My organization skills weren't all there. So, that's me, I don't know. Like, academically, it was just more challenging...I mean, it was kind of unexpected...like time management, you know? I wasn't using my time wisely...now I have a planner and stuff...all of my syllabuses for my classes are laid out in the calendar...it's kind of like my life, right there, the whole calendar...(XXXI, p. 5-6)

\section{The Absence of Follow-Through}

The students in the negative case example described what they should be doing to be successful. However, they reported not doing what they knew they should. This performance deficit impacted their success. Robby lamented the fact that he should be able to follow a schedule:

I should have gotten on more of a schedule, like I really jump around... sometimes if I'm feeling good, I might just start doing my homework in the mornings, things like that...I really want to be able to get to all my meals, I want to be able to go to the gym, for like an hour, and get all my classes done for that day, but I've never really practiced a schedule that really worked for me. (XXIX, p.3)

Jason, who attended a highly structured boarding school, chose to come to this College because of the learning support program. He considered the fact of his not using the support he came for: Surprisingly, the reason I chose this school is for the learning support but, I haven't taken full advantage of it...I mean I've used the Test Lab once or twice... I know 
how all the services work, but, I haven't [used them] on a regular basis though. (X, p. 11)

Arthur recounted that he would have benefited from using the accommodation of a note taker for his classes. When I asked him why he did not apply for the use a note taker, he replied:

Probably me just being lazy...not wanting to follow through, get the notes and read them. I keep on taking this more and more seriously. And that really is the biggest thing about it. As I go along, I'm going to have to take school more and more seriously, do more and more work. I think it's a combination of me realizing that I have to get my act together and it's getting harder. (XVIII, p. 7)

Not only did Matthew have trouble establishing a study routine and going to class as noted in the last segment, he had difficulty making it to meals:

I would even have liked it if someone would have come and knocked on my door or something; that would have been good. Because sometimes I get into that mode, where you don't want to go to do something, even though you have to do it, you're suppose to do it... Because nothing happens to me... let's say, on the weekends, I sleep past noon or something, or even more than that, and I'll miss lunch. But if I have a friend come over, and knock on my door to ask me if I want to go to lunch, it is a lot easier to get me started, than to leave me there, and let me sleep. And that way I don't miss lunch. (IX, p. 21-22)

Matthew set up a study schedule but was unable to follow it. He described his process of failing to get started and to follow through on his strategy:

And sometimes I won't get myself to do it [follow the study schedule] because I'll be like "I have class in the afternoon and I have all this free time, I want to sleep a little 
longer" or something. And so I miss that study time because I want to sleep or something. And then, usually I always sleep, and then if I don't, then around 6 to 7 , or 6 to 8 actually, when I study in the library, sometimes I'll just be like "I don't want to walk over there," so I'll just study in my room. And I will study in my room for a little bit... but not the 2 hours that I needed. And that way, I only get one hour of study in a day, instead of 3. (IX, p. 18-19)

\section{Difficulty Sustaining Effort}

The students in the ne gative case could not sustain their academic efforts throughout the semester. June described a strong start to the semester that waned. She tried to muster more energy after the reality of her poor grades hit her at the mid-term:

At the beginning of the year, we got handed out these agenda things that had day-by day [sections], and that's where you would write your assignments in...there was a monthly calendar and I wrote everything in there. And that helped me. I do have an organizer, but I don't use it too much. I'm not very good, I write everything down in it, and usually at the beginning of the semester, I'll be like: "Okay, I'm going to get organized and get all of my stuff done" and it slowly just disintegrates, the organization, and the writing things down. I haven't really been reading as much... I start off, I'm like: "This is going to be different." Every single semester, I think since second grade, I said: "This one is going to be different. I'm going to start off better." And then it slowly goes down. And usually at the middle of the nine weeks, maybe when you get the progress reports, I start again: "Okay, this is going to be different," whenever you get your grades, it kicks in: "Shoot, I better do good on everything." I get into a pattern where I get more relaxed in the class. (XXXII, p. 27-28) 
Jason observed his long established pattern of not being able to sustain energy and effort:

I sort of shot myself in the foot this year, this is a common trend with me. My first mid-term report, I had all Cs. I had a 2.3 average. Whereas now I have maybe a 1.4, 1.3 average...That's my common trend, if you look all through high school, middle school, I do very well in the beginning of the year and then it all starts to go down hill. . . that's something I'm working on. (X, p. 8-9)

Robby described losing interest in keeping up with his schoolwork as the novelty of the college environment wore off:

I think to stay really motivated would be really good. . . I think it's kind of easy to lose your motivation a little bit, or to slip off. . . starting out really strong and then as the year goes on, it just slips off a little bit. . . When I came to college, I was really excited about it. And then I just calmed down, it didn't seem like that big of a deal anymore. I didn't have the same attitude. (XXIX, p. 11-12)

\section{Difficulty Organizing Multiple Tasks}

June decided not to continue in her major. She described being overwhelmed by the detailed requirements of the introductory courses in elementary education; it was as if she felt assaulted by the assignments.

I dropped Comp II and I dropped Children's Literature. The reason for [dropping] Children's Literature is because I decided if I do stay in college, I'm not doing elementary education; I hated that class with a passion. The stuff that you had to do in there, I was like: "No way, no way am I doing this." You had 3 bibliographies due every Thursday, and then you had an extra project on top of that. And I was like "no way." (XXXII, p. 17-18) It was just a horrible class. Did you ever take that class? I 
couldn't do that. It was like due dates were coming at me left and right, and I was like: "When am I suppose to do all of this stuff?" Every night I had something for just that one class. And it was like jees-oh-man, I'm a pretty big procrastinator. I think, even my mom knows that I work best in the last 5 minutes before something is due. I've just always been like that. And, it was difficult because I would have 8 projects due Thursday, and I would put them all off, and then I just couldn't get them done. (XXXII, p. 24)

By the close of the interview, June began to relate the symptoms of her disability to the difficulty she had dealing with multiple assignments:

I'm not very good at focusing my attention on things and then, it is better if they give you one thing to direct my attention, than scattering everything around, because then I don't know what to focus on, I guess. (XXXII, p. 26-27) I think that the questions that you asked made me realize things that I didn't realize at the beginning. And I think that if I would have realized some of these things at the beginning of the semester, I would have known what to do. Since I stopped medication and treatment, I thought I was done with ADD. [Then after talking I realized] how my ADD really does...I never put two and two together, that my ADD is why I don't like these classes [with multiple tasks and requirements], I realized that. I've never linked that. And nobody has ever linked that for me. But I think this would be really helpful for kids like the first semester, to have students come in and interview like this, and just have them talk it out. . I think that it's important to talk. And I think it would be a good idea to do that at the beginning because then you would have known me. (XXXII, p. 38-40) 


\section{Unclear Personal Goals}

Five of the students in the negative case example realized they had unrealistic expectations about their chosen major and dropped it shortly after beginning school. The other 2 students in the grouping were undecided about a program of study. A clear goal to guide the students through the challenges of the college setting was absent for these students. June could not to find a reason to go to class. She was challenged by high functioning, successful siblings and believed she would disappoint and embarrass her parents if she did not attend a traditional four year liberal arts college. June described how she had come to college by default:

I've never really been the scholarly type; I've really never enjoyed school. And then I mean even from eleventh grade until graduation, my parents were like: "Are you sure you want to go to college? We don't know if you should go to college." I used to be real ticked off that they were saying that, it really hurt me. And I did kind of think that college wasn't the route for me, but, I went anyways because I wanted to make them proud, and be like: "I'll show you," whatever, because I have 3 older brothers [she goes on to describe their highly successful careers]. And so growing up after all those, and then me not going to college, I felt that I was letting down my parents. And so I decided to, and I got in here. Which I didn't expect at all... and I was so proud that I got in here, like I got into a private school, and a good school, and so I decided to come. And my parents are like "Are you sure, that's a lot of money?" because we didn't get any loans, or anything. But I said no, I want to go. And I came, and I haven't been doing well in classes, even with the medicine. I've been trying to approach it with the mentality of, just do good, so you can get out. And I'll try to do good, and then it seems like I just don't get anywhere. I don't know, I have never 
really been good at school. And so it almost didn't make sense for me to come to college, and go through more, but now-a-days, it's absurd not to go to college because anything that you want to do, needs a degree....I think that I just don't have a goal; I try to set goals and I just don't care, because I don't really have anything that I want to do. And I have no real desire to be here, and I really never have. I've always been told you're so smart, but you just don't apply yourself... (XXXII, p. 1314) I don't really know what to do if I don't go to college. So that's what I'm struggling with because I don't know what else is out there for me. Let's see, there's being a shrink, which I don't think that I could get to do. But, it's always been a little thing that I want to do because I have the gift of listening...Possibly an interior designer, I think that would be fun, hotel management or travel. I really want to work with people, what ever I do... I plan on this summer taking classes to get my credits up, to get my GPA up. That's what I want to do if I stay on the college route. I still want to try, I don't want to give up. And I mean just because the disappointment of my parents, I really don't want my parents to have to say to people when ever they see them: "Oh, what is June doing?" "She lives at home, and she is not really doing anything." I don't ever want that to be their answer. I want them to be proud of me. (XXXII, p. 21)

\section{Complicated Relationships with Authority Structures}

The students in the negative grouping were able to follow thorough in critical circumstances; when college administration threatened to withdraw them from school, students wrote elaborate letters of appeal explaining their poor performance and detailed plans for turning around their academics. Many of the students described wanting a parental type structure to 
"hold their feet to the fire" so they could be more regulated and successful. Descriptions of authoritative intervention weaved through the personal narratives of the members of this grouping.

\section{Current Intervention of Authority Figures}

All of the students in this grouping discussed their parents' involvement in the decision to attend a college with strong support services. In addition, one or both parents of every student in this grouping called the support service office during the first two semesters to check on their son or daughter's use of services or to try to influence the student's life in some way. Jason described his parents' involvement in his resolve to work harder:

I lived on my own for a year and then got accepted at the last moment, thankfully, into this school. And then, my academics weren't doing so well this year, my parents instilled a consequence on me. [They] said if I don't pull my grades up to at least a 2.0 by the end of the semester, they're not going to pay for, or allow me to come back to school next year, which means I'm out on my own, again. .. And I need to come up with a mission statement to my parents that tells them exactly how I'm going to act from this point on, because they don't want to keep on seeing this common trend, and I don't want this common trend either. And that's something I'm working on. I mean the grades are not good right now and that's why I'm here at school. I mean, even in my major, I'm receiving. . . my mid-term was an F. And that's my life. That's what I focused on the past six years of my life. . and I have an F. . I I mean it just doesn't make sense. It shouldn't happen. (X, p. 8-9)

When asked how his work on this was going, Jason responded: 
Well, it took the whole year, but I'm finally pulling together my classes and my grades and the things I should have been on top of to begin with. It seemed like I mastered the whole social thing in the beginning of the year, whereas I should have mastered the whole academic side of it and then waited until later in the year to really focus on making new friends or being more social. It took a very large, what's the word for it, consequence. . . hammered into stone by my parents to really turn my attitude around, and it's a real wake up call. (X, p. 7- 10)

Arthur recounted that his mentor from the LD support program pressed him to use the services: He pushed me to get the note takers and that was a good thing. And he let me know about other services, like the test taking lab and stuff like that, which I'm probably going to do for final exams. I guess that I'm pretty lazy, so even though I knew that it would probably help me to have note takers, I never really thought about it last semester. And after talking with him, and thinking about how much better I need to do this semester, he pushed me to do it. (XVIII, p. 12-13)

\section{The Felt Absence of Past Structures}

The students frequently mentioned the absence of structure and intervention as they considered their transition. Matthew described the structure his mom provided during the year he did not board away for high school:

I have been used to [being told what to do] all my life, and then I come here, and find freedom. .. And then of course my mom always chewed on my ear to do my homework and stuff, and I mean, it helped, it did help, but, I really don't have that here, it's just tough. (IX, p. 2) 
Jason acknowledged that his behavior in high school was regulated by the structured environment of his boarding school. When asked about his perception of the difference between high school and college, he talked about the challenge of navigating his independence:

For myself, I think it was something I just had to learn. Because boarding school is was a very structured environment where you didn't have huge blocks of free time between classes or huge blocks of free time in the afternoon. Where you had the more structured environment, and unfortunately, it took away from your free time, but at the same time, it kept you on track. (X, p. 3)

Robby recounted that his parents and teachers kept him on task and in a routine during high school as he described the difference between high school and college:

I think [now] it's mostly just responsibility. Like when I was back in high school, my parents always made sure I did everything, like I got to bed on time, I did my homework, I ate dinner, got up for class. Now, it's all up to me. . I'm really independent, here, as opposed to home. . . I got spoon-fed everything. . . In high school I was all right, though, because I always had an organized time. Like right when I got home from doing track, wrestling, or soccer, I went home, ate dinner, did my work, and then later, I might watch some TV and go to bed. I just think. . . everyone told me how... what to do. Like the teachers, they always made sure you went to class, you got all the assignments. It was pretty easy, straight-forward. Here, the teachers, they don't care as much if you go to class. So, you really have to do your own work. (XXIX, p. 1-3)

Collin's life was similarly structured during high school. He described coming to realize that he needed to be more responsible for himself: 
[In College] you live on your own, and you don't have people telling you what to do. And that's where a lot of responsibility comes up. . laundry, clean your own room, your homework, projects, you know? [In high school], you always had teachers to kind of push you every day. (XXXI, p. 1-2)

\section{The Complex Connection and Separation from Parents}

Many of the students in this grouping described the ir parents as the motivating force in attending college. A few of the students explained the complex desire to separate from their parents while acknowledging their dependence on them. In some cases, parental involvement blocked the student from developing appropriate levels of responsibility. Mary Claire considered her mother's over involvement during high school:

It used to really bother me that my mom would have to come to the school, and my teachers would know these things, it was kind of a slap in the face when they would be like "Oh Mary Claire, how have you been doing?" "You know, I know what I'm doing, I don't need you to check up on me every 5 minutes.” I appreciated it, but it was something that I appreciate because it made me feel like they really were concerned and they really wanted me to do well in school and succeed, but at the same time, it's kind of putting me down, so I really am pushing away from that. . . it was very nurturing but at the same time it was very uncomfortable. (XXVI, p. 3-4)

Mary Claire continued to reflect on her ambivalent feelings over the physical and emotional separation from her mother:

I think being on my own and having to make decisions for myself and by myself, have really helped me developed as a person. ... I know in high school I was very shy around people, and around what I said to people, and how I presented myself to 
people. . . because I didn't know what was the right way to go about doing things. And I have always asked my mom and she always gave me good advice but there was sometimes I was like: "Mom look, you're not me". . . And I finally kind of stepped out of that mentality that my mom's always going to be one that makes my decisions. .. . I think being far away from home, and not having her with me, eve n though sometimes I really do need her. . . it's really difficult to be here, without that support. (XXVI, p. 6)

When I asked Mary Claire about the negative aspects of her transition to college, she talked of separating from her mother:

I think that's got to be the hardest thing for someone. . . is to be 5 or 6 hours away from home. . . and having things happen to you that are hard. It's like relationships, friendships, I mean everything, anything that happens. I had a friend go to the hospital, and how was I suppose to handle that? I came back to my dorm, and I had to cry alone, not with anyone else. It's hard, very difficult. (XXVI, p. 29)

June described confusion over establishing personal goals. In part, this uncertainty was related to her mother's jud gment about her own lack of education:

One thing that I have always thought about doing is being a stewardess maybe for a year. . but, I'm scared to do that because then whenever you get a job, you have to get a car, whenever you have a car, you have to make payments, and then you get roped into it, and then the college goal goes out the window. And so I'm scared to do that. Because I think that is what my parents want. Again, if you don't have a college degree now, soon, a college degree is going to be like an elementary degree to people. I don't want to be left out. I mean, my mom didn't go to college, she went to 
beauty school. Which I mean was fine; she was a hairdresser until she had kids. And she has always been like: "You know, you want something to fall back on. You don't want to just have this." And then I worked with my mom over Thanksgiving and Christmas, and I could never do that. And that was her little ploy to say: "Stay in college, you know, look at this, this is what you might have to do some day." (XXXII, p. 23)

When I asked Robby how we could help a student maintain effort throughout the semester, he answered by projecting himself into the future and describing his worry over disappointing his parents; he referred to his parents as a bridge to developing internal structures: Like I was thinking about that last night, how, you know, maybe in about five years, I'm going to be living on my own, and I have to do this all by myself. And just to make my parents proud, I stay responsible, and I stay successful. (XXIX, p. 13-14)

The parents of the students in this grouping attempted to be heavily involved with their child's functioning in the college environment. In addition, parental limits were allowed to be broken. Matthew's father warned he would withdraw him from school if he did not attend class on a regular basis during the second semester. When the son revealed to the father that he missed several classes in the new semester, the father did not follow through on his decision. The parents expected their student's mentors to run interference with faculty and to explain away the irresponsible behavior of their children. Collin's mother asked his mentor to try to convince Collin's professor to allow him to make up a test that he missed during the time he was away for a long vacation weekend. If the student descriptions of their parents' interaction were representative of patterns of interaction for the students in this grouping, one could hypothesize that this pattern might be one of many factors that interfered with the student's development of 
responsible functioning. June's mother was sympathetic to her daughter's grief over her grandmother's death, however, she sends a misguided message to her daughter:

And it is really hard being here, because my grandmother lived with me for 10 years in our house; she wasn't just a grandmother, she was everything. It's really difficult.... My mom's even like "They should give you all As and just let you come home." Because we were really close, it's really hard being here. (XXXII, p. 11-12)

Mary Claire remembered the dependency that evolved in her relationship with her mother, acknowledging that she has not yet developed a healthy sense of interdependence:

My mom and I play both, we switch rolls, and we have been doing this on and off for a long time. Since about when my father left, my mom has always been there, you know. And so I'm the mommy. I did a lot of stuff for myself. As always, I'm helping my mom. . I'm bringing in the groceries, I'm doing that, I'm doing this for myself because she can't do it right now. . . But then I got older, and it switched, and it was like I was depending on my mom for all of this stuff. She has to help me with this because she knows how to do it, because she is right because she is the mom.... Now, I'm still dependent on my mother, but when I'm here and talk to her, she is telling me: “Oh Mary Claire, I haven't eaten today, or I haven't done this today, I have been so tired and so sick" and she needs me. She needs me to be the mommy again. So we switch back and forth in rolls, depending on each other... That's how life has always been for me, it's very dependent on someone. And it's not dependent on doing for myself, but doing for someone else. If I don't have anything to do for 
someone else, I'm going to be dependent, you know, on someone; that's how it's been in my life. (XXVI, p. 13)

\section{Wishing for External Structure}

Many of the students in this grouping wished they had structures to help them get started to work and to help them manage the freedom and flexibility of their new environment. Matthew openly acknowledged his need for more external structure:

I went to 2 boarding schools before I went to my local school. It was really structured, like everything was really strict, so I mean, we had a bedtime, we had a study time, couldn't leave our room, and I think that helped. I'm glad that I have the freedom that I have now and the structure [of boarding school] was good. . . I I do wish I had more structure now. I know how to study, that's the thing, it is studying in general that is the hard part. . actually getting to do it is the hard part. (IX, p.3)

Jason observed that he did not discipline himself, acknowledging that it would be inappropriate for the support system to impose controls on his behavior:

I almost wish I had a more structured environment here. Like if I had a schedule that says I had to be here at this time, you know, this is designated study time, right here. I can't do anything but study in this time. But, you obviously can't do that, but. . I need a schedule. I need to be busy all the time, and I'll find ways to be busy, but those ways, most of the time, aren't the most productive ways of being busy. (X, p. 3-4)

When I asked Jason if he thought he would have learned what he knows now about his need to regulate himself had he been structured by someone else, Jason responded: "I don't think I would 
have. But, I think I'd be in much better academic standing right now. . . it's a paradox, because you get one to lose the other." (X, p. 3-4)

Matthew pointed to the fact that there is required study hall for varsity sports; he believed he would have been more successful with an imposed study hall:

If I was told to study at a certain time, and actually forced to study. . . I think I would do a lot better. . . Sometimes I wish someone would just pull me out of bed, or pull me out of wherever I am and sit me down. I don't know why I wouldn't mind, it sounds kind of childish; still, I really wouldn't care, even second semester. But it is a college, and I think you should let [students] have the option, let the person have the option of signing onto a forced study hall. . . where you sign away your study rights. I think that would definitely help. I think some people would do that too, because they know that they can't study without it, they really need it.They really need the study structure. The football team does it. They have study hall, it's not even optional, they have to go. . . My junior year [in high school], we had structured study hall, and so it was like what I was used to, it was easy to do that. And my freshman year I did so good, it was all structured and I didn't have a computer in my room, and I had nothing to do, except study. And I got a like 3.6 or something. That was the best I have ever done. (IX, p. 21-24)

Robby suggested that he might benefit from a daily check-in with his mentor to reflect on his organizational and academic progress:

I think sometimes I get separated and I really just stop becoming productive. If I maybe was supposed to e-mail my advisor everyday, saying what I did that day, that might be really good. . . just get to look back on it. You might not be thinking about 
it [during] the day... just looking back on everything you do. You might not have realized how much time you waste during the day. . . in the end, I don't do nearly enough work. . . so, I don't get behind in anything like if I miss my classes, I can tell her [my mentor] ... she can give me pointers. (XXIX, p. 15-16)

\section{Negative Reaction to the Structure of the Mentor}

Even though many of the students in this grouping wished for more structure, all were inconsistent about attending the regularly scheduled meetings with their mentors in the disability support program. Some liked the idea and thought the mentoring process was useful; however, the students did not regularly attend the meetings for the same reasons they missed classes or had trouble organizing to work. Others were clearly negative in reacting to the mentor's attempts to help them structure themselves. Robby was disappointed that he did not relate well with his mentor in the support program. He described his ideal mentor by contrast:

I don't know how much help I really got in the transition to college. That was one of my problems. . I had some pretty bad problems early first semester, and I was able to talk to my [first year seminar] advisor about it, and he was able to help me through them. ...Dr. ___ is a really smart guy and he really loves the students. He's been around for along time, and I think he's just all love. He knows what to do, and he really wants to help out. (XXIX, p. 14) I think I'm not very close to my mentor [in the support program]. I kind of wish I had someone else as an academic advisor for this. Mrs. is really nice, but if I had [my first year seminar advisor] I could

be a lot more open, and I could tell him what I really did. Like if I got drunk last night, I could tell him that. . . I don't know why, but I didn't feel that comfortable 
... It's like, you know, if you have a psychiatrist, you're supposed to be totally honest and have that trust. . And they can just tell you, you know, if that's good, if you're doing right or wrong, ask you questions. (XXIX, p. 16)

June did not like the questions her mentor asked about her academic functioning:

I see her every once in a while, but I don't think she helped too much. She made me feel really guilty a lot. I would come in and I felt like she was talking to me like I was 2 and I didn't understand what I needed to do. She helped me a lot with scheduling; that was helpful. And with questions she helped, but I mean going in every week, I found that I could be sitting at my dorm studying for an hour rather than coming in and telling her that I have been going to all of my classes and what grades I got. I mean I kept track of that my own. I didn't see a need for it at all. And then she would kind of look at me like I was doing things wrong. She would make me feel guilty a lot. Like at the end of all of our meetings, she would say, is there anything else that you need to tell me? Like mom would say when ever I had a guilty look on my face. And I mean, and I even stopped telling her stuff because she could do nothing, so I didn't understand why I had to tell her. I mean there was nothing she could do if I told her that I missed a class. (XXXII, p. 33-34)

June continued to elaborate on her reaction to her experience with her mentor: I think she didn't approach us as mature kids that were dealing with their learning disability. I think she tried to approach us as kids who needed her help and couldn't do this by themselves, and weren't confident in themselves, because I told her at the beginning, I said "I want to try to do this as on my own as I can." I really wanted to do that. And I know that support services are here for me, but I really want to prove 
to myself that I can do this because I know that I can. And she didn't respect that, and treated me like I didn't think that I could do that. Does that make sense? Like I told her that is how I wanted to approach it, and then she didn't follow up on that. (XXXII, p.36- 37)

When I asked June what kind of relationship would have been more helpful to her, she responded most negatively to the tracking function and advised us to ask more open-ended questions:

Probably just to say "How are you doing? Okay, sounds good.” And just ask: "You have any assignments coming up? You need help?” I have never really needed a person checking up on me. I never really needed that. I felt like I had a mom here. It was like: "How many classes have you missed this week?" And I would just stop telling her if I missed a class, because then she would make me feel like absolute crap. I already had felt like crap, I missed this class, I missed the points. I mean I understand that. Because I think I'm mature enough to understand what the consequences are of missing a class, and I didn't need somebody to yell at me for it. She never yelled at me, she would do a very nice to make you feel crappy thing. I mean does that make sense whenever people are being so nice, that they are being mean? I don't know if that makes sense.”(XXXII, p. 34-37)

\section{Problems Related to Disability Acceptance}

Problems related to disability acceptance plagued these students. Embarrassment over not knowing or having to struggle to learn impacted their lives in and out of the classroom. All thwarted available services and accommodations almost as if they would rather fail than ask for help. Conflict over accepting the life impact of the disability was evident. Many only disclosed 
their LD in emergency situations such as in their letters to appeal academic dismissal. Some decided to use accommodations during the final exam period in a last ditch effort to bring up their grades.

Disability related anger, resentment, and depression were expressed by the students in this grouping as well. Most had tired of all the exceptions made in high school; they wanted to leave their disabilities there. Not wanting to stand out as special permeated their dialogue on the subject of using accommodations and services. Going into a new environment seemed to be a good time to strike out on one's own. Paradoxically, this self-proclaimed independence backfired.

Self-Embarrassment over Disability-Related Problems

Because of their life-long vulnerability, persons with learning disabilities are at risk for the development of more complex emotional challenges (Rourke \& Fuerst, 1991). Feelings of isolation often result from any one or combination of the following: unsatisfying social interaction, a sense of inadequacy, or magnified frustration because of the felt individual difference. This condition may lead to the more extreme behaviors of "acting in" or "acting out" (Ostrander, Goldstein, \& Griffin, 1998; Silver, 1984, 1997, 1999). When an individual "acts in" he or she internalizes the negative feelings which can be manifest in any number of problems: eating or sleeping inadequately, developing psychosomatic symptoms, and becoming withdrawn, depressed, or even suicidal (Goldstein, 1997; Ostrander et al., 1998; Silver, 1984, 1997,1999). Mary Claire illustrated the student who "acts in" as a result of the disability-life experience interaction. She has grown up thinking she is wrong; not that she processes information differently. Her efforts to cover her disability have become impossible in the college environment: 
There were a lot of people that wouldn't know that I had a learning disability. They would just think I was normal. And I always thought as child with a learning disability, I was really embarrassed. . . And I guess it was the same way with shyness and the learning disability. ... And in some ways I wanted people to think good things about me, and I did n't want them to think that I was any different from them, any less intelligent, or any less anything, I wanted them to just think I was a sweet, nice person, who read a lot, and "she is pretty intelligent." I wanted that. I didn't want them to know that other side of me, the depression, learning disability side, I didn't want anyone to know that. . . I think that was a lot of who I was suppose to hide. . . but, people [in college] found out, you know, because they lived with me, so I guess that was part of the breaking too, people knew, because I lived with them. . . they see me everyday, and they knew what I was going through. . . and they would see the tiredness, and they saw me struggling with work that was very simple for them. And I would say: "Look do you guys know how to do this?" And they were like "Oh yea." They saw me struggling with papers and things like that, and when it's not something you can figure out on your own, that's a problem. . . . I think when people hear learning disability, I think people think I'm not as intelligent as I am. (XXVI, p. 8-9)

Mary Claire was unwilling to ask for the help she needed in a key introductory course required by her program of study, Music Theory. She was forced to drop her music major, a life long dream, as a consequence. Mary Claire approached her professor only when she understood something in lieu of exposing her weakness, even though the latter would promote her understanding of the basic skills. She has developed a fear of being wrong because of her prior 
learning history. I could almost hear the replay of her past traumatic classroom experience in her projection of how her Music Theory professor might respond to her request for help:

I was afraid of giving the wrong answer, and I was afraid of not being able to say the right thing, and have her [the professor] continuously go "No, that's not it. What is it? You know it.” And I'm like: “No, I don't know it.” That would have been very hard, it's embarrassment, I've gone through a half a semester. . . and I still don't know half of this stuff. . very, very embarrassing. I was tremendously embarrassed. And there were some days that I had to work with my friends, and they got it and I didn’t. Occasionally I would get it, and I was very excited about that. I was like "Oh, look at this, I know how to get it.” And I got so excited, I was like [to the professor] "I know how to do this" and she would say "Great." You know, it's not like she was unsupportive, she was always very, very supportive about it. (XXVI, p. 17)

Mary Claire continued to explain the distress of not knowing, even outside of the classroom: I don't like people to know that I don't know. . . especially if it is something that I think I should know. ... Sometimes I will cover it up "Yea, I know that.” But, I'm too embarrassed to say. . . "I don't know". . . I guess it's that perfect image again. . . I hated having to tell somebody that. (XXVI, p. 19)

The individual who "acts out" his or her feelings externalizes the negative feelings by blaming others or by channeling this energy through inappropriate means (Silver, 1984, 1997, 1999). Examples include defiance of authority or the shirking of responsibility for personal actions. A student may "act out" in an effort to numb or vent the experience of abnormality. Jason has a history of social and legal compliance problems. He was sent to a highly structured secondary school setting to remedy his "acting out." Anger and conflict are apparent in Jason's 
response to my question concerning use of accommodations and services. Although personal embarrassment is shared by both students, Jason's angry narrative contrasts to the tone of Mary Claire's:

I have been diagnosed with learning disabilities as long as I can remember. So, I've had so many years to just get over the fact that I have learning disabilities. I don't like having learning disabilities. I'm not comfortable with learning disabilities, and $I$ don't have to force myself to be. Now, I know that the Testing Lab and everything is here to help me. It's important for a teacher to be understanding toward somebody with learning disabilities. That's really all I need to say about that. . I'm very open. Anybody. . . I mean any person on the street: "You have a learning disability?" “Well, sure I do.” I'm very open with it. . . . The professor only really needs to know if you have a learning disability, if it's going to directly affect maybe an assignment they have given out, or anything like that. I mean. . . there are times when it can be awkward for a whole group of people to know you have a learning disability. ... Limiting the number of people that know I have a learning disability is always preferred over everybody knowing. That's always there, that's always a factor. You know, this is a really big part of me, you know, how comfortable am I with it. (X, p. 14)

When asked about improvements we should make to our program, Jason described his discomfort over using the services:

I don't think it's changes you can make, I think it's changes that the actual student has to do, or like it's an effort that the student has to take. . because you offer everything. You're open to. . . everything that the student has to do. And it's kind of 
like you're so open that you must rely on the student then, to come to you. . . I mean, you can't force somebody to learn. . . .Personally I came here for the learning support, so I'm going to take advantage of it when I feel comfortable taking advantage of it. (X, p. 17)

\section{Conflict and Denial over Acknowledging Needs}

Standing out or apart was very difficult for the students in this grouping. The individual's reconciliation with the learning disability and concomitant problems is a factor that may influence a person's success or failure in any environment (Higgins, Raskind, Goldberg, \& Herman, 2002). In the final stage of disability acceptance, transformation (Higgins et al.), the individual has learned to view his or her disability in a positive light. Because the person is able to see the disability "as a positive force" (p. 13) in his or her life, the researchers labeled this stage transformation. This phase relates to what Gerber and Ginsberg (1990) call a reframing of the learning disability: "appreciating that the key problem is not the disability itself, but rather the capacity to confront the various challenges one faces in living with it and overcoming it" (Gerber \& Ginsberg, 1990, p. 8). The students in this grouping had not yet reframed their learning disability, nor did they view their disability in a positive way. In fact, they shrunk away from bringing attention to it. Because of this, they did not go after the help or services that may have promoted their success.

Arthur reflected on the fact that he didn't use much needed accommodations and services during his first semester:

I knew about [note takers] last semester, I don't know why I didn't use them, I knew that I could. I just think this semester it is harder than last semester, so any help I could get would be nice. I'm sure that I could have done better [last semester] if I had 
a note taker in a couple of my classes; a lot of the information given in class I didn't know because I didn't take notes. (XVIII, p. 6-7)

When asked to think about why he didn't use the note takers during the previous semester, Art described his conflicting thoughts and feelings about using the accommodations he knows are appropriate to his disability, the feeling of difference this would bring about, and his desire to handle the college experience independently:

I don't feel like singling myself out. I'm not ashamed of having learning disabilities or anything, it's just like, I would have special treatment. I don't know, I would rather just learn like everybody else, and be taught like everybody else. I guess not like special treatment because if you have a disability, then you are equaling the playing field. I don't know, I'd like to overcome this on my own. Clearly, I haven't been a good note taker, I'd like to limit the amount that I get help. I know there's no way, even if I tried my hardest, to take good notes. (XVIII, p.14-15)

The testing accommodation process in the support program at the research site institution requires the student to bring an authorized letter to the instructor at the beginning of each semester to request one or a combination of the following: extended time, a reduced distraction environment, a reader, or a scribe. The student discusses any need for additional instructional support throughout the semester at this time. The support program mentor's name and contact information is listed on the accommodation letter so the professor can verify the student's information or request recommended instructional strategies, if needed. This procedure requires the student to be an active participant. I asked Matt his opinion about this process:

No, I have never given [the accommodation letter] to a professor. I like it [controlling the process of disclosure] because I think it gives the person who has the disability 
the freedom to disclose that information. I definitely think that's better. Just because I can say, I can choose if I want to let the teacher know, so I like the discretion. Not that it really matters to me, but, I'm sure to other people that it does. (IX, p. 15-16)

Matt denied his academic reality and explained to me that he never needed testing accommodations. He completed 2 semesters with a GPA under 1.0 until his academic dismissal.

Do I feel comfortable? I think so, to use the test lab? I would just say that I was diagnosed with a learning disability, and I'm allowed to use the Test Lab or extended time. I doubt that they [professors] would have a hard time with it. . . I have never had to give a teacher the [accommodation] note though because I have been doing pretty well on the time that it takes me to take tests. I have never run out of time or anything. Once I'm sitting down, I'm as focused as I'm going to ever get. And that's it. (IX, p. 17-18)

June had a stubborn desire to stay away from the services of the support program; she balked at the idea of self-disclosure, even in the face of poor academic performance both semesters prior to her dismissal. She disliked the idea of being perceived differently:

Really, the only reason I think that a professor should know is if he needs to send a test to the [testing] center, anything like that. And I mean, with tests, I always said that I'm really good at tests. I'm good at reading by myself, I understand them. If I need help, I ask professors. I never saw a reason to go to the Learning Center. I didn't want them to look at me different, because they didn't need to, so, I never used it. (XXXII, p. 37)

Arthur explained that he could have done better had he disclosed his disability to his professors and used the Testing Lab: 
I really rushed myself through tests. I've never been cut off, but I'm sure that I could do better if I had more time; I keep checking the clock to make sure that I finish in time. I could have used more time, and done a little better. I don't want too much help because then I would feel like I'm not doing it on my own. (XVIII, p. 16-17)

As the previous examples show, the students in this grouping were conflicted about acknowledging their disability to others and using prescribed accommodations. In addition, they were reticent to talk with their professors about academic issues. Mary Claire communicated her thoughts about the social intimidation and futility of asking for help:

I was too afraid to ask for help in class because there was so many other kids. ... I was like: “Ah, they are getting it, you know, they are getting it, I'm going to ask for help and I'm going to get it once, when we're working together, and then she [the professor] is going to leave, and I'm going to not know what I'm doing and then sit there another half an hour until class is over." (XXVI, p. 16)

Mary Claire labored over taking the risk of exposing her academic questions to her professors: If you did bad, go talk to him, that is the best that I can do right now. Is to just go talk to him, and say "Look Dr. I don't know what I did wrong, and if you could point it out to me, if we could just talk about it, that would be cool." Now, the big thing is, am I really going to say that, am I really going to take that risk to go off and say: "Hey, you know, I need to talk to you about something" or am I just going to accept it, and later on in life say "You know, you should have talked to him." (XXVI, p. 37) 
Help comes in many forms. Mary Claire was supposed to take medication to regulate her symptoms of Depression. Instead, she hid the medicine in her closet: She discussed her concern about exposing this need to her family and peers:

My mom didn't have them [medication], my dad didn't have them. Nobody in the dorms seemed to have any kind of problems with anything; you would go to these rooms, and I wouldn't see these big medicine bottles, I wouldn't see medicine anywhere. And you never heard anyone talking about how upset and depressed they were, and that they were getting help. I was afraid. . . and it was like, why would 1 want to come back to college and bring these medicines, and you know, your roommate is like "Why do you have to take those?" (XXVI, p. 33-32)

\section{Problems Related to Social Functioning}

The students from the ineffective performance grouping had difficulty making the social adjustment to their new environment. They were socially constricted, lacked assertiveness, preferred to stay isolated rather than risk rejection, and had thoughts of inferiority compared to their peers. They described unresolved fighting with friends, roommate problems, an over focus on their social lives, and the struggle for social acceptance. None of the students belonged to campus organizations. Many were still seeking help from their parents, high school teachers, and counselors from home instead of adapting to the helpers available on campus.

\section{Constricted Social Interaction}

Several of the students in this grouping did not work to get to know the peers or helpers that could provide support who were part of their new environment; they failed to make the social transition. June observed that she has shut down her social interaction: 
I really don't like it here. . . and I am coming to the decision that I really don't think that college is for me. Over break, since I was home with my mom, I talked to her about it a lot; there is nothing really here that I like at all. I mean I'm very social, and I really don't have friends here because I really don't like anything too much. I haven't gotten into anything, and I usually do, which is really off the wall for me. And I'm not sure if it's just being here because I don't like it here, or if it's just because I don't like college at all. (XXXII, p. 5-6)

She explained more about her unwillingness to expand socially:

It's just bad stuff. . . I was homesick. I really wanted to be closer to home, too. I'm only two and a half hours away, but still being away from my parents, I didn't like having to leave high school, being away from the people that I love, that was the problem. . . or, make it a home away from home, I didn't feel at home here at all. (XXXII, p. 7)

When I asked Robby during his second semester who he could go to for help, given the problems he revealed to me, he described relying on his past support system: "I think I'd talk with my college counselor from back home first, because I'm pretty comfortable with her. I might talk to my parents about it." (XXIX, p. 8)

Mary Claire described withdrawing from her peers. Fearing their disapproval, she believed that she should not disclose her negative thoughts and feelings:

I didn't feel very human, I felt very, very superficial. Not that I was trying to be fake with someone, just that I didn't want people to think there was something wrong with me. . . Not being able to let someone know the feelings that I felt really kind of killed me inside I think. Maybe that is the reason why I have the depression. (XXVI, p. 7) It 
might be that I have found myself not wanting to be around anyone. Just to be around myself. I think usually a lot of the times, the only person that I really want to talk to is my roommate, because she is in the room. And we both have been going through some things that we can talk to each other about. ... But other than that, I try to avoid contact with a lot of people. (XXVI, p. 22-23)

Sometimes finding a short-term solution can exacerbate the problem. June was unwilling to experience the discomfort of feeling alone and out of place. She was unable to establish a network of friends and activities because she didn't stay on campus during the weekends:

I really haven't made any friends with the girls in the hall because they are not really that nice, the girls around me. I feel more isolated this semester, but I don't really care. I'm just kind of doing my own thing. Last semester I went home, I went home pretty much every weekend. The girl that lived next door to me [lived] 15 minutes away from me, and she went home every weekend and so I always had that ride to go home. (XXXII, p. 9-11)

Jason developed a short term solution to avoid the discomfort of making new friends. He became quickly immersed in his roommate's fast-paced social life, which involved heavy partying, instead of developing his own friends and activities. I asked him about the difficulties he encountered during his transition experience:

I would have been more apt to associate with more people, or get out of my dorm room and . . go to a social event, or sporting event, or something like that. Because, I maybe wouldn't have felt so comfortable just hanging out in the room... My roommate is a local here. He lives a couple blocks away from the campus... and he kind of introduced me all his friends, kind of got me into the town and more a part of 
the town, like everybody that lives around here. I was. . . looking at a friendship thing, and a social thing, it was terrific. I always had something to do. You have the whole school side, I mean here comes the whole manageability thing again, and balancing the two sides. Always having something social to do is terrible. Because, you know, it takes away from, obviously, the other things, schoolwork and college. (X, p. 7)

Jason talked of spending too much time on his computer at the expense of mixing into the campus community:

It's always hard making friends for the first time. . . And sitting in your room on the computer is not a good way of going to find new friends. When it gets kind of late in the year, you realize everybody's already made their friends, and you've already had a chance to, you know, see who you want to associate with and you might miss your chance. . It's tricky with me, and people with my major, because you almost have to spend a bunch of time on the computer, learning. . . It's easy to use instant message to talk to your friends ... Even sometimes, I'll sit at my desk, and my roommate will be at his desk, and I'll talk to him [on Instant Messenger], and I'll turn around and be like: "What are we doing? We're sitting across from each other." (X, p. 5)

\section{Deficient Social Assertiveness}

Several of Robby's belongings were stolen by a "friend" in his dorm. He had difficulty asserting himself and reported being harassed by the guys in the residence hall. Focusing on academics seemed unimportant compared to the insecurity of not feeling in place, socially. When I asked him how his transition was going he focused on his social difficulties: 
I guess some people in the dorm. . . some people are just a pain. . . . That's just expected, though. I'm going to see that wherever I go. . . .Before, I was living by myself at home. But now, you know, I'm living with like twenty other guys on my side of the hall. And I see them all the time. You know, it's different. We can get on each other's nerves all the time. Like last night, this kid was just being a pain. . . just walked into my room, and he was bothering me and one of my friends and, we just wanted him out of the room. He was being kind of a jerk, just stuff like that. (XXIX, p. 4)

Like Robby, Mary Claire has had problems asserting herself. She disclosed her pattern of wanting to be viewed in a positive light at the expense of expressing herself. She observed that it seemed too risky to say anything that might create conflict:

I know, I really know now, that I can't be a perfect person. And I'm not going to be the nicest person, ever. And I guess, in a sense, I haven't accepted it, because I don't want to. I don't want to accept the fact that I can't be the sweetest, nicest person so that everyone always says: "Oh she is so sweet and nice." I know it's going to be there [the need to be nice] when I'm angry with people, and I'm going to say something that I may regret later on. . . . Whenever it happens now, I feel a little more relief and at least I feel better, saying look: "I really don't like what you are doing.” [And then], I'm like: “Oh, why did I say that? They are going to hate me." And I still feel this way, but at least I'm not afraid, some days, to take that risk. (XXVI, p. 6) 


\section{Thoughts of Inferiority}

Mary Claire is a gifted singer. It is almost as if she believed that the talents of others took away from her strengths:

My friends, not a lot of them, but in the fact that some of them are very smart, I felt very, very inferior. There was one girl who lived down our hall, just musical genius, played the instrument that I used to play, and is pretty good at it, and plays all this great stuff, and I just lost it. I think I felt so bad whenever I saw her, whenever she was around, I felt so musically inferior. . . I was just like: "Why can't I do that, why can't I be you?" (XXVI, p. 20)

Mary Claire continued to describe the deep-seated sense that there is something wrong about her compared to her friends; she worried that she might not say the right thing:

It's hard, it's even hard relationship-wise. I wanted to get involved with some guy, but I knew that he was very smart, and I was always like; "Oh God, I have to be intelligent if I'm going to talk to him.” And so I always thought I had to have something smart to say. And when we started talking, I thought maybe I don't have what he is looking for. . . . I always feel that way, that I am inferior. I feel like, all of the time, that my friends think that I'm inferior to them. And I try to say to myself that I'm smart in ways that other people are not. . . I I want to sound intelligent in what I have to say, so I just don't say anything. (XXVI, p. 21-22)

\section{Difficulty Adapting to the Academic Environment}

All of the students in this grouping had problems adjusting to the fluid environment of the college setting; they had not internalized the structures that previously held them in place and productive. Academic problems came about not only from self-regulatory deficiencies such as 
the inability to multi- task, to start and sustain work, and to establish routines, but also from deficient academic preparation. The students in the negative case grouping were not ready to manage the complexity of college level work. In retrospect, the students observed that their high school resource teachers had pampered them.

Some of the students had been over-structured by their parents and teachers;

consequently, there was no opportunity to learn to self-structure with guidance. Several students cited the low academic expectations of their high school teachers as a factor which undermined the development of an appropriate work ethic; the students were given too much of the wrong kind of help. Their current academic functioning was inhibited by not knowing how much to study or how to predict performance. Academic success seemed like a game of chance to the students in this grouping. Finally, it was hard for the students to find a reason to stay motivated for academics when their dreams were dashed by failure in an introductory level course fundamental to the chosen program of study.

\section{Prior Experience: Inappropriate Help and Low Expectations}

The following description permits an understanding of June's academic culture shock as she transitioned to the college environment. June believed that short term solutions and wellmeaning modifications put into place for her disability had the impact of inhibiting her academic development. According to June, low academic expectations on the part of public school system undermined her work ethic:

They finally put me on medicine and treatment and stuff in middle school and I got the extra help and all of that stuff, and I really think that made me stop applying myself on purpose, the academic support. Because whenever they told me I had ADD, it was like okay, "I am dumb." And I know that's not what's supposed to 
happen, but I think that's what happened. . . Having to go into the other room to take tests and doing all that stuff. And I was being told that I was dumb, and on top of that, all of my learning support teachers gave me answers, gave me study guides, I never had to work. And so now I'm coming to college, and I haven't been taught anything. All of my goal setting [IEP objectives], all my extra help made it harder for me to do all of this [college work]. In high school, the reason that I would go to another room for tests is because they would give you the answers. I'm not going to lie about it, but I would go to another room where they would read me the test, and I would say: "I'm having trouble on this question." And they would say: "Well, it's either AAAAAAAAAA, or B," and I would be like: "Okay." That's how it would always be, from sixth grade on, I got all of the answers. I got study guides when other kids didn't. I got adapted tests with 3 questions and so I had no reason to try. I have no work ethic at all. I was taught that when I wouldn't turn in assignments my teachers would say: “That's okay." And so I wouldn't turn anything in until the end of the semester. I would turn all of my stuff in, and then they would be like: "Okay." And they would take off no points for it because I was in Learning Support. I turned my senior project in late, by like two months, and I got no penalty on it. And so I have gone from: "Oh, I'm so sorry, you're in Academic Support, okay, well you can get this done this way," to: "I don't care." I didn't even show any of my teachers [in college] the letter that I was in academic support and I didn't take any of the help that was offered here either because I realized I was taking all that stuff just because it made it easier. And I didn't have to work as hard. I knew that I didn't need it. And so whenever I came here, I was kind of like, "I'm just going to try and do it on my 
own." And now that I have to do everything on my own, I don't know what to do. (XXXII, p. 14-16) I've talked to another girl on my floor who has a learning disability too, and she has really struggled here. She said she had straight As in high school because everybody did everything for us. And, I mean that sounds like that wouldn't be a problem, but it hurts you so much, because I have no ability to try because I still think that someone is going to do it for me. And now in college, nobody helps you. (XXXII, p. 28-29)

Matthew explained how little he needed to study during high school:

I would like to have known how to study a little better because I studied in high school, but the material was a lot easier, and I could just study for like 10, 15, 20, 30 minutes, and it [the information] would have been in there and I would have gotten a good grade. And then I come here and I have to study a lot of material over a short period of time. (IX, p. 4-5)

\section{Insufficient Readiness and Preparation}

Mary Claire's sentiments represent the students in this grouping: "Nothing helped me to prepare for this transition. .. I jumped in. . . there was nothing to help prepare me." (XXVI, p.

26) The change in the amount of work required for his college level classes left Art at a loss for knowing how much time and effort was needed once he got to school:

For me, it's a huge change. . . My last year of high school was a joke, I did very little work. So when I came here, it was a big difference to me. The work here wasn't huge or immense. But it was a big difference from high school. It is not an intolerable amount of work, but compared to nothing, it's a lot. (XVIII, p. 2)

When I asked Art about his preparation for college, he responded: 
I don't know if I could say. I don't know if I was even prepared for college. No, I don't think, I don't think I was prepared as well as I should have been. ... You've got to work hard. . . you have to work harder than you think you have to. I just I thought I was doing work at the beginning of the semester, last semester, and my grades didn't reflect it as much as I thought they would. I just have to work harder. . . I think I opened a textbook like three times. There is so much reading, that's the big difference. (XVIII, p. 3)

June revealed her surprise at the amount of study time required in college:

Last semester at midterm grade report, I had no midterms and I was so proud of myself. . I was like: "I must be doing everything great, that's awesome." And so I kept on doing what I was doing and then I had Fs in some of my classes. And my brother said to me: "You know what? My first semester, I thought I was studying a lot because I was studying more than I was in high school. I thought I was doing everything that I could, but I wasn't. Because I never studied in high school, I was studying this much, when I needed to be studying this much in college. But I didn't know that. I didn't know how much I actually needed to do." (XXXII, p. 30) Robby was shown organizational strategies while he was preparing for college but he never practiced them. He was not given the chance to make decisions about his free time during his high school years as his parents and teachers closely monitored his behavior. The college setting demanded more behavioral change than he was capable of making:

I don't think I was really that prepared for the transition to college, actually. I worked a lot with my college counselor about strategies, things to do to make sure I'm organized and staying responsible. . I used to talk to her like every week. I 
should have practiced them a little bit more though. That could have helped a lot. . . A lot of things are just getting the routine of things. Just pretty basic things, like getting everything out of the way as soon as possible. . I just wasn't too organized, and I jumped around a lot and I wasn't very efficient with my time. . . Just the time schedule, it's a lot more free. You can do anything you want. (XXIX p. 2-3)

\section{Inadequate Effort}

The students were not experienced enough to predict well their study/performance ratio, yet many from this grouping tried to calibrate their efforts as if they would be short-changed had they given their studies more effort than was absolutely necessary. June missed the mark when she predicted that her Composition class required little effort; she had to withdraw from the class because of failing grades:

And I think why I did better at Biology, I thought okay: "This is a hard class, I need to buckle down hard core, I need to do this, I need to study every night, I have to keep up on my reading." But then in other classes, like Composition, I was like: "Oh, this is an easy class. It's going to be a breeze; I'm not going to have to do anything." And whenever I think that, I convince myself of that and then I don't try as hard in the class. I do that a lot. If I tell myself I don't have to work, I just I don't. (XXXII, p. 26)

Art also had difficulty predicting his performance. It appeared that there was no relationship between effort and performance:

I'm just used to getting by. But, I don't know, it seems like sometimes I like work really hard in a class and I expect a B or something, and I get a C. And other times I don't think I work hard at all and I get a better grade then I think I'm going to. I 
always hope to get good grades, but I never have an idea. . . I can give you two examples, in [Study Strategies] class last semester, I was pretty sure I was going to get a C, maybe even less than that. And I ended up with a B-. And another class I thought I worked really hard in was my Computer Science class, and I was hoping to get a B, and ended up with a $\mathrm{C}$. That was one thing I was disappointed about. . . But, if I work really hard, it's kind of like a crap shoot. Sometimes I work really hard and I get what I expect, like a good grade, and sometimes I work really hard and get crappy grades. (XVIII, p. 7-10)

Jason believed he could finish the semester in good academic standing even with an F average at mid-term:

I know exactly what I need to do at this point to achieve that goal. I have to be confident, I can't think otherwise because there's so much at risk for me. Like I said, it's like a pattern, I've been in this position before. (X, p. 9)

Arthur did not focus on learning his course material as a standard of measure; instead he looked for the grade to determine his study efforts. This method proved ineffective and unreliable:

Feedback really helps me determine how hard I'm going to work. And the only problem is that you get some feedback on your exams, but you don't even know how you are doing in a class until mid-term. So, I would be changing a lot of stuff if I were getting feedback from the professors. . . I don't know, even if I add all of my exams together, I don't know how they grade, so I don't know [how I am doing]. (XVIII, p. 20)

Mary Claire regretted that she was unable to persevere with her Music Theory class: 
Maybe if I did tape the class...I would have been able to listen to it repeatedly and go: "We did this and we did this," and I would have been like "Oh, yea, I know how to do this now." Going over it twice, and doing it twice would have been a big thing for me. (XXVI, p. 16) And I just did awfully in that class, but I'm wondering if I would have done better if I would have taped it. . . .And I'm wondering if I could have just gone and talked to her [the professor] after class if she didn't have anything to do. Would have that helped? (XXVI, p. 18)

\section{Losing Purpose for Being in College}

The students in the negative case grouping who had declared majors were unable to regulate their efforts to manage the introductory courses in their program of study. Out of the 7 students, 2 had not declared a major. The other 5 were forced to give up the major which they began. Adapting to the loss of specific life goals impacted student motivation. Mary Claire gave up her music major because she was unwilling to ask for appropriate accommodations and help from her instructor; she admitted that she could have persisted to finish her Music Theory class:

I was really uncomfortable being in a room [to test] with a whole bunch of other students, and there was not that much noise going on, but when the kids were leaving, and I'm still sitting there, still working on the first page, it's very hard and it's just like: "You know, I'm never going to get this test done," and then I would just be like: "Forget it. Just forget it, I can't do it." I really wish I could have done so much differently in that class. (XXVI, p. 17-18)

Robby decided to give up the Athletic Training major; his energies were sapped by the difficulty of his first core course : 
I was really overwhelmed by Human Anatomy and Physiology because I didn't realize how much work would be in that class. Like the lab? You might have to memorize a hundred and fifty different body parts, just in one week. I wasn't ready for that at all. . it took up so much time, that my other classes suffered. Like First Aid, I was doing great in that at first. I had an A for the first two tests. And then it dropped down to like a C-, or something. (XXIX, p. 4)

June learned from upper-class peers that all of the courses in the Education major required keeping track of numerous details. She had not recognized the relationship between the challenge of multi-tasking and her disability until this interview:

I just got too frustrated, and I was like: "I'll take it with another teacher, another time." I knew that I would just go nuts over the class. And I was going nuts, and then whenever I decided that I didn’t want to do teaching, I was like: “ this class, I'm not going through this for [it] not being my major; no way, if I don't need this class, out the window." It's in a lot of those classes, I've seen them coming down the road, I see people in higher grades and I'm like: “Oh no, I'm not doing any of that stuff. Teaching is not for me." Teaching is not for me any more. (XXXII, p. 29)

Jason had struggled to stay in his major up to the point of our interview. A semester later, he had to give up his intention of majoring in Computer Science because his GPA in the major did not meet the 2.0 requirement:

And that's something I'm working on. The grades are not good, right now, and that's why I'm here at school. I mean, even in my major, I'm receiving. . . my mid-term was an F. And that's my life. That's what I focused on the past seven years of my life, 
Computer Science. And I have an F. . it just doesn't make sense. It shouldn't happen. (X, p. 8-9)

\section{Inability to Manage Life Circumstances}

The students had trouble managing the everyday problems present in their life circumstances. There was often either a magnified response or a shutting down that exacerbated the original problem. They created a life for themselves outside of academics. Hard partying or playing became the escape: the students engaged in some activity which took them away from school work or helped them forget about the academic reality of the college environment. Daily mountain-biking excursions, consuming fitness programs, captivation by computer generated virtual realities, and total absorption in partying took priority over going to class. There were also signs of crippling self-doubt; the students in this grouping were easily defeated by their initial failures.

\section{Inability to Cope with Everyday Problems}

When June realized the pervasiveness of the detail required in the education major, she could not motivate herself to go to class or do her assignments. Usually when the student realizes the original major will not work out, he or she is able to work on general studies requirements and to actively seek out a different course of study. June could not cope with the disconnection between her past hopes and present circumstances; she dealt with her disappointment by shutting down:

I don't get any gratification from knowing that I have a B because I just don't care about the work, about studying. Like I don't even get gratification if I had an A in all of my classes; I don't think that it would even matter to me. Right now I'm Elementary Ed and I don't really want to be a teacher. There is nothing that I really 
want to do; I don't have a desire to do anything. I just don't know right now. It's not there. It's not as if I get an A in this class that I'm going to be one step closer to being a teacher because I don't care, I don't know what I want to do. There's no goal, there's nothing. (XXXII, p.19-20)

Mary Claire overreacted to events that are commonly experienced by first year college students. She recounted an experience where she lost her ability to cope because she let her problems build up:

First semester, I just kind of went on a tantrum. . . I really have a hard time dealing with pain, and I guess because I let it build, it just comes out really bad. And I'm so upset. . . I just broke into tears, and like I couldn't stop, and I just sat in my room, and I cried and I shut the door, and I didn't talk to anybody, and I wouldn't come out. . . I was just so upset. I couldn't do anything, I couldn't move, and all that I could do was call my mom: "Will you help me, help me. I don't know what is wrong with me, I can't stop crying, there is something seriously wrong." (XXVI, p. 33)

Mary Claire had trouble contending with competition, even in the area of voice, where she was gifted. She was assigned the lead role in a major play on campus. Even so, she could not fully believe in her talents:

If I don't get picked for that one solo and somebody else does, I'm like, you know, maybe I'm not as good as I thought as I was. And I had, there was still that period, when I'm like: “Ah, I can't sing as well as I used to. I don't have that voice tone, that quality that I used to have, where did it go?" It's nice to hear people say: "Oh, you have a beautiful voice," but I'm never like: "Oh yea." I kind of discount it and discard it. (XXVI, p. 20- 21) 


\section{Denial of Academic Reality}

The student narrative carried a denial that disconnected them with their academic reality. The academic probationary status of the students showed they were not transitioning well. June earned under a 2.0 GPA both semesters before being dismissed from school: "I never really saw a transition to it. It was pretty smooth, even though I didn't do good the first half, I think." (XXXII, p. 31)

At differing points during the interview, Art disclosed how surprised about and unprepared he had been by the amount of academic work required. In this segment, he said the direct opposite:

I expected a lot more work. Everybody talks about college as being a lot harder. But, there was nothing too difficult, nothing that I couldn't deal with. Besides the workload, there was nothing else going on that bothered me. I don't think that the workload that I have is too much for me. (XVIII, p. 11)

Mathew was a master at fooling himself and others. Saying he was doing something, like going to class or taking tests, made it true for him. In reality, he had attended a smattering of classes and completed a marginal number of tests and assignments. This deception of quite possibly himself, his parents, and the institution, allowed his negligent continuation for 2 semesters. From his point of view, if he awakened for class one day in a particular week, he was making progress and going to his classes. His GPA was below 1.0 both semesters before being dismissed for academic reasons:

I feel like I have made a lot of progress throughout the year, not just studying wise, it's just like everything, like life. I learned to live by myself, living by yourself without rules and stuff. I don't talk to my parents very often because I don't have a 
cell phone. I learned to be a lot more independent. I think I have learned a great deal too, school stuff, taking care of myself, waking up in the morning, by myself, with an alarm clock. (IX, p. 3-4)

When asked about his perception of his transition, he responded that he was pleased about his social life. His social life is a priority, academics are on the sidelines: "Pretty much everything I think is going well right now, besides a few classes that aren't going too well, but my relationships, friends, and all of that is going good.” (IX, p. 8)

The following excerpt is an example of Matthew trying to talk himself and the interviewer into believing his academic situation was not as grim as it was. Pinning him down for a straight answer was a challenge. Things are "not perfect" and he is doing "semi-poorly" but he might be "okay" if he does a good job on a Psychology Lab. He received 3 Fs and one D- in his major academic classes the semester we interviewed:

Some classes are not going well... What exact classes are not going well? I'm doing semi-poorly I'd say at Math. . . as with Psychology. . . and then I'm semi-worried about Criminal Justice. Not as bad as Math and Psychology. In Math I've done poorly on some tests and quizzes. And my attendance, because it's an 8:00 class, hasn't been perfect. Attendance, if your attendance is going bad, then it counts for your grade, so my last test is going to be my attendance. So it might not be very good at all. . . I don't know. I would say [I missed] around seven or eight [classes], would be my guess. Psychology is okay, it's just pretty difficult, and I have been doing bad on some tests, and some of the hand-in assignments I haven't turned in yet. And then I have a lab that we are doing right now, and if I do good on that lab, I should be okay. The lab should help, yea. (IX, p. 8-10) 
Facing the fact that she had several absences from all of her classes was one reason June didn't like meeting with her mentor:

I came in open, and my mom was like: "I really like all of these support services they have; I really want you to use them." And so the first couple of meetings with my mentor I was open about them, and I didn't judge anything that happened in there. I tried not to get an opinion about it. And then I found myself being like: "I don’t need this stuff." And I found myself lying to her about missing classes because I just didn't want to hear anything about it. . . and then I just stopped coming. I just shut myself off to her because I knew I didn’t like her. (XXXII, p. 36)

\section{Lessons Learned from Failure: Denouement}

A few of the students in the negative performance grouping reflected on personal obstacles to making the transition to the college environment. Although they understood what had gone wrong, the students were inconsistent about following through on their resolve to initiate better work habits. And the students who could follow through on their ideas for improvement did so inconsistently. There was a roller coaster pattern of academic success and failure for most of the students in this grouping.

Collin was able to raise his semester GPA to 2.0 for the 3 semesters following his first disastrous one. His GPA slipped again his fifth and sixth semesters. Finally, after his sixth semester, he withdrew from the College. Collin remained dependent on helpers and friends and sometimes made the 2.0 by the skin of his teeth. His narrative was full of ideas about how he could and would turn his academics around. Collin was the only student in the negative cohort that did not try to cover his disability from his professors or peers. He learned that keeping a 
calendar was essential to organizing his academic functioning. I asked him how the calendar was helpful:

When you pen it [the calendar] up, if you don't have anything to do, you look for the next day and see what you could get done.... Like you don't necessarily have to do everything in one night, on a Monday night, but, do a little bit of this, for something that's due Friday. You know, you can see it, it's more visual. I'm a visual person. So that kind of helped. (XXXI, p. 6)

In addition to living by his calendar, Collin talked about other changes he put into place after an unsuccessful semester. At the end point of his first semester, Collin decided to try using the type of medication that had been prescribed for him since childhood, believing that it would improve his focus in the demanding and complex postsecondary environment:

Medication helps...I never took it in high school, but I've always had that prescription for it...it's always been an option. But, you know, I just decided not to take it...I got by in high school, but in college, it helps a lot more, because you're able to sit down and focus.... [I started it] towards the end of last semester. (XXXI, p. 14)

Collin began to utilize strategies to learn and remember the information in his classes: Reading and rewriting, high- lighting, outline. I don't know, basically just making things visual, charts, you learn all of it in Study Strategies, reciting, asking questions...even after class...I do whatever I need to do to understand.... I try and start anywhere between like three or four days, maybe even five [to study for a test]. Study groups help, somebody understands something, you know, coming from a student, I guess it would just make it in easier terms to understand than a professor 
would...get like three, four people...not large, because you don't get anything accomplished, because you goof around, but, if it's just like a couple people, then you do get a lot done...I would say every time I have a test, I'm studying with someone...because I might understand something that they don't know. Or they know something that I don't know, they can explain it to me. You see what I mean? (XXXI, p. 12-13)

When asked about disclosing his learning disability, Collin responded positively compared to the other members of the negative case cohort:

I really don't know if I go into specifics, but you know, I tell them I do have a learning disability...I think a couple teachers asked. I shoot straight with them...It works for me...I think it's pretty efficient...Actually, I think it's better [telling the professor yourself], because that way you get to meet the professor, you actually get to talk with him, so...The more you meet with your professors, I guess the more they like you. You know, they think that you care more, or something...I found it helpful, it worked. (XXXI, p. 10-11)

I asked Collin how he thought his transition to college had gone. He observed that his grades and his skills were improving:

My grades have improved. You know, I'm still coping with all the teachers; it's a lot different from high school. So, when I write a paper, you know, their expectations are a lot higher...I try hard on it, and then I get it back and it's like a C or B, you know, and I'd be thinking it was an A or something...Like my papers...they have improved, just because I learn from the teachers. (XXXI, p. 6) 
Collin knew himself well enough to understand he would have been distracted by an urban environment:

But the only thing that was like a shock to me was the location. You know, in the middle of nowhere... Believe it or not, it's kind of more helpful, because you know, you're not in the city...you can't go out every night. Like you're kind of forced to sit it your little eight by four foot room, and study...do what you're supposed to do, so...instead of horsing around, because I know if I went to a school in the city, like as a freshman, I probably wouldn't be going back there....I still wish I had all the opportunities, but like to give you an honest answer, it's actually kind of good. (XXXI, p. 4)

When I asked Collin what advice he would give to an incoming student, he replied: Stay on top with all the work...don't get behind, get stuff done as early as possible...just do your work and go to class...It may not sound like a difficult task, but it kind of is....you don't get as much sleep, you know, you always have an opportunity to do things, but you have to make yourself sit down and study.... You have a lot of self-defeating factors that are not school-related...first work, then play...my grades, you know, they weren't so good, at first...I tried it the other way around and it seems to be working...I did more play than work [first semester]. (XXXI, p. 14-16)

Colin earned a 2.5 during the semester we interviewed. This was quite a comeback considering the 1.33 GPA he earned during his first semester. He withdrew from school after earning a GPA under 2.0 his fifth and sixth semesters. 
Although conflicted about disclosing his learning disability and using services and accommodations, Jason had several ideas about how he should approach his academics. He continued to have trouble following through on his insights and balked at disclosing his disability or going for help. Jason's resolution to do better focused more on controlling his own behavior compared to the help seeking strategies used by Collin. When asked if there was anything he wished he knew at the beginning of the year that would have helped him make the transition to college, Jason responded:

I had no idea how important it [managing myself and my time] was going to be, until it was kind of too late in the school year...Time goes by so quick here and without stopping and thinking about...what you're doing and where you're at, you could just lose a whole semester so quick...I mean it would have been so much better...to remind myself continuously: "What am I doing right now? How is my [academic] standing right now?" When I first got here, I didn't want to hear from somebody that you have to manage your time because I was convinced I could do it myself. But right now I would tell somebody that you have to manage your time... They told me in Freshman Seminar that it was going to be the most important part of this year...the responsibility for your schoolwork and the time you spend with your friends...they stressed it all the time, but it doesn't sink in, because you want to experience it for yourself...If I was sitting in this position at the beginning of the year, I wouldn't want to hear that, I would say I could do it myself, I'm not concerned about it...But now, I'm almost at the end of the school year... and I wish I could have just taken that in, and just really done it. (X, p. 2-3)

Jason talked about what he gained from the absence of external structure: 
I almost feel like I'm resetting, starting next year's school year off where I should have began this year. Because now that I have a whole school year of trying to find my way, so to speak, I can start off next year's school year with two feet on the ground.... Unfortunately it took a whole year of my first year at college...I think everybody wishes they could see into the future, but the key is figuring it out before it becomes too late. (X, p. 4)

Jason was dismissed for academic reasons after his sixth semester of enrollment.

June realized that she had to be frank with her roommate in order to take better care of herself:

I'm being a lot more selfish with my sleep because last semester I would be with my roommate, and if she wanted to stay up, I wouldn't really say anything because I would feel bad, but now, I'm kind of like: "I need to go to sleep, get out of the room.” She's really good about it. (XXXII, p. 4)

In addition, June described how she learned about appropriate study behaviors: Reading my stuff before the class, studying with friends before the tests, like in the class, we all get together, that helps me a lot. You know, the quizzing kind of thing with people, I can't just look at a sheet of notes and memorize. I need people to ask, it helps me cement it more. (XXXII, p. 38)

June left school after two semesters with a cumulative GPA of 1.72, both semesters under 2.0, the GPA required to be in good academic standing.

Art decided to try to use accommodations and services and to study outside of his dorm room. I asked him if there was anything he would do differently if he could do the semester over again. He believed he would be dismissed after his second semester: 
One is starting to use all of the help that I can get. I'm definitely not trying to study in my room any more. I found out that's impossible. There are a lot of good things that I can leave here with though, like spending more time in the library. (XVIII, p. 18)

Art began to establish a schedule:

Everyday I set a time-line for myself, like when I'm going do what, when I'm going to this and when I'm going to that. Like today I know that I'm going to the library as soon as I get back from dinner, and stay there for a couple of hours, and then I'll get my studying in. I get all I can, done, and then I go back to my room. (XVIII, p. 19) Art's cumulative GPA after 4 semesters was 1.91 . He was never able to earn the GPA required to be in good academic standing after 4 semesters of enrollment. Art was dismissed for academic reasons.

Matthew was dismissed for academic reasons after 2 semesters of enrollment. His cumulative GPA was 0.74 .

Mary Claire and Robby are the only students in this grouping that have maintained enrollment. They are beginning their $5^{\text {th }}$ and $7^{\text {th }}$ semesters, respectively.

\section{Summary of the Negative Collective Case}

Although the average full-scale IQ and the average number of diagnosed disabling conditions were similar for both the negative and positive transition cohorts, the 7 members of the negative grouping earned an average cumulative GPA, taken after each student's most recent semester of enrollment, of 1.86. During the time of matriculation at the research site institution, each student within the ineffective grouping earned a GPA under 2.0 and was placed on academic probation for at least one semester of enrollment. Individual cumulative GPAs for the 
ineffective performance students, taken after each student's most recent semester of enrollment, ranged from 0.74 to 2.27 . At the time of this writing, 2 of the 7 or $28 \%$ of the students from the negative performance grouping are still enrolled at the research site institution. The narrative of the individuals within the ineffective performance grouping was analyzed and synthesized into thematic patterns for case presentation. Several distinctive conceptual commonalities clustered the students by patterns of outlook and behavior as well as by the negative performance outcome, an average cumulative GPA of 1.86 .

The students in the ineffective performance grouping revealed the following nonadaptive patterns during their transition to college: inadequate self- understanding and self-management, complicated relationships with authority structures, a reluctance to accept their disabling condition which resulted in taking on a misguided independence, unconstructive patterns of social functioning, problems adapting to the academic environment, and an inability to manage developing life circumstances.

Inadequate self-understanding and self-management - The students in the ineffective performance grouping revealed the following problems linked to self- understanding and selfmanagement: establishing a routine, following through on strategies or plans, sustaining effort, organizing for multiple tasks, and establishing academic goals. The students' reporting revealed a disconnection between what the student understood to be appropriate activity and the student's actual behavior.

The students reported difficulty in establishing an academic routine; they had not internalized the structure of their prior environments and did not manage themselves well in the context of the freedom of the college setting. Even though the students described a life absent of academic routine, they were busy and able to organize to participate in other endeavors such as 
physical fitness, gaming, mountain biking, traveling home, and socializing. The students in the ineffective performance grouping did not follow through with the decisions, plans, and strategies they knew would help them navigate the college environment. They reported not being able to make themselves do what they knew they should. Not making it to meals or not following a selfset study schedule are examples of inadequate student follow-through which impacted student health and successful performance. Although several students from this grouping observed they had enrolled in the college because of the support program for students with disabilities, they did not use it. Personal knowledge that they would perform better with services did not impel the students to utilize them. There was a disconnection between what the students knew to be true in theory and how they acted in reality. They talked about their ineffective behavior as if they did not understand the reasons for their inability to make sound decisions to manage themselves.

If the students from the ineffective performance grouping were able to start a task or begin with a plan, it was difficult for them to sustain their effort. Their narrative revealed a pattern of starting out strong, only to lose academic momentum. When the novelty of being in the college environment wore off, so did student effort and energy. The manage ment of multiple academic tasks was overwhelming to many of the students in this grouping. Many of the students were used to receiving highly structured assistance to manage the work of their classes. The detailed, complex, and independent requirements of the course work in the college environment posed an insurmountable challenge for the students in this grouping. Finally, the students from the ineffective performance grouping were uncertain about their goals or purpose for attending college, almost as if they were in school by default or because of the students' perceived expectations of their parents. 
Complicated relationships with authority structures - The following indicators of complicated relationships with authority structures were manifest through the ineffective performing student narrative: ineffective attempts at intervention on the part of authority figures, student expression of a felt absence of past authority structures, the paradox of the student wanting both parental connection and separation, expression of the wish for external structure, and the students' negative reaction to the attempted intervention of the mentor.

Complex descriptions of authoritative involvement weaved through the personal narratives of the members of the ineffective performance grouping. Authority type figures, represented by the college administration, the parent, or the mentor from the LD program, tried to intervene in the students' college experience. The parents of the students in this grouping were closely involved in their child's functioning. There were several examples of the parents trying to control the behavior of their student by setting academic behavior and outcome targets. Many times, the parents allowed the limits they set on student academic functioning to be broken with no consequences. In addition, the students from the ineffective performance grouping missed the presence of a parental type structure to help them regulate their behavior. They recalled their past academic success within the context of prior childhood structures.

The students expressed the complex desire to separate from their parents while acknowledging their dependence on them. If the students could not establish their own reasons for succeeding in school, they clung to the idea of pleasing or not disappointing their parents. Not only did the students acknowledge the role of authority figures in their past successes, the students from this grouping pined for the structures of the past to help them get started and organized to work and to help them manage the freedom of their new environment. 
Even though many of the students in this grouping wished for more structure, they were all inconsistent about attending the regularly scheduled meetings with their mentors in the disability support program. Some students liked the idea of being mentored; however, the students attended these meetings sporadically for the same reasons they missed classes, had trouble organizing to work, or wanted to operate independently. Others were clearly negative in reacting to the mentor's attempts to help them structure themselves.

Reluctance to accept the disabling condition and misguided independence - Problems related to disability acceptance plagued the students from the ineffective performance grouping. The students experienced embarrassment over their disability and denied their need for help or accommodations. Not knowing something or having to struggle to learn impacted the students' lives both inside and outside of the classroom. The students resented having a leaning disability: they described being embarrassed by it, depressed by it, and tried to cover it up.

All thwarted available services and accommodations almost as if they would rather fail than ask for help. Conflict over accepting the life impact of their disability was evident. Most of the students in this grouping disclosed their learning disability in emergency situations only: when they were doing poorly in their classes or when they wrote letters to appeal their academic dismissal. Some of the students decided to ask to use accommodations during the final exam period in a last ditch effort to bring up their grades. They did not routinely use accommodations and services because they did not want to stand out. Entering the postsecondary environment gave them an opportunity to drop the label and to function without assistance; paradoxically, the newly perceived independence backfired.

Unconstructive patterns of social functioning - The students from the ineffective performance grouping had difficulty making the social adjustment to their new environment. 
They were socially constricted in the new environment, lacked assertiveness, preferred to stay isolated rather than risk rejection, and thought themselves inferior to their peers. Several of the students did not work to get to know the peers or helpers who could provide support in their new environment.

The students described "missing out" socially. They had problems asserting themselves and stayed isolated because of the risk involved in making new friends. They described unresolved fighting with the friends they did make, problems with roommates, feelings of inferiority, and the struggle for social acceptance. None of the students belonged to campus organizations. Many still sought help from their parents, high school resource teachers, and counselors from home instead of adapting to the helpers available on campus. In short, the students in the ineffective performance grouping failed to make the social transition to the college setting.

Problems adapting to the academic environment - All of the students in the negative performance grouping displayed problems adapting to the academic environment. They reported minimal academic expectations of their prior learning environments. In addition, the students described receiving too much of the wrong kind of help during their high school years. In short, they were poorly prepared for the college experience. Finally, the students did not put adequate effort into their college course work; many lost their purpose for being in college.

Academic problems came about not only from self-regulatory deficiencies such as the inability to multi-task, to start and sustain work, and to establish routines, but also from deficient academic preparation. The students in the ineffective performance grouping were not ready to manage the complexity of college level work. In retrospect, the students observed that their high school resource teachers had pampered them. Some of the students had been over-structured by 
their parents and teachers; consequently, there was no opportunity, prior to coming to college, to learn to self-structure with guidance. Several cited the low academic expectations of their high school teachers as a factor which undermined the development of an appropriate work ethic.

The students' academic functioning was inhibited by inadequate effort and by not knowing how much to study. They described trying to measure the exact amount of effort needed or to figure out how much to study. They were not experienced enough to predict well a personal study/performance ratio, yet many from this grouping tried to calibrate their efforts as if to save energy. In addition, academic success seemed like a game of chance to the students in this grouping.

Finally, it was hard for the students to find a reason to stay motivated for academics when their dreams were disappointed by failure in introductory level courses fundamental to the student's chosen program of study. Every one of the 5 students who had declared a major from this grouping had to give it up. Disappointment and malaise set in after the students realized they were not going to be able to continue in their chosen major.

Inability to manage developing life circumstances - The students in the negative performance grouping could not adjust to the fluid nature of the college setting. They were not able to respond to developing problems that are inherent in college life, including their own maladjustment. Their narrative revealed a self-deception and denial that disconnected them with their academic realities. There was often either a magnified response or a shutting down that exacerbated the original problem.

The students presented with signs of crippling self-doubt; they were easily defeated by their initial failures. They created a life for themselves outside of academics. The students engaged in activities which took them away from school work. Daily mountain-biking 
excursions, consuming fitness programs, captivation by computer generated virtual realities, and total absorption in other activities took priority over going to class and performing their academic work.

Reflection on the experience of failure - Finally, the students in the negative performance grouping reflected on the personal obstacles to making a successful transition to the college environment. Although many understood their barriers to successful functioning, the students were inconsistent about following through on their resolve to function more efficiently. There was an unpredictable pattern of performance for most of the students in this grouping. See Table 6 for a summary of the negative case findings.

The following section contains the findings and supporting narrative of the positive transition case. 
Table 6

Negative Collective Case Findings

Problems with self-understanding and self-management

Establishing a routine

Following through

Sustaining effort

Organizing multiple tasks

Establishing personal goals

Complicated relationships with authority structures

Current intervention of authority figures

Felt absence of past structures

Complex connection and separation from parents

Wishing for external structure

Negative reaction to the structure of the mentor

Problems related to disability acceptance: misguided independence

Self-embarrassment over disability-related problems

Conflict and denial over acknowledging needs

Difficulty related to social functioning

Constricted social interaction

Deficient social assertiveness

Thoughts of inferiority 
Trouble adapting to the academic environment

Inappropriate help and low expectations of prior environments

Insufficient readiness and preparation

Inadequate effort

Losing purpose for being in college

Inability to manage life circumstances

Inability to cope with everyday problems

Denial of academic reality 


\section{Positive Collective Transition Case Findings}

I just went and had a meeting with each one of my professors and showed them that [accommodation] letter, and then they would ask me what I thought my specific needs would be. I didn't have a problem. ... Even before I got the [accommodation] letter, first semester, I had already talked to my professors. . . . It didn't bother me to go. . . some kids are scared to tell their professors. . I don't have a problem going and telling them that I have a learning disability and I need certain accommodations ... because, I just look at it as way of life and I'm going to have to deal with it for the rest of my life.... You might as well start now, and be able to tell people, because it's something you can't fix, you're just going to have to deal with it. (XIII, 10-13)

Sixteen of the 23 students from the transition cohort whose one-on-one interviews were analyzed to completion each earned a cumulative grade point average of 2.5 or better, calculated after each student's most recent semester of enrollment. The cumulative average GPA, taken from the 16 members of the positive collective case, calculated after each student's most recent semester of enrollment, was 3.0. The grouping developed into a positive collective case example representing effective functioning during the college transition. Multiple thematic commonalities clustered the students by outlook and behavior in addition to the academic performance outcome. At the time of this writing, 14 of the 16 students are still enrolled at the research site institution. Nine are beginning their seventh semester; five are beginning their fifth semester. Two of the 16 students transferred to another institution after 4 semesters of enrollment.

This section of the findings contains a detailed description of the major themes and supporting narrative which represent the approach and effective actions taken by the students from the positive transition cohort. Key patterns of the effective performance grouping included 
the following: appreciating and applying preparative experiences for the college transition, socially integrating into the campus community, proactively managing the learning disability, seeking constructive help, recognizing and dealing with problems, taking a strategy based approach to the transition, acknowledging the primacy of learning and graduating, and identifying prior inappropriate special education experiences.

\section{Recognition of Preparative Experiences}

The students in the effective functioning grouping remembered and applied experiences they believed help them manage the transition to the college environment. One student observed that for her, multi-tasking a part time job and taking college level classes during her senior year of high school was valuable. For another, the experience of being away at boarding school allowed him to become more independent from his family. Many believed that their high school teachers and parents had "scaffolded" them to a place of preparation by gradually taking away the help to which they had become accustomed. In retrospect, the students appreciated overt advice about surviving the college environment from their teachers, family members, and other supportive individuals. This included explicit coaching to improve academic and organizational skills and to self-manage in the complex postsecondary setting. Several students mentioned they appreciated the intentional programming efforts made by their high school guidance departments to educate them about the postsecondary social and academic milieu.

The segment is divided into 3 categories: experiences that were viewed to promote effective functioning, recollection of significant figures that made a positive difference in the students' lives, and intentional programming that prepared the students for a positive transition. 


\section{Experiences Viewed to Promote Effective Functioning}

The students in the effective performance groups described experiences that were viewed to promote their independent and successful functioning. The students were "scaffolded" to independence. They described the careful and thoughtful elimination of academic instruction or parental supervision in preparation for the student having to function more independently. In addition, the students revealed that learning to handle novel experiences prepared them for the first year of college. Kevin's parents and teachers were intentional about weaning him from the help he received in high school:

I guess I'd have to say my parents helped. . . basically they made me do work on my own, told me that they're not going to be there for me. . I can't go back to mom and say I need help, or anything like that. . . I I would also say my teachers senior year helped me a lot.... They were saying that you can't rely on us as much, you need to do it on your own. It's basically what my parents were saying. . . like, I would always go for extra help and stuff. And they kept on saying that in college you can't do that. (XXI, 1-2)

Wendy was given the responsibility of making her own decisions as she neared the end of high school. She believed that her mom's approach to parenting during that time helped her to be more responsible in the college setting. Wendy's description is a fine example of parental scaffolding:

And my mom was never for alcohol, but she was never totally like: "You can't have any, I'll like murder you if you drink." I was always given a lot of responsibility to make judgments for myself, and I see some of the people that come here, they've never been allowed to do anything, make judgments for themselves. They go crazy, 
they party all the time, and then they fail out of their classes, because their parents never let them be in charge of themselves, so they don't know how to be in charge of themselves. ... Like my mom was still there to make sure I wasn't totally screwing up, but, you know, she let me make some mistakes and be responsible for things. (XXX, p. 4)

Wendy believed that taking college courses while she was still in high school helped her with the transition:

I think what helped a lot was I took a couple college courses in high school. ... Also, with my last semester in high school, with having the college courses, and working so much. . I think working was a really good thing, it helped me to learn to manage my time much better. And also my job as a cashier helped me a lot with my dyslexia, because I learned to double and triple check everything so that I wasn't coming up short on cash. . . I think it was just being used to managing my time well. (XXX, p. 4) Leah's teachers demanded that she do more on her own toward the end of high school. Again, a scaffolding approach was used to prepare her to function independently in the college environment:

I would say my teachers in high school [helped prepare me for college].... We had like smaller grouped classes with teachers that knew how to teach kids with a learning disability. But then we also had a one-on-one teacher that we met with everyday for like a normal class period. And that person. . . there's a bond you kind of have. I had the same teacher since eighth grade, and she left my junior year. . . that was hard for me. That's what I would be facing in college, meeting all new people. And I had to start with a brand new teacher that I didn’t know anything about. . . so, like in a way 
it helped me, but it was just hard in the beginning. Everybody was like: "Well, that's what it's going to be like in college, because you're not going to know anybody, you're going to have to start from step one and work up." [My teachers in high school] forced me to do a lot more on my own, where in the beginning they were helping me a lot. But in the end, it was more me doing it [the work] because that's how it was going to be here. They didn't want to baby me anymore because they knew I wasn't going to be babied here. They wanted me to start my papers on my own, they wanted me to do my homework, and if I had questions then ask them, rather than saying right off the bat: "Let's do my homework, let's start this paper." (XIII, p. 3)

\section{Significant Figures that made a Positive Difference}

The students were grateful for the important relationships they formed with family members, teachers, and other supportive individuals during the years preceding college. They internalized the values espoused by these important figures and drew a direct connection between the relationship with them and preparation for and help during the transition to college. These important figures went out of their way to support, provide direct feedback, and press the students to do their best. George appreciated learning how to commit full effort under the guidance of his swim coach. He attributed his "right motivation" to the lessons he learned though this mentor:

A lot of my experiences on my swim team gave me the right motivation. Our coach is one of the best coaches I think ever. He just has a way with kids, and he knows how to motivate kids. ... The most memorable one that I can think of is when everybody was coming late to practice. . one day, everybody was about 10 minutes late to 
practice, everybody, and he was standing there and he gave long dissertation about being on time. And he said: "Just remember, if you are early, you're on time, if you are on time, you're late, and if you are late, don't even bother coming." And that motivated me to be there on time more. . it stuck with me. The pep talks motivated me, he was a very big mentor in my high school swimming career. . . being able to get into the pool, and give a hundred percent. . . you always have to give a hundred percent. We would rather lose giving a hundred percent than win giving less than that. (III, p. 9-10)

Mark observed that he learned to value intellectual growth through his relationship with his grandfather. He described being in awe of the activity of his grandfather's mind: I was at my brother's graduation from college, and my grandfather was really smart and we were just sitting there. I was thinking "this was really boring, I'm going to fall asleep." My brother had to walk across the stage and it would be done, and my grandfather, he was counting how many people there were... wanting to see how long it took for each person to [walk across the stage].... My grandfather knew that it takes him [the Dean] about 30 seconds to tell about each person, and he asked me to count how many people are in the class. And then he was like: "All right, now let's multiply that and you can guess how long it is going to take to do all these." He has to be so smart. . . he would just sit there and not turn his brain off, he's always thinking ... he's always using his brain to do something. (VIII, p. 25)

Louisa internalized the strategies she learned from her tutor during high school; I asked what best prepared her for college:

I used to have a tutor for every Wednesday night to help me get through my 
assignments and teach me different ways to comprehend information. . just like organizing my papers. . . she actually taught me how to do that. . .[that] has helped a lot, and how to develop study skills. She had a degree in Special Education. ... When I'm writing papers, I can't just write them, I actually have to start with an outline, and I have all these "before writing" techniques that she's taught me. (XI, p. 3-4) A well respected high school teacher challenged Margaret to stay in her AP class. In addition, the teacher predicted that Margaret would be successful in life; this made an impact on Margaret's thinking about herself and her potential:

One teacher that I had last year, many students were afraid of her. She was a tough cookie. And she was a true intimidator in the classroom, she had absolute control over any class. . . especially when you're seniors, you don't like teachers who take control, you want to have fun. . . she was my AP Business teacher. . . and I remember I wanted to drop the class, in the very beginning of the year, and she was like: "No, stay with it, stay in the class, you can do it." I was like: "I can't, I have to keep my GPA, I'm going to college. . . I can't afford to take this. . . to get a $\mathrm{C}$ in this class. I have to get As." And she's like: "You can do it. Just, stay with it." And I remembered throughout the year, like the first half of the year. . kids were dropping out of that class like flies. One after another after another, and she would not let me go, but I enjoyed that class, immensely, because it was college level and so it really did take your critical thinking to another level. . . . We read many books, outside reading books. . . she gave me her personal list of books. ... The way she taught. . . is more like college and I think that really prepared me. . . I remember one day after class she was like: "No matter what you do, you will be successful." And that, from 
her, was a big thing. . . she was one of those teachers that everyone respected. I thought about that constantly. . I think about it all the time. I mean, just like this from her. No matter what I will do, I will be. . I'm like: "How does she know that I will be. . you know, what if I'm not? Maybe she won't know but I will know." She gave me such a charge, it's pressure. . . it really has made me be not so, I guess, wishy washy about what I want to do. (XXII, p. 4-5, 8)

Ben described being grateful to his parents for their support in his college preparation and search:

With all the trouble that I had in high school, I don't know, like, I wanted to go to college, but, it was so much work, that I was worried that couldn't do it. So my parents really pushed me. . I think they're the main cause that I got into that other [prep] school. And like, anytime I needed anything, or needed help doing anything, even now, like they're there, even if they're at work, it doesn't matter, if they lose their job, they don't care, they say I'm first. So that really makes me want to be in college, more than anything, the fact that they put their life on hold for me, it means a lot to me. .. . We went around. . my mom took off from work, and we went around to all the schools, and visited every school that I applied to, to actually see what everything was like, to make sure everything was perfect, what I thought was, you know, perfect. (XXVIII, p. 5)

Dan's mother and soccer coach prepared him to handle the college environment:

My mom, she's always taught me the necessity of hard work and everything like that. ... She's always been my guide, I've seen her go from the top to the bottom, to the top, again. ... She's taught me what hard work is, what determination is. . I owe a 
lot to her. (XX, p. 2, 13) My coach/best friend in high school. . . he's just been a real model/best friend. He's taught me a lot of things that I couldn't even begin to explain, just life lessons. ... More of how to live in an ethical and fun way. . . just how to carry yourself in a fashion that is appropriate for the environment that we live in nowadays. . . the way you come off to other people. Your ability to step in an environment, and to show people who you are and what your morals are. (XX, p. 2-3) George remembered high school teachers pressing him to improve and expand upon his written expression. He recounts their communication of high expectations and critical feedback and connects these experiences with his becoming a better writer:

The person who helped me with my writing is my sophomore History teacher; I'm very good in English now. He constantly pushed me and was constantly telling me: "You got to get better at this, and you got to do this, and you got to do this." My sophomore English teacher also helped me, she would come in, and say "Here is an idea, write about it." And that is how I developed my sense of taking a subject and being able to expand. [Both of them would say] that: "You have to do this, this is this is what you need to do, this is what you need to improve. . . it's up to you in order to do it." Most of the teachers, when we wrote essays, would take the essays and write in the margins on all of our papers and all of our essay questions on tests, that was kind of standard procedure, even in Spanish, I had Spanish essays. (III, p. 7-8)

\section{Intentional Programming Designed to Develop Students}

The students described their instructional experiences for college and life preparation.

One student participated in Outward Bound, a program he credited for his ability to manage adversity. The students took part in curricula that was academically rigorous or that instructed 
college level study skills. The return of familiar alumni to share the common pitfalls that the first year college student experiences, a component of several high school guidance programs, was viewed as helpful preparation for anticipating the subtle differences between high school and college.

Ben attended a small college preparatory school for students with learning disabilities; he appreciated that his high school curriculum provided intense instruction in the academic and organizational skills he would need to practice in college. I asked him about experiences or persons that best prepared him for the college environment:

I had a lot of problems in school. I basically stayed back two years, and, went to another high school. That helped the transition, because in public school, we really didn't work on how to take notes and how to study. . . . [It] was a learning disabled school, so like, all the kids there were all like I was. They showed us study skills, and every year they had a study skills program we had to be in for a grade. [We learned] everything from how to take lecture notes to, if you're watching a movie, how to take notes on it, how to take two column notes, or regular notes, and really worked on the key aspects that I think fit with college. . . Because, in high school, you really don't learn how to take notes, you sit there and you copy stuff off the board. Where in college, they [the professors] may only write a couple of times on the boards, and the rest is verbal. So that really helped. And then, also, the study skills showed me how to manage my time and keep organized, and how to keep a notebook, like, number the pages, at least, so, I can go back to them and I know which page went first, because like, a week later, you might not know. And then [I was taught] how to write essays on a test. How, like, you know what you should write for an essay. . . so all that stuff 
they really didn't teach in high school, but, when I stayed back, and went to this school, like, they really did it. (XXVIII, p. 4-5)

Ben was changed by Outward Bound; this experience prepared him for college, and life. He often used the metaphor of "trudging through" when he talked of problems during our conversation:

Right after my first junior year, I went into Outward Bound, and that really helped me out with a lot of inner conflicts. ... We had to hike, sometimes, forever. Like, one night, we had to hike over this mountain. . . in the dark because we needed to get to this place, and, if we weren't there, we wouldn't get our food. So, like, we had to hike through the night, and it was just like, no matter how tired and how wet, and just, messy you were. . . you got to do it. . . if you stop, you die. It's like, you know, do or die. You just got to go. And sometimes you need to backtrack, but like life, time goes forward, not backward, so you just got to go with it. . . . It made me see the world outside of society. Where it's just you. ... It's all about how, what you want to do. It's asking what you want to do. ... And, when you find what you want to do, then, you know, straight on from there. ... And seeing how hard things can really get....I always say, it was hell, I hated it when I was there, but I loved it. . . I got shin splints real bad, and both my ankles swelled up, and I still had to hike, you know, on mountains that go like this [points vertical], so you're hiking sideways, going like this, on your ankles that are swollen. So, you just got to endure it. . . and then, with the other people, you have to learn to, you know, cooperate with them, voice your opinion, but, not destroy or verbally bash somebody, because if you do that, then you just, you won't get anywhere. (XXVIII, p. 21) 
Julie believes the academic rigor of her private college preparatory school prepared her for the academic challenge of college:

[My] High School was difficult. We had a lot of papers to write; I feel it's really prepared me for college just because I know how to write a quick responsive paper, in like twenty minutes... and like I know how to proofread and get it over with, and not stress over it at the last minute. (XII, p. 3)

Julie described the structured college preparation program of her high school:

Senior and junior year, we had counseling meetings. And like we had college students come back and talk to us about college. And we watched videos on college, and learned about binge drinking, and all sorts of things. . just that kind of stuff prepared us. ... It's called Junior Counseling and we all had to go to it. And we learned about different schools, and what colleges expect. So, that was good. . because it's like, you get to college and think it's going to be all about academics and stuff, but there's that social part; you're just dealing with a lot of stuff. We had a bunch of kids come back and give their personal experience, and like the counselor usually left and like we got to ask them questions about parties and questions about like... how plagiarism works. And it was good to have that conversation with them, and not have an adult in the room. (XII, p. 5-6)

\section{Social Integration in the Campus Community}

The students in the effective performance group established a sense of belonging in their new environment. They belonged to their friends, fraternities and sororities, campus organizations, varsity and intramural sports, and academic departments. Their narrative alluded to the general feel of the campus, it was open and friendly. The students felt affirmed by their 
professors both in and outside of class. Many described feeling a stronger sense of self in a more diverse, less stigmatizing social environment. This was a relief compared to the feel of the rigid social groupings they had experienced in high school. For several students, this sense of integration into the campus community was due to a synergistic combination of the responsive campus environment, personal developmental change, and the student initiating involvement. In addition, the structured first year seminar presented the opportunity to meet other new students and supportive upper class advisors, to become familiar with the campus and local community, and to process the transition with an experienced adult. The findings on social integration into the campus community are separated into two segments: the sense of campus community and proactive integration.

\section{Sense of Community}

The students were grateful for the acknowledgment they received as new members of the campus community. They were encouraged by faculty who made the effort to connect and mentor them. The freedom to develop or to "come into their own" in a more diverse milieu was noted and appreciated. The students felt a connection with their peers, upper class students, and their professors. Julie expressed surprise that she has adapted so well. She emphasized feeling in place as essential:

I manage my time well. I met a lot of new people. I'm having fun. I'm having a social life, but I'm still doing better than I did high school. And I don't go home every weekend; it's like I've adapted to the school. I feel like I have a place in the school. . . I thought I would get homesick. And I thought I would just be like: "I don't really want to be here." I thought I would transfer. . . I didn't know. . . I really fit into the college. (XII, p. 10-11) 
Kenny had the expectation that his postsecondary experience would be impersonal. He was surprised at the welcoming atmosphere of the small college community:

I was really nervous about coming to college. .. I thought it was just going to be incredibly impersonal, and just scary. But it's turned out to be the exact opposite. Everyone's warm, friendly. If I have a problem, I can get some help with it, like the tutoring and stuff. I like how my professors recognize me across campus when we talk. . . and even if they're eccentric, they're fun. . . their ideas are very interesting. (XIV, p. 7)

Jim described himself as a geek. He was reassured by the connection he made with peers through shared interests and ideas:

College is a lot better, it's easier to make friends, you can trust people, especially here, a lot better. And it's a lot more fun, obviously a lot more freedom. [In] high school, for me, [there was] a little discrimination because I wasn't a jock and the people who were jocks got away with stuff, and here it's equal footing. Everybody gets into trouble for whatever they do, regardless of whatever their status. ... It's easier to make friends. . . everybody can connect. . . share common interests, it doesn't matter if you're a jock or not. . I I can talk to anybody. (I, p. 1)

Jim continued to describe his relief at the approving social community; he made the decision to not worry about fitting in. Once he was able to relax, his social life flourished. I asked him about the positive side of his transition to college:

And being able to make friends real easily. . . that's helped out a lot. . to have people to talk to. Because in high school, I might not feel I had anybody to really listen. . . . As my mom put it, I've come out of my shell since I've been in college. (I, p. 3) In 
high school, some people just didn't get along with me, so I'm like: “Okay, I'll just be myself and if they don't like me in college, so be it." But that hasn't really happened. So, I'm just like: “Okay, I got a bunch of friends.” (I, p. 10)

Jerry described that he felt less social stress compared to the tension he experienced in high school. He also observed and liked the acknowledgement he experienced as a member of a small community. Like Jim, the intersection of personal development, the nurturing community, and immersion with a broader cross section of students has enabled him to feel a stronger sense of self:

When I was getting ready for college, I had it in my head that was college was going to be so hard. Once I got here, it really wasn't that bad. I mean I didn't have that nervous feeling like I did have in high school. It's just that you can be yourself. . . so it hasn't been too bad. (IV, p. 9) My favorite part [of being at this college] is like it's a community. It would be one thing if I was at [a bigger university] and I was just another person, but it's just a lot more helpful here. Like people know you and that's my favorite part about it. (IV, p. 1-2)

Adjusting was difficult for Kevin. He valued the help given by older students on the swim team. In addition, Kevin understood that all the first year students were in a similar situation. This thought helped him to know that he was not alone in the transition: Adjusting to living on your own for the first time, and making a whole new set of friends. . . this is everyone's first time. . . everyone came together, and we all, basically, survived the hardest part, which is the first semester and getting adjusted to everything. ... And like, the upper classmen, they help the freshmen out. . on the swim team. . . or even like on campus, I mean like if you didn't know where to go, 
they would help you, and show you where to go, what kind of activities are good to do around here. .. it's a very friendly environment. (XXI, p. 8)

Wendy appreciated that the professors in her academic department went out of their way to make her feel welcomed and to help her feel like a part of the community. Their support was a significant factor in her successful transition:

I think one of the biggest things that has gone well is I gained so much in the Ceramics Department, like [my professor and work study supervisor] have taught me so much. . . [They] have just been great to me. . . like taking me under their wing. . . it's just really nice to know that there's someone who cares about you and they don't have to. That was just really great for me. To have a mentor, someone I could go to when I have problems. I think that it's just really great that there are teachers around that are like that, because they don't have to do that. It's not part of their job description. ... My work-study has just gone really well, I've learned and grown so much. ... It's helped me connect with a lot of the Art Department, Art Majors, because what I would do when I just didn't want to be in my room. . . I would kind of immerse myself in the ceramics lab. (XXX, p. 10-11)

Tony acknowledged that the close knit environment established by the professors in his academic department facilitated his transition to college:

And, all the plays, and stuff. . . and just the Theatre Department in gene ral, I think is really great because. . I think the one thing that's really intimidating is calling professors "Professor" and "Doctor." At least, for me. . . in the Theater Department, nobody goes by Professor or Doctor, it's all ... everybody is on a first name basis. It kind of feels like you're being brought up to their level, and at the same time, they're 
coming down to your level. . . it's just very welcoming, it's very informal. . . . It's like they're family. . . they talk to you that way. (XV, p. 5)

One of Kenny's “general studies” professors recognized him on campus after the class was completed:

I really liked my psychology class, because the teacher sometimes would make jokes about what he was talking about. I think I was the only person in the class who laughed at them. . . and whenever I see him, he's like: "I miss you as a student. . . you laughed at my jokes." That was pretty cool. (XIV, p. 8)

Tony appreciated the first year seminar as a transition tool. It offered the opportunity to process the new college experience, to become familiar with the local community, and to mix with peers:

I think Freshmen Seminar, I know a lot of people would disagree with me, but. . . I had a really good Freshmen Seminar leader, she really helpful. Like, everyday we would come in and she'd be like: "Well, what didn't you like about this week, what did you like about this week?" And we'd go out on field trips and stuff; she'd take us around town. . . she paired us into groups, she gave us a list of places on main street to go, and then find out one interesting thing about them; it was really fun. Then, we all met at [the coffee shop] and we ate. (XV, p. 4)

Like Tony, Margaret recounted how the first year seminar helped her to connect:

Freshman Seminar was somewhat helpful, I mean it was kind of annoying because you really didn't do anything meaningful there, but like you're still friends with those people in that class. ... And it's kind of nice because you still say hi to these people. And, you know, the upper-classmen advisors. . . they're really awesome people. . I 
think that kind of helped. It's not like a formal thing, you're just like: "Dude, how do you do this?" Seriously, just when you have a question, that really helps, because it's your first time, and they kind of already went through it so they know. (XXII, p. 10)

\section{Proactive Integration}

The effective performance students intentionally worked to interact with the campus community. They did this based on the self-knowledge that they would make a better transition if they tried to mix in. Many chose to come to a small college and to join organizations because they knew involvement would strengthen their experience. Wendy needed the right environment to establish a sense of belonging:

I like that the community was smaller in general. . . and that's always been an issue for me in trying to make friends and get involved. . I wanted to have more of a social life. I wanted it to be smaller so I didn't get lost in the shuffle. . . It's even more than I expected, particularly in the area of making friends and having a good social life. I have a whole group of people I hang out with now. And I didn't have that in high school. I have activities I participate in. . . things have just been going really well. (XXX, p. 1-2)

Kevin's personal development combined with the nurturing college environment and the decision to be proactive was a formula for positive outcomes. He described coming out of his shell in the classroom:

I'm also participating a lot in class. . I did not speak one word in high school. Like I just sat in class, and just took notes. ... Now, I'm actually asking questions. I used to be so afraid of: "what if I ask a stupid question, everyone is going to like whack on me or whatever." And now I'm asking questions left and right, and I'm actually 
participating in class. So that's a big transition right there. I think it's just a growth in expressing my own views. (XXI, p. 11)

Jim felt empowered by his involvement with the campus organization that is responsible for bringing activities to campus. I asked him about the positive aspects of his transition to college:

Being involved in the Campus Activities Board, because I feel like I actually have some power in this school. I get to say, because some people don't. . . what [activities] they might want. I feel like I have a really good say in what happens on the weekends. ... It's helped me to talk to certain people. . I talked to this one girl, she'll just show up [to the shows]. . . like with three other people. It's like wow, I have some influence over people, and they actually listen. (I, p. 6)

A sense of belonging and relief from a difficult day were the advantages of joining club level Lacrosse for Margaret:

If it was my suggestion, if I was talking to the freshmen coming to the school, it's join activities. . . I'm doing the Lacrosse Club. . . Joining activities is the best thing to do, because you're going to find friends there no matter what. And after a hard day, you're really going to have fun. ... Whatever you're interested in, go do those. . find those activities and find someone to do it with and you'll be set. . . it kind of takes the edge off of a hard day. (XXII, p. 11)

Mark's rewarding social experiences have been central to his feeling in place on campus. He joined the cross country and track teams as well as a fraternity. His language is cast with intentional connection. I asked him about the positive aspects of his transition: 
I made friends with all the guys on the track team. . . During spring break, we had a track meet, and we spent a week in Daytona Beach. . . it was really cool. . . we went one night to the Olive Garden, and it was the first time that we have come together as freshman. The thing is, when the seniors are gone, were going: "It's still going to be fun, because we have a tight group of freshmen, and we should all still be here." And we talked about the future. . . . And now, I joined a fraternity. . . I've made all kinds of new friends from all over. (VIII, p. 19-20)

Kevin's proactive involvement in the swim team and a club related to his business major facilitated his becoming a part of the campus community:

I joined a sports team. . . I joined swimming. It was really good talking to other people. And, also, this semester I joined SIFE, which is really good, you get involved in a lot of activities. ... Students in Free Enterprise. . . . You do different projects. I'm working on a project right now, Kymandia beads. There's about twelve women in South Africa who make these beads and since it's hard for them to sell the beads in Africa, they give us inventory and we try to sell it for them. ... Kymandia, it's a town in South Africa. . . It's where, basically, they live in cardboard. . . It's different projects we do to help, like unemployed or low-income families, not just in [this state], but all over. We also have Economy Five, which is an educational program for fifth graders. (XXI, p. 3-5)

\section{Proactive Management of the Learning Disability}

The effective performance students actively managed the impact their learning disabilities had on them during their transition to college. Many students talked of coming to this particular school because they realized success was possible within the context of a strong 
support program and a close community atmosphere. The members of this grouping were forthcoming on the subject of their personal educational histories, citing marker events which they carried into their current circumstances. These important lessons or events steered them in their new environment. The students expressed an awareness of their cognitive processing limitations and implemented various methods of compensation in order to progress in their academic work. In addition, the students were vigilant about pinpointing accommodations, services, and the type of support which enabled their success. Finally, even though many were conflicted over the risk versus the benefit of identifying personal weaknesses to professors they hardly knew, the students disclosed their learning disabilities to the appropriate persons.

\section{Importance of the Support Program and Small Community Setting}

The effective performance students looked for a college with a strong support program, simplified access to services and accommodations, and a small community setting. Mark mentioned the support services, the small campus community, and the willingness of the staff to become involved as important factors in his decision to attend and to continue:

The tutor who had sent her son here. . she was the first one who told us about this great academic support center. The small school, small classes are really helpful. . . I can say this was the first place we came to that could suit my needs, like getting extended time. . . I mean it's different than in high school. . . college is harder. . . . It has met all the things that I expected and more. . I never used scribes and stuff like that in high school. I never wrote many essay tests in high school. It's been a lot more than what I thought. . . you all get really involved. . . . The test lab and the language tutoring. . . my parents really liked the language tutoring. . . since I have a struggle to read. (VIII, p. 2) 
The strength of the learning support program was important to Janice. In addition, she chose this College over another because the location and atmosphere of the learning center gave her the feeling that supporting students with learning disabilities was important to the College. I asked her why she came to this school:

Part of it was definitely the program. . . every school that I looked at, I was looking at you know, what kind of service they offered. . . and [there were] two schools that interested me the most, and it was this school and I can't even remember the other school, but like the building where they had their services, it was in the basement of this building and it just seemed really shut off. . They said they were going to expand but you never know when it is going to happen. So, I was like "I kind of want to be able to have support services now" and I just really liked way the support system looked here; it just looked like I would really get the attention that I need. (XVI, p. 1-2)

Wendy understood she would have a better chance at success it she attended a smaller college with a structured support program:

With my learning disabilities, I need the individual attention that you could get at a smaller school. Like huge lecture classes where the teacher just talks and I can't ask questions, doesn't work at all. . . And from what I've heard, at bigger colleges, it's much harder to ask questions. Also, I like that [this school] had a bigger learning disability program than a lot of the schools have. Even some of the huge colleges don't have a lot of the stuff [this school] has. And so, one of my criteria, because I did the College Board college search. . . was I had to have a school that had some kind of learning disability program. (XXX, p. 1) 
Ben knew he needed to attend a small college to access help:

I was looking at a lot of schools, but, I didn't want a school that was so huge, that I was just a number, because, if I needed help, I didn't want to get lost in the shuffle. . . if I have a question in the class, it's not like I have to stand up, and it's like a thousand people around me, that's really hard. So, I thought it would be a lot easier to find smaller colleges. And then, I was looking a college, that if I needed help, it was available to me. And it was just like you guys were real open about it, I guess it made me more comfortable. . . it was just like more one-on-one. . . more of a personal touch, compared to some of the others. (XXVIII, p. 1)

\section{The Important Role of Personal Educational History}

The effective performance students carried their personal educational histories into the college environment. The marker events they disclosed advanced their determination to stay with their goals. Janice talked openly about her personal educational history. She read her first book in sixth grade:

I have been through a lot with my LD. In second grade I couldn't read and my teacher is like "you should be able to read by now," and we were kind of like "Oh! Uh ok!" And so, I got tested, and. . I basically started getting services. ... I had the hardest time learning how to read. . that was such difficult thing for me.... At the end of sixth grade, I finally learned how to read. One of my friends had this book, I wanted to read it so badly because it looked so cool. It had this lady with wings on the front and it was all colorful and everything. . . And I kept asking her what was happening and she was like: "Read it" and I was like: "Okay." So I read it, and it was the first book I ever read, all by myself, without a tape or anything. And I read every book in 
the series, there are like 22 books. . . It was a really easy book to read, but it opened so many doors for me. . . I have been reading ever since then. . . I have bookcase full of books that I have read and I keep every single one of them, now they are little trophies for me. (XVI, p. 4)

Janice made academic gains as a result of using services in middle school. This recollection facilitated her recognition that utilizing accommodations enabled compensation for her disability:

And I mean, like with my math, about seventh or eighth grade, I finally, I finally caught on to that because I couldn't ever deal with multiplication tables; that was always really hard for me. But all of a sudden we started getting into algebra, prealgebra in eighth grade, and I started really liking that, that is the first time I have ever done well in math. And that was really exciting for me.... I had to work so hard in the beginning to be able to get where I'm now... and it has given me a really assertive attitude about it because I'm really proud of everything that I have gone through. I get really defensive about it. . they took my services away [in middle school] because they were like: "You are doing well, you don't need it" and I was like: "I am doing well because I have the services." So they took them away and my grades plummeted and it took like a year to get them back. . that was really frustrating. (XVI, p. 5)

Aware of how her educational problems interconnect with her current academic functioning, Janice talked about the importance of self-disclosure:

I had to work so hard in the beginning to be able to get where I am now. . and like the only way other people are going to know is if I tell them, you know? So, I have 
never been shy about it and during the [IEP] meetings, I would always speak up for myself, when most people are sitting there. . . That was never an issue for me, like I never needed to work on self advocating. I always walked up to every single teacher at the beginning of the year, and would be just like: "Hey, you know this" and I had no issues telling them if I needed something, like [if] I needed extra time for this test. (XVI, p. 5-6)

Ben told how he has worked to understand the characteristics and life impact of learning disabilities; this information promoted a self-understanding that helped him come to terms with his own learning problems:

When my parents were trying to figure out. . . they knew I had a LD. . . at an early age, but, they really didn't know, totally, what it was. They heard what people said. . . and they started buying books to read about it. And, when they finished reading, well, I started reading them. And understanding what the disabilities are, allows you, somewhat, to cope with the disability. And I think that's one of the big things people need to do, because to learn to overcome it, or not to overcome it, just to work with it, you need to know what you're working with. And, by reading books about it. . . it starts making things click, or allowing people to work things out with themselves. .. .When you start to see that [other people have LD], you realize, it gives people confidence, or shows them, well, you know, like Einstein, they thought he had a lot of learning disabilities, and you say: "Gee, this guy was one of the smartest men to be around. So, like, if he could do stuff, then, you know, I know I could do something." (XXVIII, p.17-18) 
Ben has become aware of how his learning disabilities affect his everyday functioning. This knowledge and understanding support effective self-management:

I went to a psychiatrist for awhile. And, you know, he says, one thing about people with learning disabilities. .. one of the things they think is ADHD people always have their sonar up.... I notice change all the time, like, I'm always looking around, I'm always listening. . . but, I'm real cautious about things. I don't want to jump into something, I never wanted to be in bad problems, so that kind of helps out, because not jumping into something, allows me to not to have these problems in the world. ... Even though you want to like, run, you have to like suppress that urge. . . . I sit back and I see what everything's like, and then, I start moving. Because, I don't want to start off, with everybody else, at full steam, doing all this stuff, and then, run into problems. Or you know, like, hit a hurdle I didn't want to hit. So, usually, what I do is, I usually sit back, and I try to survey the land, and see what everything looks like, and then figure out which way to go. (XXVIII, p. 19-20)

Kenny described how he learned that his problem with alcohol may have been caused by his attempts to self-medicate his symptoms of ADHD. This self-awareness supported his ability to stay on track in the college setting:

There was a time in high school I'd been drinking a lot. . my family has a history of depression and I have depression. . . and one day I was just like: "This has to stop. I want to be successful in life. This is not the way to do it.” And I came out and told my parents. ... Our family has a family therapist, and I went to her, and she told me: "I have ADD in my family too" and she recognized the signs. My family has a history of alcoholism and self-medication, too. ... I'm happy about it [getting help]. I always 
knew I could do it. I just didn’t understand why I couldn't. And now that I know why, and I'll always have that trouble, I can work around it. . I'm really proud of being able to do it. ... When I was diagnosed, my doctor was like: "You need to do this, this, and this. You need to strictly follow this, or else you'll just fall right back into what you were doing before." She made lists. . . she was like: "You need to clean your room, empty your trash can once a day. Make flash cards, outline things." When we figured out I was ADD, I went on Ritalin. My homework assignments are on time, I take understandable notes; I'm not incredibly disorganized. (XIV, p. 4-5, 6-7)

\section{Awareness of Limitations and Compensation}

The students candidly explained how their learning problems impacted everyday academic functioning. They described a myriad of learning problems involving the input, organization, integration, and expression of information. In addition, the students coped with another layer of difficulties caused by these processing problems: inconsistent abilities and invisible disabilities resulted in credibility problems with professors. They described working an inordinate number of hours on school work and coping with the stress of managing their processing problems.

Along with the observation of personal limitation came a description of compensation: relearning and reviewing basic skills, over-learning and double checking for correct understanding, starting early and taking extra time to complete assignments, the use of alternate processing methods, taking frequent study breaks, the use of physical exercise to relieve stress, verbalizing to self or others to regroup and reorganize, listening to music to improve focus, and the utilization of accommodations and services. Sometimes, an intervention as simple as 
identifying the problem helped the student to persist through it. Kenny regretted that he did not use the organizational tutoring that would have helped him in high school:

I was supposed to have tutoring. . . and I think I really needed organizational tutoring, because I was just all over the place. I just didn't realize. . . it took me to be in college to realize that I needed to work stuff out. . . instead of just get help. . . Well, I mean I have the structure, but I enforce it, and I know from past experience that if I don't enforce it, I'll end up really messing up.... Being diagnosed with ADD really explained why I would never be able to sit down and do something; like I would always plan on it, but, now I can plan on sitting down and doing something at a certain time, and actually get it done and be satisfied with it. . . . Like I knew that I could do the stuff, I just didn't. . I just couldn't do it. It wasn't difficult, just being able to accomplish it was difficult. . I would sit down and be like: "Okay I'm going to write this paper, I'm going to research it." And then, I wouldn't be able to organize my thoughts and the stuff just wouldn't make sense, what I was trying to say, and what I was reading, and so like, sometimes. . the motivation would be there, it's just the follow through [that was not]. (XIV, p. 3-4)

Mark does not let deficiencies in visual or verbal processing speed allow him to feel inadequate. His confidence stems from that fact that he works to fully understand the concepts in his classes. He uses his verbal expressive strength to participate in class discussion:

I understand a lot of the concepts, and I talk in my philosophy class, I talk more than anybody else does. . . but when it comes to taking a test, like the words, my brain, the actual letters themselves, not the concepts or what they are saying, is what is hard. . I've gotten a little better with putting the letters into words. . . Like when we talk in 
class, even talking can still be a process that's slow sometimes, say I compare myself to somebody that can read fast, and that can respond, who's brain is working like at it's normal speed or whatever you call it. (VIII, p. 23-24)

Louisa is used to studying numerous hours in order to compensate for her learning disabilities. She admitted to her frustration and described taking frequent breaks and using physical exercise to manage the stress of the long study hours. She worked for the long term reward of feeling successful:

I had History and Science and I didn't get much sleep the first semester. Sleep deprivation was a big problem. Because [my professor] didn't let me sleep that much; he had four, five hour assignments and they usually took me about eight hours to do, so that was difficult. . It's very frustrating, but over the years you kind of get used to it, and you have to deal with it, so. . you might as well just put in the time. I pace myself. It's really frustrating, actually. I have to take breaks sometimes, and go exercise, let off the tension. ... And plus you want to get a good grade in that class, you don't want look back on it, and be like: "I should have done better, or worked harder." The work was hard, too. It was a lot of interpreting history, reading between the lines. And that was difficult, because my thinking process is a little slow. (XI, p. 6)

Margaret described how her learning disability impacted her classroom functioning:

I may have a short-term memory [problem] . . but you know what? As long as I'm not having to write down things, and I'm just listening, like that's fine, I can handle that. It's just like I can't write and listen at the same time. Like when there's two things going on, I can't multi-task like that. (XXII, p. 24-25) 
Ben struggled with verbal expression. This awareness and admission generated his acknowledgment of the problem to the appropriate persons in the environment and his working to compensate for his limitations:

Like, one thing, I have these problems explaining things, or saying stuff. . . I have a problem getting things from my head out, and a lot of times when I try showing somebody something, they may not think I know it, but I do know it. It's just that I may not explain it the right way. (XXVIII, p. 17)

Julie described an inconsistency in her cognitive processing. This factor sometimes causes persons who are uneducated about the syndrome of learning disabilities to doubt the integrity of the student's diagnosis. Julie was concerned that her professors would doubt her:

And sometimes you can overcome certain things. . . like a lot of my learning disabilities I know I've overcome. . . like writing papers, I'm not good at them, but I know I can do it better than some people because I can just really focus on it. But, it's little things. . . you're really not sick, but when you want to be sick, like that's how I feel people feel think about me: When I want help on something, I'll pretend I have my learning disability. . . because sometimes it just pops up. . . sometimes on a paper, you're just like “well, I don’t know what, I don’t understand this question, I don't get it." Some things just don't click, I guess you could say. . . . Sometimes I'll be great at writing a paper, awesome, and I'll totally have it down. . . and then, next time, I just won't know what's going on. Like on a test, I'll do really good, another test, I'll just do horrible. It just springs up. (XII, p. 24-25)

Wendy explained that certain types of instructional techniques support her learning in the classroom: 
Sometimes it's bad, because I have a hearing thing. It's not like I can't hear, it's like when there's an accent or a lot of background noise, I don't remember what it's called. It's something to do with not so much going into the ear. . . so much as it going from the ear to the brain. ... And so I had a really good [professor] this semester. He pronounces really well, he talks slow enough that you can understand, but not so slow that it's like droning. . . And he does this really cool slide thing, he puts the notes on the slides, and puts them on the board. . . it makes it much easier to write them down. And I really liked him. I have Dr. though, this semester for Math. And he talks really fast, and he switches subjects quickly, that was really hard for me. (XXX, p. 3)

Jim described finding ways to cope with his learning disabilities in the college environment. He is less distracted and more productive:

I've been able to deal with noises more now, than high school. Like in high school any little thing, I couldn't concentrate. Here, I can concentrate a lot, I'm even making progress. Like if I had a little quiz in class, I can focus pretty good unless somebody right in front of me is talking. . I'm not getting frustrated, really as much. . . because, even if I feel like I'm not organized, I mean I can talk to either my friends or adults here and. . . they listen. . . That helps me even if I'm just like talking to myself, sometimes. To get more of an organized feeling; that I know what's going to happen. ... When I'm working with the [language tutors], like if I read something, I might not necessarily know it, but if I am able to restate it in my own words, what the chapter is saying. . . I know it a lot better. . . I think part of that is I have people to talk to, my 
frustration does not build up. And I'm discovering this year [that] music helps me focus sometimes, like I can get more done when I listen to music. (I, p. 4-5)

Kevin had to improve his writing skills to meet the expectations of his professors. He did not discount the worth of his work even though his grades were lower than they were in high school:

In high school, I used to get As on my papers, but I guess high school teachers don't really grade as harshly as professors do in college. So, like right now my papers are Cs, but, I put a lot of time into my papers, and the thoughts in the papers are good. It's just that there's some grammatical errors and stuff that I need to work on. But, I think my papers [are] a lot better than what I wrote in high school. (XXI, p. 14)

Dan expected to have academic problems in college:

I knew from day one I was going to have academic difficulties. I have academic difficulties wherever I go, no matter what I do, the reading, the writing, and all that stuff. It's just hard, it's a pain. . . I don't care for it too much, but it's something that, you know, you've got to do... The exact things you have to have to make a paper, your grammar, punctuation, the amount of reading that you have to do to comprehend it. The studying for tests. . . a lot of stuff isn't for a homework grade, you don't get points for trying, I mean that's life. Nothing's really ever come easy for me. So, I'm kind of used to that. (XX, p. 8)

Even though the students in this grouping were able to compartmentalize their disability, they did not avoid dealing with it. Kevin acknowledged the academic impact of his learning disability when I asked him about the difficulties he encountered during his transition:

The only thing that makes it hard for a disabled student, is getting prepared and going to class. . like during exam times. . . or like taking notes... or talking to the 
professors, or participating in class.... I think that's the only difficulty that a student with a disability will have. . . . Like I try not to think that I'm disabled. I try not to think about that, I just, you know, try to be like a regular person. (XXI, p. 26)

\section{Active use of Accommodations and Services}

The students in the effective functioning group regularly used accommodations and services to facilitate their success. Testing accommodations such as extended time and a quiet environment helped the students adequately express learned information; the students were relieved not to agonize over keeping up with the "normal" pace of testing. Several students used readers and scribes so they could spend their energies delivering the answers without getting bogged down in the laborious mechanics of punctuating, spelling, and letter formation. Note takers were able to capture the gestalt and significant points of the lecture the students missed because of auditory processing and writing speed deficits or problems with attention and focus. Finally, the students explained they benefited from the preferential pre-registration process and scheduling their classes with a mentor who understood the limitations posed by their learning disabilities.

Julie described coming to terms with her learning disability in the college environment. Initially, she was reluctant to enroll in the support program because she perceived there would be a stigma attached to using the services. She recounted how her involvement in the support program facilitated her transition:

Just like. . learning how to spell, you know how you kind of learn how to spell, too, when you read a lot more, and so, that helped me. . . because I might struggle with papers at home and things like that, and it seemed like if I could get just past learning how to spell things correctly... just getting the phonics sound, like the reading down, 
like I can read it, understand it, and then write a paper. Since [in prior settings] they never knew that I was dyslexic, they couldn't teach me the way that I needed. . . they taught the way that all of the kids that were normal, how they would learn. So, it's like I learned it, but I really didn't grasp it. I just didn't want it [the program] because I didn't want to be different from all the other college students. But then, I thought about it for awhile, and I was just like: "I need it." I mean there's no way of getting around it. . My parents told me about it, and I really didn't understand it. But then when I got here, and I was learning about it, I was like: "Oh, this is what it is? Oh, okay.” It took a little convincing, too. I was like: “I don’t think I need this, I really don't want to do it. With [language tutoring], I've learned. . I can just look at a word and figure it out. Like now I can, if I don't know it, I can figure it out because I remember my phonemes. Like I never knew that before, and then it's easier to spell things out because I can just think it in my head. And with the student support system, that. . . that's always helpful because it's like a way to plan your stuff all out. Like I can go to [my mentor], and she'll ask me about my grades, and how I'm doing in certain classes. I can tell her, and like I can think in my head "Oh, I'm okay, I'm doing good in that class, need to work on this class." It's kind of like things opening up for you, somehow. It's also neat, because if you're having any problems with classes, or with reading, like you can get the textbook on tape. There's someone there to help you out; it's not like you're alone at college. (XII, p. 1-3)

Mark observed that his utilization of accommodations have allowed him to express the complex conceptual information he has learned. With the use of a scribe for testing, he is no longer limited to write what he can spell correctly: 
The help [of having a scribe] on tests. . I couldn't spell what I wanted to say, and in high school, it didn't really matter, I could write it down, and they would ask me what I was trying to say. . . and then I could get a good grade. But here, you need to write, and I need to spell clearly, because the professor is not going to come and ask me what I'm saying, he is just going to mark me off. And sometimes I will use a lesser word, you know, when I can use a bigger word that will fit what I'm trying to say, but I'll have to water it down, in order to spell it. And so I don't have to think about the spelling, I can just focus on the actual content that I remember. (VIII, p. 2-3)

Jim described his use of accommodations to compensate for several disabling conditions: With fine motor skills [problems] in general, let alone with ADD, being able to focus . . . if I don't get something, I can pretty much count on that the note taker will be able to get that picked up. Something else. . . [that helps is] another person's perspective, how they interpret the class. And extended test time; that was very nice. I was concerned when I was looking at colleges; that was one of my big questions: "Would I be able to get extended test time?" With them being able to read it [the tests] and scribe for me, I can just focus on how to actually answer the questions. (I, p. 18-19)

Denise talked about her trouble processing the gestalt as she listens to a lecture: Sometimes when I take notes, I take too much, so having the note taker kind of tells me what is actually important, and what's not. I know I take too much, I take down too much detail that I don't need. I just know that I do that. (XIX, p. 40) 
Mark enumerated the accommodations he uses for testing. He feels more at ease starting his tests in a separate location. In high school, he began his testing with the rest of the class and was moved to the teachers' lounge to finish up:

I use. . . extended time on tests, a scribe, a reader. . . I got extended time in high school, but I would sit in the classroom and start the test with everyone else. And they would finish, and put pressure on me, and they would take me out of the room to finish, I never liked that. . just to be the last person, people always get up before you, but to be the last person and then you're like the only person in the room, and everyone has left or gone to eat lunch or whatever. . because it just took me longer to process things. . . I knew the answers, it just took me longer to read it. I never liked having to leave the room and everyone was like: "Oh, he's dumb." (VIII, p. 23-24)

Margaret illustrated the worry she felt in high school when she tested in the classroom. She has been relieved to take her exams free of the distraction of others leaving the test:

I used the testing services. . I've taken numerous tests in the testing area for quiet, extended time. [And a quiet environment] really does help because you do not have people around you, you know, who are like bringing their papers up, while you're still working on it. . I know it affected me because I did not have that privilege of being in a separate area to take my tests in high school and so it really bothered me, it would get like: "Man. . . you know, I don't want to do this, I still have so much more to go." And it's like: "How did they do it?" And you just think: "I must have not studied right or studied enough," you just feel like you're not getting it. (XXII, p. 16) The quiet testing environment facilitated Kevin's concentration and academic success: 
I get extra time so when I take my exams, I take them to the Testing Lab, and sit down and actually take my time. . . being in the room taking a test, that also helps, like you're not in a classroom, because I know back in high school, we would start the test with everyone else, and then, if we needed the extra time, it was just go with the teacher to the faculty lounge or whatever. . . and that's all noisy. Here, you can just take your test in one room where it's quiet and there's no one around. There might be a few people in there, but it's still not as bad. . . because in high school the teachers were always rushing you. (XXI, p. 15-16, 23)

After experiencing problems with mental fatigue and hyperactivity during testing, Janice concluded that the use of a reader might help her stay focused. She described her difficulty with processing language, hyperactivity, and sustaining effort while she was mentally fatigued. Janice did not want to continue giving up on her tests and admitted that it would be helpful to have someone to support her persistence to work on exams until she could learn to better manage her ADHD symptoms. She recounted giving up after tiring on one of her tests:

I talked to [the professor] about it and I was almost in tears, I was like: "This is so frustrating.” I was like: “I needed to stop, you know?” But I just didn’t answer the question the correct way, or not completely, and I was writing so much that I got frustrated and I wanted to stop, so I didn't put everything that I was thinking down. . . I was talking with my [language tutors] and they were saying if someone is there to read it to you, they can keep you on track and so I thought that would be a good idea [to have a reader]... And it will keep me from getting quite as antsy. I will probably still get antsy, but they will. . just keep me going, where I would just give up, and be like: “Whatever, I'm done.” (XVI, p. 12-15) 
Julie explained that testing in a separate location made sense if she needed the extra time.

However, she preferred to test in the classroom for access to the instructor:

Like what I do usually, is I take the test in the class, the first test, and see how it goes. And they know that I need extended time, so if I need more time, I just run up and go to the Test Lab. But, if it goes all right, then I'm like: "Well, why don't I just take the test in class?" Because when I'm in a class setting, it's better sometimes because I can ask the teacher if I have a question. So, I like that better, but the Testing Lab's good, because it takes me forever, sometimes. I get to use the computers too. . . because of spelling and grammar. And when I type something out, it's better than if I write it out, with a pen, because of scratching out. (XII, p. 17)

Kevin explained how the accommodation of preferential pre-registration and specialized academic advising was supportive to his transition:

For the freshman year, having my classes scheduled was good. . . they [the mentors] showed us. . . the good classes to take, not to put too much of a load on yourself. . . instead of cramming in all the classes, like, one after the other. . . That way you have time if you need the extra time for a test, you have the extra time to take the test. (XXI, p. 15-16)

\section{The Benefits and Conflicts of Reasoned Disability Disclosure}

Most of the discussion concerning disability disclosure emanated from the interview question regarding self-identification procedures. A personalized accommodation letter, written on departmental letterhead, stating that the student has been dia gnosed with a learning disability and should receive services and accommodations that provide equal access to the educational experience, is provided to each student. The student may present this letter to the professor 
during the disclosure process. Identification to the professor is the responsibility and choice of the student. The student's mentor offers to the student the opportunity for rehearsal of the disclosure statement during the first few weeks of each semester. In addition, the mentor's name and contact information is included in the accommodation letter in the case that the professor has questions regarding strategies for assisting student learning or concerning disability verification.

From the student point of view, the accommodation letter served the purpose of disability verification or as an object of introduction. All of the students in the effective performance grouping disclosed their learning disabilities to their professors. Although several students expressed an ease with the disclosure process, many were conflicted about revealing cognitive processing problems to the person responsible for evaluating their performance. The students worried the professors would use less rigorous standards when assessing their academic work. Nevertheless, the members of the positive collective case tolerated their discomfort for the longterm benefit of using accommodations and services to achieve success.

The students revealed that it was reassuring to read an invitation to self-identify in their course syllabi; this type of syllabus statement proved a willingness on the part of the professor to accommodate special needs and made the disclosure process less intimidating for the students. The students mentioned that they were relieved the professors trusted the integrity of the Test Lab in the support program offices. The students in the positive performance grouping understood the importance of disclosing to their professors early. Some students were comprehensive in their description of how the disability impacted their academic performance in an effort to circumvent credibility problems that might occur as a result the student's uneven academic performance. Many of the students in the positive performance grouping wore their 
disability as a badge of fortitude. Janice was pleased she had come so far with her education, given the limitations of her disability:

I told them. . I have never had any problems telling people about my disability, I'm very proud of it, you know, everything that I have come through, so it is not, for me, it's not like a shame or anything, it's something that I love to share with people. And so I've got teachers and [I say]: "I just want to let you know that you I'm a student with the Learning Center. . . and that sometimes I will take my tests over there." And they're just like: "All right, if you need anything just let me know," and they're usually pretty perceptive about it. (XVI, p. 2-3)

Kevin described having a positive experience with the self-disclosure process:

Most of the professors are really nice about it, they'll be like okay. . . they'll give you the extra time, they'll give you whatever you need, I'll find you a note taker. . . they know that you're telling the truth. I would approach them, and I would say my name, and then I would say: "I'm a student who has a learning disability in communication, and I usually take extra time to process the information and so I get extra time on my exams." And they usually accept that, they go with it. . . . I think it's a good idea [to have an accommodation letter]. I haven't had to use it much, but I think, you know, it's a good thing to have just in case something does happen. But most professors really don't care about the letter. If you just go up to them, and explain to them what your situation is and why you need the extra time, then they won't mind. And most professors actually write in their syllabus: "If you have any special needs or requirements, please stop by to me." That's pretty good to see that, because then you know that professors do care about you. (XXI, p. 19, 21-22) 
Mark believed that his accommodation process had been facilitated by the fact that the professors trust the integrity of the test lab in the support program office. He has chosen not to describe his processing deficits in detail:

I think [the accommodation letter] is good for people that might not be entirely comfortable with going up to the teacher and telling them. But most of the teachers. . . I'm just like: "I need to take a test in the test lab" and they are like: "Okay." I don't need to go into a great amount of detail because the teachers are fine. . None of the teachers think that the test lab is a place anyone is going to cheat because it has a good reputation. ... I don't have to explain to the teachers that I have a processing problem, they just need to understand that I need extended time on a test. Most of teachers I have are like: "Fine, I'll send the test over there." They have their classes to deal with, and all their grading, and the fact that they can send tests over here, that you all have it under control. . . they know they can put it out of their mind. (VIII, p. 27-28)

Louisa observed the disclosure process went easier when the professors were educated about the syndrome of learning disabilities:

It [accommodation request process] went pretty well. A lot of the teachers are really understanding because I'm sure they had many students with learning disabilities before. . Some of them didn't know what leaning disabilities were, and you kind of had to explain to them why you need extra time. But, besides that, it went pretty well. And then, you had to say what a learning disability is. . . this definitely made it harder because they didn't know what I was going through when I was doing the assignments. (XI, p. 17-18) 
Wendy understood the importance of disclosing early in each semester:

I have a hard time doing things quickly, or I'll have a hard time with writing things down as quickly as people talk. Sometimes I've had my English professor be like: "Are you going to need extra time on your essays?" Usually I'm like: "Probably not, because you give us about two weeks to do it." I don't feel it's right to take advantage, be like: "I need an extra week." If you're ever going to identify yourself, it helps to do it at the beginning. Because if you wait until half way through and you're like: "Wait a minute, I have a learning disability, I want this." It's kind of like: "But you didn't need it before. And we're doing the same sort of stuff. What happened?" So... then they [the professors] can understand, and it's not like you're popping something up in their face, at the end of the course, and they're like: "What?" (XXX, p. 17)

For Leah, disclosing is routine; she has begun to understand that her learning disability is a lifelong condition. In her opinion, hiding the disability creates another set of problems for the individual:

I just went and had a meeting with each one of my professors and showed them that letter, and then they would ask me like what they thought my specific needs would be. I didn't have a problem. . . Even before I got the letter, first semester, I had already talked to my professors. . It didn't bother me to go. . . some kids are scared to tell their professors... I don't have a problem going and telling them that I have a learning disability and I need certain accommodations. . . I think it's [the letter] good for kids that are kind of shy about it. Maybe the [accommodation] letter will explain it for them, so they don't have to do any talking. It didn't really help me in any way. I 
guess maybe some professors might not believe kids, and therefore this letter confirms that they really do have a learning disability... So, this way where you go by yourself, like [the professors] get to see your face, you get to talk to them personally. . . Because, I just look at it as way of life and I'm going to have to deal with it for the rest of my life... You might as well start now, and be able to tell people, because it's something you can't fix, you're just going to have to deal with it. (XIII, p. 10-13)

Approaching his professors for accommodations became customary for Jim as well:

I'll just say: "Professor, I have a couple of questions...they'll say: "Sure," and I'll say: "Well, I was wondering if I could take the test in the Learning Center" and if they ask why, I'll just say: "Well, I have a learning disability." Or sometimes I'll just start off by saying I have a learning disability, and if they ask what it is, I'll tell them, and try to explain it the best of my knowledge. And if they need proof, I just give them that letter; I think only one needed proof. But after like the second one I told, I felt confident in how to approach the professors about it. It's kind of like a ritual, I guess you'd say, or automatic now. (I, p. 16)

Tony explained his coordination problems to his Dance instructor. This segment also shows Tony's persistence as he worked to "get" the dance steps during practice. He has performed well in several campus productions:

I have Intro to Dance...dancing is really hard for me because it's a lot of coordination, like just getting one foot aligned with like a finger...that's really weird for me...I get really discombobulated. So basically, she [the professor] has a meeting to find out where you are in her dance program, I said: "Like the only thing I need 
from you is to be really, really patient. That's all I ask." She's like: "That's fine." And I explained to her [about my disability) and I was like: "If you want me to do the letter, I'm sure I can dig it out of my drawer, somewhere...I learn at a different speed that way and in everything...in general movement, I'm just not a graceful person, so, couple that on top of like learning at a slower pace." I mean, sometimes like I'll go in there and we could have been doing one move for like a week and there's no way my body will let me do it, and she'll be like: "Why can't you do it?" I'll be like: "I know it, I do, I can't do it, though.” I keep trying. . I just have to resign myself to just keep trying. (XV, p. 17-18)

In case he was asked to verify his need for accommodations, Ben stood ready: I have my [accommodation letter] in my book bag, and I just carry it around with me every place. Because, I never knew. When I went in for Pre Cal, my professor didn't need to look at it, but, now, in the second semester, my calculus teacher did ask for it. And like, if I didn't just put it in my book bag, and have it with me all the time, like, I could have lost it. (XXVIII, p. 13)

Dan disclosed his learning disability because he anticipated his instructors questioning his uneven performance:

I showed all my professors [my accommodation letter] the first couple weeks of classes. I said this is something that I was struggling with, this is my problem: "that I just wanted to let you know that, so if there's an area that I should start struggling with and it falls in one of these categories, just know that I am working hard at it." I pretty much knew exactly what I was going to say because I've done it before in 
many different situations. ... And they're normally very receptive to it. (XX, p. 1618)

Some of the students in the effective functioning grouping were not comfortable with the disclosure process but identified themselves to their professors anyway because they knew accommodations made a difference in their performance. Disclosing was not easy for Jerry: I'm not really shy about it, I don't think of it as a real big weakness or anything. But, it's fine. When I first do it [disclose], I feel kind of weak, I just tell them I have a disability. And some professors would be just like: "Oh, that's okay," and others would be like: "So, what's your point?" Like my ___ teacher did, he'd be like: “Am I suppose to care?” (IV, p. 28-29)

Julie worried about how her professors would respond to her disclosure:

To be honest, I don't really get nervous about talking to professors, but I was really nervous about this, just because I was a new student, and I didn't want him to think I was retarded at this or something. So...I just talked to [my mentor] about what I was supposed to say and she told me that you need to show them the letter, and they'd probably understand it....Another thing I was scared of, was that they'd be like: "What is this?" And then, you'd have to explain it to them. And...they'd just look at you.... But I talked to my teachers, and they were really good about it. I just said: "I'm a part of the Student Support Services and I might be e-mailing you sometime, or come in to talk to you if I need a note taker, or if I need extended time on my tests." Like a lot of them were like: “Oh, okay, well, just keep me up to speed, that's fine." And they were real good about it. (XII, 16-19) 
George admitted to not liking the disclosure process; however, he understood that he must go through with it in order to receive appropriate accommodations:

A lot of my professors, I just went up to them, and I was like: "I have a disability." They're like: "Okay." "I have a disability so I will be taking a lot of my tests in the Testing Center.” And a lot of the teachers said that they know how it works, they have been around the block a few times. So, it wasn't a big deal... One of [my professors] did say: "Do you have the letter?" [He] kind of asked me to prove it. I was like: "Okay, I have the letter here.” I think going up and talking to a teacher is fine. Actually, I did have to talk [with my mentor] and say: "Okay, How do I do this?" She explained how to do it, and she explained the testing center, explained note-taking. . . I don't like talking about [my disability]. . . But I have to do it in order to get my [extended] timed testing so, yes, I say: "I have a disability and I use the disability services, I need to take the tests in the testing center." Nobody has scowled at me for it. You know, most of them are like: "Okay, I understand.” (III, p. 33)

Margaret disclosed her learning disability in spite of her worry that her professors would think of her differently. She knew she needed to use accommodations to be successful. This piece of her narrative illustrates the distress of living with a sense of being different:

You have to kind of let the professor know that you have a learning disability, which I never liked at all. I never liked having my teachers know that I have a learning disability. I actually started writing an essay on it.... What it is to me is a red flag to the professors that I'm incapable of doing the work, and. . they have to modify or make it easier for me to do the work, and I don't want that at all. ... Give me the same challenge. I can do it. And that's why I don't like telling professors because. . . 
it's nice to be an individual, but they're going to have an eye on you. . . and you don't really want that, you kind of just want to, especially when you have a learning disability. . . you just want to blend in, you don't want to really stick out. . . it brings all that up for me. When you have to go to the professor and be like: "I'm dyslexic and I have a short-term memory [problem], you don't want to do that. . I just did it [disclosed] because. . . you always have to, I'm like: “Well, just, you know, admit it to yourself that you have it, and then just go and do it." (XXII, p. 20)

Kenny was conflicted about revealing his learning disability and was careful to disclose only to the instructors he believed would handle the information well and in classes in which his disability had a pronounced impact on his performance. Like Margaret, Kenny struggled over how he would be viewed by his professors; he imagined and worried that the professors might grade his work using a less rigorous standard. I asked for his reaction to our disclosure process:

I guess it would be like. . the natural reaction would be like I don't think I want to just go up to somebody I don't really know at the beginning of a time period where they're going to be marking me, like in my efforts, and to be like: "I have a problem." I mean, that just seems kind of scary. But...the professors here seem really approachable, so it wasn't that difficult. I didn't end up doing it for all of them because I realized I wouldn't really need to. And, a professor of mine this semester actually found out about it, and sought me out. He was like: "If you need anything, tell me about it, I'm here to help you.” That was really, really cool. But, I mean, I like the fact that it puts the responsibility of asking for help in the students' hands. . . It just feels like you're saying: "there's something wrong with me" because you don't know how accepting other people are. It's just. . . it's kind of weird. But, I think it's a 
good thing....And it also, like the end of the first day of classes, it's a good way to go up to the professors and say hello, I'm this person. So, I know what I say kind of contradicts. . . I mean, it's a good way to introduce yourself, and just have something to say, and have the professor remember you. But, it just kind of bothers me sometimes that what they have to remember me by is that I have needs that I need taken care of in order to be successful.

This is the way my mind works, I would be afraid that if a teacher knew about it, automatically, that he would be more lenient and like easier on somebody. . . I want to have earned the grade, so I don't want somebody being like: "Oh well, this is the best they can do." Because I feel like I can do as well, better, just work like other people. . . I feel it's one thing for them to help out and make the services you guys provide easy. But it's another thing to lower. . . the way they see . . because I'm not able to do what some other people can do. . . It's just a strange thought that I have.... In high school, I thought it, but not so much here, because I'm getting really good grades back. . . . Nobody else in my English class earned ninety on this essay. . . especially since. . . in my English class, I don't think I told my professor about the Student Services and my disabilities. . . and I have one of the highest grades in the class there. So, I know he's not grading me. . . with something [my disability] at the back of his mind. . . . And I read articles and it says people with dyslexia and ADD. . have high intelligence. So I know it's not like I'm stupid. . . I just want the professors to know that, too. (XIV, p. 19-21)

Ben disclosed regularly, but, like Kenny, did not want his professors to change their standards for him: 
I don't know; I just wouldn't want people to say: “Oh, yeah, he's LD, so we have to give him an easier time." I want to get the grade that I deserve. I don't want to get a grade because they take pity on me. . I know that I can do the stuff, and, it may take me a little longer to do it. . . but I want to earn the grade, I don't want to be given the grade. So, it just comes down to. . I I want to know that I got there, because I got there, and not because somebody took pity on me or something. . . Because, you know, I'm still doing all the work. (XXVIII, p. 14)

Julie expressed concern regarding her professors' image of her ability and level of effort. She debated about the lesser of two problems: for her professors to doubt her abilities or for them to think she did not put in full effort on a consistent basis.

I don't want the professor to come in thinking: "She's not at the level everyone else is. . . so that means that she's going to get all her tests and quizzes wrong." I just want them to think that I'm smart. . . like if I come across as being smart. . . . With dyslexia, it's like: “What, you can't read?" This one girl, I was reading something, and she was like: "Are you dyslexic?" Because I reversed the word, I was like: "Yeah," she was like: "No you're not, people like that can't read." I'm like: "What are you talking about?" It's just stupid little things that. I'm just like: “All right, people think you can't read if you're dyslexic." I don't want teachers to be like that, think that I couldn't do it. So, it's like I have to prove to them. . . I don't want to prove to them, I just want the same chance as anybody else. And then, sometimes [disclosing] helps. . I I don't want them [my professors], if I get a bad grade on my test, to be like: "Gee, she's really not trying." So, it's like you're going to have to decide which one's better. (XII, p. 21-22) 
Julie continued to consider her conflict. She has run into credibility problems, because, for the most part, her learning disabilities are invisible:

And it's hard for me to explain to them [my learning disabilities] because I feel like they're saying in their head: “Oh, she's just fine, she's just saying that." It's hard because I'm like: "Don't you know what this stuff is, you went to college." I wish the teachers knew. . . like they should have to take a course. . . because they're teaching kids. . . and so that's why I have fears when I say something to the teacher that I'm going to have to explain it to him, and it's going to be this long drawn out thing where I just wanted to tell them in case I got a bad grade on the test, or just in case I needed to go to the Test Lab. . . . It's just people's ignorance, and that bothers me. I don't know why but, I guess because I can't see myself as having it [a learning disability], so I don't think people can see it. I feel like people are like: “No, you don't, stop it." But my friends have picked up on it sometimes, and when I say I'm dyslexic, they're like: “No, you don’t. No, you're not.” And I'm like: “But I am.” I guess I can hear them in the back of my head, and you don't want people to tell you no when you know it's true. (XII, p. 23-24)

\section{Positive Use of Constructive Help}

The students in the effective performance group openly discussed their use of help during their transition semesters. Seeking assistance to navigate the new levels of academic rigor did not appear to preclude the students' development of personal autonomy. The students described their perception of the appropriate type of support contributing toward a successful transition. They examined the scope, depth, and meaning of their work with their mentors who specialized in providing support to students with learning disabilities. The student-mentor relationship was 
confirmed by the students in this group as one of the significant factors that facilitated their transition. In addition, the students who were enrolled in the langua ge tutoring program acknowledged and appreciated the fact that they had the opportunity to develop basic academic skills. Finally, not only did the students actively seek support, they made realistic suggestions for augmenting the current support system, thinking outside its current boundaries.

\section{A Posture of Active Help Seeking}

The students in the effective performance grouping were open to receiving help from multiple sources. They decided to come to a college with a strong support program because they knew they would function better with assistance. Mark came to school concerned about where and how he would receive the help he needed. Like many students with learning disabilities, he turned to his parents for academic assistance during his high school years. Mark described how he has been able to adjust to new helpers in the college environment. He described working to find the balance of interdependence:

That's a big, big thing that I've gone through. When I came to school, I didn't want to depend on anyone other than myself. And at times I've put to much stress on myself ... it's good not to be completely dependent, but it's good to know that you can. . . count on some people. I'm not going to say that I'm not going to count on anybody, all on me, that's a lot of pressure to put on someone. . I felt that way when I first came here. . . . It's almost like the longer you're here, the less pressure you feel you have on yourself, because you get more comfortable. . More comfortable with the people you can reach to for help. Like I didn't know who to go get help from. . . at first, it's kind of scary, because I put a lot of pressure on myself, and I didn't know how I was going to deal. (VIII, p. 12) 
Ben openly acknowledged his need for academic support:

I'm not afraid to ask for help. . . I really need it, so I might as well just ask for it. So everybody has some disability like, mine might be in reading, where somebody else's may be in. . . writing. I'm not ashamed to come in here and ask for what I need. (XXVIII, p. 14)

Jim wanted the assurance of strong support to alleviate the stress of the transition. I asked him why he came to this particular school:

Probably feeling when I visited I would be comfortable here, and able to connect and not feel really stressed out about homework. That I'd have somebody that I could ask like: "How does the professor want this done?" Like with the Writing Center and all the tutoring opportunities. ... And I feel I can ask you stuff anytime, or [my mentor]. ... The help I felt I'd be able to get when I was even looking at it [the College]. (I, p. 2-3)

I asked Ben if his expectations of support were met on this campus:

The Learning Center was a big help, I took notes, but if I thought I missed anything or if I did miss something when I was trying to, like spell something, or just if [the professor] talked too fast while I was writing, they supplied me with all the notes that I could copy. . . . [My mentor] helped a lot with picking out the schedule, which was a big help. . . . The student tutors also really helped because like, sometimes you might be doing the homework, and you might not know what to do, and you might read the book, and you still might not have a clue. . . they have them for everything, I use them for psychology, physics, and calculus. (XVIII, p. 6-7) 
I asked the students to evaluate the help they received through the support program.

Wendy used several elements of support provided by the specialized program for students with learning disabilities:

The Learning Center helped me a lot too, just because [my mentor] was really good about helping me get notes, and she was just someone to talk to, too. . . . Somebody to talk to on how to organize myself and help me keep track of my grades and stuff. . . And the notes were really good. That was really helpful, especially since they were able to arrange it so that I could get photocopies. (XXX, p. 7-8)

The students were not shy about asking for support when problems occurred. They knew when they were missing the mark, admitted it, and went after assistance before it became too late. Wendy sought the help of the Counseling Center when she needed it:

The counseling service has really helped. I haven't gone at all this semester, but particularly when I was having a lot of problems with my roommate and, you know, I hadn't had that many friends, and didn't really have anybody to talk to, it was a really good place for me to go. They were really supportive and helpful. (XXX, p. 7-8)

Leah observed that she was persistent in her help seeking behavior:

I can stand up for myself, and I just don't sit back and let people walk over me, like if I'm not doing well, I'll go talk to the teacher, and I'll do what I have to do to succeed in that class. So, for me it's not a big problem. . . . They weren't worried about me at [my high school] because I could stand up for myself, I knew what I wanted, and I knew how to get the help that I needed. (XIII, p. 1)

Leah described working directly with one of her professors to improve on her homework: 
I just went to [the professor] and showed him my letter and told him my learning disabilities. . . because there was a paper that I didn't do well on. So every time we have a paper due, I do it on the day before, and he looks it over and gives me corrections, so therefore I can get a better grade. He just goes through and looks for what he's looking for and if it's not there he'll jot it down the side, and say this is missing. Or we have quotes in every paragraph, and if he doesn't think my quotes are that strong, he'll say go back and look for a new quote. . . like if he's not busy, or anything, he'll sit down and do that with me. (XIII, p. 2)

Denise used a commonsense approach in deciding when to seek help: I guess if I'm doing poorly. . . In one of my classes I'm not doing well. . . I just go and talk to [the professor] and see what I have to do to improve. We have had two tests; I got a C on one of them, and a D on the other. We have quizzes and I get A's on all of the quizzes. (XIX, p.32)

\section{Evaluating the Right Kind of Help}

The students in the effective performance group acknowledged that the right kind of help was based upon the principle of interdependence: the type of help described guided the students to more autonomous functioning. The students observed they internalized strategies for more independent social and academic functioning. Communicating belief in the student's ability to be successful and concern for the student's well-being, on the part of the helpers, facilitated student confidence. In addition, relearning and reviewing basic skills needed for the complex level of college study was acknowledged by the students as beneficial. 
From Wendy's point of view, the help offered from the learning support program required effort on the part of the student. She was glad that students were expected to function with as much independence as possible:

I think that this program does a good job of doing that ["helping students to feel like they've accomplished something'] because they give the m supports, but they don't do things for them. They don't say: “Oh, you know, here, you have learning disabilities, so you pass this class." They say: "You have to work at it, and we'll work with you. But, we're not just going to hand it to you." And I think that's a good thing. So. . you can feel like you've achieved something. ... I feel so much more competent this year than I did last year, or the year before. . . just because I've done so much and I've come here and done well. (XXX, p. 21-22)

Denise believed that she benefited from the structure and skill development provided by the language tutoring process. She valued practicing the visualizing/verbalizing technique used in her language tutoring sessions to master the comprehension of her textbooks. I asked her what services she used in the support program:

Language tutoring, Testing Lab. . I like knowing they [the language tutors] will help me with my schoolwork. . visualizing/verbalizing and its application to course work. I like the people, I get my school work done, I sit down and it's a structured time for me to do my work. I feel like I accomplish more in 50 minutes than I would in my dorm room. (XIX, p. 28-30)

Janice described improving her reading and writing skills through the language tutoring program: 
I do enjoy my language tutoring. . . I am learning a lot about my reading and that's been really kind of nice. Because I can definitely see where the changes are being made, I just feel a lot more confident in my reading and writing ability. (XVI, p. 24) Mark appreciated that the language processing tutors communicated concern for his overall wellbeing, not only his academic progress:

Language tutoring. .. I worked with them all year.... You come in and you're tired, and they are like: "You look really tired" and I'm like: "I'm working on this test" and they're like: "Well why don't I look at it and help you get organized." And that was helpful. (VIII, p. 16)

Jerry acknowledged the usefulness of the Study Strategy class in which he was enrolled during the second semester:

One of my favorite classes this semester is the Study Strategies class. There is a lot of information that's really helpful. And the book that we have just gives a lot of information about the person. . Like I was reading about the right brain or left brain, and some of the stuff is dead on. Like how I'm right-brained, strategies you need to do, and I was like: "That is actually me, like I really need to go and do that." So, that has pointed out a couple of things; I wish I would have taken that first semester, instead of now, at the end of the year. That's a class that I would definitely recommend. (IV, p. 8)

Mark talked of his growing autonomy within the context of a more independently structured academic environment. He described learning to work ahead in order to take full advantage of the walk-in peer tutoring service: 
That's another thing, in high school, the teacher would sit down with me, and actually help me do the work, project, or whatever it was. I stayed after school, and had both of my parents. Here, they will get you started, you go to the tutor. . you have to take down your own notes. . . then I will go back and finish the assignment. Where [in high school] I would take the assignment and do the paper with the teacher. And you don't do that here. . I want it to be all my work. Even though I get help, but the finished project, I know it's mine.... I try to ask questions and when I have gotten enough help, then, I can go and write the paper. (VIII, p. 13)

\section{Utilizing the Special Support Mentor}

The students in the support program were scheduled to meet with their mentor on a weekly basis. All of the effective performance students attended even though initially some were not convinced the meetings would be productive. The focus of the mentor relationship is the successful transition to and persistence in the college setting. Denise acknowledged the importance of the guidance function of the mentor: "It was nice having [my mentor] to talk to like once a week. I just let her know what was going on. . . for her to help guide me in the right direction" (XIX, p. 5).

Kenny appreciated that he could talk to his mentor about a variety of things, not only his academic standing. He acknowledged the benefits of this connection and support: "We just kind of stay in touch to make sure everything's going well. Sometimes we'll talk about things like... he plays the guitar, and he's kind of interested in me playing music.... And he's really supportive." (XIV, p. 14) Talking through the ups and downs of the transition was important to Jerry: 
I like how I go and see her [the mentor] every week. At first I thought it was kind of a burden, and once I found out how useful it was, I was like: 'I can't wait to get over there and tell her that I aced this test," or whatever. And now I get to tell her that I failed . That's one of my favorite parts of my accommodations. (IV, p. 24-

Jim, diagnosed with dyslexia and ADHD, frequently diverts to tangential strands of conversation. His mentor has worked with him to stay on topic:

Well, one of the main things, at least for me, [my mentor] and I, we talk about me staying on track in conversation and organization overall. And how my classes are going. . . And he'll look over my papers sometimes, too, if I remember to bring them to him. ... He suggested stuff like going to the library to study. (I, p.14)

Wendy observed that her mentor provides academic, social, and emotional support:

And if I have other problems, I know I could go ask [my mentor] and she'll help me with that. She helps me with my schedule anyway.... She taught me how to do brain maps, so that I could do notes easier. We talked about my classes, how I'm doing in my classes, what troubles I'm having and how to work with those troubles. ... Just in general, strategies to help with any kind of problems I'm having, keeping organized, that kind of thing. ... Sometimes we'll babble about things I'm having a hard time about, you know, we'll get off topic, I'll be like I don't know, I hate my roommate, you know, stuff like that. (XXX, p. 13-14)

Ben described a broad range of work with his mentor:

Usually [we talk about] how the courses are going, and he offers advice, like if something's not going good. Then, we'll usually talk about how thing's are going 
socially, or how I'm adjusting to [college]. He'll offer insight, ways around a problem with a teacher... So, it's usually, anything dealing with academic or social life, depending on what your problems are... it's real helpful. (XXVIII, p. 11-12)

Julie was direct with her mentor about the type of support she needed:

We go over each of my classes, and she asks if I had a test, and when my next test is coming up. We do the GPA before exams; we do the five-day study plan. And. . . [during the] first part, we did time management, but I really didn't feel I needed it because I had it under control, so she just got rid of it. . . . And then, if I'm having trouble with any teachers, she'll give me suggestions on studying, which is good. (XII, p. 13)

Dan described the extent of intervention within his mentoring relationship:

We go over grades that I've been receiving in courses, we go over upcoming projects, we go over scheduling, then we go over little things like how I'm doing, how my daily life is, what's going on with me. Mostly going over grades so I can keep on track of what my averages are.... We've definitely done studying tips, time management tips... we sit down and make up schedules for study times, and testing times.... I'd say it's definitely been somebody I not only can vent to when I'm frustrated with the teacher, but definitely someone who keeps me on track with stuff. I definitely think it is a good bit of help. (XX, p. 14-15)

George appreciated the tone of the advice his mentor offered. I asked about supports that facilitated his process of transition:

Well, my Comprehensive Advisor, 100 percent. She has been one of the most helpful people in here... She has she pitched ideas to me, she just gives me new ways to do 
stuff. . I tell her a problem and she will give me suggestions for that problem. She will suggest to sign up for the note-takers, how to organize better, how to keep on top myself, just a lot of different things. Because I would forget assignments, I do that often, so she gave me a different way, to put them into my notebook. (III, p. 18-19) She basically tracked my grades, planned out my schedule, and did long term planning with my schedule. .. she suggested [that I] go to [the counselor] because I was severely, severely in the hole. Not to make a habit of talking to her about personal things, but, when I needed it, she referred me. (III, p. 30)

The mentoring relationship grounded Mark. It helped him to navigate both the academic and social terrain of the college environment:

[My mentor] is a lot of help. . . he gets an A from me. . . we have talked about everything. . . his advice has always been helpful. . . he's nice, and [his guidance] fits the college advice that I need, like to help me get organized: "I think Mark, I think that you should do this, slow down, write it out or whatever, because I know how this stuff is." It's seemed to fit well. . . he's a lot of help. With organizational things, I could tell him, I was hanging out with these nice girls, and it kind of threw me off, and it always seems like it's bothering me, and I don't feel like doing anything. . . . But I would come into him and say: "I'm having girl problems." We would discuss exactly what the problem was. . I told him. . that that would make me not want to work, or distract me; he was able to guide me back in the other direction. (VIII, p. 17) I asked Kevin about the types of things he discussed with his mentor. He believed the relationship with his mentor supported his transition: 
We talk about how the week went every Monday. We talk about my grades. . . how I am doing in classes and stuff. I talked about, basically, what's going on in each class. She got me into SIFE [an organization for business majors], she told me about it. . . I'll talk about some of the projects that I'm working on. . . . And like, [she asks]: "How was your weekend, did you do anything interesting?" (XXI, p. 16-17) Margaret's mentor supported her in setting career goals, choosing a major, and scheduling classes to meet those objectives. She observed that she was able to talk about nonacademic concerns within the mentoring relationship as well:

We mostly talk about academics and where I want to go, what direction I want to go in, what classes I want to take. And basically what happens is, I tell my advisor my goal and focus, and from there, we kind of backtrack and be like okay: "How are we going to get there and what kind of classes do I need to take to get there." We talk about out of school stuff. ... You know, like situations at home that have brought me to the point where I am at now. So. . . when you're feeling kind of like. . I guess when you kind of feel a little lost or whatever, or you're not quite sure how this class is going. . . she really helps, because you talk it out. Like when the class is not going well, you come and talk it out, and then you begin to realize, okay that's why I'm not doing well in this class. . . Like you may try to do it on your own, maybe just having another person there to talk it out with really gets it, really kind of defines the bumps in the road. . . through dialogue. (XXII, p. 16-17)

Meeting with her mentor helped Margaret to stay on track and to begin to self-monitor: And like it also, at the very beginning, you have to meet at a certain time every week and like it really helps, because you talk about tests and grades, and so you learn. . . 
you realize how well you're doing in each class, instead of just like well: "I think I'm doing all right." You would talk about how you studied for a test versus how well you did on the test. And, you know, grades don't lie. That will be it. . . You got a measure, and, you know, you do feel kind of ashamed, when you're like: "I got a sixty-five" You're just like: "I stayed up watching Buffy last night. . . instead of studying." Your parents aren't here. . . even if you're parents are involved in school, they're not here, and so they're not here to ask you: "How well did you do on that test?" So you can't just skip through, pretending nothing's wrong. . . . It's nice to have to tell that authority and it keeps you on track, and kind of forces you to study. So, next time you're going to be like: "Yeah, I got a ninety-five, what now?" It's worked for me. (XXII, p. 18)

\section{Suggestions for Support Program Improvements}

Not only did the effective functioning students openly accept the help that was offered through the support program, they offered solid suggestions for additional services. Problems with social interaction prompted George to make the following recommendation:

I think a class on how to socially interact. I think a lot of kids with ADD act completely differently than kids without it. I mean, stories that I have heard from other people that have siblings and other people with ADD, observing and watching them, I think there needs to be a program that teaches kids the social norms, and how to interact. . . Social problems just add to the stress, it adds to the problems. It makes your life just that much harder. If they know how to deal with that, it will not only help the college transition, but it will also give life skills that they will probably need in the office. I would have loved a class like that. (III, p. 37-38) 
Tony recommended that we set up a required support group for first year students with learning disabilities. He believed that participation in this type of group would help to alleviate the isolation felt as a student on the margin:

I think that if there was a course where. . . everybody would kind of get together. . and just talk about the different things so that people could relate. . . Because right now I don't know anybody else [who] uses the services here. . . I think it would help a lot if there was a place we could just come and do some work, but like at the same time, talk about other experiences in college that are either helping or hindering. Kind of like how to balance things, a good rapport with your roommate, a good rapport with your professors. So, if we were required. . . I think you would have to make it a credit [bearing class]. . . . I think after we got into it, we would like it. . . . Sometimes you feel really alone. And you don't know how to explain to people that you have a disability. In general, [for] any kind of minority or small group of people, it just feels good to have a place to go, and kind of either talk about it, or work on it as a group. . more of an informal meeting. ... When we come here, it's refreshing to see us, see ourselves as part of the group in general. (XV, p. 23-24)

Louisa suggested offering social and emotional support to assist students with learning disabilities in working through the stress of the transition to college. When asked what more we could do to help first ye ar students make a successful transition, she responded:

[College is] very frustrating so definitely help students have a positive attitude about things, and talk to them about how like: "We know what you're going through" and just, I guess, be kind of like a guidance counselor. . . . In some ways, I think it [orientation] was really useful. Most of your friends don't know what you're going 
through. And they don't understand why you're frustrated from having difficulty in the classroom. And you try to explain to them, they really don't want to listen. So, just being in those little groups maybe like at the beginning [during orientation], maybe once a month would be really helpful, [to] see what kind of feelings we are going through. Just because if you hear somebody else say something, you're like: "I'm missing home," it just makes you feel better. (XI, p. 21)

Jim suggested we set up an evening study area staffed by generalist type tutors who were capable of covering several content areas, a place where students could go to do homework and ask questions if they were having trouble comprehending their coursework:

One thing that might be able to be done. . maybe set up, not necessarily a study session, but maybe the availability of someone to help to explain stuff. . . I don't know how everybody else is, I just know that some people do have trouble. . . like even if they go to tutors and they still don't quite understand. . . or just somebody in general to be able to [help with] work. Let's say, History. . . that has a general knowledge to be able to explain or make suggestions. (I, p. 19-20)

\section{Acknowledging and Managing Problems}

The students in the effective performance group openly described the difficulties they experienced during their transition semesters. They identified problems that interfered with effective functioning and worked to solve these difficulties by taking direct action for themselves or by seeking help from an outside source. The students were able to apply to current circumstances lessons from past experience. The narrative of this group illustrated a selfawareness of internal dynamics that could be used to correct problems for more effective 
functioning; the students displayed a capacity to take action to manage the thoughts and feelings that lie beneath their behavior.

\section{The Psychological Impact of Disability-Related Problems}

The effective performing students described disability related problems that impacted their sense of well-being as they related to self, others, or (academic) work. The students explained how they viewed themselves within the context of their disability and how they learned to cope with certain aspects of the disability under the new circumstances of the college environment. Difficulties acknowledged by the effective performance students included the conflict over using psychoactive medication, becoming aware of and working through social skills deficits, undergoing public humiliation as an invisible disability turned visible, developing autonomy while acknowledging cognitive deficiency and the need for remediation and accommodation, coping with performance anxiety which has been grounded in a personal history of academic struggle, coming to grips with years of living with the label of being "not able," and managing tenuous levels of self-confidence.

Janice dealt with the internal struggle of needing psychoactive medication to function well. The approach she took to working through this problem contrasted to the avoidance tactics used by several of the students in the low performance grouping. Many times, students mentioned they were uncomfortable taking medication because of felt physical, mental, and relational differences. When this is the case, the choice of medicine or the dosage may not be right for the individual. Adjustments to medication cannot be made if the student chooses to avoid the problem instead of working it through with the prescribing physician. Janice did not like the idea that she functioned better with medicine; however, she decided to take it because it mitigated her extreme symptoms of ADHD. She described the conflict: 
Well, sometimes it's not even something that I have an option about. Like, if I'm not taking my medicine it can be really, really bad. Last semester I had an issue with taking medication, it can be really kind of depressing. And sometimes you do battles with yourself about taking it because you get all high on yourself and then be like: "I can do this by myself and I don't need meds to help me." And you want to be able to say that, you know? And be like: “'I don't need something there to help me to do this, I want to be able to do this on my own." And so I won't take my meds for a while, and it would cause a lot of issues. I would get in fights with myself, basically, about taking my meds. It was really frustrating, eventually you lose, and you are like: "I wish I could have been able to do that, instead of needing something else there to help me." So, that is kind of something you have to deal with. . . And like every once in a while it gets to me. But then I get over it, and I'm like: "I need it." Just every once in a while there are these little outbursts where I don't want to take it. (XVI, p. 15-17) Janice revealed her experience of trying to complete school work with out medication and talked more about how the medicine impacted her emotionally:

We had this Chem thing that we had to do like most every week for Intro to Chem last semester, and there is this little thing on the internet, we had to answer all of these questions too. I was trying to do it with out my meds and it was a very bad thing. Like I had to do numbers on the calculator and stuff, and so a lot of it was in my head. Remembering what I had to do, and I couldn't do anything in my head because my head wouldn't hold anything at that point. And so, I was writing every single thing down. Like my brain just wouldn't hold any numbers, and so I had sheets filled with numbers that I was trying to remember. . . I had to write everything down, and it was 
getting so frustrating I was crawling in my chair. And I mean sometimes there is just no way around it, you physically can't do certain things without medication. . . Some things you just can't do, and it's not a bad thing, but you just have to learn to accept that. ... Like on the weekends, I don't take it. I only take it when I have to do homework. That's why I have to argue with myself about it, you know, just accepting the fact that I do have to take it sometimes. And that you just have to let go. ... I mean, it does affect me emotionally. ... I'm not as happy when I'm on it. And so, that is one of the big reasons why I don't like taking it.... It's very business like and I just want to break loose and have fun. You can't do that when you are on your meds. (XVI, p. 16-19)

George has learned that his disability impacts his social functioning:

I think I am a different person than when I came here. . . I'm not as timid. . I I don't get knots in my stomach when I try to come up to somebody. I was very nervous about approaching new people. Now, it is no big deal. And I'm also more confident about myself and how I can how I interact. . . I know a lot more about social interactions than when I came here. ... I just think that my ADD hindered me a lot socially.... I wasn't quite where everybody else was mature wise, and it did indeed take me going here in order to figure that out. A lot of what I have learned is kind of new to me, but everybody else is like the social norm. And I didn't know that. . . I found out about boundary lines, and things like that which are socially acceptable. . . what is too much. I think that it took the whole first semester in order to see what am I doing wrong and took me going to the school psychologist in order to figure out what it is not quite right. . I have taken a lot away from it. (III, p. 16) 
When I asked Louisa if she experienced difficulty during the transition to college, she described embarrassing incidents of not being able to learn the routines in her dance class. This occurrence brought up the deep-rooted distress of standing out because of her disability, an invisible disability which becomes visible when directions need to be followed, when text is read aloud in class, or when an exact pattern of physical movement is required. Louisa disclosed this painful embarrassment and displayed an awareness of how she contributed to her own humiliation by making fun of herself in front of her peers. She identified routine exercise as one of the methods she used to deal with her angst. This piece of narrative highlights important ingredients to Louisa's resilience: she disclosed her distress, she was open about her contribution to the problem, she was persistent, she used the compensation strategy of repetition to learn, she challenged herself to take on the barriers she experienced as a result of her disability, and she employed strategies to relieve her stress:

In dance class, I get very easily embarrassed because I always mess up the dance because I can't remember what spot I'm supposed to be in, so, I have a lot of people directing me, and I feel like a complete idiot. I just want to cry sometimes. But, usually afterwards, I just go exercise. . . I just get rid of the tension. But I am completely. . . embarrassed in that class, I think everyone thinks I'm a idiot. . . . We're going to be performing at the end of the year. . . and I still don't have all the moves down. . . I'm usually off by a beat or something because I can't feel it, I have my headaches trying to comprehend everything. So, hopefully, by the end of the year, I get the dance. [The professor] is a really sweet and understanding person, but I guess I get easily embarrassed; it was the same in my karate class. I had trouble with the left and right and just making my body do what my head wanted it to, and it 
wasn't working. . . . In some of my other classes I get really easily embarrassed, I guess. When I'm supposed to read something out loud and I stutter, I stumble on some word, and I think everyone's. . . I'm a little paranoid. . . so I get a little depressed over that. . . My friends and people around me love to make fun of me. I'm an easy target. . . And some of it is very hurtful. But, I'm kind of used to it. Some of it is just joking, and I understand. . . . Sometimes, I tend to make fun of myself. I guess, in some ways, I encourage it. . . . The people I'm around, I'm around them all the time, instead of when I choose to be around them. . I can't hide anymore. In high school, everyone thought I was pretty smart, nobody knew I had a learning disability but now everyone can pretty much guess it, especially in dance class. I just can't seem to get over the embarrassment part. And then, my confidence gets really low, I can't do anything. ... [I took the class] because I wanted to get over my fear of dancing. . . I wanted to see if I could do it, that's all, just to prove it to myself. I'm glad I took the class. . . I I don't really want to perform on stage because I'm afraid I might ruin it [the performance]. I don't know the pattern yet, but if I knew the whole pattern, I usually practice it over and over again, and usually, I can do it. . I used to play piano, that's what I used to do. I had to practice it over and over and over. (XI, p. 10-11)

Margaret remembered that she was afraid of participating in the class discussion expected by her AP business teacher. When she first entered the class, she became concerned about the level of work required; her fear of failing caused her to want to drop it. Margaret described being reassured when she learned that other "intelligent" students had to work to understand the material for the class as well. She allowed this circumstance to influence her thinking about 
staying with the class and her feelings of fear. In the end, she remained in the class and benefited from the challenge.

I have never liked expectations, because I'm always. . . that's my biggest fear, is failure, and I do not like to disappoint people, and so therefore I do not like to have expectations.... Oh, it was terrifying, like I remember at times I'm like: "I do not get this at all." But the thing is, I realized, when we were doing class discussions and everything, that I was not the only one who didn't understand. There were many other very intelligent students. I had the valedictorian in my class and he was just so brilliant, like he scored a perfect score on his SATs and he had troubles with it. That was comforting. . . It was kind of that group thing, like: "You're not the only one, don't worry." (XXII, p. 7)

Margaret conveyed the dilemma of understanding and accepting the unevenness of her cognitive abilities. This inconsistency impacted how she related to herself and others:

That's what I had to do, figure it out, how to handle it. . . because most people when talking to me or like when I'm studying or writing, they have. . . absolutely no idea that I have a learning disability. They have no clue, they think, actually, I'm like a genius or something. . . that there's nothing wrong. And so, you kind of like that, in a way. ... But at the same time, when you do tell them: "My short-term memory, it has a span of a gold fish." they're like: "You're not as cool as we thought you were," it's kind of a let-down. . . there goes that ego, you just see that blowing up, it just falls apart. (XXII, p. 28) 
Participation in special education has impacted Margaret's sense of self. She described enduring humiliation as a result of being separated from regular classes during her public education experience; she still questions if she is able:

Being pulled out of the mainstream. . I did not like it at all. I was like: "Why do I have to be here?" Like especially. . . when I was in fifth grade, and I was being taken out of these classes, and I was in a small class. We were. . relearning our alphabet. We were making every sound of the alphabet, and it was a new program. . And it was just like: "Why are we, we're ten years old, why are we doing like, you know, kindergarten work?" It really upset me. . I remember I was probably one of the toughest students because I was like: "This is stupid. . . I don't want to do this. It's ridiculous, you know, I feel like a little child, here.” I didn't think I was [supposed to be there]. . . I was like: "I don't like this at all, I just want to go back over there. . . and be with my normal friends." I did not like that isolation. . . and then of course they have the doors open in the small classroom at the high school so when people are walking by, they're looking in to the view of retards.... Because, you know, it's because you're incapable of. . . learning disabled. . . You are disabled, you're not able to do it. [The label] is still a problem. . . I don't know. . . it's very tough. . . It's hard to deal with. . . you lose self-esteem because you're not in the mainstream classes. You have to be isolated from everyone else, because you're not good enough to stay in the mainstream. And then when you're put back in the mainstream and you're called on to read. . you don't want to read, because you're so afraid of your disability coming out.... And then like a lot of the LD students end up taking easier classes. . . and not challenging themselves so they don't have to work as hard to 
overcome whatever problems and like it's a shame because everyone has told them their entire life that they're not able to do it. ... It has like a lot of psychological problems with it. (XXII, p. 24-25)

Wendy emphasized that students who have learning disabilities have problems developing self-confidence. She acknowledged that she personally benefited from the fact that her mentor had confidence in her:

I think the biggest thing with learning disabilities, with kids, is they need to be treated like they can do stuff, not treated like they're dumb, or incapable... They may need to do something different, but that's okay. And encourage them to try and do things without the extra help if they can, to give it a try. I have the note taker, but [my mentor] was like: "I want you to take notes. . they may not be everything, but work at taking notes and maybe [in] some classes you won't need them.” And, I mean, so treating me like I can do it. . . I I think the biggest thing I noticed: a lot of kids that have learning disabilities. . . they don't feel like they can do anything. They feel stupid; they feel like losers. . . . And I think self-confidence is the biggest issue for [students with] learning disabilities. If you could give every kid with learning disability self-confidence. . . I think you'd see a monumental improvement. Like if you could just wave a wand and it would magically give self-confidence. (XXX, p. 21)

Margaret described having a negative reaction to the conversation with her mentor on the subject of individual learning strengths and needs. This piece of narrative conveys how difficult it is for students to talk about personal weaknesses, even within the context of learning support. Balancing autonomous functioning with utilizing support and assistance is a fragile process that 
is different for each student. I wondered if Margaret would have had the same reaction had the mentor started the discussion by asking what she already understood about her learning process: [At first] I did not enjoy going [to the learning support offices]. . . everything that was like told to me, or you know, said to me. . I'm like: “This is nothing new, you know, I already knew this. And you're just bringing it up again." It's one of those buttons you push: "Don't push that button.” It was just like: “Yeah, I know, yeah, I know, right, I know." It's the same thing over and over again, and you don't want to hear the same thing over and over again. . we went over my learning style, basically, and like it was cool. . . she was surprised because. . . she didn't know me, and I was just like: "Yeah, I'm not surprised by that, you know. This is how it is, this is how I learn. You know, I'm just kind of telling you." And like that whole thing can be kind of uncomfortable because you're just like, you don't want to talk about it because it's something you feel kind of bad about in the first place. . . and I don't like talking about it. . . . I really feel like the whole student support thing. . . with a lot of students ... it's a very sensitive thing. Because people like to be independent and rely on themselves and they don't really like going to others and asking for help. . I I think when they need to go for help. . . they feel they're kind of giving up, you know what I mean? They're not strong enough to be on their own. .. and like it's kind of sensitive because a lot of people, they want to feel strong, like they can do it, and then. . . so when you have to talk about your disability, and you have to talk about what kind of support you need, I think it's a very touchy subject. (XXII, p. 27-28) 
A history of failed or uneven academic functioning caused several of the students in the effective performance group to express nervousness about their school work. Julie revealed her performance anxiety. She talked through the worry that the worst would happen with her mentor: Just keeping like the grades in order, because I'm one to freak out about grades. And, I'll think if I fail one test, that my whole grade is screwed up and everything. And, like I can go to [my mentor]: "My whole GPA is messed up." and we can do the GPA sheet. I'm like: “Oh, all right.” It reassured me: "Well, if I bring that up, it's okay, I still won't be failing or dropping out." That was one of my big fears the first semester, getting a $\mathrm{C}$ in a class might get me down, just stupid, silly things. . . I thought my GPA would drop really low, that really freaked me out. Because in high school, you had so many grades, like you had homework grades, you had participation grades, you had classroom, class work, and also test grades. But here, you get the shock, you're like: 'Only three tests? And he doesn't check homework? And doesn't take participation, what is it on?" And it's like, if you mess up on one test, you're like: "My GPA is going to drop." But then. . I could always go to [my mentor] and work it out on paper and she could always be honest with me and just say: "Well that is probably going to bring you down, but not too severely low." (XII, p. 7)

Tony recounted trying to alleviate his fear of failing by continually checking with his professors. I asked him about his basic strategies for success:

I just write, read whatever they tell me to read. I do the work. . I also have to reassure myself: "I can write about this, I can do this, right? I'm not going get an F on this if I write about this?” And they're [the professors] are like: “No, no, no.” And 
then I ask the questions over and over and over again. . . But that's just for my sanity. I just. . . constantly want to make sure that I'm at le ast on the right track. (XV, p. 18-

\section{Problems Adjusting to the College Environment}

The effective performance students described the challenge of adjusting to being away from home and of dealing with new levels academic and social complexity. Many struggled with learning to be independent and handling the freedom of the college environment. The students had to learn to manage academics without the familiar help structures of home and prior academic settings. Taking control over their living circumstances in the residence hall posed another challenge. Julie described worrying about how she would handle the unstructured environment:

Just because like coming to college. . . because it's so unstructured and everything, I didn't know how I would be. Like if I wo uld sleep through my classes, or if I would forget a class or something silly. Or get too tied up with something and forget to go somewhere and do some homework. I thought I would totally bomb out because I was so used to structure. But then, I came here. . . and it wasn't like what I thought it would be. . . well, it is, but it isn't. . . I thought I would fail out, but I didn't. And, it wasn't as difficult as I thought it would be; the transition wasn't as difficult. I handled things better. ... I learned that if you just do the work when you get it, get it all done with, then you don't have to worry about it. (XII, p. 8)

Margaret was concerned that she was not prepared to do college level writing:

I did not feel completely prepared. I was really mainly concerned about my teacher [in high school], my English teacher was supposed to teach our class how to write 
good college essays. And she did not touch on it, at all. The entire year was left unfinished. ... I really do not feel like in my Literature and my English, and my writing techniques, that I was prepared. . . I I was like: "When's she going to do this? When's she going to do this?" And then when I got here, I was like: "She didn't do this." So, it was just like I knew it was going to happen. And when I came to [college] I was very nervous about that. I was very scared, especially the first paper that I got, and it was a major paper. . . actually I got a decent grade on it, I didn't do too bad on it. . . but I really wish I felt more prepared. (XXII, p. 10)

Denise observed the differences between the high school and college environments. She is learning to function more independently:

[There is] a lot more independence. People aren't holding your hand, and telling you what to do next. It's hard. I went to a small high school. So, everybody really cared about everybody else. And they wanted to make sure that you did well. It was also easier in high school to go and talk to a teacher because they knew who you were. It's nice to know that somebody was always there. [Now I am] being pushed into a different situation. (XIX, p. 2)

Even though Jerry was reluctant, he did force himself to utilize the tutoring program. He described adjusting to the absence of family support:

Well just being away from my frie nds and family; it's a lot more independent. Because my mom or my dad would help me like with my math homework or something like that. And I can't really get their help seeing that they are 4 hours away. I just probably need to go to tutoring, which I have been dreading. (IV, p. 2-3) 
Mark understood that the college tutoring service did not provide the kind of impromptu and unconditional help he was used to getting from his parents. He learned to plan ahead in order to make the most of the tutoring sessions:

The fact that I don't live at home is a huge difference, because at home. . . I could basically get help any time that I needed. And they [my parents] could sit down for as long as I needed, and we could work out whatever the homework situation was. Here, it's like go to a tutor, and they are there for an hour, or however long they are there, and like, your parents would stay up all night with you, they are your parents. . . here, it's like you're on your own, there's lots of help, but you just have to, you really can't wait until the last minute quite so much, if you really want help. . . if you wait until the last minute here, you're on your own. (VIII, p. 4)

I asked Kevin about the differences between high school and college. He observed he has had to become proactive in his learning and decision making. Kevin seemed appreciative of the difference, expressing the belief that he would be better prepared for the future as a result of the college experience:

Well, in college, I'm more on my own than high school. High school is more like. . . they fed information to us. They told us what to do, what to decide. And college is more like: "All right, here's your syllabus, here's what you have to do, and then hand it in when it's time." You're on your own. ... because once you go into the real world, you're on your own. So, it's a good preparation for the real world. (XXI, p. 1) Louisa experienced sleep deprivation during the first semester until she learned to manage the heavier course load. She was not daunted by the experience of failure; instead, she used it as a 
tool to rework organizational and academic strategies. When I asked her about the differences between high school and college, she painted a grueling picture of her transition:

Well, the work load is totally different in high school and college. . . I wasn't expecting some of the classes to be so difficult. Like in high school, you might have to read four pages, and that would be a chapter, but in college you have about thirty to forty pages or fifty. That's always different. ... At first the workload was really hard, but I got used to it. Because at first I think every subject I took, I got a failing grade on my first test. Except one class, I got a D, but still, I was really disappointed because I was used to getting Bs or Cs when I was in high school. (XI, p. 1) Managing the sleep/study environment in the college setting is a significant issue for students with learning disabilities. Aware of the optimal study/sleep conditions which would contribute to her success, Louisa became frustrated that she could not negotiate enough quiet time with her roommate:

I find it very difficult living with somebody else in a dorm room. . . Like when they're asleep, they can't have the light on, and I still have to study. . . she likes to watch Nick at Nite, and I couldn't stand that because I couldn't get to sleep. It's very distracting in terms of getting your work done. . . She left after the first semester. I really enjoy being alone. . I I don't feel at all secure when somebody else is in the room. It's just easier. ... And the room is much quieter because when I study, I like it completely quiet because I can't get distracted. (XI, p. 1-2)

Like Louisa, Margaret described the challenge of living with an unfamiliar person: Living with someone. . Y You can never be prepared for that. . it's very difficult. . . like you're already stressed out about some classes, and then you come back to an 
annoyed or a frustrated roommate, it's not something that helps your ease. And like I think there really is nothing you can do prepare for it. I think it's always going to be like that, and no matter what you do, that's the real shocker. . That's the one that drives you crazy. . . . I would say the roommate situation is really tough. (XXII, p. 910) It hit me hard, because. . . when you're talking to your friends or your parents, and they're in the same room, you have to be careful with your words, because you may not want that person to know that information about you, and then you have to be sensitive to their feelings, their emotions, and their schedule. It's so hard to find a compromise. . you have to really watch your actions and what you say. . they don't know you, you're a complete stranger. You don't know how they were raised, and so you've got to be sensitive to that. (XXII, p. 12)

Julie described her adjustment to living in the dorm without privacy: My roommate's a little crazy. I don't know. . . this is a big thing. Because like when you're at home, you can go to your own place if you're angry or just in a mood, and no one would bother you. But, here it's like you have people around you twentyfour/seven. And it's like when it was the wintertime, you couldn't go outside, because it was too cold. You couldn' t go sit in your car because you don't have a car. And then, when you want to close your door, she'll [my roommate] go, what's wrong? Mmmmmm, and it would start, and then you would just blow up. That was probably the worst. But, it's better now. . . . Sometimes it's just too much people. But that's the only thing about college; it's like you're around people too much. And you just need to be careful. Because at home, I could just go to my own place, and be like: 
"Whatever." Here, I'm getting better with it, just where I can talk it out with someone, and then, I'm better. (XII, p. 11-13)

Because of Kenny's previous encounter with alcohol abuse, he struggled to find nonalcoholic activities on the weekends. I asked him about any problems he encountered during his transition:

It's really more socially, that I'm bored, because I never have anything to do on Friday nights. That's really the only thing that's bad. . . . The campus activities. . . like things are over at eleven. Or like movies start at eleven, end at twelve. And I want to do something. But, I mean, I can't really complain. Like I would go to Frat parties, and I've been to a few, and it's just like a high school dance, you can't really talk and get to know people, it's just dark and loud dance music. . . . But, my friends kind of feel the same way, so we just sit on the sidelines and talk about whatever we want and entertain ourselves. (XIV, p. 11)

Jerry worried about how he would respond to the freedom of the college environment. This self-awareness enabled him to begin to monitor himself:

Just being on your own, the responsibility, and not having your parents tell you to do your homework. Or: "Okay, it's time to come home." Stuff like that. I can stay out as late as I want and I can go out and do what ever I want because my parents are so far away. It's like you're an adult now. I didn't turn 18 until around the beginning of the semester. . . [I didn't know] if I was just going to goof off the whole time. . . like was I going to be like studying 24-7, or partying 24-7? Or just hanging out, you know? Because it is up to me now, it's my decision (IV, p. 10) 
Many effective performing students missed home. They connected with their families to alleviate the sadness and talked to the helpers on campus and to each other to normalize their feelings. Leah was homesick; with the advice of her mother, she decided to stay at school:

[The CA] tried to talk to me like when I first got here, since I was like. . . it was rough and, she said everybody's first semester at college was always rough, the transition from high school, and not being at home anymore, and making new friends and learning where you fit in, and where you don't fit in. ... I've learned to deal with the part that I'm seven hours from home. ... After Thanksgiving, I really didn't want to come back. . . I guess it's harder for me, just because I'm an only child, I'm a lot closer to my parents. ... Either I wasn't going to come back this semester or I was just going to transfer at the end of this semester, but my mom was like: "You need to stick with it, it will get better" and so, I did. (XIII, p. 5-7)

Tony talked of missing his family:

I guess the hardest thing for me was, dealing with being really, really far away from home... it's an eight hour drive. My parents try to get down here when they can, but it's just weird. And it's always a flight to get me home. (XV, p. 6) Me and my mom are really close, like I would come home from [high] school and just talk to her about anything, and so it was weird. (XV, p. 9)

Dan described missing his family even though he boarded away during high school. He is used to being anchored by family relationships:

It's been pretty much the same thing my whole life, I'm a very big family person. I always am home sick, no matter where I am. Being away for three years already, I've gotten to a certain point where I can cope with it. . . It just seems to stay a constant 
steady fact that I'm homesick all the time. . . if I didn't have a phone to talk to my mom everyday, then I'd have major issues. My parents are divorced, so my mom and I are close. My brother and I are close. I talk to at least one or the other everyday. If I couldn't talk to them once a day, I don't know what I'd do. (XX, p. 11-12)

\section{The Ability to Acknowledge and Correct Mistakes}

The students in effective performance grouping took responsibility for their behavior and made changes in order to manage themselves better. They worked at becoming better students, better organizers, better thinkers, and better friends. The second semester course load was more challenging, compared to the first, for Janice. She described being displeased with her performance as she dealt with the complexity of living on her own and the increased academic workload. To accommodate these circumstances, Janice made the decision to use testing accommodations for her Communications class and to use a planner on a regular basis:

I think there was more going on in my personal life, and also my classes were harder .... I'm taking French again, but it is something that I'm not as familiar with and so I have to study for that. And, Chemistry, I'm not familiar with at all, it is a lot of names and stuff that I'm not good with. . . and so, it is just a lot more work this semester.... I was not happy with my grades. . . and then I fell in love with my planner. I didn't use it at all the first semester, but all of a sudden everything is in there, you know? And I need it to be organized. . . it is definitely my best friend right now. [I was] very distraught in the beginning. . . . It was very bad, but things are slowly working out and I'm feeling good about it. ... I wasn't testing very well in my Oral Comm [Communications] class.... So now I'm testing in the lab and I have someone 
reading [the test] to me, keeping me on task, and calm and focused, and I'm not getting antsy toward the end [of the test] (XVI, p. 8-11)

Janice discussed her conflict over taking medication and using support to compensate for her disability. She was able to pinpoint the tension she felt over wanting to be "normal" and has tried hard to work through this conflict. She described being aware that she has been dishonest with herself about her disability-related needs. She observed that she wants to be able to be independent of the help; however, Janice knows from experience that the use of medicine and support are essential to her academic success:

Every student is finding their own way through it. . . there are certain things that I needed to be able to do, but, I was not going to do that until I was ready to. . . . Like I really didn't tackle the whole medication issue until it became a really big issue. . . until I couldn't lie to myself anymore and be like: "I don't really need this" you know? Or like testing in the lab, I didn't want to do that, it takes more effort and I would rather just take it [the test] in the classroom, and be done with it, and it is easier for me that way, but then I realized that I really couldn't. And it was just taking one thing at a time. . . and just as things come up, you get ready to deal with it. . . it's a continual battle. I mean like next semester, probably for my next class that I will need to take [tests] up here, I'll be fighting myself against it, but. . . you have to deal with it. . . I have no problem asking for services, sometimes you do want to do it on your own. And you. .. want to see how far you can push yourself and see exactly what you can do on your own. And then, eventually, you realize that there's some things you can't do on your own. ... It's fun, you learn more about yourself; it's frustrating but 
it's fun. . . you come to grips with it. . . . It is more like finding the middle ground. (XVI, P. 33-35)

Jerry realized he was not studying on a routine basis; hanging around with his friends took priority during the first semester. He described beginning to internally direct himself, verbally, in order to follow through on his plans to work consistently:

When you're just sitting in your dorm, you look at the clock, and an hour flies by, you're goofing around and you go outside to the hall and just hang out with your friends. The next thing you know, it's 10:00 at night. [My sister] knew that I would say that I'm going to take a break for 5 minutes, and 5 minutes will turn into a half an hour, or an hour. And I did that, and then it hit me, I was like: "Wow, I should have paid attention to that at the beginning of the year." I goofed off a little bit, just hung out and met the guys on the floor, but then I gradually settled in, like: "I need to start focusing on my school work now." I guess I should have worked on my homework instead of hanging out with the guys or watching TV. Every time that I have had a big test, I was like: "Man I should have studied earlier." It's that I kept having to cram. And then once I got towards the end of the semester, it really hit me, I was like: “Okay, next semester after break, I'm going to think and act wiser, you know?” So, at the beginning of this semester, I told myself: "Okay as soon as I'm done with something in the chapter, I'm going to review it." And I haven't exactly been doing as well as I wanted to, but I'm doing a lot better than last semester. It's in my head: "I need to go do this, I need to go do that." So I just actually go do it. First semester, I was like: "This is fine, I can handle it." And then I get to the test, and I'd stay up late and cram. I mean I still did well; I have almost a 3.5. That's the thing that really 
frustrated me because if I tried a little harder in one class, I could have raised that to a 3.5, and been on the Dean's List. (IV, p. 4-6)

George had trouble "reading" social cues. He entered counseling because of the personal created by his social problems:

Socially. . . if there is something that I could tell myself, it would be sloooow down. Don't get too overbearing to everybody. I wish I would have taken that advice. . . . My relationships this semester, I kind of rushed into. . . I have learned a lot about myself socially this year. . I'm going to see [the counselor on campus]. I have learned a lot more about myself and how to deal with it, and how to how to control myself better socially. I have pulled away a lot from this year. Actually, me going to him [the counselor] stemmed off me being under the complete and utter stress. . I knew that I needed help, and I was just like: "I need to talk." Then discovering it myself came out of talking. ... I made a huge mess, in the beginning of the year, and it is not easy trying to fix it. . . some days it is a little much. (III, p. 12-14)

George became aware of specific behaviors that led to his social problems; his disability interfaced with his social skill development:

I have a lot of social problems, still. I am still learning, still making mistakes. . . I think that my short attention span and my hyperactivity kind of hinders me, kind of makes me do things that aren't good, aren't socially acceptable, aren't nice to the other person. ... Listening, forgetting what people say. I'm a forgetful person, so you might tell me something one day, and you know, the next day I will forget it. It's not like I want to forget it. And, listening to people but, then thinking about it, and you know, just kind of putting out that I'm not [listening]. . . I'm working out a lot of my 
social problems with [the counselor]. That's a lot of my problems last semester, not wanting to admit that I had problems. ... It was just me looking back at what I had said, and what I did the first semester. I mean like... I'm being something completely different than who I want to be.... One of my friends had to be very rough on me in order to in order for me to see that, and she really confronted me to drive me to that point where I would be like: “I can’t act like this, I need help.” (III, p. 24-29)

Wendy examined her pattern of withdrawing from relationships over minor problems. She described taking more "risks" to develop friendships:

I didn't have [a social life] in high school. Like I thought I'd probably get one here. Just because, you know, you live together and you see each other and, nobody wants to go to dinner by themselves. So, like I figured I'd have friends here, but I didn't know whether I'd have close friends... I used to be very picky about my friends, and it was like. . if you did something really nasty once, it was like: "Okay you're not my friend anymore. You're not good enough to be my friend.” But. . I've started thinking like a part of college is making a lot of changes, reevaluating things, and I was thinking about it, if you always did that, you'd never have any friends because a lot of being friends is working through the hard times. . I've become more open, I guess. . I'm still picky. If you're just really horrible to me, I'm not going to be friends. . . but if I feel betrayed once, I'm not going to be like: "You're totally not my friend anymore." I'll come to you and work it out. Which is different now, like I used to be really afraid of getting hurt, and I still am, but I learned that ... taking a chance is better than never trying at all. (XXX, p. 5) 
Mark took responsibility for dwelling on his problems; he described how his thinking patterns interfered with optimum academic functioning:

The girlfriend thing has been an issue that I hope I'm pretty much done with. . . I made it hard on myself for reasons that are probably too long to explain. . . and I got distracted from my work, and then I took on pledging, which has been a great experience, but it does take up a lot of time... I was still dealing with the emotional aspects of [my girlfriend] going out with somebody else. . . it's a lot, and that took away from how well I continued to do. I was also trying to compete with myself to do as good as I did the first semester, and I have more classes and they are harder. I was putting a lot of pressure on myself. . . I mean most of the stuff I have been having trouble with is coming from me. . . I was just dwelling on things. (VIII, p. 21)

Louisa observed that, compared to her college peers, she lacked background information for many of her courses. She was able to make up for this by studying long hours:

And also in the classes, like I felt like one of the poorest students in the class. Because usually in high school it was all about if you work hard, you can be on the top of the class, but it wasn't like that in college. . . feeling like [I was at] the bottom of the ladder, and just not knowing anything because a lot of people have background on the information already. I actually did pretty well. I'm surprised, I failed all my first tests, but the second ones and third ones, I did much better on. I improved on my huge tests, so that helped. (XI, p. 8)

At the time of our interview, Dan had not yet made his target GPA of 3.0. This fact was disappointing to him; however, he stayed optimistic: 
I'd say that I'm not exactly to where I want to be with my academics. I haven't broken 3.0, yet. Which I'm kind of upset about. Still, I know I'm putting my $110 \%$ into my classes, but at the same time, I'd like to see my effort rewarded [through] grades. ... That's just the way the chips fall sometimes. I think I'm going to fall a little shy of it, again, unfortunately. ...You learn how to cope with one thing, and something new pops in... there's always that one element that you struggle with that effects everything else. . I'd like to come home at the end of the year, saying: "This is what I got for my efforts this semester," and I'm just a little shy of that, so... hopefully. .. we'll get it next semester. (XX, p. 12)

\section{Dealing with Problematic Circumstances}

The students in the effective functioning group dealt with the reality of life's everyday setbacks by taking action. During the first semester, Jim was shot at with a BB gun by students living on his dorm floor. He did not allow himself to be victimized by the students who were trying to intimidate him and reported the incident to the proper residence life officials right away; the harrying stopped:

That BB gun episode was resolved fairly easily. . . I didn't really feel threatened, but I'm not as naïve [to think] that something couldn't have happened. . . I went to housing and just told them what happened and they said. . . they were able to get the BB guns out of there.... I have not seen or heard any of them. ... I didn't know all that were doing it. ... And those kids have put. . . mostly it seems, or at least they're making it appear that way, that incident behind them. ... They didn't care that they got in trouble. It somehow seems like they knew I told. . . but I'm like: "How would they know?' (I, p. 8-9) 
Jerry described coping with an unreasonable professor. Even though he was put off by the professor's distancing attitude and unreasonable policies, Jerry was not daunted in his attempts to follow up when the professor made a grading mistake. Jerry pressed himself to study and finish out the class, and did not yield to his thoughts about giving up the class and his major: I know that I'm not even close to making [the Dean's List] this semester. [This class] is killing me, the professor is pretty tough. . The professor is really, really strict. . . he has deducted points because I wore a toboggan in class when it was snowing, and you can't wear a hat in class. I walked in his classroom and I sat down, it was like 5 degrees outside, and he's like: "What's that on your head?" And I go: "I forgot," my hat was still on: "Sorry, Dr. ___." And he said: "No need to apologize, that's just 5 points off your grade." And he pulled out his pen and marked points off my grade .... And if you bring a cell phone to class, and it goes off, he deducts; like if you get a 100 in class, the highest you can get is a 95 . Which nobody is getting. ... This thing that I thought was ridiculous was I was sick one week, I had the flu, and I went home, and I emailed him, and told him that I wasn't going to be in class on Monday, and Tuesday's class was cancelled. So when I got back to school. . . I went to slip my homework assignment under his door, I told him that I was going to try and do that, to try and turn it in. When I went and saw him on Wednesday, I was like: "Did you get my email?" And he was like: "Yea." And I was like: "So you got my homework?" He's like: "Yea, okay," but then he goes: "I'm not accepting it." I was like: "Why?" He said: "Because you slid it under my door." And I was like: "I told you I was going to slide it under your door, and do the responsible thing," like because it says in his syllabus: "If you're not going to be in class, and there is an assignment due, you have 
to tell me." And he's like: "Yea, I just don't accept homework under my door." I was like: "I was suppose to assume that? I thought I was doing the responsible thing getting the homework in as soon as I can, not waiting until Wednesday's class.” And he just didn't care. So, I got a zero on that assignment. . . he's unforgiving basically. He has no emotion towards the students. . . He's just not a nice guy, there's too many things that have gone wrong in his class, so I'm probably going to have to retake it. I just got my grade, I had a $\mathrm{C}$ as of 2 days ago, now I have an F. Because of the test, and he graded it wrong, and I have to go and see him about it. My grade report is wrong. I maybe have a D. . . You try and have a conversation with him, and he just demeans you, makes you feel stupid. I have to [talk to him] in order to try and raise my grade up, I don't want to. You want to stay as far away from the guy as you can ... I just don't want to do anything with the class. . . It makes me want to change my major. I don't feel like studying for that class. I almost don't even want to look at the book, like I'll look at my book, and I'll be like: "I don't feel like having anything to do with that." (IV, p.6, 12-15)

Jerry continued to describe managing the situation with his cranky professor. He struggled to force himself to study for the class and continued to try to connect with the professor even though he judged the professor's policies to be unfair:

I don't even want to go to class. I haven't missed a single class really unless I'm sick, I just don't want to go. I have no motivation to be there at all and do anything. . . it probably looks better if I don't miss class. . . He has kind of taken over, I don't want to admit it is affecting me, but it is. (IV, p. 16-17) [My mentor] tells me to try my hardest, and go to the tutor as much as I can. [I am] just picking up the book and 
trying to do the best I can and trying to figure things out. I mean I finished my last test and all that I have left is the final. . someone told me that the final had some questions from previous tests, so I'm going to try and study that and figure it out. I'm just riding it out now. (IV, p.19-20) I have no motivation. I mean if it weren't for me telling myself I need to do it, I would just not do it. For homework assignments, I don't really care. I don't feel like putting myself through the trouble. I'll do it still. And every chance I get, I try and raise my grade. (IV, 23-24)

Tony described the difficult decision to switch majors from Musical Theatre to Theatre. He was able to accept the reality that he did not have the appropriate background or skills to manage the Music Theory class, a requirement for the Musical Theatre program:

I've never had any kind of music class. I look at a staff, and it's just a jumble of funny things. So, I dropped out of that, because. . . when I feel I can't do my hardest work in something I don't like to be in it at all. Even [the professor], she's like: "Oh, you're doing fine," because, she knew I was doing work, I just wasn't doing it right. So, I'd constantly be at the tutoring. And, not only was that taking a lot of my time, but, even though I was doing work. . . I felt like I wasn't progressing at the rate I wanted to. Like, I wasn't learning anything. ... I was relieved, but, I was also disappointed at the same time. Because I kind of I wanted to stick it out, and just get it over with because I know if I decided to stay in Musical Theater, that I was going to have to take it again anyway. But, also, at the same time, I feel that my first semester would have been a lot more stressful, if I had tried to stick it out. . . . Because I know those first couple of weeks. . . I was either in [Music] Theory, or doing homework in [Music] Theory at some point in my day. There was really hardly 
any break, except for when I was [withdrawn] out of the class. I was constantly thinking about it. ... I didn't have a problem dedicating myself completely to it; it's just, it gets exhausting. . . . I was disappointed in myself, I felt like I was kind of giving up or failing. And then I was like: “Whatever.” I think, overall. . even when I was disappointed in myself, I knew it was the right decision. But. . I wish it didn't have to be that way. And you know what? Like at no point did I ever doubt my decision, I just wish I had other options. (XV, p. 6-8)

\section{A Strategy Based Approach to the Transition}

The students in the effective performance group planned to operate productively during the transition semesters in the following ways: first, the students made decisions to productively participate in their new environment and to develop plans and rituals to function well on a general basis; second, the students purposefully managed their thinking in order to adapt to their changing context; third, the students used self control strategies to cope with their academic workload; and fourth, the students used intra-cognitive and social networking strategies to effect their academic performance.

\section{General Strategies Used for Adjusting to the College Environment}

The students in the effective performance group applied lessons learned from past experience to their current functioning. They acted out of self-awareness to transition successfully, conscious of possible pitfalls. The students engaged in physical exercise, talked to their friends and their mentors to relieve stress, carefully selected their friends, living situations, and study areas, stayed active for better focus and effectiveness, and set up informal support networks. Wendy intentionally worked on mixing in with the campus environment: 
And like so I would try little things, I wouldn't try the hard things. . . that's what I've had to do a lot of. . . oh, that helped me a lot, when I first got here. . . I said to myself: "I know I need to join activities, I know I need to make friends." Otherwise, I'd sit in my room. And like, almost every activity that they offered, I went to at least one meeting of. . . to see. Because I don't have to join it, I can just go see it, I went to a $\mathrm{CAB}$ meeting, I went to APO, and like that was a rule for myself. I have to go to one meeting, if I don't like it, I don't have to go back, but it got me out of my room and then I picked a couple. I picked APO to join. And that was really helpful; I think that's especially helpful for people who are kind of introverts, and don't get out. (XXX, p. 5)

Wendy set up a support network during her transition:

That's one of the first things I started doing, I set about looking for people who I could count on to support me, and help me. . . Adults that I could talk to . . . and it helps because you guys assigned me [a mentor], so I already had one person. (XXX, p. 20)

Kenny was strategic about who he befriended. He knew his relationships would have an impact on his resolution to stay away from alcohol:

It took me awhile to find a group of friends who had similar interests. Drinking is such a big thing on this campus, and I'm just not into that, so it's kind of difficult to find a group of friends who I was comfortable with. And that was an unexpected difficulty because. . . I normally don't really ever have trouble making friends. . . I was like: "I'll be able to do this." This shouldn't be a problem. But, it is, it's kind of silly that this, out of anything else, is a problem. . . but it's [alcohol is] such a huge 
common ground for people, and to not be able to chime in about like your drinking experiences last weekend. . I've made friends. . they drink and whatever and I hang out with them still, it's not that big of a deal. But, we have enough in common. . . and it's not as huge of a part of their life. ... (XIV, p. 8-9)

Julie talked to a friend who, like her, has learning disabilities, to combat feelings of isolation: [My friend] and I talk a lot, and she sometimes is just the same as me. We'll be like: "Really not good news, and really not failing this test." There's someone else that's just like you, so you could talk to them about it. . . And if something's bothering you that seems so, so small. . . like if you messed up on your grammar quiz, then you can get it out, you'll be like: “Oh...you too? I didn't understand it." You're like: "Yeah, I didn't either, I didn't get it." So, they understand, they've been there. It's kind of like, if they're worse at certain things, and you're better at them, you can help them, and then they can help you. . . . that's why I like it, because it doesn't make me feel like I'm like a complete reject. (XII, p. 25)

Kevin observed that his involvement in campus organizations and sports helped him to deal with stress and to function effectively:

I think it's a lot better to be active in a sport. The way I see it is that I need to be active in order to do well in school. If I'm just sitting in my room doing nothing, or just chatting online, it's not going to help me at all. Like I won't get any work done, like if I'm busy, I know that, all right, I'm here to be busy today, I need to get some work done, and I'll do that work. I'll study. . . do what I need to do. . . . And then, like after swimming. . . my mind gets refreshed. And just coming out of the pool, it's great. ... During the day, I get all tired, and then I'll go swimming, and then I'll get 
better. I'll stay up as long as I need to and get my work done. . . Even like, if not a sport, just get involved with an activity. . . join a club or something. . . Volunteer your time; that will keep you busy, every day. In high school, my grades kind of dropped, because I wasn't really active, I wasn't really doing much. (XXI, p. 25)

Jim acknowledged that he becomes easily stressed. Participating in Aikido has helped him to handle the strain of the transition and to be more self-reliant:

Aikido has helped build up my confidence some, the martial art that I'm in. Besides knowing martial arts moves. . . there's some meditation, and common interest, I guess, with other people. ... I can relax, be myself, and if nothing else, if we spar, which is kind of the equivalent of fighting, but controlled, relieve any aggression I might have, or stress. It's a major stress reliever. (I, p. 7)

Jim described leaving his room to study and to periodically regroup. I asked him what advice he would give an incoming student:

Try going to the library or just out of [your] room to study. Because a lot of times, it's hard with a roommate to study. . . Just every once in a while clear your mind, but not necessarily forget what you were told throughout the day. Try to get organized what you were told. Because I know I have to take breaks from studying and clear my mind, plenty of times. (I, p. 14-15)

Dan's decision to wait on joining a fraternity was an example of his decision to work on curbing his tendency to act impulsively:

The ability to reflect on things before you do things: a lot of times people don't think before they act and they get themselves in a big mess. And. . . I often do that, this is one time I actually stood back and looked at something. . . . I definitely got caught in 
the wave [of joining the fraternity], but I guess I just popped up for fresh air for a second. It opened my eyes to a lot of things. It opened my eyes to something that I would really be interested in doing, but at the time, just wasn't for me. (XX, p. 7)

Denise was careful to plan her living situation for the coming year:

I'd like to live alone. . . It would be nice to live with somebody, I just don't want to be put with like a random person. If it was between both of those, then I would rather just live alone. Some of [my friends] have asked me to be roommates, but I know that I would freak out because they have different study habits than I do. It wouldn't work out with those people. . . when you look at them from the outside, they just don't look like they have good study habits, and I know I don't need somebody watching TV all of the time or listening to music all the time. I told them I have problems studying where there's tons of noise and distraction. And I feel like some of these people just have so many distractions; they are good to have as friends, but... (XIX, 7-9)

Ben has learned to handle the distractions of the college environment:

And then, there's more distraction [here], so, you got to figure out what works best for you. Like, some people are able to study in their room, if people are talking, and there's something going on. And other people have to learn, you know, maybe go to the library, or go somewhere else, quiet around campus. (XXVIII, p. 3)

Wendy made sure that she was in control of the important things that would impact her college experience. I asked her what advice she would give a student with a learning disability coming into the college environment:

Be on top of things. Just try and get things done. Learn as much as you can about how to do things. And get them done. Talk with your teachers. Like with me, I made sure I 
knew everything I could. . . I made sure I knew my course requirements. . Instead of being like: "I'll just wait until somebody tells me what to do." Because somebody doesn't always tell you what to do, and sometimes the people who are supposed to know what to do don't know what you're supposed to be doing. . . Basically, be proactive. Take care of yourself; don't expect other people to do it. (XXX, p. 19)

\section{Managed Thinking and Changed Expectations to Adapt}

The students in the effective performance grouping adjusted their thinking to function more productively. They changed their expectations when the situation demanded and realized that perfection was impossible, in life, and in their work products. They were able to shift their relationship to a problem and the problem itself by changing how they perceived it. In addition, these students carried into their new environment metaphors from previous successful experiences, changed their goals to reflect effort instead of outcome, and adapted to their changing circumstances. Wendy explained that she learned to stay away from the perfection trap: I've learned not to have to have everything absolutely perfect, 100\%, because I'd make myself crazy, like I do enough to get a good grade, like an A, or a B. And then I say: "you know what, it doesn't have to be perfect." You need to have something of a life, or you will go insane. Like if I spend all my time on my art project, trying to make it A+++, then I'm like: "Oh, I have my Math to do.” I try and give everything equal attention and then after I've done all my stuff, if I have more time, I'll go back and make stuff better later... so, I'm not getting an A in one thing, and Cs in everything else. I'm getting Bs in everything. (XXX, p. 18-19)

Wendy has learned to adjust her expectations in order to handle "life": 
Not necessarily looking at everything like everything's going to be hunky-dory, but looking at it [like]: "It's going to be hard, but I can do it. I can overcome this." Any kind of problems, bumps in the road, just say that. . . have confidence in yourself, that you can deal with whatever comes. And that, if it's something that you can't deal with by yourself, that you can go to someone to help you. (XXX, p. 20)

Wendy believed that she could influence her behavior by managing her thinking:

I really like the pin you have on there [the bunny in my office]: "Attitudes are the Real Disability" because I think if you have a good attitude and say: "I can deal with this, I can overcome it, I might have to do things differently" then you can do anything. But if you have the attitude you're going to fail. . then you're going to fail, because you're saying: "I'm going to fail." (XXX, p. 19)

I asked Ben what problems he has encountered during his transition to college. He has been able to call forth his Outward Bound experience and to use the metaphor of "trudging through" to the finish to keep centered amidst the difficulties of the transition:

You could never not have any problems [in the transition]. I would say [I have had] many difficulties but I have learned to cope with the college setting because you're always going to find something that's difficult, but, you just learn to overcome it, or to deal with it .... Life is never easy, so anybody that would say there's no problems, they must be really easy going, or on Zoloft, or something. . . so, just learning to cope with it. . . and not getting overwhelmed. . . You've just got to trudge through it. . . both in and out of school. (XXVIII, p. 7-8, 21)

Ben was proactive in solving his problems; in addition, he reframed them so he did not become overwhelmed: 
At times, I want to go home because I miss my friends, but, it's not like, all the time. So, it's not a major factor because I really don't like to look at things as bad. . . I try to look at things on the brighter side, so, like, usually, if something is going bad, like, I mentioned earlier, how, like, my Composition II class wasn't going good, but, now, I was able to find a way to make it go good. Usually, if something doesn't really work out, I'll try to find a way to make it work good, or seem, you know, a little bit easier. So, it's really hard to say what's not going good. . you try to work a way around it, some way. . you know there's another side at the end of the tunnel. (XXVIII, p. 10) Dan has decided that the outcome, whatever it is, will be okay if he puts in his best effort. This effort-based strategy keeps him working and his anxiety levels down:

I've come to the reality that some things I'm just not going to be good at, and some things I'm going to struggle at. You know, you can only put in your best. . . you can't put in more than that. . . . As long as I know, personally, inside, that I put my hundred and ten percent into it. . . that I couldn't do much more. . . . And that's what I've always been taught. My mom had the same learning disabilities I have, and struggled all the way through college with them. And she's always told me: "It doesn't matter what grade you come home with, as long as you know that you come home with your best effort, then I'm happy with you." (XX, p. 10-13)

Janice expected college to be more difficult. This expectation made the transition easier: A lot of people were very excited to get to college, and I knew that it was going to be hard. .. I knew exactly what to expect. I was thinking. .. that everything was going to change and that it is going to be hard. . . so when I got here everybody else was 
freaking out, and I was like: "Okay. I expected this." I was just ready to do it, accept it, and keep going. (XVI, p. 36)

Mark described worrying in advance as strategic. It was the way for him to make sure he gave himself enough time to complete assignments or study for a test:

First semester I would get a little stressed out about getting behind in my work before I was behind, because I was afraid that I was going to get behind. This is something that [my mentor] pointed out. He thought I was putting too much pressure on myself, that I have to do this semester as well as I did last semester. But I would worry in advance. . . and it would get me ahead. ... I go in to [my mentor and say]: "I got this stuff, and I don't know if I'm going to get it done." He was like: "How much time do you have?" I'm like: "I just got the assignment today" and he is like: "That's good." Just worrying in advance. (VIII, p. 31)

Tony has learned not to expect high grades. It sounded as if he controlled his expectations to keep his performance anxiety in check:

Like, I never shoot for an A. Like shooting for an A is just kind of crazy to me. What I mean is. . . shooting for an A seems nuts to me because it's like trying to be perfect at it. When alls I really want to do is get it. . I'm always happy with Cs. Cs are my friends. And a lot of people here are just very anti C and I don't understand that. I've always been happy with Cs. I'm happy if I get something higher, but never am I upset if I get a C in a class, unless I really, really, really feel I deserve a higher grade. A lot of people are like: “Oh, I want to be in the top of the class." I don't care. I've never been in the top of the class. . . but I've never been at the bottom, either. I've always just done whatever I can. If that's not good enough, it's not my problem. . . It's just 
I'd rather get a $\mathrm{C}$ in something than shoot for an $\mathrm{A}$ and be disappointed. Or shoot for a B, and be disappointed. (XV, p. 19-20)

\section{Self-Control Strategies}

The students in the effective performance grouping designed strategies to help them stay with their school work. These techniques prevented the students from giving up on scholastic endeavors, even though it often took them 2 to 3 times as long as their non-disabled peers to complete academic tasks. They paced their work, reorganized, and forced themselves to bear down on academics. They put work before play, started with the challenging tasks first, directed their behavior by self-talk, committed to full academic effort, and decided to regroup when academic progress broke down. Wendy described pacing herself so that she could persist with a long term task:

The biggest thing is just learning to keep myself going, like to be able to do something, take a little break and come back to it. . . . I have to pace myself because I cannot sit for five hours and do a drawing in one sitting. I just can't. . . or I get sick of it, throw it out, or like don't throw it out, but stop doing it. So, I've learned to do two hours and say "stop" and, you know, go to lunch or whatever and come back and do another two hours. . . [to keep me from getting] overwhelmed, [from saying]: "This is never going to get finished. I hate it. . . I'm just not doing it!" (XXX, p. 18-19)

Ben balanced work and play to promote personal stability:

[My] social life is going good. . I keep active. I go out, and I hang out with people, because, if you keep in your room all the time, you'll go nuts. If you study too much, you' 11 go nuts. You got to have a little bit of time to do something. Like, a little free time, because, you can't study all day, you know, 24 hours, 7 days a week. Like your 
mind can't take that. . . you got to learn how to balance it, because, too much play, your academics will go bad, and then, if you don't manage, if you have too much work, and not enough [free] time, then you get real stressed out, and then you're not going to be in a good situation. . . I try to complete one thing, and then I may work on, you know, something that I like to do. . I may draw a little bit, or go get something to eat, or go for a walk, and then, come back, and then do something else [academic]. So you got to figure out what works for you, because nothing will work the same for everybody. (XXVIII, p. 8)

Ben talked about how he managed his academic energy to help sustain his effort: What works in high school, doesn't work in college, because, I guess in high school you could play a little bit more, than work, where in college, it's a little bit more work, than play, and you got to figure out, I guess, what works best. So, usually, I start with the harder stuff, first, and then, the easier stuff, last, because, you use more energy up on the hard stuff. [If] I start on the easier stuff. . . by the time, I get onto the harder stuff, I won't have any energy left. . . Some stuff you may get centered on, like, you want to get it done but you may get a block or something like that. So sometimes you have to just get up and walk away, and come back to it. While other times, you just get stuck in a flow and you don't want to stop because you're doing good, so, it all depends on what it is. (XXVIII, p. 9)

Julie learned that it is better to not to put off her school work:

I learned that staying up really late one night, I was really tired in the morning. And then, I wasn't as nice and I was always in a bad mood during the day. I was like: "Well why don't I just get my work done because I'll have free time after the class." I 
just go to the library and get it done, and go to the other class. I told myself: "Make school days like a work day, and get all your work done." And then after it's all done, you're like: "Ah it's such a relief." And you can take a nap without feeling guilty about it. . . or just do nothing, and not feel guilty about it. (XII, p. 9)

Organizing his time and giving academics his best effort were the important strategies Dan used: If you don't have time management, you're not going to get by in college. The classes with homework, with sports, with social activities, if you want to have a part in all of them, you need to be able put your all into all of them, and be able to manage time wisely. (XX, p. 1)

Dan explained his attitude of putting $110 \%$ effort into all of his commitments:

Not only do I use that internal measure for school, but $[\mathrm{I}]$ use it in every other aspect of my life. Whether it's me working at home in chicken coops, looking for a job, stuff around the house, or soccer. . . I like putting in my $110 \%$ and if it doesn't come out well, then I'll know I did my all. I'm not a fan of doing something crappy and then being like: "Oh well that's her fault for not giving me this, or teaching me that." It helps in every aspect of life. If you can set goals for yourself, say that you can do everything to this percentage and you do it, then, it's great. If you let that percentage there [he points down], and say: "Oh I don't really care about this, I'll just do this to this amount," you're not going to get very far in life, and people are going to start saying: “Oh, he's pretty inconsistent, he doesn't work all that hard, sometimes, and sometimes he can do great." If people know you put in $110 \%$ all the time, they are going to commend you [no matter how] it comes out. ... That was just the way I was 
raised, if you don't put your best in, there's no point in doing it. . . If I didn't put any effort into school, I'd fail out. (XX, p. 10-11)

Janice offered an example of how she monitors her performance; she is intentional about recuperating her energy to stay with her schoolwork. Instead of letting things progress on a down hill course, Janice regrouped to reenergize her efforts. Many students in the ineffective performance grouping described how they started out well only to lose stamina to continue at the same level:

There were some transitions to make, like toward the middle of the semester, I redevoted my self to my studies. . . this kept on happening: I will get lazy about it and then I'll have to re-devote my self again. . . when you get too laid-back. . . because I'll do bad on a test, and I'll be like: "Something isn't going so well." I can pick up on the little things and I know all of a sudden: "You are starting to slip." (XVI, p. 23) When asked about basic strategies for success Denise recognized the need to develop self- talk to self-discipline:

Self discipline, I've never really had that before, like I'm a big procrastinator at home. . I came here and it clicked to me that I wasn't going to have someone to tell me to do something. So I had to sit myself down and tell myself that I had to do it. [I study] maybe 4 or 5 [hours a day]. Because I do my homework, and if there is anything else I need to do, like rewrite notes, or put things on note cards, then I also do that. (XIX, 38-39)

Denise described list making as her method for staying on track and motivated:

I have a list of what I have to do, like every night I make myself a list of what I have to do. And sometimes it all gets done and sometimes it doesn't. ... I just do it the 
next day. It makes me feel like I have accomplished something, it's good I guess. (XIX, p. 40-41)

In addition to using preemptive worry as a strategy to complete his work on time, Mark explained how his to-do list helped him to stay on track:

The best thing to do though, which is the hardest thing in the world, is to write down everything that you have to do. Like when you get it, just write it down, get a notebook, and each day, have a page. ... You write down all the things that you have to do, so you don't have to carry them around in your head. This is something I learned from [my mentor]. (VIII, p. 33)

Margaret described how she debates the decision when she is tempted to miss class:

Yeah, and like there are days when like I just don' t want to go to class, and I have missed classes, and I'm just like: “Oh, I don't want to go to class” but I'll think about it, and I'll assess where I am in the class, and if I think I'm doing all right, and I'm heading in the higher percentile, I think: "All right, I can afford to miss a class." But if there's a class I really don't want to go to, and I'm not doing well at all, I will awake. . I'm like: "I got to go to class." (XXII, p. 6)

\section{Academic Strategies: Intra-Cognitive Systems and Social Networking}

The students in the effective performance group designed personal study methods to help them understand and learn their course material. They employed individual cognitive processing techniques and networked to promote academic success. The students stayed awake in their classes, they asked and answered questions, and took notes. They worked to understand the material before they attempted to memorize it. Some of the students described reading actively and testing themselves to augment retrieval at a later time, others moved around while reciting 
the information to be encoded. They practiced problems and asked themselves questions about the material. They used repetition to over- learn until a comfort level with the to-be-learned information was reached. In addition, the students described "being social" with their work in the following ways: by talking with their professors to gain understanding and clarification, by finding a "study buddy," by connecting with their tutors, by asking around to find out about the professor's teaching methods before enrolling in the course, and by living with students enrolled in the same major.

This example from Julie's description of strategies used to help her succeed contains ingredients of self and environmental control; she manages her thinking and employs intracognitive strategies to understand and encode the course material. Julie studies in small segments so she doesn't get overwhelmed. She describes using the environmental control strategy of getting away from her friends to focus on her work. She is aware of her tendency to get overwhelmed and contains it by breaking up the work into segments:

Like [studying for big exams] is overwhelming, the exam is difficult because you have like five chapters. And it's difficult that you have to memorize all the information. Trying to understand it all, trying to get in your brain. Usually, I just get away from people, because I'll get distracted very easily. So, I'll go to the library, and I will sometimes reread the information, which is a task, and reread notes. . . Instead of just reading the notes. . saying them out loud, if you're in your room. Or sometimes I'll make flash cards. Or if there essay questions, and [the professor] gives you the questions, going into the book and looking it up. . . that's pretty much what I do. . . . And then, sometimes I'll start like a day or two early. . .getting all the information down that I need to, and then, the next day, looking it up, and then the 
final day, finally looking over it . . . When I spend two hours studying, it's like: "I have to know this information after two hours" and I'll just stop. And then the next day, I'll be like: “I don't know what I'm doing," like I won't feel prepared. But I'll just stop because I'll be like: “Oh it's two hours, I should know this by now." But if I do little segments, like even half- hours. . . I'll get that done, and then go do something else and then come back to it later. (XII, p. 20-21)

Kenny explained his study techniques :

It's really easy for me to participate in class, and that keeps me there and paying attention. I highlight things and whenever I write a paper; I usually outline. When we have to read books for classes, I take notes as I'm reading them. I usually like to read the books two or three times before I write about them, just so I can understand as much as I can about them. To study for tests, I make flash cards a lot, and repeat things out loud. I think I learn better if I hear things. Sometimes I end up walking around because. . . I feel like it makes more sense, or I understand a little bit better if I'm moving, and I don't feel cramped and stuff. (XIV, p. 22-23)

Even though Wendy has the accommodation of a note taker, she decided to record her own notes in classes to keep focused. She described practicing math problems to gain confidence and cognitive facility in the arithmetic process:

Basically, what I do is I try to take my own notes in classes. That helps, and it also keeps me from falling asleep, because as long as I'm taking notes, I have to pay attention. And then I take. . . the copied notes and I'll study them before we have a test or whatever, I'll go back over them like a couple days before, reread through them. . . and like with Math, I'll do practice problems. (XXX, p. 18) 
Ben explained the benefits of utilizing the SQ3R method to survey, question, read, recite and review his course material:

Yeah, it makes it [the information] stick in your head too, a lot more, because, you're reading it, and then, highlighting, and then, writing notes in the margins. . . and then, making up a review sheet. . . When you get into the test, you just know the answer [because] you've worked with it a lot. So, it's just keeping up with the work. . . You're thinking of questions, and trying to answer them. . . because, if you can't answer them, then, you go back and try to look for the answer; by doing that, you learn the answers to the questions. (XXVIII, p. 16)

Janice described using her strong visualization skills to check her retrieval of the course material while preparing for tests:

Basically, when I'm studying for my tests I just go over all of my notes, all of the copies from my note taker. . . all of my past tests and quizzes. . . I look at what I have done wrong, and I just go over and over and over the material until I'm comfortable with it. . . Like, when I see something, if I know everything else about it, like I'm flipping through my notes and I happen to see you know, like SN2: "Do I know every kind of reaction that happens with the SN2 reaction, and like what all the steps are of it?" And I mean if I can see it, and not see everything else in my head, then I know I need to look over that some more, and keep studying. . . If there's any question in my head, then I know by the next day, I'm not going to know it. (XVI, p. 31)

Denise is aware that she does more work than necessary to learn and remember the course material. Over-learning is an important academic strategy for many students with learning disabilities. It assists in the information retrieval process and promotes academic self-confidence: 
I have a note taker for Western Civ and that helped a lot, it helped organize the information, I don't know how to organize myself while I'm taking [notes]. . I I have classes on Tuesdays and Thursdays, and I usually come in after those classes and then I rewrite [the notes], but I keep the notes that I took in class, and I can look at those too. And then for the exams, I take my notes and their notes and put them together, I probably do more work that I should have to do. I outline, he gives us a study sheet, I answer all of his questions, but it takes me forever to do that. (XIX, p. 39-40)

Margaret described looking for examples from the lecture and textbook to help illustrate abstract concepts for better comprehension:

Looking at examples. . . of concepts. . . that's mainly how I do it. . . because there's a lot of times when things are specific, yet vague at the same time and you need. . . you're like: "Okay, so what would be a good example, whereas, what would be a bad example?" I look for examples in my books all the time. . . to tell me: "Oh this is how it's done; all right, this is where this goes, okay, I get that now." (XXII, p. 26)

Louisa explained the strategies she uses to understand and remember the course material. She talks with her professors to make sure she is focused on the right information and to check her understanding of the concepts:

I'm really big on note cards, and saying things out loud, reading it over again. And when I had a paper [to present], like in [history] class, I practiced writing it over again, and I highlight the main points. And then go to one of my friends, or somebody else, and ask them to listen to me about what I wrote, to see if I have it all down. . I I definitely talk to the teachers and set up meetings, so I know what to study.... I just ask them the main points that we're going over, what I need to study, if I have any 
questions on any of the concepts. ... I have some pretty good teachers because [my mentor] made sure that I had teachers that are understanding. (XI, p.18-19)

Aware of his auditory learning strengths, Dan emphasized the importance of going to all of his classes. In addition, he believed that his attendance record would influence how he is viewed by the professor:

I listen very intently in class. [I] take very, very good notes. I'm definitely an auditory learner, so anytime I hear it, and then, can apply it to something, I definitely learn it .... I've only mis sed two classes all year. The teachers also look good upon it if a student comes to class every day. . . say you're maybe hung over, and you look like hell, or you may be sick. . just the fact that you came to class everyday, you know, compared to that one person who skips or just doesn't come because he doesn't feel that great. . . they definitely look highly upon you. Whether you're the one that looks like hell that day, they don't really care, you're there. (XX, p. 18)

Jim has been proactive in talking with his professors to clarify conceptual elements or assignments for his classes. He has learned that he needs to be prepared with questions in order to make the most out of his tutoring sessions:

One recent thing that I've noticed [that] helps was I highlight key terms or. . . knowing how to focus on what is key for studying. . . . Trying to ask the professor questions in class, or right after class, or even setting up an appointment if I have questions about a paper or something. And tutoring does help in some regards. There might be some days I just don't understand it, but I can't form specific questions so it's not as much help as if I know specifically what to ask the tutor. (I, p. 17) 
Julie formed a working relationship with her instructors and established a "study buddy" for each of her classes. She checked with students who had previously taken her classes about the professors' testing formats. I asked her about factors she thought had contributed to her success: Well, if I need help, I go right to the teacher, or I get help. Like with Composition II, we're doing a research paper, and there's an outline. . I have no clue where to start, no clue whatsoever. So, instead of just trying to do it myself, or trying to do it without any help, I went to the teacher, and I was just like this: "These are my ideas, and this is what I thought. . . what order I'll put it in, what do you think?” And she totally helped me, and then I wrote my outline. . . . So, she gave me the topics I should do, and I was like: "Oh," the light bulb was turned on, and I just wrote it, and I got an A on it. . . seeking help. Another would be I try to find someone in the class that I know, so that if I have trouble, I can always run to them, and ask them a quick question. Or we can work on homework together. I always try to find someone. And then, I sometimes find people that take the class before me, so they can give me a "heads up" about it. They can be like well: "He's pretty hard with the tests." I always like to know how the tests are. So, I try to find an upper classman that maybe had the teacher: "How was he on tests? Does he do essay form, does he do short answer, multiple choice?" And that's always helpful. It's kind of. . . like being active with your work, and being social with your work. . . if you need help, then seeking it, and not just going: "I don't understand this. I'm not doing it." (XII, p. 19-20)

Wendy tried to determine the teaching methods and expectations of the professors to seek out a compatible learning situation: 
But you have more control over that [the professors you take], too. . . If you kind of do unofficial surveys, and ask people you know are in people's class: "What's their teaching like? Are they really hard-core, like you have to have everything perfect?" You know, if you ask, you can usually find out and try and get a professor you think will match, which I think is good. (XXX, p. 3-4)

Janice asked to have a roommate who was in her major, Biology, so she could live with someone who had a similar workload. She reflected how helpful the arrangement has been:

My roommate, we have both of our science classes together, and she has been unbelievably helpful in studying for all of that. I'm really glad that I have the roommate I do. Just because she does help keep me focused...we both asked to be put with people in the same major and that has just been really nice. (XVI, p. 30)

Jerry knew that he needed to transition away from his parents' assistance to the new helpers in the college environment. He developed a connection with his physics tutor so he would feel more at ease exposing his weaknesses while he worked to understand the course material:

You have to find that bond with the tutor. I have become good friends with the physics tutor. I had to build that bond, that friendship, so like we are friends now and she helps me. It just brings you closer I guess, and you can ask some stuff without being afraid, so they are not judging you. [I can say]: "I don't know how to do this, how do you do it?' You don't want to say that to a total stranger and have them think I'm stupid or something. (IV, p. 3-4)

Jerry befriended one of the tutors who shared important "insider" facts about his professor: I have become friends with the tutor for that class, and like she's like teacher's pet, so she has given me a lot of advice about him, like there's things about him that you 
would have to know, but he would never tell you. Like, if you were going to go to his office, and you stood outside of his door, he would get furious. What you have to do, is you have to go up to him, and show him that you are there, and then go out in the hall and sit down. I'd have no idea; I would just stand out side his door, until he could come outside. (IV, p. 19-20)

\section{The Primacy of Learning and Graduating}

The students in the effective performance group considered their education and success in the college environment to be of primary importance. They had clear cut reasons for attending college and acted to prioritize schoolwork over socializing, keeping their goals at the forefront of daily endeavors. They valued learning for its own sake and appreciated the personal growth that occurred as a result of the knowledge acquired from their courses. The students made a commitment to their studies and worked even when they didn't "feel" like it. They were able to see past their immediate desires and looked to the future advantage that hard work would bring. They took initiative to learn and understand their course material and to keep track of their grades. They understood it was their responsibility to succeed and were proactive to that end.

\section{Valuing the Educational Process}

It was refreshing to hear the students talk about the value they placed on the learning process. They enjoyed the intellectual practice of taking in information, reflecting upon it, and expressing their viewpoint. Even though grades were important, the students in this grouping conveyed that learning and academic skill development took precedence. Mark's narrative illustrated several examples of how he has come to value the liberal arts education. Even though he struggled with his Bible class, he wanted to learn the information instead of taking the easy way out; he believes that what he learns in his classes will change him for the better: 
I might be doing poorly in my Bible class, like I've been working really hard in it, but I've had to struggle, because it is the first time that I have learned about the bible. But like, I haven't tried to get old assignments from people to copy because I really want to. . . know at the end, when I'm done with it, I'll have that knowledge. . It's more important, the things that I learn here seem to be a lot more important than the things that I was learning in high school. . .I know that every time I write a paper, I write a better paper. (VIII, p. 7)

Mark emphasized his commitment to becoming well rounded:

When I made the transition to college. . . like I don't want to cheat myself. It sounds kind of corny, I'm a political science major, the fact that I'm struggling with Bible, I'm like okay: "I'm not just going to work on my government, I want to understand it all." Because I feel like this is the time that I have to understand it all, and then the rest of my life, after school, I'll focus on the job that I have. (VIII, p. 10)

When I asked Mark about the strategies he used to be successful, he responded by telling me that he values the learning process:

I can follow all of what the teacher is saying in class, and when he is telling things, and breaking them down. . . I guess usually when I get asked a question in class, after following along, I can come back with an answer. . . I think the fact that I choose to follow along. .. I want to get as much out of it as I can and some people just want to get through the class. . . but I want to learn everything that I can. . . it makes me smarter. (VIII, p. 25)

Knowledge gained is more important to Mark than the grade. This segment illustrates his sense of balance; he monitored his work load so that his other classes would not break down. 
My brother always tells me, whatever you put into things, that is what you get out of it. And he's a teacher himself, and he helps people too. ... I put a lot of effort into by Bible class, and I haven't been able to quite meet her standards. I'm getting all the work in, but the fact that I went in knowing zero, like going to church and knowing some stuff, but I consider that about zero. And reading the bible, now I know how the Old Testament breaks down, that's huge to me. It's like better to me than an A. ... I'm not going to get an A, but I have learned what I believe I can learn, because I have put a lot of effort in. I have put as much effort into it without making that the center of all of my homework, all the papers and things to do. And so that actually is more important to me than that [the grade]. (VIII, p. 8)

Again, to Mark, understanding the material is fundamental:

In Philosophy [class] I try to understand the concepts. . . because I will read it and once I feel like I understand the concept, then I hear them talk about it in class, and I'll say: "Oh, that's pretty cool" and I'll think about it for a little while, but then maybe I won't have it memorized quite like some other people who just memorize what they are saying and don't care what it all means. . I don't see the point. . . I I was studying with some people, and I was like: “Oh, let's talk about it." I feel like that in the long run, if I have a better understanding, it would help me out. . . the thoughts kind of mesh together and it also helps me memorize a little more, if I put a little more into it. (VIII, p. 8)

George talked about the benefits of his liberal arts exposure:

English [is going well]. I can I can write an essay and now I can get a B on it, no problem. I mean it just makes me happiest man in the world, I can write an essay, and 
not take forever to write it. I take tests, and I'm not getting Cs or Ds, I'm getting Bs, well a couple of Cs, but, it's not like the low Cs and Ds that I used to get .... Chorale, I have learned a lot this year in chorale. I have learned how to sing in German, and my voice has progressed so much this year. I have been thrown into different experiences; I have never been in front of a symphony orchestra before. It is a lot of work, but all worth it. (III, p. 22-23)

Margaret described the enjoyment of intellectual challenge in her history class:

My History professor. . . well I'm doing actually very well in that class, he'll just call on me for my opinion, and I'll state my opinion and. . . after you state an opinion, he likes to kind of put doubt in that opinion for you. .. it's kind of a game, I realized his game so I kind of play it back with him and I won't change my opinion and I'll stick to it. (XXII, p. 24)

Tony compared his experience of learning in high school to that of college; he enjoys the college process:

High school was a lot more tedious. I like college a lot better because everything I'm learning and taking, for the most part, is stuff that I want to take. . . Like [there are] required courses, of course, but, there's a variety of different ones that I can choose from. I like that. . . . You have more big papers, but, less little assignments to get in the way of writing those big papers. ... You get to stick to the same subject which I like. . I like it a lot better. (XV, p. 1)

I asked Kenny about the differences between high school and college. He enjoyed taking on the responsibility of the learning process: 
Well, it's a lot more of my responsibility, but I feel like. . . I can do everything and succeed, and I like this independence. My hand was being held in high school. . . . I really like that it's my responsibility to go and get my good grades and do my research and do my assignments and tests. So far I've been pretty successful at it. (XIV, p. 2)

Margaret described doing additional background reading so that she could fully participate in the class discussion:

With my History teacher, we were doing something on Andrew Jackson, and we were reading. . . it was just a chapter in a book, but he [the professor] was one of the authors that the chapter used for a quote. . . I would go online, or go the library to see if I could find his book to find the quotes, and finding out what he thinks. So in class, when he's trying to get the information out of us, trying to get us to talk about it, and state our opinions, I know ahead of time what he's trying to get out of us. . and therefore, I can make more of a solid opinion and/or argument for or against what he's trying to teach. (XXII, p. 2-3)

\section{Prioritizing Academic Work and Effort}

The students in the effective performance group struggled to make themselves work; they knew they would not succeed without great effort and follow-through. Prioritizing their studies did not come easily or naturally; it was an approach that was intentionally taken by the students. Jerry talked about his process of learning to establish priorities:

Like my neighbor studies 24-7, does nothing but homework and swim practice, but he doesn't have any fun. And you don't have to do that but you should sit down and do some studying. My neighbor studies 24-7, and the guy down the hall doesn't study 
like until the night before the test, and stays up all night long. So you have to find a balance. I just want to have it in my head: "Like I need to go and study" but yet I find myself saying: "I can wait" and cram at the very last minute. So, you need to find a balance. That's what I'm trying to do right now. I'm trying to build up my time management skills. It would be boring [to study 24-7]. I mean, you would probably get better grades, but you have to live life. You just want to do nothing and have fun, [but] you have to have a conscience and do your homework. (IV, p. 30-31)

Jerry used self-talk to guide his behavior. He contemplates both the internal and external reasons to work first to combat giving in to the draw of immediate gratification:

My conscience tells me: "You need to go, get this done," and I just want to do nothing. I have to tell myself "I have to go and do it." I have to get it done, instead of blowing it off. It's hard. I try and find benefits to like if I do this, I'll make myself feel better, and I can get it over with. Also, I can help my grade. That's my key. I have had to do that in physics. Like if there is a real hard test, and I was like: "Screw that, I don't feel like studying for it," I just tell myself: "If I can do good on this one, then I can get a good grade in the class." (IV, p. 31-32)

Janice described engaging in a new level of effort to survive the college environment. Her willingness to examine the thoughts and behaviors that contribute to academic breakdown has been a factor in her successful transition. Janice identified a pattern of "regroup ing" to regain her stamina to work through the semester:

As soon as I got to college it seemed to me that I needed to try. Like, this wasn't something that I was just going to get; it required a lot more effort from me. It is definitely requiring a lot changes from my part. Like, the beginning of college you 
know, I was working at it and everything, and that was fine, but then, all of a sudden this semester I have had to do a lot more work. And it was more than I was ready to handle. And it has just been interesting trying to balance my personal life and my schoolwork and all those things that I need to do to take care of myself. . . . I have had a lot learning to do in order to keep up with it. . . . I have had to be much more planned and organized the second semester. I had to reorganize my study skills, just re-devote myself again back to my studies, in like a whole new way. (XVI, p. 6-8)

Janice made academics a priority over socializing:

I never went off to parties. My roommate, like we just didn't do that. That wasn't our gig. It seemed like we didn't have that whole drinking problem: coming back, every night, drunk. Like we would just look at the people in our hall, and just be like "I don't know how they are doing it." Because we would be studying every night. . . around eleven o'clock, all of a sudden, you would just start hearing noise, and people were coming back drunk, and you were like: “All right, whatever.” (XVI, p. 22)

Kenny completed all of his assigned work even though it seemed overpowering at times:

I try and do all my reading. My history class is pretty overwhelming. We have to read a Chapter of thirty pages for each class. . . out of one text book, and then a lot of other stuff from another text book, and then books and poetry from the time periods. So, it's kind of difficult to do that, but, I mean, I end up catching up with it anyway. And I like reading. . . . I just feel like common sense shows that if you do what they ask, you'll be able to do well in the classes. (XIV, p. 22-23)

Ben talked about dealing with the freedom of the college environment: 
It all depends on, I guess, where the students come from, because I had more freedom at home. A lot of kids here. . as soon as they get here, the parents aren't here, so they just bounce all over, the leash isn't there, they just go wherever. And where, I guess I didn't have such a tight spring, and when I got here, it's really not that big of a difference, with my parents not here. . I It's more freedom, but, you've got to learn how to mana ge your time more. (XXVIII, p. 2)

Dan established his priorities and followed through on them. I asked him about any problems he faced during his transition to college:

[There was a] struggle of trying to do as well as I would like to and fulfill all the goals socially and in soccer that I have for myself. I set a lot of goals for myself, but to be able to accomplish all of them, you have to set priorities.... You have to accomplish what you have to get done before you can accomplish what you want... putting your stuff in priority, without a doubt. ... It's going much better, now. School's definitely first priority, get it done with, then, I can go have fun. (XX, p. 4)

\section{Taking Initiative and Personal Responsibility}

The students in the effective performance group did more than keep up with their assignments; they worked ahead and reviewed on a regular basis. They were committed to putting in the extra time needed to succeed and revealed that they were going to school to achieve their own goals, not tho se of their parents. Even though there is a strategic tone to the narrative in this section, these examples are not included in the strategic segment of the findings because they illustrate an overall commitment to successful learning, not the particular individual and interactive processes that promote academic success. I asked George about his strategies for succeeding in the college environment: 
Hard work, making sure I know the information, I usually make sure that I have a general grasp of it at the very bare minimum. Studying, I pretty much study when I'm done with homework. If I have a paper to write, then I will study, anywhere from about 6:30 until whenever I get done. That is usually what I did at home, I usually stop at 11 . I look over my notes from that week. If I have a test coming up, that is what I'm going to be doing, studying for that test. Sometimes I will just review what happened in class. (III, p. 36-37)

Kevin required himself to complete assignments early in order to rework drafts of his papers with the writing tutors. He attends class even when he doesn't "feel" like going, delaying immediate gratification for long term success:

Better time management. . . like in high school. . . basically I did everything last minute, and now, I'm not doing that. Like for an essay, I would do it the night before, but, now, it's like a week before, I'm actually doing it. . . because I'd have more time to take it to the Writing Center, and have them look at it, and then correct my mistakes. ... And I always go to class. .. as much as I don't want to, you know, some days I'll be in bed, laying there, like: “Oh, should I go to class or not?" But, in the last minute, I'll just get up and go. . . I make myself. And then I feel better, I think, that I went, or I would have missed this material. (XXI, p. 12-14)

Margaret's commitment to her studies is clear; she discussed the difference between high school and college:

With high school, you had multiple classes, and the work was kind of minimal. Now, you have minimal classes, but you have to do more, and go the extra step with the work. In high school, even though the teachers say they wouldn't chase you down. . 
for you to follow up, they do that anyway, no matter what they say. . . Here, the professors are like. .. they do care, but they aren't going to go chase you to your dorm, and go get you. You really have to take that initiative and see the professor, or go to the tutoring service.... [There is] more background reading. . . you have to do a lot more of that. Like just follow it and. . make sure like you actually stay on task, like take your time to understand the information in your own mind. . . that's what I'm saying is like taking that extra step. (XXII, p. 2-3)

Janice described studying the to-be-learned course material until she knew it. She observed that the college environment has challenged her to become proactive with her academics:

I have taken a lot more of an active part in like my studying. And the last Chem Test, I was up to like three in the morning studying for that test. I had studied before, but, I was just not comfortable with the stuff yet, and my roommate went to sleep around eleven and I stayed up to 3 studying. I got an 85 on the test and she failed it. And that definitely made me really happy, to know that it paid off. (XVI, p. 11)

Wendy has developed an internal structure to govern her behavior. She explained feeling a sense of accomplishment in setting and keeping priorities without external structure:

You don't have anyone on your back telling you do it, but I never really had that at home because I did my work. . . Particularly in the Art Department, you've got those major projects that take forever, it's like wahhhh, I don't get to sleep until like 2:00 in the morning now. But, I mean there's so many rewards for it. ... I think that basically you've just got to be responsible for yourself. Like you can't go: “I want to do this, so I'm just going to do it." You have to think about what the consequences are more, because you don't have anyone to bail you out. (XXX, p. 2-3) 
Leah has adjusted to the differences between high school and college. She realized the need to take responsibility for herself:

[College is] a lot more work, but also, the teachers. . . if you don't go to class that's your fault. . it just takes a lot more on your part to get motivated and go to class, and do your work. . . you have to follow up with your professors instead of the teacher following up with you. .. It's basically you're responsibility. You have to get motivated to go talk to the teacher if you're not doing well. You're on your own, you don't have your parents here to kick you out of bed in the morning to make you go to class, it's all you. (XIII, p. 1-2)

Kenny attended class even when he when he was not interested in the subject:

If I don't like [the class] I take, I make sure to always be in the class, and always be attentive. Obviously because my grade depends on it, and my opinions always change so. . . when I like something mo re, I talk about it more, and if I disagree with something, I talk about it more. . . And it's not really fair to my parents who are helping me pay for [college]. There're a million reasons to... and not really any to not go [to class], other than laziness. (XIV, p. 22-23)

Ben recognized that proactive study is required to understand and apply material for his classes. He also learned to take the initiative to check on his grades with his professors. He discussed the differences between high school and college:

Well, obviously, the courses are a little bit more difficult, like, they're not totally difficult, but like, you learn on your own. They present you the information, and give you a broad sense of it, but you have to take the initiative to go further with it. And, if you don't, then, it will show up. Here, I guess it's more of you taking the initiative to 
do the work. You have to learn it. . . and understand it. . . and apply it. (XXVIII, p. 12) With high school, if you had a problem, say, your grades were slipping, they would always tell you about it. . . A At college, they really don't do that. You might not know you're slipping. You have to kind of ask the teacher how you're grade is looking. (XXVIII, p. 3)

Julie learned to control her academic behavior. She observed that she enjoys having the independence to make responsible decisions:

You just have to be very organized and you have to plan your time out. You have to say: “Okay, free time here, so why don't I do this homework, and then when I come back from my other class I'll get this homework out of the way, and then tonight, I can go [to the restaurant] with everyone, or I can go do something fun." It's just getting your stuff done and time management. I feel like in college, I'm more productive, even though it is difficult, and even though the teachers do expect more out of you. But I feel like they're always willing to help, too. . . There's more flexibility, but if you can manage your time, it's like, you have more control. . . . Because it's not like people are telling you [what to do]; you can do whatever you want. If you want to go to class, you go to class. You're going to school for you, it's not like people are telling you what to do. . . I l like it. It makes you feel like you have control of yourself. That if and when you go to class, it's because you wanted to go, and because you want to work hard. It's not like: "Oh, I have to go to class because my mom told me to.” (XII, p. 3-4) 


\section{Establishing Goals and Staying Goal-Directed}

The students in the effective performance group had a purpose for attending college: a better quality of life, personal enrichment, a specific career choice, or the belief that additional and enhanced career opportunities would be obtainable after graduation. The students kept these reasons at the forefront of their daily activities and remained focused on academic success. Margaret believed that her quality of life would be enhanced as a result of attending college. She observed differences in perspective between herself and her friends, who were going straight to work:

As the summer was ending, I realized in my relationship with my best friends, the differences, how I was more independent, and not so reliant on others. . . And I remembered this one time, they wanted to go out to party, and I didn't want to do that. I just wanted to be with them, because it was the end of the summer, and I was going to be leaving them and I just wanted to be with them and not with anyone else. In my mind's eye I was not in a high school frame of mind, I was already in college. Whereas they were not going to college, they were graduating and going to the work force. And I really saw a difference there. . I wanted something better for myself. (XXII, p. 5)

Margaret continued to discuss her internal reasons for coming to college. Her narrative described a motivational attitude that enabled her to push through adversity and the occasional mundane task that accompanies academic work:

I want to better myself; this is why I'm here. To give myself a better chance. . . do what I want. . . and I try to reflect [on] that everyday that I'm here. Like I have posters in my room that say, you know, study hard, train hard, play hard. And you 
have to, you know, you can't do a half job on anything. ... I don't like leaving anything unfinished, because that drives me up the wall. I always have to finish it. Even though it might not be a great finish. . . but I just can't leave an essay half done ... I'll come back, and revise it, but it has to be fully done, that's the way I've always been.... You know, you want to party, you can party but I believe you're not paying tuition to.... It's just like you know, it's fun to live your life and be young and everything because you honestly can't do that when you're older, but at the same time, this is why you're here, to better yourself. . . You're paying tuition to go to classes and even though you don't love them and they give you work and anxiety, and they're not the fun part of it, that is why you are here. (XXII, p.6)

Margaret described being oriented toward her goals:

My classes are going pretty well, I think. ... Even though I've changed my major, I still feel like I'm on track, and I still have my focus. Which I do enjoy, because then, what else am I working for if I don't have that focus? And being involved in the school, like lacrosse. . . . I feel involved like when I'm going to school activities, going to the games. . . when I feel like I have a part in that. . . I feel like I belong. (XXII, p. 12-13)

Janice did not want to repeat the mistake of her brother; she was determined to succeed in college even though she often was frustrated by the academic process. Janice's strong motivational outlook carried her through the hardship of learning with numerous disabilities:

I've always been very motivated in terms of school work. I hate doing the work itself, but past that, I always just had the personality to succeed and do well, drive. . . . It has a lot to do with my brother not doing well in school, and he never went to college. . . 
there have been a lot of personal issues with that and with my family and stuff. . . He always wanted to go to college, but there was nothing that he could do. Because he didn't want to take his "meds" and so, he wasn't committed enough to be able to do well in college, he always felt stupid for not [going]. (XVI, p. 20-21)

Leah's awareness of her limitations allowed her to make healthy decisions for self-care and academic success. She was able to sacrifice her immediate need for social acceptance for the long term goal of academic success:

I just know it takes me longer than my other friends, and I know that I can't goof off as much as they do. Like I can't go out on Wednesday nights like they do, and come in a 3 o'clock in the morning, and get up for a nine thirty class and function because it takes me longer to read, and I need my sleep to get up and function normally. If I don't have more than 5 hours of sleep, there's no point in going to class. I know that about myself. And some people don't know that. They try, because they think if they don't go out, they're going to be looked at as: "that's a loser because they sit in their room all the time." That doesn't bother me because I know what I need to do to succeed. And that's what I'm going to do. I'm not going to try and be in with the in crowd and fail out of college. Because then, people are going to be like: "Well, she failed out" instead of: "She stayed in her room on Wednesday nights and studied." And some weekends, I'll go out one night and not the other, because I've got too much work. And I need to be alert to do my work when I wake up Saturday morning and Sunday. I'm not the type of person that can go out until four o'clock in the morning, come back completely drunk, wake up Saturday at like two, then go to dinner, and then go back out and then just not do anything on Sunday. I need to have 
sleep in order to be alert and do well. Because I couldn't write a paper half asleep. . . . I guess just the fact that I know I have a learning disability, and I know it takes me longer to learn. ... In the beginning, like it took my friends a little bit of time to understand, because they'd be like: "Come on, come out with us," and I was like: "I can't, I have too much reading." Because reading takes me a lot longer, sometimes, I have to read it twice, three times to understand it. (XIII, p. 13-15)

Leah talked about her motivation and hard work. She explained that motivation to succeed should come from within the student, not from their parents:

I think everybody just needs to have a positive outlook. . . the best thing to help is that you want to do well. ... If the parents are forcing kids to go to school, and they really don't want to, then that's going to be a problem. Because they're not going to want to learn so they're not going to learn. But, if you want to be here, and you have a learning disability and you know it's going to take more work and you're willing to do it, then I think you can get through everything. . . . Your parents can't motivate you. . . if it's all them [parents] telling you to be here, their motivation won't help you. . . . Some students are like: "Yeah, yeah, I want to go to college," but party. . . some kids want to go to college to succeed. (XIII, p. 15-16)

Becoming educated was Kenny's first priority. I asked him about the positive aspects of his transition:

My success in my classes, like I've never really done this well, ever, in school. . I came to college to succeed academically and if I made good friends, that's cool, if I found an interest, that was cool, but I recognized that this is the foundation of my life. ... Like I know a lot of kids who worked really hard in high school, and now they 
just party and are failing out of college, and that's really sad, because they worked so hard to get to this point. . . they're just ruining it for themselves. (XIV, p. 10) Jim enjoyed the flexibility of the college schedule. When I asked him to tell me about the differences between high school and college, his response reflected his priority: the freedom to complete his schoolwork at his own pace:

Even though I might have a little more homework, I have the ability to do it whenever I want to. Granted I'm not going to stay up until 2 a.m., and do homework. My cut off is 11 or 12, depending if I'm at the library. . And I know when I'm tired, there's no point to go past it. ... Here, I guess I'm more capable of getting stuff done. (I, p. 2) Ben entered college to learn about his major field. I asked him about the positive aspects of his transition:

Well, I think my sciences and stuff are going well. I'm a physics and engineering major, so I think that's going well, because I'm doing good in that. I would say, like overall, all my course subjects, everything is going good. ... Like, I was having problems at first with Composition, but now that I was able to go talk with everybody, it's in a good pattern right now. (XXVIII, p. 8)

Ben described the reasons for his academic effort. His response reflects both an internal and external source of motivation:

I think a lot of it all goes down to what people's motivation is. If somebody has a full ride here, and has to keep that full ride, then, they'll have more motivation to do everything, or just to keep up with everything, than somebody [who has] the parents paying for it, and the parents are making them go to college and they just are going along for the ride... What you put into it, is what you'll get out of it.... I want to be 
here. . . and, I don't want to be asked to leave. . . I got a science scholarship, and so, I have to keep up my scholarship because my parents, it would be hard for them to pay for the whole tuition. And that [also]. . works on motivation, for me. (XXVIII p. 910)

Dan received "bids" from 2 fraternities during the rush period, the second semester of his first year. He struggled with the decision; still, his educational goals took precedence:

I had two of them [fraternities] bid [on me] this semester; I didn't take either one of them, just because there was too much riding on the semester. Maybe next spring when stuff's settled down a little bit, and I have more of an opportunity to think about it. But for right now, it's just not feasible. ... It was a tough choice. I wanted to go pretty bad. ... There's just too many important things riding on the semester with academics and sports, so. . . me trying to get my grades up... and trying to get into the athletic training program.... For me to jeopardize all that by, you know, having to rush. . just the time commitment. It's that prioritizing thing again. (XX, p. 5-7)

Dan carried the importance and meaning of a better life into his daily functioning:

You've got to prioritize. . . unless you're extremely capable of blowing things off, and forgetting about important stuff. Which I'm not good at. . Half the time, I go out and I'll think about the paper I need to be writing. . . . If you have priorities, you can't just blow things off because everything builds on itself. ... You have to find the things that help you, make you happy, and you have to take those things with you all the time. You can bring those things with you and make everything else easier. ... If I'd partied the way I could of. . I could have been very capable of partying, I probably wouldn't be an athlete, anymore. . I'd feel like hell, I probably wouldn't be 
here, I'd probably be home, in a two-year community college. . . . A lot of ifs, ands, and buts; you're fully capable of controlling them if you choose to. Just drinking, working. . . that's probably what I'd be doing. And I know that because a lot of my friends are doing that exact thing. They're great guys; that's what they chose to do. I saw that, and I didn't want to do that, I chose a different road. But I could have very easily been like: "I'm going to go do what everyone else is doing." (XX, p. 19-21)

\section{Inappropriate Prior Educational Experiences}

Although not fundamental to the effective performance narrative, student criticism of prior special education experience is included in this final segment of the positive case findings. Seven of the 16 positive performance students were critical of their earlier educational experiences. In addition to the complaints expressed by the 3 students in this section, 4 additional positive performance students' criticism is embedded in illustrations reflecting the significant themes for the positive case. I chose not to deconstruct these additional examples as they mostly illustrate the thematic section into which they were placed; the student distress is apparent within those contexts. Taken together with the inappropriate prior educational experiences expressed by the students in the negative performance grouping, the student concerns may raise meaningful questions regarding specific areas of special education practice. The examples of narrative in this section express the student perception that the type of help described, although well intended, missed the mark and possibly caused more harm than good. The illustrations are akin to the negative educational experiences addressed by many of the students in the low performance grouping.

From his college perspective, there were too many exceptions made for Kenny during high school. An exemption from time constraint for assignment deadlines was required by his 
IEP; he believed he would have benefited more from the accommodation of organizational skill tutoring:

I had IEPs and stuff. . . and basically they let me turn in any assignment I wanted, whenever I wanted, so sometimes I would end up writing three papers for a quarter, like a couple of days before it ended. So, I could turn it all in and not fail the class. And. . . I mean some of it helped, and some of it didn't. . I did need the time. . . the extended test time, because I get nervous and stuff. But, some of it I don't feel like I really needed, like I could have worked around it to get the skills that I would have needed to eventually work with it [the disability] but. . I f felt like I depended on them [accommodations] more than I should have been allowed to. . .I was supposed to have tutoring and stuff. And I think I really needed organizational tutoring, because I was just all over the place. (XIV, p. 2-3)

When I asked Tony who or what helped to prepare him for the transition to higher education, he described his family's reaction to his guidance counselor's recommendation to not apply to a 4 year college. The counselor advised that his certain rejection would undermine his self-worth:

I guess my parents [helped prepare me for college]. ... they're really supportive, they've always wanted me to go to college. And even when I was a senior in high school, we went for my [IEP] meeting, which is where the parents come in and talk to the Special Education teachers. . my guidance counselor told them that I'd be lucky if I got into a community college, and for me not to shoot for a four year college. Not to even try, because it would just be a blow to my self esteem. So, I got really spiteful and. . that's why I applied to two or three four year colleges. I was going to do it, 
anyway, but it kind of made me feel better when I did. . . But, overall, nobody really sat me down and told me what college is about. . So I just kind of came here with a clean slate... I had no expectations of how I would do. (XV, p. 2)

Tony suspected that he was placed into special education classes with a student whose academic ability was significantly different than his own. This perceived mismatch influenced how Tony felt about his own potential, his trust in the special education structure, and his perception of future helpers:

In high school, I hated being part of the Special Education program, because it was so annoying. They treated you like you were and like you were in classes with people that were much. . . Like me and my friend, we were seniors. .. there was a Down Syndrome kid in there. I guess that'll really blow your self esteem. It's just like: "Why am I here?" (XV, p. 16)

Tony observed that he had more control over the disclosure process in the college setting. $\mathrm{He}$ recounted troublesome memories of being underestimated by his high school guidance counselor:

Yeah, I really like the letter process because when I was in high school, anytime I'd go into a mainstream class, my guidance counselor didn't think I could do it. . . I took mythology. .. it was a college prep English course, so, she really didn't like me doing it. And I'm a mythology buff, I love reading it, I've always loved reading it. So, I really fought against her. .. and of course since it's my schooling, I got my way. But, she would go up to my teachers. . . and say that she didn't feel I should be in their class, and tell them that I was going to be in there, and that they had to do this and this and this.... The teachers were usually calm and didn't care... I don't want to 
have any misconceptions, I don't want people thinking that they have to baby me, or give me any extra special help. Like if I need it, I'll ask for it. I'm very humble, but I don't want it thrown upon me. I'll just reject it. (XV, p. 21-22)

Margaret described a demoralizing encounter with one of her mainstream high school teachers, who operated under an erroneous misconception about the syndrome of Learning Disabilities. This experience has been a factor in setting a tone of angst for Margaret's subsequent selfidentification; even so, she disclosed her disabilities to her professors in the college setting: I'm one of those students who does not like to have their professor know that I have a learning disability. . . like as a student, you have to have control [over disclosure]. . . and I've had that experience before, like my sophomore [in high school] English teacher, she got a memo from, I don't know. . . the learning disabled support in our school, that I was one of their students. And she stopped me after class, and I was kind of embarrassed, and she was like: "I didn't realize you have a learning disability. You don't seem the type. Your handwriting's neat, you're organized.” And I was like: “Thanks." And it kind of proved my point, I don't like teachers knowing that. ... They expect less of you, because you're not up to par. . I think that's true, because I've witnessed it, I've experienced it first hand. (XXII, p. 22-23)

Margaret continued to reveal her negative experience with special education in high school. She was cautioned to drop out of the college preparatory Algebra class because of the teacher's testing style. She believed this experience had a negative impact on her academic development: My school handed out memos of who's who. And my first year, first Algebra class, my teacher was notified of my learning disabilities. My IEP said that I was not allowed to have pop quizzes and this teacher absolutely loved giving pop quizzes. 
And she tried her hardest to get me out of that class, because she will not give up her pop quizzes. And she did, she got me out. . . My counselor. . . was like: "You will not have to put up with this. Just leave. Just go to another class. And it may be too easy" which it was. After I dropped back to a lower level math, all the classes were so easy to me. Like it wasn't a challenge. . . I did not like that because if I'm not challenged to do something, I'm not motivated to do it. If it's easy, I'm not going to do it, just because it's so easy. I'm like: "Why is it worth my time?" Because I like challenges, [they] make me work. And for something to be easy, I'm just like: "What's the point?" (XXII, p. 22-23)

\section{Summary of the Positive Collective Case}

Although the average full-scale IQ and the average number of diagnosed disabling conditions were similar for both the negative and positive transition cohorts, the 16 members of the positive grouping earned an average cumulative GPA, taken after each student's most recent semester of enrollment, of 3.0. Individual cumulative GPAs for the effective performance students, taken after each student's most recent semester of enrollment, ranged from 2.64 to 3.53 . At the time of this writing, 14 of the 16 or $87 \%$ of the positive performance group members are still enrolled at the research site institution.

The narrative of the individuals within the effective performance grouping was analyzed and synthesized into thematic patterns for case presentation. Several conceptual commonalities clustered the students by patterns of outlook and behavior as well as by the positive performance outcome, an average cumulative GPA of 3.0. The students in the effective performance grouping revealed the following adaptive patterns of outlook and behavior during their transition to college: they recognized, appreciated, and followed through on preparative experiences for the 
college transition, they integrated socially into the campus community, they were proactive in managing their learning disability, they sought constructive help, they recognized and managed problematic issues, they took a strategy based approach to the transition, and they acknowledged the primacy of learning and graduating. In addition, the students in this grouping identified prior inappropriate special education experiences.

\section{Recognizing, appreciating, and following through on preparative experiences for the} college transition - The students in the effective functioning grouping recounted the events, relationships, and intentional instruction they believed helped them to manage the transition to the college environment. They described experiences that promoted self-sufficient and successful functioning. Careful and thoughtful elimination of instruction or supervision on the part of their teachers and parents prepared the students to function independently once they entered the college environment.

From a retrospective point of view, the students appreciated the overt advice about managing college from their teachers, family members, and other supportive individuals. This included explicit coaching to improve academic and organizational skills and to self-manage in a non-parentally structured setting. The students were grateful for the important relationships they formed with family members, teachers, and other supportive individuals during the years preceding college. They internalized the values espoused by these important mentoring figures and drew a direct connection between the relationship with them and preparation for and help during the transition to college. These important figures went out of their way to support, provide direct feedback, and press the students to do their best.

Several students mentioned the value of intentional postsecondary preparation programming efforts. The students alluded to the lasting effects of specific academic, social, or 
recreational curricula geared to prepare them for college and life. They valued the lessons of endurance, fortitude, and tolerance taken away from such programs. They described taking part in college preparatory curricula that was either academically rigorous or that instructed the students in the study skills needed to succeed. The return of familiar alumni to share the common pitfalls of the first year student experience was viewed as helpful preparation for understanding the subtle differences between high school and college.

Integrating socially into the campus community - The students in the effective performance grouping were proactive in establishing themselves as members of the campus community. They belonged to their academic departments, friends, campus organizations, and varsity and intramural sports. The students felt affirmed by their professors both inside and outside of class. Many described feeling a stronger sense of self in a more diverse, less stigmatizing social environment compared to the feel of the rigid groupings the students experienced in high school. For several students, this sense of integration into the campus community was due to the dynamic combination of personal development, the student initiating involvement, and the nurturing campus milieu.

The students were grateful for the acknowledgment they received as new members of the campus community. They were especially encouraged by faculty who made the effort to connect with them. The students reported feeling the freedom to "come into their own" in a more diverse environment. It was observed that the structured first year seminar helped student integration into the campus community: it presented the opportunity to meet other new students and supportive upper class advisors, to become familiar with the campus and local community, and to process the transition with an experienced adult. 
The effective performance students intentionally worked to interact with the campus community. They did this based on the self-awareness that they would make a better transition if they tried to mix in. Many chose to enroll in the particular college setting because they believed a small campus presented the opportunity for involvement. The natural course of student's personal growth combined with the small, nurturing environment, and the decision to be proactive resulted in a formula for positive social outcomes. Several of the students in the effective performance group joined service fraternities/sororities. These organizations offered an appealing alternative to the "Greek" organizations as the ritualized elements of joining and belonging to service fraternities/sororities were not as time consuming as those of the social fraternities. This commitment was more compatible with the academic demands of higher education for these students.

Proactively managing the learning disability - The effective performance students actively managed the impact their learning disability had on their functioning in the college environment. Many students observed that their success would be possible within the context of a strong support program and a small community atmosphere. Enrolling in a college that expressed a mission to proactively program for students with learning disabilities was crucial.

The members of this grouping were forthcoming on the subject of their personal educational histories, citing past experiences that contributed to self-understanding. The students carried these marker events into their current circumstances to sensibly and assertively navigate the college environment. In addition, the students expressed an awareness of their limitations and how they could compensate for them, they utilized accommodations and services to promote academic success, and they disclosed their disabilities to the appropriate persons in the college environment. 
In addition to having a myriad of receptive, integrative, organizational, and expressive processing problems, the students coped with another layer of difficulties. Their disabilities were invisible and their abilities were inconsistent. This resulted in having to work through questions of credibility with their professors. In addition, the students described working an inordinate number of hours on school work and coping with the stress of managing their cognitive processing problems.

The students were vigilant about pinpointing accommodations, services, and the type of support which enabled their success. All of the students in the effective performance grouping disclosed their learning disabilities to their professors. Although several students expressed an ease with the disclosure process, many were conflicted about revealing cognitive processing problems to the person responsible for evaluating their performance. They worried that the professors would use less rigorous standards when assessing their academic work. However, the members of the positive collective case tolerated this discomfort for the long-term benefit of using accommodations and services to achieve success. The students revealed that it was reassuring to read an invitation to self-identify in their course syllabi; this type of syllabus statement proved a willingness on the part of the professor to accommodate special needs and made the disclosure process less intimidating. The students were relieved that their professors trusted and used the support program's test lab to provide accommodations.

Seeking constructive help - The students in the effective performance grouping openly discussed their use of help during their transition semesters. Seeking assistance from multiple sources to navigate the new levels of academic rigor posed by higher education did not appear to preclude the students' development of personal autonomy. The students had decided to come to a 
college with a strong support program because they knew they would function better with assistance.

The students in the effective performance grouping acknowledged that the right kind of help guided the students to more autonomous functioning. The students observed they internalized strategies for more independent social and academic functioning. They acknowledged that they felt more confident when their helpers communicated a belief in their ability to be successful. In addition, relearning and reviewing basic skills required for the complex level of college study was acknowledged by the students as beneficial.

The perception of the appropriate posture and type of support contributing toward a successful transition was described by the students in this grouping. The students examined the scope, depth, and meaning of their working relationship with their mentors and language tutors who specialized in providing support to students with learning disabilities. The student-mentor relationship was confirmed by the students in this grouping as one of the significant factors that facilitated their transition. The mentor relationship focused on successful transition to and persistence in the college setting. Not only did the students in the effective performance grouping actively seek support, they made solid suggestions for supplementing the current support system, thinking outside the current boundaries of the support program.

Acknowledging and managing problematic issues - The students in the effective performance grouping openly described the difficulties they experienced during the transition semesters. They identified problems that interfered with effective functioning and took direct action and sought help to solve them. The students applied what they had learned about themselves from past experience to current circumstances. They possessed an awareness of thoughts and feelings that could be used to correct problems for more effective functioning. 
The effective performing students experienced disability related problems that impacted their sense of well-being. The students explained how they viewed themselves in the context of their disability and how they learned to cope with certain aspects of the disability under the new circumstances of the college environment. Social and emotional difficulties acknowledged by the effective performance students included deliberating the benefits and risks of using psychoactive medication, becoming aware of and working through social skills deficits, undergoing public humiliation as the invisible disability turned visible, developing autonomy while acknowledging cognitive deficiency and the need for remediation and accommodation, coping with performance anxiety which has been grounded in a history of academic struggle, coming to grips with the label of being "not able," and managing a fragile sense of self-confidence.

The effective performance students described the challenge of being away from home while dealing with new levels academic and social complexity. Many struggled with learning to be independent and handling the freedom of the college environment. The students had to learn to manage academics without the familiar help structures of their families and their prior academic settings. Taking control over their living circumstances in the residence hall posed another challenge. The members of the positive performance grouping took responsibility for their behavior and made changes in order to manage themselves better. They worked at becoming better students, better organizers, better thinkers, and better friends.

Taking a strategy based approach to the transition - The students in the effective performance grouping planned to operate productively during the transition semesters in the following ways: first, the students made decisions to productively participate in their new environment and to develop plans and rituals to function well on a general basis; second, the students purposefully managed their thinking in order to adapt to their changing context; third, 
the students used self control strategies to cope with their academic workload; and fourth, the students used intra-cognitive and social networking strategies to effect their academic performance.

The students in the effective performance grouping acted out of self-awareness to transition successfully, conscious of possible pitfalls. They engaged in physical exercise, talked to their friends and their mentors to relieve stress, carefully selected their friends, living situations, and study areas, stayed active for better focus and effectiveness, and set up informal support networks.

The students adjusted their thinking to function more productively. They changed their expectations when the situation demanded and realized that perfection was impossible, in life, and in their work products. They were able to shift their relationship to a problem and the problem itself by changing how they perceived it. In addition, these students carried into their new environment metaphors from previous successful experiences, changed their goals to reflect effort instead of outcomes, and adapted to their changing circumstances.

The students in the effective performance grouping designed strategies to help them stay with their school work. These techniques prevented the students from giving up on scholastic endeavors, even though it often took 2 to 3 times as long as their non-disabled peers to complete academic tasks. They paced their work, reorganized, and forced themselves to bear down on academics. They put work before play, started with the challenging tasks first, directed their behavior by self-talk, committed to full academic effort, and decided to "regroup" when academic progress broke down. They designed personal study methods to help them understand and learn their course material. They employed individual cognitive processing techniques and networked to promote academic success. The students stayed awake in their classes, the y asked 
and answered questions, and took notes. They worked to understand the material before they attempted to memorize it. Some of the students described reading actively and testing themselves to improve information retrieval at a later time, others moved around while reciting the information to be encoded. They practiced problems and asked themselves questions about their course material. They used repetition to over-learn until a comfort level with the to-be-learned information was reached.

In addition, the students described "being social" with their work in the following ways: by talking with their professors to gain understanding and clarification, by finding a "study buddy" in their classes, by "connecting" with their tutors, by asking upper class students to find out about the professor's teaching methods before enrolling in a particular course, and by living with students enrolled in the same major.

Acknowledging the primacy of learning and graduating - The students in the effective performance grouping considered their education and success in the college environment to be of primary importance. They described their reasons for attending college: for a better quality of life, for personal enrichment, for a specific career choice, or because of the belief that additional and enhanced career opportunities would be obtainable after graduation. The students acted to prioritize schoolwork over socializing, and kept their goals at the forefront of daily endeavors. This motivational outlook or attitude became a platform or catalyst for daily behavior.

The students in the effective performance grouping valued learning for its own sake and appreciated the personal growth that occurred as a result of the knowledge acquired from their courses. Even though grades were important to them, they conveyed the belief that learning and academic skill development took precedence. They made a commitment to their studies and worked even when they didn't "feel" like it. They were able to see past their immediate desires 
and looked to the future advantage that hard work would bring. They took initiative to learn and understand their course material and to keep track of their grades. They understood it was their responsibility to succeed and were proactive to that end.

Event though the students from this grouping placed value on the learning process and enjoyed the practice of intellectual discourse, they struggled to make themselves work; they knew they would not succeed without strong effort. Prioritizing their studies did not come easily or naturally; it was an approach that was intentionally taken by the students from this grouping. They did more than keep up with their assignments; they worked ahead and reviewed on a regular basis. The students described being committed to putting in the extra time needed to succeed and revealed that they were going to school to achieve their own goals, not those of their parents.

Identification of prior inappropriate special education experiences - The following retrospective concerns of the students in the effective performance grouping raise meaningful questions regarding specific areas of special education practice. Although not fundamental to the effective performance narrative, 7 of the 16 positive performance students were critical of their earlier educational experiences. The student narrative expressed the perception that the type of help described, although perhaps well intended, missed the mark, and may have caused more harm than good.

One student stated that he had become too dependent on the accommodation of an exemption from assignment deadlines. Instead, he believed organizational strategy training would have benefited him over the long-term. Another student had a series of problems with his guidance counselor who underestimated the student's potential. The counselor discouraged his enrollment in college preparatory classes and his application to institutions granting a 
baccalaureate degree. The underestimation of his abilities coupled with being placed in a resource class with students who had been diagnosed with significantly differing disabling conditions caused the student to mistrust the special education system. It is not a surprise that these occurrences influenced how the student perceived his own potential.

A demoralizing encounter with a "main stream" high school teacher, who held erroneous misconceptions about the syndrome of Learning Disabilities, was a factor in setting a tone of anxiety for disability disclosure for one student. The same student was cautioned to drop out of the college preparatory Algebra class, in which she had been correctly placed, because the teacher's expectations were "too high." The student believed this experience had a detrimental effect on her academic development.

Another student described being passed through the educational system during middle school even though he had not learned the requisite skills. After much frustration and angst, because he knew he was behind the other students in his classes, his parents pulled him out of public education to repeat 2 grades in a private setting. Two other students from the effective performance group expressed concern over the way their testing accommodations were managed. The teachers' lounge was not an appropriate setting for the accommodations of a quiet environment or extended time. See Table 7 for a summary of the positive collective case findings.

The final section of the findings will illustrate student perception of internal and external facilitators and barriers to transitioning to and persisting in the college setting from the point of view of a cohort of students who have persisted or earned at least 60 credit hours toward graduation. 
Table 7

Positive Collective Case Findings

Recognition and application of preparative experiences

Experiences viewed to promote effective functioning

Significant figures that made a positive difference

Intentional programming designed to develop students

Social integration in the campus community

Sense of community

Proactive integration

Proactive management of the disability

Importance of the support program and the small community setting

Important role of personal educational history

Awareness of limitations and compensation

Active use of accommodations and services

The benefits and conflicts of reasoned disability disclosure

Seeking constructive help

A posture of active help seeking

Evaluating the right kind of help

Utilizing the special support mentor

Suggestions for support program improvement

Acknowledging and engaging problematic issues

The psychological impact of disability related problems

Problems adjusting to the college environment 
Acknowledging and engaging problematic issues

The ability to acknowledge and correct mistakes

Dealing with problematic circumstances

A strategy based approach to the transition

General strategies for adjustment

Managed thinking and changed expectations to adapt

Self-control strategies

Academic strategies: intra-cognitive systems and social networking

The primacy of learning and graduating

Valuing the educational process

Prioritizing academic work and effort

Taking initiative and personal responsibility

Establishing goals and staying goaldirected

Inappropriate high school educational experiences 


\section{Persistence Collective Case Findings}

By the end of the class, the end of that semester, I didn't feel that I really received enough [knowledge] to go on to the next thing [Calculus class]. I had to stop and then everybody else [in the class] was like: "We're going to keep on going on with it and take this C." I said "Nah, I can't do this." When I was going through the public school system where I had a reading problem, they just kept on pushing me through, pushing me through, and it came to a point where I was in high school and my reading level wasn't that great. I learned when that happened that I had to stop, I had to go to another school. They were able to start me all the way back, even though I was in high school, they were able start me off wherever they saw that I made the most mistakes and then start from fresh there. If I had said "All right, I'm just going to take the C" and then tried to survive in Calc III...I found out previously that it doesn't work .... I missed something. I missed these key concepts and these key concepts are the foundation, the bottom of the triangle, and all the other classes stack up on top of it. And if I'm missing the bottom then when I get up to the other classes, I'm going have these gaps that are going to hinder me. (XXVIII, p. 18-19)

The persistence narrative allows us to understand the students' experience of transition in retrospect and how the students persisted in the postsecondary setting. The students were asked to think about supports and blocks through the vantage point of their present and prior experience. All of the 10 interviewees had completed at least four semesters; seven were on the brink of graduation and have been graduated at the time of this writing. For the most part, the students in the persistence grouping indicated solid academic performance. Even so, they were forthcoming in describing barriers they experienced. 
An effective and ineffective functioning profile was constructed on the basis of positive and negative performance outcomes of the students undergoing the transition to college (see positive and negative transition findings). All but one individual in the persistence grouping, students who earned 60 or more credit hours toward the baccalaureate degree, fit the effective performance profile by grade point average. The student from the persistence grouping who fit the ineffective performance grade point average criteria, presented a mixture of the effective and ineffective profile. His narrative matched the effective category in the following ways: he integrated into the campus community, he acknowledged and began to engage in solving personal problems, and graduating from college was an important goal. His description fit the ineffective category in that he described being unable to control the problems he experienced in self-management and struggled with using the help of authority structures. He is, at the time of this writing, beginning to come to terms with his disability by seeking to understand the nature of his disability and its impact on his everyday functioning.

The narrative within the collective persistence case illustrated student perception of internal and external facilitators of and barriers to transitioning and persisting in the college setting. For this study, the descriptor internal refers to a thought, feeling, or activity that is perceived to emanate or have its source from the individual. The descriptor external refers to an event or opportunity which is perceived to exist outside of the individual, or mainly grounded in the environment of the individual. The presentation of the persistence case findings will focus on the manifestation of facilitators and barriers perceived by the students.

\section{Internal Facilitators of Successful Performance}

The students in the persistence cohort presented numerous examples of narrative illustrating internal facilitation which lead to successful functioning. The internal facilitation 
process involved multiple steps: self awareness led to the development of an outlook or approach which facilitated the student's self- management or management of the environment through individual or interactive practice.

Self-knowledge was the first step in the process of internal facilitation. Self-knowledge encompassed student awareness of goals or strivings, limitations, and strengths; these formed the foundation of the student approach to navigating the environment. The approach or outlook provided a platform that formed everyday practice. Everyday practice involved individual or interactive activity that facilitated academic, social, and emotional well-being.

\section{Self-knowledge}

The students within the persistence grouping described their goals and strivings, their strengths and limitations, and their unique approach to navigating the college environment. Student description demonstrated vigilance in staying goaldirected. Many were able to identify inner strengths that have promoted stable performance; in addition, they were unguarded in describing personal limitations and challenges they worked to overcome. Finally, the student narrative displayed a strong will or attitude of determination that activated them to overcome hardship.

Goals and strivings. The goals and strivings of the students energized their will to succeed. The students were in school for a reason and kept their goals, accomplishing good grades, finishing the degree, learning from their classes, participation in extracurricular activities, and preparing for their future careers, at the forefront of their college experience. Ben explained his goals. He was in the process of learning the requirements to begin a career in the field of engineering and physics. In addition, he was excited about planning his senior capstone project: 
The first goal that I reached would be making it this far. That's my number one thing, to come here and get an education. That's the main goal of college, to graduate and to actually walk away with something. I think, so far, I've been able to walk away with a lot from my classes. (XXVIII, p. 1)

[For] the Research Project....[I want to] think of something new and different.... It's going pretty good...it's harvesting ambient energy out of the environment....Like you could use vibrational energy, just pure vibrations that are in the environment, and actually turn it in it into electrical energy...it might be heat, it might be sound, acoustic energy, or light, you know how there's light around, it can be any type of energy. (XXVIII, p. 2)

Alexandra and John had the objective of earning high grades:

I think keeping my GPA up, I really wanted to graduate with a 3.5 GPA, and at this point I know I'll graduate with at least that, as well as I was able to get into the National Honor Society...last year. (XXVII, p. 3)

Well, I know that one of my goals wasn't to fail out and, I've, obviously, accomplished that one so far....I have ninety-two credits, and, I think, my GPA's about a 2.8. I'm also trying to make the Dean's List this semester, that's one of my current goals. (VII, p. 1)

Julia has worked toward beating the negative prediction made by her high school teachers: Becoming an educated adult, succeeding in college, that was a very high one [goal] for me because my high school never thought I would actually make it this far. And I'm actually doing really well, academically wise, so, not only succeeding but succeeding with good grades.... I'm making it with A's and B's. (XXIV, p. 1-2) 
Gavin experienced first hand what it is like to labor in a job he doesn't enjoy. This knowledge has helped him to continue working toward his degree even though he has struggled. His view of the future includes having a job that requires a college education:

I think I wouldn't have been here if I didn't know what working is like. Like going home, over the summer, I'm a laborer, I'm with people who do not have their college education, and they always tell me "You better stay in school, or you'll be doing this." And, I know that, and by the end of the summer, I hate my job, and don't want to do it anymore, and I can't imagine doing that every day for years. (XXIII, p. 10) I don't want to be home, working everyday, at, you know, maybe an unskilled job...I would never make enough money there to support a family in the future, and that's another reason why I'm getting a business degree. . . getting a job with a degree is much better than not finishing up. (XXIII, p. 4)

For some, participation in campus sponsored clubs, organizations, and sports were almost as important as academics. Swimming was one of Darla's primary activities. She valued the structure that participation in a sport provided. Darla explained that she was not concerned about the lack of sleep demanded by her busy schedule:

I'm going to graduate, I was able to do a sport for four years, I was able to do social activities. The main thing is graduating, you just have to learn to balance your time. But, I've done that since I was eight years old...I put in over twenty hours a week [for swimming] because I love the sport so much and I have a scholarship...I don't sleep a lot...I did sorority, too. I did sorority for fours years, and I'm an Art Major. It's a lot of time. (II, 2-3) 
Tying together current education with future work possibilities provided momentum for many of the students interviewed. Kelsey's internship pulled things together; the experience gave her an idea about the type of work she would engage in. I asked her about rewarding experiences: Well, being on the Dean's List this year....My internship last summer was really rewarding because I got to fully start to understand what I want to be in my future life....And with that, switching from Psychology to Christian Education, even though I had to stay an extra year. (XVII, p. 8)

Connie realized her vision of becoming a teacher as she progressed in her classes:

Also realizing that this is what I'm doing for the rest of my life. That's always a big turning point for people, even though I've wanted to be a teacher since I was very young, I'm really going to do it now....I've wanted it for so long, but you see what it's really like now, this is really what you want to do and I guess I'm fully going for it. (V, p. 30)

Although John was not sure about a specific type of position within his field, his mind has been on the future:

Thinking about after graduating... having a good GPA tends to help to you get jobs, knowing that is another reason for me to try and do well....I haven't really narrowed it down because there's so many different aspects of graphic design that I could take, I just don't know what I really want to do day in and day out, and I think the only way I'm going to figure it out is to actually go out and start working and see what I enjoy doing. (VII, p. 6)

Abbey has gained the confidence to think of making application to graduate school: 
Well, I'm really unsure of what I want to do when I graduate. Honestly, I think last semester, I showed myself that...because I never really thought that I would maybe even have the opportunity to go on in higher education....So, that's [grad school] something that I've been thinking about....And, I've also started applying to jobs....I guess with applying to grad school, I think to even know that if I got in, that would mean a lot to me. (IV, p. 3)

Strengths. The students recognized their accomplishments in the face of hardship and identified areas of personal transformation. Connie broke through her academic frustration after she was evaluated and diagnosed with her learning disability. She made it a point to learn about methods of overcoming the limitations imposed by her disability:

[In] high school my grades severely dropped and I could never get them back up, that's when I realized that there was something wrong. So, making the Dean's List was a big accomplishment. Also getting through all my classes even though they were hard and I had a lot of trouble with them, that was another accomplishment for me, especially this semester with everything that's been going on. (V, p. 1)

John soaked in the smaller success of finishing out each academic year:

Just coming back every year has been a turning point, and knowing that I'm that much closer to graduating and being done...I'm happy when I come back, and look forward to it, and I feel that every year....Well, this is my last, and I probably won't want to leave when I'm done, but, just knowing that I succeeded the year before to get to every...next year. (VII, p. 13-14)

Abbey was pleased she has been able to juggle a varsity sport, sorority, and a cumulative GPA of 2.72: 
I've never failed a class, I've always been pretty happy with my grades. Actually, it means a lot to me that...I will be graduating in four years....I've played tennis for three years, up until this year... and I'm in a sorority. I feel like I've done a lot with what may seem to be set backs. I guess I was just proud of myself, that I really could do all of it. . . it just meant a lot to me that...I can do that, too. (IV, p. 2)

Darla was anchored in the success of her Scouting "Gold Award":

I did my Gold Award on learning disabilities, so, I was able to talk to people about my disability...I've been doing that for years....The highest award in Girl Scouts....I did it with one other girl who's learning disabled. We did the program for kids on what works and what doesn't work for learning disabled students...We spoke to the parents and then they asked us to do it for the faculty at the high school, so we did....We had to go through training because we were on national TV, then we went to this forum for young women of distinction....We won because we inspired people. It was awesome....We touched people, that's why. (II, 25-26)

Mandy appreciated the growth she experienced as a result of her exposure to the college environment:

I know a lot more, and have become a better student. I think I have become a better person, because of all I think that you experience in college, that you take part in, and that you're stuck taking part in. I've made a lot of good friends that I'll always carry with me, and learned a lot about who I am and how I need to deal with myself, and how I deal with problems, management techniques for work and for emotions that I'll carry on.... I've become a better person because I'm closer to God. And, I've grown in my ability to share myself with others. (XXV, p. 13) 
Julia acknowledged the relationship between her personal development and the college experience:

I'm maturing as an adult....I don't call my grandma every minute of the day, asking her to help me make a decision...I see myself, like when I go home, and I continue to work at the apartment, I've learned more skills to help me deal with the tenants, and how to deal with situations whereas, before, I probably would have been running to the manager. My [improved] decision making skills have helped me realize that I have matured. (XXIV, p. 5)

Abbey explained how the college environment helped her "come into" and believe in herself: Being satisfied with how I've done grade wise. That really does mean a lot to me...I have great friends....Socially, I think that would have to be my favorite part of my college experience. Actually me growing up, me changing...I like who I've become...I would say confidence wise, and academically, how I said this program has helped me. And even in the sense of, like my best friend, she's taught me to stick up for myself....I guess in every aspect, being sure of myself, socially and academically, and personally within myself, being okay with myself...just growing up I guess. And, I feel good that it happened in a good way, here. Like if I was at some big place, [I might be] trying to be like other people...I feel like I'm actually myself...It helped me be myself. (IV, p. 7-8)

Gavin's position in the fraternity has provided him the opportunity to learn more about how he reacts under pressure:

Stuff I've learned about myself has been satisfying. Even though I hate the fights and stuff like that that happen at the fraternity, I've learned how I react in a time like that, 
and I like the way I react.... It makes people mad because I don't fight whenever they think I should, but I don't fight, and I like that, and I like how, if I need to be, I can be a mediator between two groups. (XXIII, p. 7)

John reflected on his personal growth during his college experience:

I feel more mature. I feel like I have a better sense of what the world really is like. I definitely feel I have improved on my art skills and abilities and academics.... I am not so oblivious. (VII, p. 14)

Kelsey intentionally tapered the amount of academic support she received from the program. In addition, she recognized the progress she had made in other life areas:

I have basically graduated from taking tests here [support test lab] and doing note taking to doing my own notes and taking tests in the classroom. I haven't taken a test in here in about a year and a half...I felt that I could do the same if I were here that I could do in the classroom...I'm about to graduate from language tutoring, too. .. I'm flying the coop. (XVII, p. 19-20) I feel like I have more potential to my life than I felt, I'd say, six or seven years ago. Six or seven years ago, my ultimate goal was to go to college, well I'm in college. So...I have now a more positive outlook on life, I have narrowed my job, what I want to be...Another thing is that I'm learning a lot and actually enjoying it. (XVII, p. 22)

Limitations. The students met face-to-face with their limitations. Compensation became possible with the realization of weakness. Ben "back tracked" to be able to complete the math sequence required for his major. Although it created more work for him, he knew better than to take an offer of passing a foundational calculus course with a C: 
By the end of the class, the end of that semester I didn't feel that I really received enough to go on to the next thing [Calculus class]. I had to stop and then everybody else [in the class] was like: "We're going to keep on going on with it and take this C." I said "Nah, I can't do this." When I was going through the public school system where I had a reading problem, they just kept on pushing me through, pushing me through, and it came to a point where I was in high school and my reading level wasn't that great. I learned when that happened that I had to stop, I had to go to another school. They were able to start me all the way back, even though I was in high school, they were able start me off wherever they saw that I made the most mistakes and then start from fresh there. If I had said “All right, I'm just going to take the C" and then tried to survive in Calc III and everything else...I found out previously that it doesn't work because . . I missed something. I missed these key concepts and these key concepts are the foundation, the bottom of the triangle, and all the other classes stack up on top of it. And if I'm missing the bottom then when I get up to the other classes, I'm going have these gaps that are going to hinder me. I didn't feel that it would be any use to do that, so I had to bite the bullet and say "I didn't get it here, so I got to back it up and then start off again." And since that, it showed a lot, because, I mean, in Calc I and Calc II I got Cs, and after having to retake it, [in] Calc III, I was able to get a B. Now in Differentials, I'm doing really good. . . . So, it helped out a lot. I knew that I needed it to get the knowledge. . . I don't mind having to redo something if it helps me...in the long run. (XXVIII, p. 1819)

Julia took responsibility for not communicating in significant relationships: 
I think the turning point was just that whole relationship with [my boyfriend] and the big break-up and then, evaluating it, and realizing that it probably wasn't so much that the relationship wasn't working, it was that I wasn't communicating what was bothering me, so he didn't know what was bothering me, and didn't know to change. I really learned a lot about communication. It has to happen... if you don't communicate, people around you don't know what's bothering you and they can't help. (XXIV, p. 16) It is more like an empowering change, something that I learned about myself. . . . Like I would say "Yeah, yeah, yeah, that's okay" when it was really bothering me. I was afraid of conflict and confronting people so I needed to get over that, and that really helped me mature and grow....I guess I was just deathly afraid of confrontation in that...it was challenging to actually want to do that, because I think, in my past, I was always teased and harassed by my peers so, I didn't want to do anything that would cause more teasing or harassing. I had to learn that you've got to do that even though you may have other complications from it...the lid has to come off...to be able to be a person.... [It] wasn't as scary as I thought it would be...You have to open your mouth, and then, maybe it will stop [the teasing], or maybe, things will get better, and things did. (XXIV, p. 5-7)

Kelsey lacked social awareness as a result of having a Non-Verbal Learning Disability. Becoming aware of this limitation was essential to Kelsey's social development: I guess that's the way of me maturing...I'm maturing more in the social skills department and learning more things. . . . I'm learning how to be social and be more acceptable than I was about five years ago. ... I'm starting to understand more facial expressions. ... I mean there's some facial expressions and body language that I just 
really can not read. It's a challenge for me but it's getting a little better. I think I've gotten more friendly...I think the library job is helping because I help people and I get to interact with people, especially at the circulation desk. (XVII, p. 16-17)

Connie took the lead in trying to understand the reasons behind her academic problems. She was relieved when she found out about her diagnosis:

My diagnosis, during high school, I was extremely frustrated when I could not figure out what was wrong with me. So, that was, as weird as that sounds, that was a turning point for me, knowing that I had something wrong and it just wasn't that I couldn't do it....Yes, it's more like a relief because it's not that I'm stupid, it's not that, it's that there's a reason I can't do it. Now, I can move on and work to try and do better. Whereas before, no matter how hard I worked, I didn't get any better. (V, p. 29) I was the one who asked my mom. I said "Mom, there's something wrong"...because I was just so frustrated and it would take me six hours to do a paper that took everybody else half an hour. Because my mind would travel, I couldn't focus on what I wanted to say. It would take me 5 minutes to come up with one word, because I wanted the right word, you know, and I still do that, I'm not going to lie....I first did take medication and first did get diagnosed with it, one of my friends said "Why are you doing that? You're not dumb." Now it doesn't bother me. I mean...we talk about ADHD in my SLD [Education] classes and I'm like "Oh, well I have that." And I can relate to what she's [the professor is] saying because I am and I'm interested in why, what the characteristics are... what goes on in your brain when you have ADHD...it helps me with school. (V, p. 17) 
Connie emphasized how important it was for her to understand and to talk about the limitations imposed by her disability:

Knowing the learning disability, knowing how it affects you, knowing the different aspects. . . Because I know it's gotten so much easier for me since I know what's going on. . like personal experiences that a person has been through. I know that some people don't like to open up but, I know since I have, it's been so much better for me. I know I have somebody there I can talk to. (V, p. 32)

Alexandra tried to stay aware of her tendency to over work at the expense of her well-being: I think like relaxation ... still sometimes, my friends would have to be like "breathe." I'll have to go and listen to music, to sort of relax. And, also, my freshman year, like all I did was homework, I found adding other stuff, and even though it takes time, kind of helps the process....Basically all I did was focus on homework and I think I almost stressed myself out, wore myself out more by doing that. Now, I'll take time out to watch TV or go out to eat. Plus, I have my job in the Department. I think that helps keep me unstressed and relaxed, that gives me something else to think about so when I do go back to my work, I'm actually probably more focused and better prepared to do it, than if that was all I was doing.... I learned I need to balance. (XXVII, p. 9-10)

Awareness-based outlook. Many of the students possessed a mind-set based on selfawareness that they utilized to facilitate their education. These characteristics included academic diligence, determination, and persistence. In addition, the students carried a will toward selfreliance and independence, even though they understood and accepted their need for services. 
Abbey explained how she thought about the pressure of spending time with her friends over the years:

I couldn't possibly go to class without having that [assignments] done. That would scare me, like, what would happen? He'd probably kick me out of the class, probably not, but. . . I wouldn't push it. I wouldn't test the limits. . . It was like breaking the rules when I was little. . . you're too scared, I couldn't do anything that bad. . I had to be at class and I had to finish my work....I don't give in to peer pressure, that doesn't mean much to me. . .but, they're still your friends; of course you would rather spend time with them, than do whatever it is that you're doing. ... All my girlfriends are really smart. . they all worked. . They all said "no" too, at some point. (IV, p. 22-23)

Mandy graduated magna cum laude; I asked her about internal facilitators that supported her success:

Wanting to learn, sort of knowing where I wanted to go, eventually, and knowing I had to get through this to get there, just trying to get the most out of everything that I went into, like all the classes and things like that. ... I guess, also, knowing I needed help to get there. And...being okay with that. . . . Being able to get help from Support Services because a lot of people come to college and don't want to, I did. (XXV, p. 6-7)

Ben was a plodder; he brushed aside any self-defeating thoughts about failure:

There's times that I thought maybe I wasn't cut out for college, even though I could make it, you fall down a little bit...It's just that "do or die." I'm here, I'm spending a lot of money to get an education, and I'm going to try my best, do my best, try to 
plug away...you can't stop. If you stop and just give up, you get nowhere....There's times I get loaded up in my classes, and I don't want go to classes: it's like "Nah, you have to go to class." You're here, so you might as well just get up, go to class, do your best, and if you fail, try again...don't give up. (XXVIII, p. 11-12)

Connie's long range goal of becoming a teacher outstripped any temptation to avoid doing the work for general studies classes that she considered uninteresting:

I have to [do the uninteresting work] because I want to become a teacher, to be successful in what I wanted to do since I was three years old. I have to push, no matter how much you don't like something you've got to do it. When you're in the class room, you're going to have many things that you don't like that you're going to have to do. So, you've just got to push and do it....And, I mean, it's hard. I'm not going to lie, it's hard to pay attention when you're in a class that just makes you want to fall asleep. (V, p. 15)

Alexandra was determined to wean herself away from accommodations and services after she completed her semester long internship in a large city.

Again it's an independence thing where like next semester, I'm not even going to do language tutoring for my learning disability....I'm doing everything mostly on my own, like me and my mentor are working, next semester, to get back to taking my tests in the classroom instead of the Testing Lab...being back to not having any accommodations and being able to do it without any help...Because once I'm working, my employer isn't going to be like “Oh well, I'll extend your time because of that." I want to be able to do it without my employer having to say "Oh well, she 
can't do this such as it is," I just want to be able to do it ... . I'm ready to try to start cutting back and doing things on my own. (XXVII, p. 2)

Darla described a gutsy determination:

I have drive....I finish all my work....I have to finish everything; I can’t just do something and not turn work in...I'll stay up all night until I know it, or I'll stay up all night to write a paper... as long as I get it done...or until I fall asleep....I'm not worried about sleeping, I can sleep later. As long as I get to know it [information for classes] or feel like I know some of it....But that's always been me, I'm not a big sleeper. (II, p. 8) I'm a hard worker, I don't like to give up on anything. . . I'm real competitive, so I don't like to give up and I don't. (II, p. 13) I know my strengths, I know my differences. I know what I need, I know what I don't need. And I'll say what I need and...that's actually one of the reasons why I came, because they [the support service] had everything that I needed. (II, p. 17)

Alexandra explained that her attitude makes a difference. I asked her about internal facilitators: I think just assuming that "I'm going to do well and make it through" not even questioning it...Being very positive about it. That's something I can't do all the time. . . but for the most part, that's it. (XXVII, p. 10)

Adversity brought out the fighter in Kelsey. Her persistence in overcoming her disabilities has proved to be a positive force:

My determination, my stubbornness, saying I will not quit, I will not fail, I will strive to do my best. I think I've had that since I was about one. (XVII, p. 14) The last thing that gave me difficulty was figuring out about getting and keeping a job in my future. And for a long time, I still think it too, I thought 'I'm never going to get a job. I have 
a learning disability. I have problems with my stomach...I'm going to get fired from my job, I'm going to move out on the street. I'm going to be poor." But there's another part of me that says "don't give up." I didn't give up when the doctors told my mom that I wasn't going walk or talk, but look at me right now, I'm walking and I'm talking...And then there were the doctors who told me I would never graduate from high school and go to college. Well, I proved that wrong, too. (XVII, p. 10) Julia's potential was questioned when she was a youngster. This doubt fueled her energy to achieve:

When they found my learning disability I was a freshman [in high school], they basically told my grandma "You need to start saving for her future because. . . it would be remarkable if she is even able to attend college...you might need to start thinking she's doomed to a minimum wage job, that she won't get any further, and put away a savings account or something, so that she can have a better life." One of my teachers actually told me that I would not make it into this College, and if I did, I'd transfer within the first year....One of my motivating factors was like "Watch me"...You give me the environment and I'm going to run. I've just never had the environment. A lot of the teachers had given up on me. The y never helped me out with school. They basically said "Oh, she's just there. There's no hope for her, and just passed me." Once I had teachers that cared about me, and actually tried harder with me I "flew" and worked very hard. In high school that's all I did. Anything that helped me out, academic wise, that's what I did. And, I didn't really care about social life because I had a one goal, get to college; next goal, graduate from college. Now, my grandma's trying to get me to think of graduate school. (XXIV, p. 1-2) 
Abbey felt pigeonholed by her family while she was growing up. For her, making it through college wasn't the issue, possibility was:

My dad always really wanted me to be an Education Major...I think the world of him, I don't think he meant it, but I really felt like that's all they thought I could do. Really I just did it [changed majors] to be stubborn. I didn't know what I wanted to do. It's not that I had something else in mind that I wanted to do besides being an Education Major. But, I didn't want to do it because I felt like they thought that was all I could do, and I just felt like "Well, I'll prove them wrong, then." Not that that's even right, because it's not as if there was some big, great thing that I wanted to do instead...I just didn't like the feeling that someone was like "Well, that's all you can do." I've had fun with it [the Public Relations major]...I enjoy it. . . it definitely wasn't easy...it wasn't the easy way out, necessarily. (IV, p. 11-12)

Abbey continued to create more possibility as she achieved success:

I would say this past semester, getting a 3.8, was like winning a Nobel Prize or something. That was really, really, really big, and I don't know that I would ever have thought about applying to grad school.... I was like 'I'm definitely not going back to school because that was never a happy place.” I didn't think I would want to continue to be in a classroom if I didn't have to. So, I guess that was the big turning point, and, you know, maybe I still won't, but it's something I'm not terrified of....Maybe I wouldn't get in, but, for some reason I have the confidence that it's at least worth applying, like I have a shot at it, or as much as the next person. (IV, p. 2324)

Connie worked through a different kind of adversity coming into her third year of college. She 
found a way to continue to be inspired by her father while trying to resolve the devastating effects of his sudden illness and tragic death:

He [my father] was such a successful teacher, and I'm going to be a teacher, too. So that is very helpful to go through my day and I know that he is watching down and wants me to do well. But then again, there's the nights when I know that when I call home my mom's going to answer because he can't. You know that you can't make memories with him and he won't be at graduation. ... Things like that are hard...to continue on with college but, you get past them eventually, you go to sleep. When you wake up in the morning, sometimes you're so depressed, sometimes you're not, but you go ahead with the next day...You just go through, I mean it's just like any other tragedy that's happened, you know, you have to go on. (V, p. 6) [My dad] gave me something else to work towards and somebody else to work for....That's one of the things I tell myself, just because he's not physically here....He's still going to be there at graduation, just not...I won't be able to see him. (V, p. 30-31)

\section{Practice}

The students described specific practices that facilitated their success. These processes enhanced not only their academic functioning but sustained their social and emotional well being to maintain a stable presence. Even though many of the descriptions of practice are seamless, I separated them out in terms of their individual-interactive focus.

Individual practice for academic well being. Students described individual study strategies that included drill and practice, overlearning, organizational planning, and the application of procedures taught through study skills instruction and language tutoring. Abbey used the strategy of retrieval practice: 
I had a hard time taking tests, a really difficult time...it was preparing for tests. I would have to make like a mock test. I would type things out and then read them, and read them, and read them, and quiz myself until I knew that I could pass my quiz. That was probably the only thing that really helped me. (IV, p. 16)

Ben acknowledged that the use of multiple sensory channels help him to understand and apply his course material. He described studying for his tests early enough to learn the information: I have to read things, and reread them, and reread them, because if I read it (once), it doesn't stick...I just have to plug away at it. Rereading it, and then trying to write it down, or taking notes and then, after taking notes, going into class, hearing the discussion, then, highlighting the points that the teacher thought were important...if you're not persistent, you don't get anywhere. (XXVIII, p. 7) Reading and writing it out, but then, usually I take it a couple more steps further, I'll read over the notes, and then whatever I don't really understand in the notes, or can't remember, then I write them on another set of notes, and giving it awhile, and then coming back to it, and then, rereading those notes and whatever I don't remember off that, condense down to another set of notes....If we went over stuff in class and they pointed to different readings that we had, I'll reread the chapters after reading them once more, to try to get it in there better. It's just a lot of reviewing, and not waiting until the day before the test, and then, just cramming it in there. Like a week or two ahead, (I) actually start practicing. (XXVIII, p. 8)

For Julia, organization came first:

Be organized first and everything else follows: organization is the key because you have to know what homework assignments you have, and you have them all written 
down in one area. Then you can get those homework assignments done in a more timely fashion. And just overall, like, reading strategies, like, highlighting, so you can find things. But, I really think if you're organized, studying comes from there. (XXIV, p. 7-8)

Abbey described how she learned to carve out enough study openings during her internal prime time so that she could adequately prepare for her classes:

I think it took me awhile to realize this, but I do a lot better in the afternoon. I can't look at my watch at 8 o'clock in the evening and be like "Okay, now I'm going to start my homework for tomorrow." I don't do that because that would stress me out to think that I only had a couple hours... or a few hours or to pull a "all-nighter" even...to finish something....I think I learned to manage my time... (If) I had a morning class and then I had a late afternoon class, I would love to take that whole afternoon and go the library and do what I had to do to get done....Tennis helped me with that, too, because we would go away for practically a whole week, in season, we'd be doing stuff all week. So you work, tennis, and then you could do something (fun), if you wanted to. That was the big thing I had to learn. (IV, p. 15-16)

In addition, Abbey illustrated how she integrated her school work into the weekend: I like to enjoy my weekend and not have to worry about it but honestly, I would, when I had time in the afternoon, like right now I have reading so, say I like was in my room right now, I would read throughout the weekend. Like when I wake up tomorrow morning, I'll read for a little bit. I like to do my actual work...I'll probably get up early on Sunday morning and do that until like late afternoon or early evening, and then, I could probably be done. (IV, p. 17) 
Connie explained how she applied strategies learned in the language tutoring program:

Well, when I first started doing the Visualizing -Verbalizing, I realized that I do picture things as I read them, but I just never put that into comprehension skills. Like it teaches you to remember, so that was really helpful. I had started taking my medication during the same year, so that kind of helps, too. But, it (the VisualizingVerbalizing) really has helped me and I still use it even though I don't really do my clinician time anymore, I still use that in my....in my daily reading....I visualize. And most of my books are education books so when you're reading, you can kind of picture yourself in the classroom and when they're saying "When you put a student in timeout, you're only supposed to do this"...I can picture myself doing that, which helps me because it helps me remember. (V, p. 12-13)

Interactive practice for academic well being. The students paid attention to the cues in the environment to learn how to study better. They were able to "go back to the drawing board" after failure, using specific feedback, via returned tests and papers, to improve academic performance. The students utilized the support services provided by the College. They intentionally interacted with their professors and members of their classes to stay in control of their school work. Ben described realizing that he would be required to work with the course material at more complex cognitive levels:

When I first came in, I didn't know what I was getting myself into. In high school, you just have to memorize things. But in college, they want you to memorize it, they also want you to interpret it, and that was really hard for me....I can write technical papers, but when it comes to writing like how I feel with something, or my standpoint...it was definitely something high school didn't prepare us totally for....I 
had to come here and almost...well, basically flunk a couple of tests, and be able to, actually, you know, feel it out, and see what they actually want, or are looking for. You were able to come back (from initial failure in the class) as long as you tried, it just took a lot more work....It showed you, if you wrote it this way, it wasn't the right way, so you have to try to do it this way. And then finally you kind of get the groove, or see what they grade for. So you do walk away with something. . . I've always said. "Even if I failed the test, I feel like I still walk away with something, I had to learn something in that time I that I had been sitting there (in class)." (XXVIII, p. 9-11)

Reading the text takes enormous amounts of time for Mandy, an honor student. She talked of learning the professors' teaching and testing style to economize on her study time:

Learning the professors, especially as you get up higher in [the major], you know what the professors want, and you know if you actually need to read the text book, or not, and what types of questions they're going to ask on tests. (XXV, p. 5)

Connie saved time by recognizing the professor's interpretation of important course material by listening for the cues:

One particular professor, when she lectures us, she says things like she made them up, but they're in the book, and we know that. So highlighting things that are in the book is the one big thing for me. Especially because she basically says it word for word and I know if she says something word for word from the book, then it's probably important. There's 62 paragraphs and if she says two of them out loud, that's got to be important if she chose those... Reading the teacher. (V, p. 18-19) 
Mandy acknowledged that actually making use of accommodations and services offered by the support service of the College was fundamental to her success:

Making use of the services available from the Support Services, like taking tests up here and using the notes to study for the tests. I would have note takers in most of my classes. And coming up here and talking with my advisor and going over classes if there were any problems, figuring out strategies for how we would talk to professors, what we could do if things weren't going well. (XXV, p. 5)

In addition to using services appropriate to her learning disability, Mandy emphasized the importance of checking with her instructors if she was unsure of an assignment. Taking notes on class lecture interfered with Mandy's comprehension of the course material. She relied heavily on her auditory processing strengths and used them to take in every word:

Strategies...talking to professors, if you don't know what's going on.... Not taking notes, for me. For me, if I was to write things down, I would miss everything that was going on at the time while I was writing it down, so I would draw, and make extensive doodles. Some professors objected to that until they got my test scores, and then they decided they didn't care anymore. But I definitely had professors give me some real strange looks because I appear sometimes to be paying absolutely no attention, and then I'm the only one who can answer any questions, and it kind of confuses them. ...I learn by listening. (XXV, p. 4)

Since she learned by listening, class attendance was an important strategy for Mandy:

Going to classes, not missing...Rarely, rarely would I ever miss a class. It would normally have to be that a friend was real sick and had to be taken to the hospital, then I would miss a class, but, other than that, I did not miss classes, which for me 
was a definite strategy, because I need to be able to hear everything, in order to remember it. (XXV, p. 5)

Kelsey listed several interactive strategies that contributed to her success:

I go to class everyday....I talk to my teachers, I do the homework, I take notes. I talk to [the counselor] sometimes. But, I haven't talked to [him] in about a year and a half. So, those are your basic strategies: stay connected with the teachers, go get help when you need it; go to class. (XVII, p. 12)

John learned to set priorities and networked to establish a milieu socially conducive to academic success. I asked him about his strategies for successful functioning:

Mainly managing my time, properly, like knowing what I need to do for my work, and finding friends that have the same class, or making friends in the same class to study with, knowing when you need to do your work, you know when you have assignments due, you have one another to make each other go to class. (VII, p. 5) I email my professors every once in a while just keep in touch with them to have that communication open, and kind of check in every once in a while to see if there's anything I can improve on. Sometimes I don't get responses until couple weeks later, until I ask them a couple times, but they usually give me good tips on what to do and to keep up the good work, or things like that....It's been pretty helpful. (VII, p. 8) Individual practice for social and emotional well being. The students worked on managing their thinking in order to replace their worst-fear perceptions. They stopped themselves if they were moving in an unproductive direction and talked to themselves strategically in order to manage stressful conditions brought on by academic work or social and emotional concerns. Mandy described how she has been able to claim a more balanced life since 
she adjusted her attitude about performance outcomes. In addition, she intentionally engaged in other activities that played to her talents to break from her demanding study schedule:

I normally thought I was doing worse in classes than I was and I got a lot of "As" I didn't think were going to be "As." I think it's better that way because then you're not surprised when you get an "A-" or "B+" or something. At some point you need to get over the fact that you're not going to get all good grades, and it doesn't really matter, because all classes are not equal in college. An " $\mathrm{A}$ " in one class could be a "C" in another, and you just have to realize that. And people that may look at your transcript aren't really going to care anyway. They won't know that that class was the hardest class you've ever taken in your entire life, and that's the only reason you got a "B" and you worked your butt off for that "B." You will know it, and you'll still get satisfaction, sometimes from those lower grades much more so than the higher grades. (XXV, p. 5) Also, probably, having something to do, besides [academic] working, so for me, playing tuba was a break. I had rehearsals everyday, it's an automatic study break, so is practicing. (XXV, p. 6-7)

Ben managed his angst about grades by shifting activities. He explained how he breaks from his academic work in order to problem solve with a fresh perspective, less mired in performance worry:

I find when I've got a lot on my plate, a lot of things on my mind about school, and I start thinking about grades. The best way that I found to get away from it, or to get it out of my mind is to maybe stop, take a break. I'll just go shoot some pool for a little bit, and try to get my mind off of school for an hour or two and then I come back and, it's like how some people scream sometimes, and then it's all out, you feel a lot 
better, and then you jump back into it. (XXVIII, p. 13-14) I'm just like "whoa, I got all this stuff to do, I can't handle this" or "I'm not going to finish it in time" and then I start stressing out. That's when I just have to get out of there, leave my room, or leave the library and just take a walk, then come back, and take a different angle at it....Go take a break, get out for a little bit, then come back to it, and then like you might think of a different way of doing something, or a better way of fixing the problem that you're having....It helps out. It really helps me a lot. (XXVIII, p. 13-14) Julia emphasized the importance of taking breaks to prevent exhaustion. She has learned to overcome the lure of continuing to work without pacing herself:

Knowing to take breaks, so you don't get burnt out, that's been really hard for me this semester. Because I just don't have time to take breaks. But, you have to, and you have to make the time to take those breaks, and realize that studying will come from there, and if you're burnt out, you're not going to study anyways. Otherwise you get too tired and you won't study when you actually have something new. Even though you really don't think you have the time, it's tough to make the time. You can [only] concentrate for a certain period of time, like your body just says "Uh, no." (XXIV, p. 8)

Connie described using self-talk to dissipate her anxiety over the academic work. She talks herself out of believing that she is unable to complete the work, an irrational idea which causes her great strain, and is able to identify the work for what it is, time consuming but not impossible. I asked her about her strategies she used to be successful:

Not getting too stressed out is one strategy. I'm not going to say that I'm not stressed out, because I am extremely stressed out, but if I keep telling myself "Well, this isn't 
that bad." Even though inside I may be very stressed out; if you keep telling yourself that you're not, you're going to start to believe it. It's like mind over matter. And when I start getting very, very frustrated, I, kind of, you know, tell myself "This is stupid. Why are you getting frustrated over this? This isn't hard." Because the work I have to do isn't hard, it's just a lot. I mean, some of it is difficult, but it's not like you have to rack your brain to come up with answers. It comes naturally. (V, p. 18) Connie offered another example of using self-talk to stay on the right motivational track. In addition, she writes in a journal to release some of her burdens:

I've always had the mindset to be a teacher, so like I said when I get things back that have "excellent" on them or something, I tell myself "you're doing a good job, you're really going to be a good teacher." So, talking to myself, not necessarily out loud, trying to say things that keep me positive to myself....Talking my way through things, especially with Dad dying, sitting in class and, you start to get depressed, you're just like "Snap out of it. You can do this at another time." You can start to focus...focus back on what you're learning about. Just talking myself through everything, like I said, not out loud, but just thinking about things that will help me....Even if I'm in a bad mood, I try to keep myself positive. It doesn't happen every day. Everybody has bad moods and yeah I have been depressed a lot more this year, but I try and save that for night time. Save that for a time when I'm not in front of my friends or just don't let it interfere with college. I've read that you're supposed to get your feelings out when you feel them. And I have a book that I write in. That's another thing that really helps me out, I don't know if that would be included in this but I write a lot...If I'm feeling something I get on my computer and I just write it. I 
try and get everything out. Or, you know, if I'm by myself, I will talk out loud...because it's almost like I'm talking to somebody even if there's nobody there to listen....That's one thing that really helps, whether it's about Dad, whether it's about friends, whether it's about school. That really... has helped me succeed, because if you keep all that in, you have a lot of problems. (V, p. 19-20) Sometimes students tell themselves they are not going to perform as well as they actually do. This way of thinking helps the student cope with expectations of the emotional effects of success and failure. Defensive pessimism (Garcia, 1995) refers to setting lower than expected goals to check angst in the case of failure. Connie illustrates this dynamic:

When I am taking tests. . . I aim lower than I know that I can actually get. . . it might even help me succeed because if I know the information on this test, I'll still be like "I hope I got a B" even though inside I know that hopefully I got a better grade than just a B. If I tell myself "I'm just shooting for a B," that way if I do get a lower grade, it doesn't bother me, because I'm like "Well, this is what you were shooting for." And if I get a higher grade, I'm psyched about it. (V, p. 23) Abbey reported feeling more confident in the classroom as her college education progressed. I asked her to explain what she meant when she said she was intimidated in the classroom during her first semesters. She has learned to manage her thinking in order to have a place in classroom discussions:

Always feeling like someone really smart is sitting behind me, and if I answer, they might laugh. Like I have a class now, and we're reading this really difficult book that I'm sure is over my head, but I'm not an idiot, I can read it and I could answer a question. I think, then, I thought "I don't understand, I'm reading it, but I could never 
raise my hand and say what I think this is about," if that makes sense. . . [Now I think] "Everyone else is reading it, I'm sure there's someone in here that's brilliant, that really knows what this is about, but, pretty much everyone is on the same page you're on. I've had as much education as everyone else here." I'm not the most outspoken person in every class but I'm not going to have an anxiety attack if I have to answer something. . . I'm sure there are moments that I'm unsure of myself, but not like a terrified anxiety feeling. (IV, p. 13-14)

Abbey continued to talk about her increased self-confidence:

The biggest thing for me is confidence, I think I used to have the mindset "not everyone's better than me," but that "I'm not as good as everyone else." So, I would say, not in a really confident way "I'm just as good as everyone else. I'm not better than everyone else, but I'm just as good as everyone else." So, that would be my success....I guess I wouldn't have thought that if I didn't, at some point, prove that I was just as good. (IV, p 17)

Gavin made a decision to cut down on the amount of alcohol he consumed to improve the quality of his life at school and because he is a leader in his fraternity. He has learned the connection between the amount of alcohol he uses and staying in control of his behavior. I asked him if he experienced anything like a turning point since he had been to college:

Whenever I decided that that whole drinking thing isn't that big of a deal, I can't put an exact time on it but, I don't remember that it's made me a better student, or anything, but it has changed me. Like I don't want to do that, it's a maturity thing, I think. . . Even last year, I didn't drink very often at all. (XXIII, p. 18-19) 
It doesn't appeal to me to be worthless the next day if I drink that much...Like Saturday, I was talking to my dad on the phone, and we had our big theme party on Saturday, expecting lots of people, and my dad said “Are you going to drink?" I said "No, I'm not." He said "Why not?" He tends to think that I drink more than I tell him I do, but I really don't drink that often. And I said "Well, I'm expecting that there'll be a fight tonight." I was like "There's going to be so many people at the fraternity house, and people are going to be so intoxicated, that it's inevitable." I feel it necessary to stay sober, so I can regulate, if I need to. . . . If something big were to go down, I'm on the exec board, and it is my responsibility. I love the responsibility. . . but, I'm tired of people doing stupid things when they're drunk. People tend to think it's okay, that they can do what they do when they're drunk because they're drunk. . that's ridiculous. (XXIII, p. 5) I would, personally, rather stay sober and drive one drunk person home than have them maybe walk home and have something happen to them in town or get a "public intox" or heaven forbid, they drive home. I would rather prevent that. (XXIII, p. 11-12)

Interactive practice for social and emotional well being. The students intentionally participated in nonacademic activities for release and relaxation and sought social and emotional support from others. Some talked with the campus counselor as a way of coping with the difficulties they encountered and to increase personal stability. Connie joined a sorority the semester after her father died:

Joining sorority, that was nice. I wanted to because I wanted to meet more people. That's just this semester...It already has been rewarding because I have people that 
care for me, my "big" [sister], anytime I need anything... and the other girls that were in my sorority, they're just there for me and I like that. (V, p. 13)

Darla's participation in a varsity sport was time consuming and viewed to be an academic barrier by some of her friends and instructors. However, she believed that this involvement coupled with taking part in sorority kept her stable. Both activities offered stress relief and a place of full competence:

This year $\left[5^{\text {th }}\right.$ year without swimming], I've done so much better in my classes. My art has been so much better... because I like my projects. Before, it was "Let's just get it done." But...I would never have given up swimming or sorority... I was able to balance it out.... I mean, people think "Oh, how you could have? You could have done better!" but I wouldn't give it up. . . because swimming has nothing to do with learning disabilities. And sorority gives you ano ther group of friends too. . . . Swimming for me, I think a lot of times it gave me a break from thinking about doing my other work; I got away from doing it, and then it's also like you can blow off steam. (II, p. 3-4)

Since Ben did not gravitate to the fraternities for friendship, he worked to find friends with similar hobbies and interests:

I have different sets of friends that I hang out with all the time, but I guess since it's a smaller college, most of the kids automatically go and join the fraternities or the sororities, and I'm just not into the big fraternity-sorority thing. I think it makes it a little bit harder, because, if you don't go into a fraternity you don't make the friendship bonds, in the sense of having to do the stuff in a fraternity. But I don't think it really hinders me that much. Whatever field or things you like to do, you start 
to learn [about] people that like to do the same things. You can make friends that way...or just activities that you do on campus, or off campus, you usually find people that like to do similar things....I go up to [the lake] a lot of times, or I'll go out to different wilderness areas around here to walk around and take pictures....And then there are kids that like to play pool a lot, so, we go down there and play pool....Even though it's a small school, you still find people...even though you're out of the fraternities. (XXVIII, p. 4-5)

Mandy adopted a family who lived in the town of the College. This strategy helped her gain social and emotional stability during her transition:

Another strategy would probably be like...because I was so far from home, finding a family that sort of adopts you, and at a small college, that's really good, and the s really took me in, especially Freshman year. So having a family away from home was definitely something that kept me together when I didn't have a family at home to really go to. (XXV, p. 5)

Mandy described her shift in willingness to open herself to others and to seek social and emotional support:

Fall semester my Junior year, that's sort of when the whole grade mentality changed, and, also, when I first started to be willing to accept more emotional support and help from other people. Because, before, I tried to do everything on my own and it just sort of killed me, so that really helped....For me, I definitely became more emotionally stable and much happier after I did that, and was willing to get the help. Then, like a couple months later in second semester is when I got involved with [my boyfriend] in a serious dating relationship. . . it was good for both of us because we 
are able to support each other. That definitely helped me, to have someone who you can tell everything. And I had some very good roommates who I was really close to, too. $(\mathrm{XXV}, \mathrm{p} .11)$

Alexandra described the changes she made to adapt to the college environment. Even though it seemed counterintuitive to her at the time, she forced herself to move out of her "study mode" to participate in nonacademic activities and to seek support for emotional change and academic assistance:

I think second semester my freshman year was [a turning point]. First semester I went home, I didn't want to be here, everything was falling apart, my grades...like I had Cs in a lot of stuff; in my mind I was failing out. And then I think I went from that, to second semester, I went to like a 3.7. That's when I started actually going out and doing extracurricular stuff, and so I think that's really when I sort of turned everything around....I started language tutoring, I was in counseling...I think it's really the combination of both of those. Between the counseling and doing the extra activities, I think just getting at the stress and anxiety, that made everything else better. (XXVII, p. 17)

\section{External Facilitators for Successful Performance}

The students described two broad sources of external facilitation for successful performance: defined and informal support structures and general environmental and individual systemic qualities. Support systems included the faculty and academic department, the special support service, the special support mentor, the family, and peers. General environmental qualities which made a difference to the students surfaced from the small community atmosphere which presented the opportunity to become involved and to establish a sense of belonging on 
campus. Individual systemic qualities were defined by the character of the faculty members, professional staff on the campus, and other helpers in the students' lives. Exemplary helpers trusted in student potential and were described to be authentic, available, and optimistic. The students reported that effective helpers required the student to self-reflect and encouraged the student to develop independence.

\section{Support Systems}

Support systems described by the students included the academic department and teaching faculty, the individualized support system struc tured to fit the individual needs of students with learning disabilities, the mentor who specializes in working with students with learning disabilities, the student's family, and peer support networks.

Faculty and departmental support. The students verbalized the importance of interacting with the teaching faculty. They were encouraged by constructive and supportive comments from their professors. In addition, faculty observations of concern when things were not going well were taken to heart by the stud ents. The students believed they were enriched by responding to the rigorous academic requirements of their coursework and curricula. They valued their professors' expertise and enthusiasm in their teaching discipline. Departmental teaching practices and policies that supported the student learning process were favorably acknowledged. The students appreciated internship opportunities which provided the occasion to apply academic knowledge to the work-field of the discipline. On the whole, the students viewed the relationship with their faculty as primary in that it opened a path for personal and professional enrichment. Ben is struck by the intelligence, openness, and support the faculty in his department display: The best part of being here? I'd say finding the Physics teachers that we have here. They teach it in a sense that you can actually grasp....It's just amazing, because half 
the stuff in the Physics Department, they built themselves. It's phenomenal that you've got these great minds...You learn a lot from it, you've just got to look there, and find it....It's more on a personal level with them, they like to joke around with you, they're really friendly, you can always knock on their door. (XXVIII, p. 5) They always try to show you, if you don't want to go to grad school, you can get good jobs that are opening up, for, like someone who wants to be a geophysicist, or new fields that are opening up. (XXVIII, p. 12-13)

In addition, Ben appreciated the structured practice that is built into his major coursework: Also, one of the things with my major that really helps "lay down the tracks" is you do all the homework, so it's in...It's like when you learn something that takes a lot of practice, and the fact that you go over it in class, and we do examples of how to do things, and then you go to the homework. I lay the track that way, so by the time it comes to study for the test, I don't have to lay down [new tracks]... because I've already done it twice or three times in class and out of class. (XXVIII, p. 9)

Mandy appreciated the gains she made as a result of the strong challenge her music classes presented:

For like Music Theory, for me going through it, and even though it was really hard and I failed dictation almost every time, I still enjoyed it, and went back for more...It was the classes where I didn't feel like I learned anything where I couldn't stand them, and didn't want to go, and didn't want to do the work. So I really enjoyed the hard classes and the teachers that challenged me in them, where you actually learned things. (XXV, p. 2-3) 
Alexandra thrived knowing her academic advisor believed in her capabilities; she lived up to the high expectations held for her. I asked her about external facilitators to success while she was a student:

I think Dr. was one of them [external facilitators of success]...She's my Academic Advisor. And I think because she expected so much out of me that I had to do well. When I was signing up for classes she wouldn't even take into consideration my learning disability, she looked at it just as, I want to go to grad school, this is what I want, she's like "You need Statistics, you need this." So I think really, she pushed and made me do it...I think for me that really worked...for some people, not taking into consideration the disability could be a problem. (XXVII, p. 12-13) Dr. had confidence in me and believed in me, [she] kind of pushes me further than where I am. (XXVII, p. 14-15)

Connie was encouraged by supportive feedback from her professors:

I have my professors who give me my work back and they say "excellent." I know that's something that, professors write on papers...but it makes me feel like, well maybe she is being serious. Maybe I did do an excellent job and you know I have professors pull me aside and say "Have you done this before?" or something like that; it makes me feel good because it makes me feel like I'm going to be a successful teacher...It's just nice to have somebody in your ear telling you that you're doing a good job, even if it's not verbally, it's just through [nonverbal] signals or written comments ... It's good to have that. It helps you. (V, p. 12)

Julia's professors were open to helping her with academic assignments: 
All the professors are always helpful and willing if you go in and talk to them.

Everyone's very nice, and that's what I thought when I first came here, and it's continued to be true.... The professors are very willing to help you out if you make the first step, and ask for help. (XXIV, p. 4)

In addition, Julia's professors helped her navigate her response when she ran into trouble in one of the classes required by her major. I asked her if she could think of any barriers encountered as she progressed through the college environment:

I think of getting bad grades and that slowing me down...For awhile, it was bringing me down like "maybe I really can't do this," but then, people encouraged me to just keep trying and that if I just keep trying somehow I will succeed in the major and to not give it up. That one class, Principles and Practice in Public Relations is hard for a reason...one professor said “Just keep trying, I don't think you need to give up, I just think you need to learn some skills that you will learn in this class. I don't think it's that this major is the wrong major, I just think that you don't have some skills that other students have." (XXIV, p. 11)

When professors take the time and energy to show students how they can improve their performance, when they are genuinely concerned, students respond:

I would say one thing that does pop into my head with that is maybe not necessarily a way of studying, but, the way a teacher teaches, maybe. Dr. I think he is a great professor, he's a hard professor, and he's so brilliant, it hurts my head. But, at the same time, whenever I took him for U.S. History, I didn't do well on that first test. But that little bit of "Gavin, you need to talk to me after class about this test. Okay, talk to me. How are you studying, what can we do?" I definitely, studied 
differently than I ever have for that class, and it pushed me....If I'm not doing well, and a professor is taking a personal interest in me, they're saying "What's going on...why, why, why?" For me, I'd better step it up...And, I mean, he's a hard professor, but I'd take his class again. (XXIII, p. 12-13)

Initially, John was bothered that one of his professors asked him to think about whether he really wanted to stay in the Art major. This challenge became a motivating force in John's developing a stronger work ethic:

I'd say the most frustrating [experience] was my freshman year in my art classes because it was just the core classes and they're pretty tough on you down there. I actually had one of [my professors] tell me to think about changing my major. Just to see what I'd do about it, I think, but, hearing someone say that made me think really hard about what I wanted to do. I actually stuck with it and it's paid off, so far. (VII, p. 3) I think it was a good incident that happened because it let me know that I needed to really work hard at everything, and just put my all into everything....At the time, I was rather ticked off and confused, but now, a couple of years later, I think back to then, I think it was really good. (VII, p. 4)

Theory turned into practice for Alexandra as she interned in the public relations area: It's not as dramatic, but, I see a big difference in myself since I went to DC. . . .It wasn't like things were bad before, but I think things got even better. . . .I was finally to the point where I was really at full independence. . . I'm happy with myself about it, just because it turned out so well. I think prior to going, I was worried and afraid: "What if I really can't do what they want me to do? Am I really going to be able to meet the expectations of all these other people?" And I think I was able to see that I 
actually am able to do it. ...I learned how to do a press release, but can I really do one... . Now I'm at the point I don't want to be here, I want to be graduated and out working now... I'm kind of past wanting to be the student. (XXVII, p. 17-19)

John's confidence was boosted when a piece of his artwork was recognized by a campus magazine sponsored by his academic department:

I'd say one of the more rewarding things was I submitted one of my pieces of artwork into the [campus literature and art magazine] and actually won the Graphic Design Award. And that was nice to know that I'm actually doing something that people like, and think is good. (VII, p. 2)

Julia emphasized the importance of faculty attitudes in the student deciding whether or not to use accommodations and services:

The other thing that I can think of that's like maybe educating new professors, as they come in...because professors' perceptions have a lot to do with if someone will try to get the help that they need, and to succeed, you need to use the help up here.... All my professors are very accepting of it, and even my professors that are new this year are accepting of it. (XXIV, p. 19)

John discussed the importance of establishing cooperation between the support system for students with learning disabilities and the teaching faculty. He believed that setting up and communicating clear guidelines for using the support services enabled him to use the service in an independent fashion. I asked him what more we could do to respond to the needs of the students in our program:

I think it's pretty good how it is now. I mean, we all have our own advisors here, and all of the professors on campus are aware of the program. I think it doesn't even 
matter if there's a student with a learning disability or not in the class. I know a lot of mine [professors] have said if you have testing requirements for the Testing Lab, to go and talk to them [lab staff]. And just having them [faculty] say that, and having our [accommodation] letter, it's just been pretty easy...Just to be able to understand how to do things, and how [this support service] works. It was good to know, and I think it helped me to become more independent, and understand how I needed to do things for myself. (VII, p. 14-15)

Special support services. The students appreciated the availability, scope, and depth of the support services offered by the College. It was their safety net. The students commented on the importance of the staff response to the individual needs of the student. Most of the students who were enrolled in the language tutoring program mentioned the positive difference this program made in their academic performance. Julia attributed her success to the support services and her academic program:

One reason I came here was the learning disabilities program, and I think it has helped me meet where I want to be of becoming independent from that. And I think just the college in general, I mean, from academic major standpoint, I think I'll be prepared...I've learned stuff I can actually use on a job. (XXVII, p. 3)

Abbey learned how to learn and to compensate for her weaknesses through her work with the support program:

I'm not saying this just because of this [interview], but, I think this program meant a lot more to me than the campus as a whole, education wise. That was a huge part... And my parents will say it until they're blue in the face; they attribute so much of how I've done to this program....And just the people, you know, just knowing 
there's a backup...Maybe a confidence builder, too, because after my first semester, I really had struggled and I was playing tennis, and doing all that, but with classes specifically, I was struggling. And I hadn't even been tested, or I wasn't in the program at all. And then, over Christmas, I was tested at __ , and I came back to school, and entered into the program....it was a huge difference...knowing that you could count on someone... someone that understood that you didn't just not do your homework last night, or something, for the fun of it. You know, you really do struggle, and, you have a reason. (IV, p. 4-6)

Ben compared the support program to a safety net:

It's kind of mostly like a net under you so you feel like if you do fall or you do have a problem...you've always got this net to catch you.....because if you didn't have some place to get help, you're always scared of hitting the ground. That's not the best thing...like if somebody's thinking about it, because if they feel that there's no net, then if they hit the ground, it's over with, game over, so they'll maybe get even more nervous. It's really helpful sometimes. Because with me, taking tests when I'm in the classroom, I have that always in my mind: I have 50 minutes, I have 49 minutes, I have 48 minutes, I have 47 minutes, and I forget about the test. Just being able to come in to the testing lab gets it [worry about time] out of my mind. (XXVIII, p. 1516) Academic wise, you come into the Testing Lab and being able to take tests and get notes if I need the notes [note taker], that's one of the main things that really helps me out. (XXVIII, p. 15)

Julia, like Ben, described being able to focus on the test rather than the time limit when she used the accommodation of extended time in the test lab: 
The Support Center gave me the testing environment to be able to achieve, and succeed on a test... It wasn't that I can't do the test...Like the testing center gives you the environment to succeed on a test... I need to know there's not a time constraint because if I know there's a time constraint there, then forget it, I'm going to worry about the time constraint, and not about the test. (MQ, p. 12)

John selectively used the test lab:

Having the ability to take tests up here in the Learning Center. . . (In) my $20^{\text {th }}$ Century Art class, I'd see other kids finishing real fast, and they'd distract me, and being able to come up here, and go at my own pace has been helpful. . . I've tried it with other classes but I find sometimes that staying in class is a little more helpful than coming up here all the time just because you can always ask the professor questions. (VII, p. 10)

Julia described her appreciation of the how the support staff responds to the individual needs of the students:

Like say the professor's kind of leery about letting me...not knowing how to deal with a pop quiz or whatever. We figure out well, the professor can e-mail the test lab, then I won't know about it, and I can still get the testing accommodations I need. Or like when I was using Kurzweil [text-to-voice software], but I couldn't really use it up here [in the Center], because there wasn't enough time in my day to get up here during the open hours, it's now in the library. So, like, they're really good about working out the kinks of a barrier.....they're like well "let's figure out a way to blow it up and make it not there."(XXIV, p. 15-16)

Julia enrolled in the clinical language tutoring program: 
I picked this campus because of the support services, knowing that I was going to need help, and probably pretty decent help my first year, and hopefully be able to wean myself off....I think if it wasn't for language tutoring, I wouldn't be as successful...They helped develop my reading comprehension skills which allowed me to better understand my textbooks and to be able to actually perform as well as I did on tests. Before I was getting Cs, but now I'm back up to As and Bs on tests. They basically gave me the academic skills to succeed. . . . I comprehend higher levels of text, and, my grammar and writing skills have gotten better. (XXIV, p. 4) Abbey described how she benefited from the language tutoring program:

Working with people [in language tutoring] one-on-one with specific work, and with them saying, "You're right!" Like me second guessing myself. Say we would read something, and I know that seems really little, and not really specific, but a lot of what bothers me is being unsure of myself, it was more of a confidence thing. . . And not having any choice, no one else is going to answer. I'm the one in the one-on-one with the answer and they're saying "Well, you can say that, you're right." (IV, p. 6) That [the language tutoring program] made probably the biggest difference in me and my experiences here...the fact that they know me, they're talking to me. . . they know how to explain things to me that would best help me. (IV, p. 20)

Kelsey also realized the benefit of her connection with the language tutors:

[The language tutoring] helped. ...it helped me understand the homework, the readings. It helped me take better notes, to determine what to write down and what not to write down...to put information into my memory. (XVII, p. 13)

Alexandra appreciated the way her mentor introduced her to the support services: 
My mentor, she sort of like, step by step, my freshman year [said] "Here's what we can offer you, maybe you should take advantage of this more." And it was the same with language tutoring, one of my problems, like I have a short term memory disorder, so they [worked with] symbol imagery. I can tell it has really helped my memory disorder. Like it has helped my spelling, I can now check my own papers, because they taught me grammar. I really didn't learn, or pick up grammar at all when I was in [elementary and high] school. I didn't use commas when I came to college. Now I completely do my own papers and edit other people's papers ....When I first came here, I wasn't used to accommodations, I didn't want to use anything. She [my mentor] kind of slowly, step by step got me to actually take advantage and use the testing lab and readers and note takers. The note takers is another thing, like at first I could use them, and see what peoples' notes were and then that enabled me; now I don't use them, I can take my own notes. . . and I could see this is a format people can use for their notes, that's the kind of thing I need to be jotting down. (XXVII, p. 3-4)

Mentor support. The mentor was viewed as an anchor to most of the students interviewed. Students enrolled in the support program worked with the mentor to balance their academic schedule, to develop academic, organizational, and self-monitoring strategies, to talk about priorities and motivational outlook, to assess the need for accommodations and services, to practice disclosing their learning disability to their professors, to connect to services within the program support system, to link with other campus offices for extra-curricular referral and support, and to process events that occur which impact the student's college experience. Ben 
worked with his mentor to resolve the inevitable problems that surfaced during his college experience:

Especially like when I had the problem with my Calculus teacher on getting extra time. Coming here and talking and being able to just try to get advice, then to go back to the teacher and try to talk it out with the teacher to figure out what to do or how to handle it, like resolve the situation, has really helped. Just being able to talk, to go to [my mentor] and be able to sit there and tell him how things are going or if I'm having problems with different things....It's good being able to talk about stuff....Because I feel that sometimes things get bottled up. Sometimes you have stuff that you try to resolve and you think about it yourself but when you go and talk to somebody, you get different angles or different ways to approach things, and it also gets it off your chest. It frees your mind up a little bit. (XXVIII, p. 15)

Julia used the help of her mentor to make the transition to college: Just knowing that [my mentor] is there, if I need anything, like... knowing she's there if I'm running into problems with the professor not wanting to give me certain support. She was mostly really useful for my first year, and then like after that, it's just a mindset of knowing she's there, and will help you advocate if you run into trouble. . . I don't need the confidence of her [saying] "Oh yes, that's good, how about we try this?" (XXIV, p. 12-13)

Connie emphasized the importance of the mentoring relationship for first year students:

Especially for freshman who have never been away from their parents this long before need, I don't want to say a mother or father figure, but somebody who treats them like they do care about them. I don't think it always has to be about school. I 
don't think that success is always about that, I think success is inside of you, too, not always about showing it in your grades. . . having somebody that will talk to you about anything. Some people just need an authority figure to talk to. I know our mindset is always "Well, they're older so they know more than us." Just giving advice and being there, I think, is a big part of succeeding, especially with students with learning disabilities. A lot of times, like I know when I was frustrated I just wanted to scream because I didn't know what was the matter with me. I didn't know why I couldn't get this work done successfully. . . . When you have somebody to talk to about it who understands what's going on with you, it's so much easier than just talking to somebody else. I mean you guys being here is big help for anybody with a learning disability, I think....I was so much more, I guess you would say, angry my freshman year when I couldn't do things or when something bad would happen because I didn't really have anybody to talk to. So, when I came here last year and I had my mentor and language processing tutor, everything like that helped me and I was less angry. (V, p. 33)

Alexandra believed that her adjustment to college was facilitated by the relationship with her mentor from the support program:

I think it was just mostly kind of the adjustment. . . .I think that was accepting the help, and just asking for it. Always before, if I asked for it, well I didn't get it, so, that didn't make me want to ask for help at that point... The more I met with my mentor... like once a week, that would really help me because, she was able [to ask] "How are things going?" I had no choice but to tell her, when ordinarily, I don't think that I would have. With me, getting used to being there with the help, was really 
helpful.... It also forced me to be up here [in the Center] and get to know the other people who worked here. (XXVII, p. 6-7 I think when I first came in she was the only person that I knew, and I could go to her, and say "Okay, I need to do this, how do I do this? Where do I go?" She sent you to the right places, she helped me figure out "Well this is how to talk to your professors." She was someone there to lead me to somewhere else. (XXVII, p. 13)

Abbey trusted her mentor for academic advising, support, and guidance:

Yeah, I always came up here and it was reassuring to me. [My mentor] would ask me about a test or my class. It was reassuring to me because I'm making these [academic] schedules and I don't know what I'm doing. She made sure that I was on the right track; it's scary to me, graduating. My mom was like "Now, did someone sign something, are you really going to graduate?" I'm like "She wouldn't let that happen, I know I'm going to graduate." (IV, p. 9)

Family support. The students appreciated their parents' understanding of their unique needs for making a successful transition and finishing the degree. Many of the parents made sure their students understood that it was acceptable to take an extra semester or more to complete the degree. Students described that their parents' intentionally held back from imparting advice to encourage them to work with their mentor in the support program. Communication of high expectations instilled confidence. Parental support and understanding when things did not go well communicated a tone of acceptance that was appreciated by the student. Alexandra's mother held back advice so that Alex would have to make the connection with her mentor on campus: My parents, they're not on campus, but. . . they would always at least be there to be like "Okay, so now, do you not think it's time that you should go tell your mentor 
this?" Because at first I would tell them, for example, [they would say]: "Well no, that's what you need to tell your Advisor" At first it was Mom who I always went to, Mom solves the problems... and now Mom was telling me "You need to go do this instead." So, I'm like "No, I want the answer, and I want it now." Looking back, I'm very glad for it.... I think it goes back to the independence, I know I can do it. Now I'm very comfortable with my mentor. I've done this so much that I don't have any problem going, talking to people, where, if not, I probably would have just stayed clung to Mom. (XXVII, p. 13-14)

Ben acknowledged that he has been motivated by his parents' support:

I've got to make my parents proud. I ended up having to go extra years in high school, they put a lot into me, and it's like I want to show them that I can succeed. My old high school said I wasn't going to be able to go to college. I want to show them that I can graduate from college with good grades and maybe go on more. (XXVIII, p. 12) My parents keep on telling me "If you need any extra semester, an extra year, take it." They want me to do good, so they say "If you can do better by taking a couple of less classes, then, do it." (XXVIII, p. 23)

Julia worried about the cost of her education and cited this concern as an internal barrier which occupied her thinking. She was grateful for her grandmother's perspective: the right educational environment ranked above other financial needs of the family:

I felt guilty, like “Maybe I really shouldn't be here, maybe I should have found somewhere less expensive. Grandma's picking up a lot of the bill, maybe I should go back home, and be somewhere where it's less money, can Grandma really afford this?" So, I was just asking all those questions to myself. . . .My Grandma told me 
"Absolutely no." She said "Stop feeling that way, you're succeeding there, and that's where you need to be, we'll figure out a way to make it work. Don't worry about it.” She always told me, finances are not my thing to worry about. The thing for me is to get those good grades; succeed academically and personally. And then, the finances will come somehow. (XXIV, p. 10)

Gavin was grateful that his parents stopped monitoring his academic functioning:

My parents do their best not to push me. They know from trying to push me in high school that if they try too hard it's a reverse effect. The more they push, the more I don't want to do it. That's how it was in high school. So, they don't ask often, I try to tell them stuff [about how I am doing] every now and then. XXIII, p. 15)

John admitted that he allowed parental expectations to influence his work habits. I asked him if he could tell me about external facilitators to his successful functioning:

Knowing that my parents expect me to do well and try and at least get a 3.0 every semester. That's really been in my mind ever since I started college, and knowing that I have that to shoot for, knowing that they expect it has helped drive me to probably do better than I would have...I mean my parents always say I can do better, and they expect nothing less than a 3.0, so, when I know I'm doing bad, it's kind of like I know I need to step it up a little bit....They'll get off my back, and then...it'll be a little bit easier on me. (VII, p. 6)

Abbey described the relationship between her achievement and feeling unconditionally supported by her parents. I asked her about external facilitators for her success:

My parents really, no matter what I do, are really proud of what I did. . . maybe knowing that they were, you know, still happy with me....I wouldn't want to 
disappoint them. (IV, p. 18) I can do the dumbest thing ever, and they would be like "That's great." (IV, p. 20)

Connie emphasized the connection between functioning well and the support she has received from her family and friends:

Support is always a big thing. . . . It was always my parents and I have really good friends, too, from home and here, that are there when I need them. (V, p. 3) Having my mother there to support me, having my father previously there to support me. . my brothers, my aunt, even my godmother. I have so many people at home, even friends that just call to make sure I'm doing well in school. I think, support from friendship and family is important to succeed in anything. I'm not just saying it, I really feel it; I've always felt that way. (V, p. 19)

Peer support. Peer support systems were viewed by the students as beneficial. Students who were enrolled in the same major supported one another. Affiliation with a fraternity, sorority, or a sports team enhanced the student sense of belonging and importance to the campus. Both affiliations valued academic success and supported effective functioning. Peer mentors from the support program were perceived as a significant source external support. Finally, informal friendships facilitated student stability. Mandy cited the support she has received and has given to students who are enrolled in the same academic major:

That's another part that's hard with those General Studies classes. Your freshman year, if you don't know those professors, and they don't know you, you don't get any slack and you don't have any clues for how you're going to get through it. . . In the Education Department, there's a lot of help in between the years like with the General Ed classes that have to be taken. People share strategies and tips on how 
professors test, and what they should take notes on. That's really helpful, which a lot of people look at when making their schedules: what types of professors they want to take. (XXV, p. 5) The Music Department was its own support group because we were all going through the same tortures, the same experiences together, and failing the same classes; you form support groups within your major. The Special Ed [major] students had their own group in the Education Department. There's always students from the year before, at least, sometimes two years before and students below you, like as you get up, you all support each other, and then you kind of move into that role of supporting other people. ... "Yes, you do live through these experiences, even though you don't think you're going to right now." [They] can understand the jokes and the pain that you're suffering through, and will help you out. (XXV, p. 9-10)

John explained the support he was able to draw from affiliation with his fraternity. His brothers modeled academic success:

Well, for me, being in a fraternity has been really helpful, just having the group of guys that are there for you for anything. (VII, p. 3) I'd say some of the fraternity brothers, I see how well they can do and knowing they can do well and live in the house and live with all those distractions and still get like a 4.0, that it's possible that I can, too, as long as I work hard. Knowing that it's possible just from seeing them succeed is kind of a support. (VII, p. 10)

Joining a fraternity also contributed to John's sense of belonging on campus:

Going through pledging, and being done with that was a sense of accomplishment, and knowing that I will not have to go through that ever again was definitely a good 
feeling, and something I was really glad I did...Knowing that that group of guys, we've all done the same things with pledging and it just brings us all together, and because we know no one else is like us, it kind of creates a small unit, and we all see each other as brothers, we all joke around...I mean all of us would do anything for anyone else, and it's nice to know you can ask anyone of them for anything, pretty much. (VII, p. 13)

Darla relied on her informal network of friends for moral support and academic assistance: My friends have also been a factor... a good factor. There's certain friends you can trust or roommates in college who have helped you, like correct papers and stuff like that...If they're a true friend, they're not going to judge you. All my high school friends were honor students. So, they were always willing to help me. They still do, I'll read something wrong, they're like "No," they'll tell me. (II, 14-15)

Mandy was a peer mentor for the support program's orientation. She made the recommendation that student mentors have more contact with the first year students:

It would be helpful to do more with the peer mentoring, like, we have the day when they [first year students] first come for orientation, but it would probably be good to have another meeting a week later. Because that first day, they're being overwhelmed with everything, and they don't really care. But, after a week, they know some people, they know their way around campus, they've had some classes, and it might be helpful to meet again, with the same students. I don't know how you could arrange time for things like that, but, if you could, I think that would help. They would be able to ask better questions, and maybe listen to the same advice, again, and actually hear some of it. (XXV, p. 12) 
Kelsey benefited from her affiliation with her service sorority:

I have met people, just like me, who. . . want to do service, devote their lives to God. So the common answer to what do you like most about [the service sorority] is the sisterhood. I feel like I have like thirty sisters. . . because in high school...I did not feel like it was a family. There were people who still made fun of me. . . and it was terrible for me. .. .I've even felt a part of [this town] sometimes...its amazing how everybody knows everybody else here. (XVII, p. 7)

Participation in a varsity sport tied Darla into the campus and helped her establish structure for study:

This year I sleep a lot, because I have free time...But, I like having structure. I liked having swimming, it's a difference when you're not swimming, you just don't have the discipline. Like, you're in a schedule, it's nice, you know what you have to do every day. And it makes a difference because when you're not swimming in the spring some people are like "Wow!" I have to say to myself like "Okay I got to go do this, and do that" but with swimming you just had a routine. You do this, you do that, and then you go do work. . . it was a factor, I think. (II, p. 3) Without swimming, I don't think I would have been as happy, because [the swimmers] were my best friends....I think that's why a lot students do sororities; they want to be involved. . . it gives you a place to be. . . having close friends. . . and also, you know a lot when you're in a lot of different groups, you get to know the way that campus works; if you're at a bigger school, you don't really see that. (II, p. 5-6) 


\section{Qualitative Factors Supporting Success}

The students described environmental and individual qualities that promoted their success. Qualitative factors described by the students resided in the feel of the campus and in the qualities of the exemplary helpers they described. When the institution sets a tone of acceptance and connection from the beginning of the student partnership, an atmosphere of affiliation is generated.

Qualities of the college environment. The students noted various other external factors that facilitated their success in addition to the departmental faculty, the support service, their mentor, family, and peers. They reflected that there was a general feeling of acceptance and a sense of community on the campus which promoted their welfare. Opportunity to be involved in various activities and organizations promoted the experience of belongingness and campus ownership. When John began to feel "at home" on campus, his grades improved:

It was at that point when [this College] started to feel more home to me than my actual home, and I often now find myself saying "I'm going home to , not really thinking about what I'm saying. I really succeeded that year with my grades, just being comfortable...I think that was the turning point. . . it was more like "I like being here" and it just kind of flowed into doing well, and not really thinking about where I was at, or what I was doing. (VII, p. 12)

Mandy commented on how the friendly campus environment and the opportunities to become involved contributed to her success:

It's been a very friendly environment and I've gotten a lot of help from the support services here. The professors have been really good, a few exceptions, but there's always a few exceptions. [I have been] able to succeed in a lot of different 
organizations and activities and be involved. There's definitely fun things to be involved with, in all different areas. And then there's music...the music staff and faculty were definitely wonderful, and I enjoyed my experiences with them....Students are very friendly and make friends easily. People smile at each other around campus. (XXV, p. 2) People on campus are really good about getting involved with kids in the community. ... That's been real fun, being able to be part of that with multiple groups, throughout the years, doing things with the community. (XXV, p. 3)

Kelsey felt welcomed on the campus from the beginning:

It was small and now that I look back at my decisions, if I picked a large campus, it would be kind of rough, there wouldn't really be a student support program as good as this one, because it's small and it's basically one-on-one. I wouldn't really know my teachers if it were a large campus because the teachers would have like 500 students per class. . . . I felt that I was welcomed here, even my first day being a freshman. And I remember the first week of being a freshman, all my fears were gone. I wasn't even homesick.... I felt a little bit of interconnectedness.... I belonged. (XVII, p. 5-6)

John conveyed that he has been more comfortable communicating with his professors because of the small size of the classes:

It's a small school which I know is a turn-off to a lot of people when they think about college, but I find it to be more personal. That helps me a lot with getting to know my professors, that sort of thing....It's helpful to me, it makes me less intimidated to go talk to them if I have a problem, or am struggling in a class. And they, sometimes, 
will just e-mail me, if they think I need to do something and, I know, that is something you don't really see at a big school so much, just from what I've heard from my friends. (VII, p. 1-2)

Abbey related the personal atmosphere of the campus to her success:

I don't think I would have done well on a huge campus.... I like being comfortable with, and especially in my major, being in classes with people I know very well, simply from classes and working together. .. having the same teachers over and over again, and knowing them well, them knowing me. (IV, p. 7)

Individual qualities of exemplary helpers. The participants defined attributes of faculty members, campus professional staff, and other helpers that promoted their success. Exemplary helpers trusted in student potential. They were authentic, available, and optimistic. The effective helping relationship required student self-reflection and the development of interdependence. The students recounted their experience with exemplary helpers and listed characteristics of helpers they believed facilitated their growth: authenticity, availability, acceptance, kindness, patience, encouragement, honesty, and optimism balanced with realism. Exemplary helpers recognized student accomplishments, questioned the student to generate personal and academic development, and taught and interacted in ways that facilitated student independence. Gavin benefited from being asked questions that spark self-reflection. I asked him about desirable helper attributes:

It's someone who doesn't nag, doesn't get real mad if I don't do well. Those are switches, they shut me off if this happens...It doesn't work for me. But, in the same respect, not saying something, I don't know if that works either.... I think it's "Are you happy with how you've done?" Because, in the end, it's all comes down to 
where I'm going with my life, not where my parents are going...they're not earning the degree, I'm the one, so, I know my parents intentions are the best....They've been through it and they know what you need to get somewhere. But...their motivation really doesn't work with me anymore. (XXIII, p. 16-17)

Gavin's summertime boss helped him to understand the importance of developing an internal measure of success:

A boss from an old job, I go back and see him where I worked at a car dealership. He asks me how I do. He's probably one of the ones that really pushes me because I go back, and he says "How did you do?" And I say "Not very well. Why?" And I give him an excuse. He says "Well, you can do better." We talk about it for a couple a minutes and he's like "It's not good enough until you're happy with it. It's all internal. Are you happy with your grades whenever you look in the mirror and see what you've done...look at yourself... are you happy with yourself?" He gets me on that one. It's like "Well, no, I'm not, but...."(XXIII, p. 15-16) He asked me how I was doing, it was just last week, maybe two weeks ago. I said "I'm doing all right, I've done worse." He said: "What's that mean?" I gave him an excuse... and I said to him: "I'm going to try to do better because of you...my parents don't work anymore...It's hard for me to come back here, and say hi, knowing that you're going to ask me how I did, or how I'm doing. And it would be real hard for me to say I failed this, or I'm not doing well." I let him know that he's actually helping....He's always made it clear that it's all for me: "Am I happy with my performance?" (XXIII, p. 17) 
Ben's Physics professor created a climate of availability and support. He "scaffolded" Ben through the learning process:

Mostly I go to Dr. ___ because if I have problems with the homework, I can go straight to him, and he'll sit down there and explain the whole theory about something, that really helps out...I don't feel I could ever ask him a dumb question...he'll be there to help anytime that I need it. I can call up, leave a message on his machine, and he'll check it, and then call me right back and be like "Yeah just meet me down in my office and I'll be there to help you." It's really nice when you can find somebody that's not really supposed to be in for the day, and them be like "Yeah, I'll meet you in my office." And he'll take you through it, he'll kind of lead you a little bit, and then let you run and then if you hit a block, you can turn around, ask him and he'll kind of explain it a little bit for you, and then see if you can run with it a little bit more. You hit a hurdle, he'll back you up and show you how to start off again. Some teachers won't do that, they'll be like "Well, you're supposed to do this" and they'll just say "Go find out how to do it." It's not like he'll give it to you, he won't give you the answer, he'll try to lead you in the right way, or give you the right tools, or say "All right, read this." (XXVIII, p. 16-17)

Connie recognized that she has thrived because of the encouraging response of the helpers in the support program:

The Academic Center... it's helped me out so much. I'm never...I was just tested for my ADHD the summer after my freshman year of college, it's a new experience for me...People just seem like they care about you so much...I don't know how to explain it, it's just really nice. I really appreciate it and it's definitely rewarding. I 
was kind of hesitant to do it and now that I have it...I've always had very low selfesteem, so having people there for me, just makes me feel better about myself and makes me want to learn more and want to not feel bad about myself all the time, I don't feel sorry for myself. I used to do that. I used to just sit there and feel sorry for myself and now it's just, you know, I've got people telling me that I'm a good kid and I've got people telling me that I'm doing a good job, that's very rewarding in itself because it makes you...It's raised my self-esteem. (V, p. 11) Support is the thing that helps me move on, like helps me go and get it. (V, p. 24)

Mandy observed that she responds better to the helper who thinks of her in a holistic manner, instead of a narrowing in on academics:

Someone who takes time, who meets with students, who gets to know them. . who doesn't just help with the academics, but, also, personal things and is there for students, and cares about them. It's definitely real important. (XXV, p. 10)

Julia valued patience. I asked her about characteristics in a helper that facilitated the helping process:

Understanding and patience, knowing that like "I need you to spell the words slowly, or you're going to have to go over the concept probably 40 times with me before I may get it." And they can't get frustrated in between those 40 times, otherwise I'm going to be like "Forget it." (XXIV, p. 14)

Kelsey admitted to needing some prodding now and then. She emphasized the importance of the helper communicating a tone of acceptance:

If I'm slacking, people would say "You need to try harder" and people do encourage me, people are glad for my success. They're even happy with little successes, like I 
got an A on a test. They're glad I'm going to graduate...They have to love me...if I didn't feel accepted or loved, I don't know, to tell you the truth...I guess it's the will for me to go on, if I'm accepted and loved. (XVII, p. 20-21) I guess the... about the only advice I would probably give you is to accept [the student] no matter what. It's really hard for someone to not be accepted, to be rejected because they have an LD. I mean, that does not make somebody less of a person because they have a learning disability...We just have a different way of learning. And to love them like you would love your kids or something. (XVII, p. 23)

Connie mentioned that she looks for optimism, patience, and an understanding of the how her disability affects her daily functioning. I asked her about facilitative helper characteristics: Understanding is one big thing, patience. I am a slow learner, so, hopefully somebody tells me they understand that and they're not trying to rush me....Caring, of course, being caring....Just being positive. Don't be negative...If there's a teacher who I think has treated me unfairly, that's going to stay in my mind and it might influence how I act in the future and how I am with that person. So just try and stay positive with me and know that I have a learning disability. (V, p. 25)

Alexandra communicated the importance of the helper believing in the ability of the student. She was complimentary of the language tutors who taught her skills that facilitated her independent academic functioning:

Somebody who is really going to teach me how to do it myself, because I really like to do things by myself...with the language tutors, they taught me to where I could edit my own papers. Instead of editing my papers for me, we sat down and had editing school. They would put together things for me and we'd read through the 
English books and they'd quiz me on "Okay, where does this comma go?" or they'd come up with sentences and have me fill in the punctuation. ... I told them that I wanted to learn the grammar. (XXVII, p. 14-15) I think just making sure that the students realize they can do it, and it's possible. Students with learning disabilities [do well in college] every day...I think once people realize that and they're actually confident in themselves to do it, they're more likely to do it....As I've said over and over again, I'm so much more independent...I do things on my own, I'm much more confident with everything. (XXVII, p. 21)

Patience, encouragement, and honesty are important helper characteristics for John. Constructive feedback facilitated his academic performance:

When I look for a person to help me, I like them to be patient, but I don't want them to be slow. Like I don't want to go at such a slow pace that it's boring. I, also, like them to be able to explain things, how they do them, how it works, and being complimentary of the things that I do....and even tell me when I'm doing bad...I mean I don't want someone to blow smoke at me ["lying to you, just telling you things to make you feel good"] and tell me I'm doing all right when I'm not. That's real important to me, because then I know I need to change what I'm doing; having someone that's able to tell you that is real important in my eyes. (VII, p. 11)

\section{Internal Barriers to Successful Performance}

Although the students in the persistence cohort worked through the barriers they experienced, most of them were able to reflect back and describe how their performance was impacted by the internal problems they endured. The students cited the limitations of their 
disabling condition and problems grounded in self- understanding and self- management as internal barriers to successful performance in the college setting.

\section{Limitations Imposed by the Disabling Condition}

When I asked about internal barriers to successful functioning, the students identified the impact of the technical difficulties caused by their learning disabilities. I asked Darla about the internal barriers she faced as a college student. She responded by describing the grueling process of test taking:

Testing...tests are hard, some of them. I've taken up to 6 or 7 hours to take one. . it depends what test it is. The average [time to take a test] is like 4 or 5 [hours] for finals. But, I can sometimes pull it off in an hour or two, it depends what it is and the format of it.... I don't really have a choice....If I want to pass, then, I have to take it [the time]. . . It takes me that long anyway. I'm not going to finish a test without finishing every answer. (II, p. 7)

Later on in our interview, Darla spoke candidly about her learning difficulties and their impact on her everyday functioning:

I mean I'm quiet in classes, I don't speak, I don't like to speak, sometimes I don't know what they're talking about....I know my strengths and I know my weaknesses in school. I know that my [oral language] processing is a lot slower than my mind works. And when I try to take things from my head to paper, I stumble over the things. And my reading level's lower, too. But, it doesn't mean my IQ is low. My IQ is above average...you're just slower in other factors....And when you're frustrated, you're just like "I can't do it." I used to not understand jokes. My mom told me when I was younger to come home and tell her the joke, and she'll explain it to me. She's 
like "Don't worry about it, just laugh along and then you can come back and ask me." (II, p. 15-16)

Connie described her experience during the first year of college before she was evaluated and diagnosed:

With ADHD, another frustrating experience is trying, especially my freshman year, when I didn't have medication or anything. . . . I mean I know I would have papers and I would start a paper and my roommate liked to watch TV and we're in a room with two people trying to do two different things with a person who has ADHD and is unmedicated, it was just very frustrating. You would sit there and try and study and one of the very frustrating things is when you have somebody screaming outside in the hallway and you're trying to study or you're trying to study and you hear a train going by. . . .I would be paying attention to the professor and I would realize that my mind was drifting so I'd be like 'focus." And I'd focus on focusing. I'd be like “Okay, am I focusing? Oh, I'm doing a good job on focusing” but I wouldn't get what the teacher saying. . . I mean, you can tell the big difference between being diagnosed and not being diagnosed, I went from a 2.9 to a 3.6 in one semester. . . that tells you right there how difficult it is to be an ADHD student in your first year of college without medication, without anybody helping you out, because you don't know what's wrong. (V, p. 16)

Ben spent inordinate amounts of time completing writing assignments and working to commit to-be-learned material to his long-term memory. I asked him about internal barriers he has faced as a college student: 
Doing the verbalizing, having to read and then be able to analyze and then write a paragraph or essays, it's pretty hard. . . it's kind of my disability. . . after a lot of practice, it would work it's way out of me. ... I know kids who can read things once and then it's like they know it. Since I have a proble m memorizing things, it's having to really get it. It's like when you learn something, you lay down a railroad track. But, for me, when I lay down a rail road track, it's more like a dusty trail, and then I got to try to lay it a couple more times, to actually make that a permanent track. It's just a little harder for me, so, I don't win out in the sense where I have to study more, but I mean, in the end, I'm not in the race with the other guys. . . and I can remember it later on. (XXVIII, p. 7-8)

John described his trouble handling multiple strands of work. This led to putting some assignments off until it was too late:

I'll just get so busy that I'll put one thing off and then it just keeps getting put off until the very last second...it's like all the different classes, having tests, having art projects, sometimes I'll have three tests in a week, and an art project due that same week, and it's a matter of deciding what I want to work on first, and then when I finish that...I guess it's kind of like multi-tasking...I won't say I don't like to multitask, but I'd rather just focus on one thing at a time. It gets kind of hard when you have all that at once...Focusing on one thing at a time helps me because I won't be distracted with other information from other classes. There kind of is a disadvantage I also see, because I'll be trying to study one thing, then I'll be thinking that I need to be studying something else, and then, it kind of is a circle. (VII, p. 8-9) 
Kelsey did not have the appropriate skills needed to complete the upper level requirements of her major. Persistence, a quality that had served her well in other critical circumstances became a stumbling block as the evidence called for a change in her program of study:

I would say basically finding the strength to switch from Psychology to Christian Education....I just felt like I could do Psychology, well...I could do it, but that would take me a very long time to get me through it. I mean I could do it, but. . . my parents would probably be out on the streets when I'm finished. . I was stubborn and I was like "My mom's wrong, I'm going to do Psychology, I'm going to get through it" and then, probably by last May, I was like "No, wait a second. Mom is right. I am not going to get through this." I loved Psychology, I loved taking the courses, but I couldn't get through it. And I felt kind of bad about leaving Psychology because I felt for some weird reason, I would have let the Psychology teachers down. . . In fact, they were kind of encouraging me to switch majors. They liked me...they liked me being in class, but they knew I was having a difficult time. (XVII, p. 9)

\section{Limitations Grounded in Self-Understanding and Self-Management}

Not only did the students discuss the negative impact of the technical aspects of the learning disability, they conveyed secondary self-related problems associated with it. Performance anxiety, concern over exposing vulnerabilities, frustration over processing limitations, low self-confidence, the need to prove oneself, being driven by the achievement of perfection, difficulty finding internal motivation, being easily defeated by failure, and problems in self- management represented additional internal barrier issues expressed by the students who persisted. Ben described catching his irrational thinking which linked his high average grades to future failure in the job market. I asked him about his internal barriers: 
I've stumbled sometimes when I would think about my grades. I hear all these people saying like how, depending on your grades, you'll end up getting a superb job, or if you don't have the best grades in the world, you'll end up not getting a job anywhere. That's one thing that kind of freaks me out sometimes, because I think about it, even though like I have a 2.9 now, I wonder sometimes if I need better grades...but then after a couple days you realize that you can't even think about it. (XXVIII, p. 13) Mandy struggled with thinking she needed to perform to perfection. She graduated with high honors:

Needing to learn that grades didn't really matter. . . especially individual grades in classes, needing to learn that it doesn't really matter, you should not worry about it. And learning how not to get stressed out. Because I was real good at getting stressed out. . . it made it a lot less stressful, once I didn't care if I got good grades. Didn't always lead to the best study habits, but it was sure a lot less stressful. (XXV, p. 7-8) Alexandra identified her need to achieve perfect grades as an internal barrier:

I think my striving for perfectionism; like the other day, I made a 99 on a test, so I was mad at myself because I lost one point. I do that a lot. Even though "Yeah I did do well, it's not well enough" I think is my biggest thing. . . .It's one of those things, I know I really am doing good "This is a 99, it's really the same A as the 100" but I just get stuck on that one point. It is something in my mind. . . then I just realize that's it's really not a bad thing, but thinking it at the time is the whole other thing.... I think just by continually telling myself that it is the same A as one other point. . . really, it's not any different letter grade-wise. It's not going to change anything, like 
even when I get my grades at the end of the semester, it's going to be the same number of points going towards my GPA. (XXVII, p. 11)

Abbey described how easily her confidence was shaken in the classroom:

This sounds really bad, I didn't enjoy one of the teachers I had. I know that sounds really mean... But, it's honest. I just felt...She didn't make me feel good about myself, and for some reason, I didn't feel comfortable around her. (IV, p. 10-11) She probably wouldn't even know me if I walked by her, right now. . I I think I was only in one or two of her classes. ... That feeling I get that I'm scared to answer because she'll make me maybe feel like that's not the right answer. I know there's not supposed to be a right answer to everything, but just that feeling. Maybe she was doing the right thing to me, I was young, maybe she was trying to weed people out that didn't really want to be in that program. . . [she was] very critical, and not constructive criticism, just criticism to be criticized, but that was just my feeling. And at that time, I hadn't gone through everything that's here in this [support] program that would maybe help me get past something like that. I was still young, and I was still really intimidated by somebody like that. That was a big problem I had in like every classroom kind of situation. (IV, p. 12-13)

Gavin recounted his cycle of becoming easily defeated by failure and losing motivation: I don't know...it's just...trying to do well at the beginning of the semester, kind of go into it running, and then you get the first test back, and you don't do well at all...not even close. That seems to happen to me every semester. And, it's really difficult because, you know, you think you're doing well, and then you get that [test] back, and there goes all the motivation you had coming into it. And it kills me every 
semester, because it happens every semester. And if that underlying goal wasn't there...to just get that degree, I don't know if I'd still be here....I don't know if school really is for me. . . and I honestly don't think it is. But, you got to have it to get some where....It kills me because I can't do well, from that point on, I read the chapters before, and I studied and I thought I understood it, I go and take the test, and I get a 65. And, it's not good enough. And then you're playing catch up for the rest of the semester. And my motivation's gone. . . that's why my grades aren't very good. Because I do enough just to get by...It's just discouraging. (XXIII, p.8-9)

When I asked Gavin how much he believed the statement that school wasn't for him, he responded by admitting that the thought protects him from feeling badly about his grades:

A fair amount, and whenever I start doing bad, I tend to believe it more. Because it's an easy out for me. . . it's a copout. . . mentally it's like well maybe I shouldn't be here. . . it makes that bad grade not seem as bad. (XXIII, p. 10)

Gavin identified this cycle as an internal barrier to his successful performance:

By saying I shouldn't be in school, by losing motivation after that first test. I'm a fairly modest person, I don't think I'm very smart, to be honest. You know, your parents always tell you different because they have to. But, I don't think I'm very smart, I may have street smarts, if you will. (XXIII, p. 13-14)

Gavin reflected that talking to his mentor may cause him to face the reality that he usually doesn't have a plan to correct his lower grades at mid-semester:

With that parents nagging thing comes the advisor's nagging. . . so maybe it's one reason why I don't come around very often because it's up to me, not my advisor 
... Like if I'm asked how classes are. ... When it starts getting into details, I'm in and out real quick. . I think that I was kind of like "I just stopped in to do schedule stuff" and I had to go to class or something. I think if the time was there, he [the mentor] would be asking a lot more questions, and that probably is the reason why I don't come around very often. . . . I think if I would probably roll with the punches, you know, tell them what's up, afterwards, I'd kind of be like "I don't know if I liked that." Maybe it's because I fear that I don't know what the plan is, and I don't do well, then they bring it up: "Well, that didn't work, what can we do next time?" Maybe that's why I don't like to disclose that information. (XXIII, p. 19-20)

Mandy identified the need to prove independence as a barrier issue for first year students: This is really important for people, their freshmen year, to have that support, and freshmen coming in think they don't need any, so, trying to figure out a way to give them that support without requiring it. . . they really need it, and they don't want it ... . Partly because they're coming off high school, where, normally, senior year, they don't have to do much work, and they did pretty well, and they knew everything, and then they come here, and they're away from home, and they're free, and they don't want anything tying them down, anything taking away from that freedom, and they want to do it on their own, and prove themselves. . . It's often like they have to go through a period of failure, first semester, to realize that they need the help, and it would be good if they could get it [help] before they go through that because it's never fun to go through a period of failure. But, for a lot of people, it's what they need. (XXV, p. 12-13) 
Kelsey was finally able to recognize the line between persistence and perseveration. She viewed her unwavering, unrealistic determination as a barrier:

Stubbornness, I mean...there is stubbornness, the good thing and then there is stubbornness, the bad thing. For instance, switching majors, I think I was really determined to finish it out, but that was a bad thing to do. (XVII, p. 15)

Kelsey admitted that her obnoxiously frequent classroom participation was linked to trying to prove her intelligence:

Trying to prove to the teachers and the fellow students that I am smart and I am a capable as much that guy whose name is John Doe over there. Nobody really has openly told me, except for the teachers, that I talk too much in class. Dr. has teased me, on one hand he appreciates me talking, but on the other hand, he teases me that I shouldn't. . He's like "Wait a minute, Kelsey, wait a minute.” (XVII, p. 15-16)

Mandy acknowledged the barrier of being afraid to expose social and emotional vulnerabilities: Learning to admit weaknesses and problems and be able to talk about them and work through them. . . I was definitely more okay with getting help for my learning disabilities than I was for just emotional support. I had to learn that it was okay to get stressed out in college, and almost everybody does at some point in their college experience. (XXV, p. 7-8)

Darla experienced frustration and isolation because of the limitations imposed by her learning disability. She recognized that she compared herself to her siblings and parents:

I wanted to go to __ University. I don't know, it's hard seeing your siblings, who aren't learning disabled, be so successful with grades. They're really smart. . it's 
frustrating, being the only one in the family who's learning disabled.... Architectural Engineering is my brother's major. My sister was [on the] Distinguished Dean's List at . My parents went to I mean, wasn't the right school for me, they didn't have the program, but, I'm still jealous. . . I would have loved to go there. It's hard being like. . your parents have two different expectations. One's for your siblings, and then one for you, and it's hard being the one who's the other one. I've gotten over it, you have to live with it, it still comes back. (II, p. 13-14)

In the prior semesters, Gavin hung by a thread to "good academic standing" status. He described himself as wanting in motivation as he lacked a specific vocational goal:

I'd like to find out what I want to do after graduation. I have no clue right now. I'm doing the Business Administration Major because it's generalized in the business field. I don't even know if that's what I want to do. I just need to get a degree and business is something to kind of relate to. I can honestly say I don't even know if I like business, but. . . I've got to get something out of here. . . I've already taken. . . I believe it was freshman or sophomore career planning, and taken all their tests to see where your interests lie, and, it didn't seem very helpful for me. I don't perceive myself being behind a desk my entire life. . . I don't know what I'm interested in . . . kind of weird, but I'd like to find a way to motivate myself to do better. I can't now. The drive isn't there. I guess it's got to come from within. But, right now it's not there. . . I've always kind of thought that if I knew what I wanted to do, or, you know, have a general direction of where I wanted to go with my life after college, it would be easier to push myself, because it would be like "If I don't get these grades, I can't do that." I think it's directly related. (XXIII, p. 2-4) 
John described his lack of motivation and the will to work on his general studies classes as an internal barrier:

In some of my classes that were for not my major, I know some of the times when I've done bad in them, it's because I just generally didn't care, I didn't see how it pertained to what I wanted to do, and I would get frustrated with a class because I wouldn't understand, and wouldn't want to ask for help, and just end up getting a bad grade....I wish I would have just sucked it up, and worked harder, and actually talked to the professor more...I was struggling in a communications class, and I really wasn't paying attention in class, and was doing bad on the tests, it was probably about half way through. . . I I started going to the professor and asking how I could do better and improve and different things I could do to try and help improve my grade and it helped, but I don't think I did it soon enough. (VII, p. 7-8)

\section{External Barriers to Successful Performance}

Although the students in the persistence cohort worked through the barriers they experienced, they were able to reflect back and describe how their performance was impacted by the external problems they encountered. The students in the persistence cohort reported having difficulty with the following externally perceived barriers: time constraints in managing a full course schedule along with extracurricular activities, limitations in the professors' understanding and treatment of their unique needs, difficulty meeting certain requirements of the college curriculum and the demands of coursework, and interfering familial and social factors. 


\section{Time Constraints}

Even though they were eligible for and did use appropriate accommodations such as extended time for testing, the students felt the pressure of juggling the time demands of their academic course load with their involvement in extra curricular activities. Mandy described her predicament with time:

The fact that there's only 24 hours in a day, and you have to sleep for part of it....Oh, there's just never enough time. Because you have to go to classes, and you have to study, and you have to go to rehearsals, and you can leave your room at 7:30 in the morning and not get back until 8:00 at night, and then you get to start your homework, you just have no life. (XXV, p.10-11)

Sometimes Darla had difficulty carving out enough time for a good night's sleep. I asked her about external barriers she experienced:

The hardest was balancing my time, the time commitment for everything. If I wasn't swimming, I was studying...Seven or eight [hours a day]...It depends because of our projects. I have to spend all night in the Art Department, and I've gone straight to 6 a.m. [swim] practice. It really depends, like I could be in there [the Art Department] from 9 o'clock to like 6 a.m. (II, p. 6-7)

Abbey remembered that is was difficult to incorporate the demands of varsity tennis with her studies:

I've played (tennis) my whole life...My Freshman year, our team was very good....Our coach was really demanding, in a good way, I enjoyed him...I remember it being really difficult to do everything. That was a really big challenge. I got used to it my Sophomore and Junior year. (IV, p. 4) 


\section{Limitations in Faculty Understanding of Student Needs}

The students experienced difficulty when their professors made impromptu changes to the course assignments and deadlines, were not well organized in the presentation of the class, or did not take into account their unique needs as individuals with disabilities. Mandy could not attend review sessions set up by her professor and suggested that professors schedule these during the regularly scheduled class times as all students should have access to class review sessions. I asked her about any external barriers she experienced as a student: "Professors who hold study sessions during musical rehearsals. That happened a lot. They think they can plan anything in the evening, and assume people can show up, and it's normally not true. (XXV, p.

10) Connie criticized a professor who routinely announced assignments at the last minute:

When professors don't give you your assignments until the day before they're due, that is a big problem with me. And as a student, if I have a question before I get started on this huge assignment, and Dr. is not in class, what am I

supposed to do? And [the professor] does the same thing with tests, sometimes she won't be in class the day before a test. (V, p. 28-29)

Alexandra's overall contact with faculty was positive. However, it was easy for her to recall the negative experience with one professor while requesting accommodations:

Most professors are very good at dealing, if you have a learning disability, they are more than happy to do anything...but, I think there's the few that still don't get it. Like I know the Department...they weren't always the most...you kind

of had to push for it, and they weren't real "Oh well, sure, what can I do to help?" it was "Oh well, if you really have to." It would make you be like "Okay, well I guess I'll take my test in the room" because you don't want to do anything to make them 
mad or affect your grade. If you need help with anything else, you don't really want to ask them for that either because it's going be more risk or a burden on them to have to make any accommodation at all.... Normally, you would first ask them, and they would be like "Well no, you need to be here to ask questions." I really have to explain well "No, I have to have this read to me, this has to be reworded" and basically once it was more of a burden for them...for you to be there in class and them read it to you, it finally seemed better to send you here [to the Center]. They changed their mind....I was like "Well, you're going to have to read it to me, somebody is." [Then] he said I could come up here....I'm not sure why, because he was a really nice person....He just didn't get it.... I don't think it affected me asking my other professors, just because so many of them were so great about it....In the department, they just have an all out policy, they do anything they

possibly can to help.... They all automatically ask the class "Okay does anybody need to take their test there [in the Test Lab]?" (XXVII, p. 7-8)

Darla recounted the awkwardness of being asked to read aloud in class even after disclosing her reading disability to the professor:

People that don't understand it, they still are still struggling with understanding learning disabilities. It bothers me. A lot of times they think you're faking. . . it's the attitude. . . you tell a professor "I can't read out loud" and then he goes and calls on you because he's so air-headed and doesn't remember. And you have a sorority sister reading it from behind you looking over your shoulder into your ear so you can read it. . . every time I got stuck on a word, she would tell it to me. I mean I had the book 
up here, almost [points to her face]... I was like "Why did you have to call me out?" (II, 18)

Alexandra struggled to follow the organizational style of one of her professors who frequently changed assignment requirements and skipped around during the class lecture and discussion. I asked her about external barriers met while she was a student:

I have professors who are so lax, out there, and scattered that there's no structure. I think for most kids with a learning disability, structure is a good thing...It was hard enough with a learning disability adjusting to college and then, you have Dr. and she changes things so much. ... I don't know her teaching style, but, it's scattered, I think. . . .It's even harder to take notes, harder to comprehend. When everybody else, that normally wouldn't have trouble, is having trouble, that just doubles yours. (XXVII, p. 16)

Believing that she had asked a legitimate question in one of her classes, Connie was embarrassed by her professor's belittling response. It has been necessary for Connie to take this particular professor a few times because of the course requirements in her major. Perhaps Connie had missed the instruction when it was stated earlier, maybe the answer seemed implied or obvious to the professor. The professor's flippant remark demonstrated a lack of respect for the student: Dr. , in my head, she does not like me. . . When I asked a question she said "Well why don't you answer that for me." And I was like "Well, that's why I asked you the question, because I don't know the answer to it." And I don't think she liked that because I said. . . and I told Mom "You know, maybe I shouldn't have said that, but when you ask a teacher a question, it's because you don't know the answer to that question." And when they say "Why don't you answer it for me" you feel like 
an idiot, you don't know the answer to the question, that's why you're asking. And so, I was just like "Well that's why I asked you." And I think that probably embarrassed her. But, I didn't mean it to be rude. I just didn't know the answer and that's why I asked. (V, p. 26-28)

\section{Limitations Related to the Requirements of the Academic Curriculum}

The students revealed the challenge of navigating a range of factors connected with completing the academic requirements of the Liberal Arts degree. Managing their disinterest in various general studies requisite classes, comprehending thick, detailed, and highly technical text, coping with the cumulative impact of a taxing course load, handling large amounts of reading and writing fundamental to the general studies classes, and dealing with difficult testing formats were perceived by the students as external barriers to successful performance. Ben described having a difficult time with his nonscientific general studies class requirements:

Some of the tough times for me were having to take classes that incorporate a lot of writing and reading, because it takes me awhile to do both. . . . A couple of times, I felt really overwhelmed, and thought I had to drop the class because I was going down. . . those were the hard times. . . the tests were all writing, I usually stressed out over that. . . I passed the classes...I got Cs on them. . . sometimes I didn't get the grade that I thought I would get, but, for having disability, I passed them, it's an accomplishment. . . I like to keep my average high. (XXVIII, p. 6-7)

Mandy worked through her frustration over the general studies requirements. She was finally able to view them as a necessary part of advancing her long term goal:

The general studies classes that you really don't want to take in the first place; they're as good as the professor. . What do they care if your life is miserable because it's 
their class. . . .I guess that's always difficult. . . knowing you have sit through this class every day for the rest of the semester, even if you don't like it, and you're not learning anything. You have done this all since you were in high school, you have to do it again anyway. So that can be frustrating, even if it isn't challenging in the academic sense. (XXV, p. 3)

Connie struggled with the collective effects of an intense work load and questioned the usefulness of some courses required by her major given her goal of teaching elementary students with learning disabilities: “This semester especially I've had so much more work than any other semester, it's just been very hard but I've been able to make it through with complications. . . I made it, so that's all that matters.” (V, p. 2) I asked her about any external barriers she has experienced:

[Taking] courses that I wasn't interested in, Science and Social Studies are not my strong subjects, at all. And we have to take two Science courses and two Social Studies courses, plus a Methods of Science, Methods of Social Studies. Needless to say those four classes were just very hard for me. It's hard to concentrate. One of my Science classes was before I was even diagnosed with my learning disability, so I didn't know what was the matter. I would pay attention and then start taking notes and I would only get half of what she was saying. I would forget the other half because I'd be interested in something else that she was saying. That was very frustrating. . . that was before, my medication has helped, it does help me focus. . . it's hard to get interested in something that you've never been interested in before. Especially when you're mindset is 'I'm not going to teach an elementary SLD 
student Physics." It's hard to pay attention and to want to learn something that you don't think you're going to use in your classroom. (V, p. 13-14)

Julia struggled in one of the foundational classes in her major. She perceived the course as a barrier when she was enrolled in it but admitted that working her way through its requirements made her a stronger student. I asked her about external barriers she encountered:

The Principles [class] really was a struggle for me. It was the only class I've ever got a mid-term in, and I just kept struggling through it, and if I hadn't had to struggle through that class...I don't think I would have prospered as far as I have. That was a frustrating semester. (XXIV, p. 5)

The complexity of John's $20^{\text {th }}$ Century Art text was daunting. He tried to take what he could from the book:

One of my classes, the 20th Century Art, the reading in that book was just...I'd never seen half the words, and the sentences were forever long, and didn't really make any sense, and there's no real way around it, I just kind of had to read it, and get what you get out of it, whatever you think it meant, that's kind of what I went with. But, that's the only thing I can really think of as being an external barrier. (VII, p. 11-12)

Darla spent hours processing information to complete her tests successfully:

The format of tests. . . that can sometimes be a problem. . . three hundred fill-in-theblanks is kind of hard for a learning disabled student when they have a hard time with language. . . word banks, I mean you could just put word banks in. . you could put five hundred words on the word bank, and I'll still pick it out [the right word]. I've struggled with that, but then they changed the format of tests for [Survey of] Art, and I started getting 90s. (II, p. 23-24) 


\section{Social, Emotional, and Familial Factors}

The remaining external barriers perceived by the students were founded in personal rather than academic experience. Although most of the problems the interviewees exposed would be difficult for anyone to navigate, it is possible that the learning disability may impede the student's facility to manage the circumstances or even intensify the overall personal impact of the situation or conditions. The common dilemma of keeping the social side of college in perspective challenged Abbey:

Social [life] really is always a barrier that you have to overcome. When you're trying to succeed, academically, I mean, there are always distractions that you could buy into...That would actually be my biggest obstacle.... I'm surrounded by my sorority, there's always someone doing something that you could possibly do... there's always something going on, especially in the dorms. I live in a house with my girlfriends, and that's distracting enough, having your best friends all living with you, but in a dorm, we had a whole hall full of girls. . . someone doesn't have homework at some point. . . they're very persuasive... . Even a couple nights ago, my friend pulled the "This is our last semester." It's very easy to be like "You're right," that's easy to buy into. So, that would probably be the biggest obstacle (IV, p. 22)

Kelsey had the opposite problem of Abbey as her learning disability impacted social perception and skill development. She worked to not catastrophize the fact that she couldn't keep a roommate throughout her college experience. Kelsey countered her feelings of isolation by joining campus organizations that welcomed diversity.

Another difficult thing was keeping roommates. I've had very bad problems, I mean I had about two roommates who left after a month, one roommate that lived with me 
for a day and another roommate which was the longest, which was just last year, stayed with me for a whole semester. ... And I felt very bad and I was like "Well, I'm going to be alone all my life." Which can be true but it can not be true at the same time because I could find somebody. (XVII, p. 9-10)

Major family transitions posed a burden as well. Mandy experienced her parents' divorce during the early years of her college experience. It is easy to understand how this situation could have interfered with her academic concentration:

As I look back, things I've achieved are maintaining good grades, not having to withdraw from classes and being able to succeed no matter what else was going on, you know, family situations, and still being able to succeed. (XXV, p. 1) I don't go home much. That didn't really bother me, too much. Sometimes I wanted to be far away. . but, at times it would have been nice to be closer, to be able to go home, especially when there was difficult family times that you wanted to be there for. You really wish you knew what was going on, and not just what you heard over the phone every once in a while, because people can be deceptive over the phone. So, that was kind of frustrating at times. . . But sometimes when family things weren't perfect, I was real happy I was far away. (XXV, p. 3-4)

Connie was devastated by her father's sudden illness and death. She continued with school while grieving for him. I asked her about external barriers she experienced:

He went to school here, and it's just hard to walk around campus and participate in classes where, you know, I'm going to become a teacher when he did the same thing, just everything that's going on in your head and still having to pay attention to the teacher. Like when they play the Alma Mater, he always used to cry when he'd hear 
it, or the Chapel Bells. . . just it makes it hard to be here, but I'm glad that I've made it through this semester. (V, p. 1) Definitely not going to class, telling myself "Oh well, you're not doing anything really important, so...you really don't need to go." I have missed a lot of class this year, and that makes me feel bad because I'll start thinking about it and be like "Geez I'm such a slacker, I just never want to go to class." But I think that it does have a lot to do with just being depressed, just feeling like being by myself. And I think the "I don't care" has to do with the fact that Dad has died. Sometimes I feel like I don't have anything to work towards, even though that sounds bad, because I do have my mom and my family and all these other people that care about me. But when you're in a mood like that, you don't think about that. You're just like "Well somebody who was...is a big part of me becoming a teacher isn't here anymore, so what's the point?" Having him not there is kind of like "Oh, what do I have to work towards, now?" Sometimes I just don't go to class and other times I'm like "You can't keep doing this. You're not going to be able to do this for the rest of your life. What happens if you have a "bad Dad" day when you're teacher? You can't just take off." I'm just like "You can't do this. You can't sit here and feel sorry for yourself and feel sorry for everything that's happened. Your mother's going to school everyday. Your brothers are going to work every day and living their life." I can't stop...I can't just stop my life because something tragic has happened. You have to move on. I'm not saying move on and get over it, just saying, you have to take it day by day, move forward. (V, p. 21-22) 


\section{Summary of the Persistence Collective Case}

The 10 students who made up the persistence grouping completed at least 60 credits toward graduation and earned an average cumulative GPA, taken after each student's most recent semester of enrollment, of 2.95. Individual cumulative GPAs for the persistence cohort students, taken after each student's most recent semester of enrollment, ranged from 2.28 to 3.83 . Only 1 student in this grouping earned at cumulative GPA less than 2.5. At the time of this writing, 7 of the 10 students within this grouping have been graduated, 3 continue to make progress toward graduation. 10 of the 10 students or $100 \%$ are still enrolled or have been graduated from the research site institution. The students in the persistence cohort revealed an internal pattern of successful functioning and conveyed a student perspective of internal and external facilitators of and barriers to persistence in the college setting.

Internal facilitation of successful performance involved a process of self-awareness based practice to promote well-being. The knowledge of personal goals and strivings, limitations, strengths, and a mindset supported by self-knowledge formed the stage for individual and interactive practice to promote academic, social, and emotional well-being. The students identified two broad sources of external facilitation for successful performance: defined and informal support structures and general environmental and individual systemic qualities. Internal barriers to successful performance were twofold: limitations posed by the students' disabling condition and problems grounded in how the students viewed themselves, including inadequate self-understanding and insufficient self-management. External barriers to successful performance communicated by the students were general time constraints in managing a full course load along with extracurricular commitments, limitations in professors' understanding 
and treatment of the students' unique needs, difficulty meeting certain requirements of the college curriculum and the demands of coursework, and adverse familial and social factors.

Internal facilitation of successful performance - Internal facilitation involved a process of self-awareness based practice to promote well-being. The knowledge of personal goals and strivings, limitations, strengths, and an outlook or mindset supported by self-knowledge formed the stage for individual and interactive practice to promote academic, social and emotional wellbeing in the postsecondary setting. Self-awareness oftentimes led to the development of an outlook or approach which facilitated student management of the environment through individual or interactive practice.

The student description demonstrated vigilance in staying goaldirected. The goals and strivings of the students energized their will to succeed. The students were in school for a reason and kept their goals, accomplishing good grades, finishing the degree, learning from their classes, participation in extracurricular activities, and preparing for their future careers, at the forefront of their college experience.

Many students were able to identify inner strengths that have promoted their stable performance. The students recognized their accomplishments in the face of hardship and identified areas of personal transformation. In addition, they were unguarded in describing personal limitations and challenges they worked to overcome. The students met face-to-face with their limitations and "moved on" from there. Compensation for personal limitations became possible with the realization of weakness.

Finally, the students displayed a strong will and attitude of determination they activated to overcome hardship. Many of the students possessed a mind-set based on self-awareness that they utilized to facilitate their education. The qualities of their outlook included realism, 
academic diligence, determination, persistence, and a will toward self-reliance and independence, even though the students understood their need for appropriate academic assistance and accommodation.

Specific individual practices that facilitated academic success in the college environment were described by the students. These processes enhanced not only their academic functioning but sustained their social and emotional well being to maintain a stable presence. Students described individual study practices that included drill and practice, overlearning, organizational planning, and the application of procedures they had been taught by study skills instruction and language tutoring.

The students intentionally interacted with their professors and members of their classes to "stay on top" of their school work as well. They paid attention to the cues in the environment to learn how to study better. They were able to "go back to the drawing board" after failure, learning to improve through professor feedback via returned tests and papers. The students utilized the special services program for students with learning disabilities.

In order to replace their worst-fear perceptions, the students worked to manage their thinking. They stopped themselves if they were moving in an unproductive direction and talked to themselves strategically in order to manage stressful conditions brought on by academic work or social and emotional concerns. The students in the persistence grouping described intentional participation in nonacademic activities for relaxation and sought social and emotional support from others. Some talked with the campus counselor as a way of coping with the difficulties they encountered to increase personal stability.

External facilitation of successful performance - The students identified two broad sources of external facilitation for successful performance: defined and informal support 
structures and the qualitative factors of the college environment and individual helpers. Support systems described by the students included the academic department and teaching faculty, the support system for students with disabilities, structured to fit the individual needs of the student, the mentor who specialized in working with students who have learning disabilities, the student's family, and the student's peer support network.

The students verbalized the importance of interacting with the teaching faculty; they were encouraged by constructive and supportive comments made by their professors as well as by observations of concern when things were not going well. The students believed they were enriched by responding to the rigorous academic requirements of their coursework and curricula and they valued the ir professors' expertise in and enthusiasm for their teaching discipline. Departmental teaching practices and policies that supported student learning were favorably acknowledged. The students appreciated internship opportunities which provided the occasion to apply theory to practice. On the whole, the students viewed the relationship with their faculty as primary in that it opened a path for personal and professional enrichment.

The availability, scope, and depth of the support services offered by the college were significant to the students. It was their safety net. The students commented on the importance of the staff responding to the individual needs of the student. Most of the students who were enrolled in the language tutoring program acknowledged the positive difference their working with the tutors made in their academic performance. In addition, establishing cooperation between the support system for students with learning disabilities and the teaching faculty was an important factor for student success. Communicating clear guidelines on how to use the support service enabled the student and faculty to trust the system. 
The mentor was viewed as an anchor to most of the students interviewed. Students enrolled in the support program worked with the mentor to balance the academic schedule, to develop academic, organizational, and self-monitoring strategies, to talk about priorities and motivational outlook, to access the need for accommodations and services, to practice disclosing their learning disability to their professors, to connect to services within the program support system, to link with other campus offices for extra-curricular referral and support, and to process events which impacted the student's college experience. Finally, the mentor helped the students troubleshoot difficult circumstances that come about in the natural course of events.

Parental understanding of the child's unique needs for successful transition to and persistence in the college setting facilitated student functioning. Many of the parents communicated to their children that taking an extra semester or more to complete the baccalaureate degree was acceptable. Parents intentionally held back on "advice giving" to encourage their student to transfer their questions to the helping relationship with the mentor in the college support program. Communication of high expectations on the part of the parents instilled confidence in the student. Parental support when things went amiss communicated a tone of acceptance that encouraged the student to continue, if it was realistic to do so, in the face of failure.

Peer support systems were viewed by the students as beneficial. Students who were enrolled in the same major supported one another. Affiliation with a fraternity/ sorority or a sports team enhanced the students' sense of belonging and importance to the campus. Both types of memberships valued academic success and supported effective functioning. Peer mentors from the support program for students with diagnosed learning disabilities were perceived as a 
source of external support. Finally, informal friendships imparted a sense of stability for the student.

Qualitative factors supporting success included specific qualities of the small community and individual attributes of exemplary helpers. The milieu of affiliation on campus presented the opportunity for the students to become involved and to establish a sense of belonging. The students reflected a feeling of acceptance and a sense of community that promoted their welfare. They felt welcomed by the College from the very beginning of the partnership. For the most part, they were comfortable communicating with their professors because of the small size of their classes. The opportunity for connection because of the personal atmosphere of the campus led to student persistence. The chance to become involved in various activities and organizations contributed to their experience of connection and ownership of the campus. The students called the College a home away from home and attributed their successful academic performance to the establishment of this sense of belonging.

Individual qualities supporting student success were defined by the character of the faculty members, professional staff on the campus, and other helpers in the students' lives. Exemplary helpers trusted in student potential. They were authentic, available, optimistic. The effective helping relationship required student self-reflection and the development of interdependence. The students recounted their experience with exemplary helpers and listed characteristics of helpers they believed facilitated their growth: authenticity, availability, acceptance, kindness, patience, encouragement, honesty, and optimism balanced with realism. Exemplary helpers recognized student accomplishments, questioned the student to generate personal and academic development, and taught and interacted in ways that facilitated student independence. 
Internal barriers to successful performance - Although the students in the persistence cohort worked through the barriers they experienced, most of them were able to reflect back over the previous semesters to describe how their performance was impacted by the internal problems they endured. Internal barriers to successful performance acknowledged by the students in the persistence cohort were twofold: the limitations posed by their disabling condition and problems grounded in how the students viewed themselves, including inadequate self-understanding and insufficient self-management.

The technical difficulties caused by their learning disabilities had an unremitting impact on student functioning. This included trouble with focusing and sustaining academic effort; sustaining effort during the lengthy process of test taking; and staying with, while spending inordinate amounts of time on assignment completion and learning course content. The students had difficulty managing multiple strands of work which resulted in putting off assignments until it was too late. One student could not overcome the barrier she faced in completing the requirements of her major. Persistence, a quality which served her well at prior critical times, became a stumbling block, as the evidence pointed to her need to change majors. This example illustrated a blending of the limitations posed by the disabling condition and insufficient selfunderstanding.

Not only did the students discuss the negative impact of the technical aspects of their learning disabilities, they conveyed secondary internal problems associated with the disabling condition. The following self-related issues impacted the academic, social, and emotional functioning of the students in the persistence cohort: frustration over processing limitations, depleted self-confidence, the need to prove oneself, performance anxiety, apprehension over exposing cognitive vulnerabilities, intellectual defensiveness, the ambition to achieve perfection, 
and easy defeat by failure. In addition, a few of the students observed they had difficulty tapping into internal motivation because they were not focused on a major of interest. This same few observed they had, but were overcoming, problems with self-managing academic behaviors.

External barriers to successful performance - Although the students in the persistence cohort worked through the barriers they experienced, they were able to reflect back and describe how their performance was impacted by the external problems they encountered. The students in the persistence cohort communicated difficulty with the following externally perceived barriers in the college setting: time constraints in managing a full course schedule along with extracurricular activities, limitations in their professors' understanding and treatment of their unique needs, difficulty meeting certain requirements of the college curriculum and the demands of the coursework, and adverse familial and social factors.

Even though they were eligible for and used appropriate need based accommodations such as extended time for testing, the students felt an external time pressure of juggling the demands of their academic course load with involvement in extracurricular activities. The fact that there is only 24 hours in a day was a common complaint for the productive students. Carving out enough time for a good night's sleep posed a challenge.

The students experienced difficulty when their professors made impromptu changes to course assignments and deadlines, were not well organized in the presentation of class, or forgot to take into account their unique needs as individuals with disabilities. They had problems following the lecture of professors who referenced multiple and varied time, place, and conceptual frames without making the transitions evident. It was awkward for the student to be asked to read aloud in class, especially if specific disability disclosure had occurred. A recurrent 
flippant or inpatient response on the part of a professor demonstrated a lack of understanding and respect, particularly for a student whose self-confidence is easily eroded.

The students revealed the challenge of navigating a range of factors connected with completing the academic requirements of the Liberal Arts degree. Managing their disinterest in various general studies requisite classes, comprehending thick, detailed, and highly technical text, coping with the cumulative impact of a taxing course load, handling large amounts of reading and writing fundamental to the general studies classes, and dealing with complex testing formats were perceived by the students as external barriers to successful performance. Even though some of the students perceived prerequisite and general studies classes as a barrier, they admitted the courses helped them to develop important knowledge and skills that enabled their continuation.

Social, emotional, and familial factors were perceived by the students to be barriers to successful functioning. Although most of the problems the interviewees exposed would be difficult for anyone to navigate, it is possible that the impact of the learning disability may impede student facility to manage the circumstances or perhaps intensify the overall impact of the difficult conditions. The common dilemma of keeping the social side of college in check was difficult. On the other hand, social isolation was a problem for the student whose perception problems impacted the development of social skills. Working to become involved in campus organizations that welcomed diversity combated the challenge of developing informal friendships for the students who were taxed socially. Major family transitions such as divorce and death posed a burden to the students. It was difficult dealing with the sadness and grief such circumstances present away from the family support network. See Table 8 for a summary of the persistence case findings. 
Table 8

Persistence Collective Case Findings

Internal facilitators for successful performance

Self-knowledge

Goals and strivings

Strengths

Limitations

Mindset and approach

Practice

Individual practice for academic well being Interactive practice for academic well being Individual practice for social and emotional well being Interactive practice for social and emotional well being

External facilitators for successful performance

Supportive systems

Faculty and departmental support

Support services for students with learning disabilities

Mentor support

Family support

Peer support

Qualitative factors supporting success

General environmental qualities

Individual qualities of exemplary helpers 
Internal barriers to successful performance

Limitations imposed by the disabling condition

Limitations grounded in self- understanding and self-management

External barriers to successful performance

Time constraints

Limitations in faculty understanding of student needs

Limitations related to the requirements of the academic curriculum

Social, emotional, and familial factors 


\section{SUMMARY OF THE ANALYSIS AND FINDINGS}

After several iterations of thematic analysis were completed, the researcher tracked aptitude testing scores, the number of disabling conditions, and the postsecondary performance outcomes of the transition cohort participants. Analysis of the student GPAs revealed a split in the academic performance of the participants. Two distinct transition cohort performance groupings emerged. The negative performance grouping consisted of seven students whose average cumulative GPA was 1.86 . The positive performance grouping consisted of 16 students whose average cumulative GPA was 3.0. The average of the number of disabling conditions and the average of the full-scale intelligence quotients were similar for both the negative and the positive performance groupings.

In addition to a marked divergence in grade point average, the student narrative of both groupings showed corresponding patterns of outlook and behavior. The outlook and behavior patterns of the negative grouping illustrated ineffective student operation. The outlook and behavior patterns of the positive performance grouping illustrated effective student operation. See table 4 for additional background information on the positive and negative transition groupings.

The original research topic, the quest to understand the experience of students with diagnosed learning disabilities from their own perspective as they made the transition to the college environment, took on an additional focus as the interview and research project progressed. The decision was made to explore facilitators and barriers to managing the college environment from the point of view of students who had persisted. The focus of the persistence interview protocol was narrowed to reflect the specific topic, understanding the facilitators and barriers experienced by the population. 
The questions from the transition interview protocol focused on both positive and negative aspects of the student experience, general supports, and special service program elements that impacted the student experience. The questions from the persistence interview protocol focused on student perception of internal and external facilitators and barriers the students' experienced while managing the college environment. With this addition, the study grew to encompass both the broad experience of the transition to college and a more detailed perception of facilitators and barriers.

The full scale IQ scores, the number and type of disabling conditions, and college grade point averages were tracked for the students in the persistence grouping. The number of disabling conditions for the persistence grouping was 2.4. The average Full Scale IQ score for the grouping was 108 . The students in the persistence grouping earned an average cumulative GPA of 2.95, which was calculated after each student's most recent semester of enrollment. See Table 5 for additional background information on the persistence grouping.

The transition narrative enabled the researcher to understand the student response to the transition as it was experienced during the second semester of the first year. The persistence narrative allowed the researcher to understand the student experience of transition in retrospect. The students were asked specifically to think about supports and blocks through the lens of their present and prior experience. All 10 interviewees had completed at least four semesters. Seven were on the "brink" of graduation during the interview and have been graduated at the time of this writing. For the most part, the students in the persistence grouping indicated solid academic performance. 


\section{Negative Transition Collective Case Summary}

Although the average full-scale IQ and the average number of diagnosed disabling conditions were similar for both the negative and positive transition cohorts, the 7 members of the negative grouping earned an average cumulative GPA, taken after each student's most recent semester of enrollment, of 1.86. During the time of matriculation, each student within the ineffective grouping (negative transition cohort) earned a GPA under 2.0 and was placed on academic probation for at least one semester of enrollment. Individual cumulative GPAs for the ineffective performance students, taken after each student's most recent semester of enrollment, ranged from 0.74 to 2.27 . At the time of this writing, 2 of the 7 or $28 \%$ of the students from the negative performance grouping are still enrolled.

The narrative of the individuals within the ineffective performance grouping was analyzed and synthesized into thematic patterns for case presentation. Several distinctive conceptual commonalities clustered the students by patterns of outlook and behavior as well as by the negative performance outcome, an average cumulative GPA of 1.86 . The students in the ineffective performance grouping revealed the following nonadaptive patterns during their transition to college: Problems with self-understanding and self-management, complicated relationships with authority structures, a reluctance to accept their disabling condition which resulted in taking on a misguided independence, unconstructive patterns of social functioning, problems adapting to the academic environment, and an inability to manage developing life circumstances.

\section{Positive Transition Collective Case Summary}

Although the average full-scale IQ and the average number of diagnosed disabling conditions were similar for both the negative and positive transition cohorts, the 16 members of 
the positive grouping earned an average cumulative GPA, taken after each student's most recent semester of enrollment, of 3.0. Individual cumulative GPAs for the effective performance students (positive performance cohort) taken after each student's most recent semester of enrollment, ranged from 2.64 to 3.53 . At the time of this writing, 14 of the 16 or $87 \%$ of the positive performance group members are still enrolled.

The narrative of the individuals within the effective performance grouping was analyzed and synthesized into thematic patterns for case presentation. Several distinctive conceptual commonalities clustered the students by patterns of outlook and behavior as well as by the positive performance outcome, an average cumulative GPA of 3.0. The students in the effective performance grouping revealed the following adaptive patterns of outlook and behavior during their transition to college: they recognized, appreciated, and followed through on preparative experiences for the college transition, they integrated socially into the campus community, they were proactive in managing their learning disability, they sought constructive types of help, they recognized and managed problematic issues, they took a strategy based approach to the transition, and they acknowledged the primacy of learning and graduating.

It is noteworthy that the students from the effective functioning grouping were not overcome by their problems. The students identified situations that interfered with effective functioning and worked to solve the difficulties by taking direct action and seeking help from environmental support structures.

Within their description of proactive adjustment to the postsecondary environment, the positive performing transitional students referred to external events and experiences that promoted their successful functioning. These results corroborated several findings from the exploratory study and were again corroborated by the findings that emerged from the persistence 
cohort in the current study. In addition, the students in this grouping identified prior inappropriate special education experiences.

\section{Persistence Collective Case Summary}

The 10 students who made up the persistence grouping completed at least 60 credits toward graduation and earned an average cumulative GPA, taken after each student's most recent semester of enrollment, of 2.95. Individual cumulative GPAs for the persistence cohort students, taken after each student's most recent semester of enrollment, ranged from 2.28 to 3.83 . Only 1 student earned a cumulative GPA less than 2.5. At the time of this writing, seven of the ten students within this grouping have been graduated, two continue to make progress toward graduation. 10 of the 10 students or $100 \%$ are still enrolled or have been graduated. The students in the persistence cohort revealed personal or internal patterns of successful functioning and conveyed a student perspective of internal and external facilitators of and barriers to persistence in the college setting.

Internal facilitation of successful performance involved a process of self-awareness based practice to promote well-being. The knowledge of personal goals and strivings, limitations, strengths, and a mindset supported by self-awareness formed the stage for individual and interactive practice to promote academic, social, and emotional well-being. The students revealed two broad categories, individual and environmental qualities and defined and informal supportive structures, for external facilitation of successful postsecondary performance. Internal barriers to successful performance were twofold: limitations posed by the students' disabling condition and problems grounded in how the students viewed themselves, including inadequate self-understanding and insufficient self-management. External barriers to successful performance communicated by the students were general time constraints in managing a full course load along 
with extracurricular commitments, limitations in professors' understanding and treatment of the students' unique needs, difficulty meeting certain requirements of the college curriculum and the demands of coursework, and adverse familial and social factors. 


\section{Chapter 5: Summary, Conclusions, and Recommendations}

\section{OVERVIEW OF THE STUDY}

The number of students with diagnosed learning disabilities attending post-secondary institutions has increased significantly in the last fifteen years. In 1998, 58,000 college freshmen reported having learning disabilities compared to 18,000 who reported them in 1988 (Heath Resource Center, 1999). Although the American legal system has begun to ensure protection of the civil rights of postsecondary students with diagnosed learning disabilities, outcomes for the success of these students are weak compared to the outcomes of their nondisabled peers (Wolanin \& Steele, 2004).

The complexity of the college environment requires a new level of personal and academic regulation that is challenging for all students. The student with learning disabilities may have magnified difficulty adjusting to and building resources within the intrinsically structured context of higher education. A review of the literature showed that we are missing mark by focusing merely on the academic remediation and civil rights of these students. The condition of learning disabilities is wrought with psychosocial considerations that need attention, at any level, if this specialized grouping is to reach its true potential (Adelizzi, 1995; Cohn, 1998; Goldstein, 1997; Neilson, 2001; Osman, 1996; Price, 2002; Ramsay \& Rostain, 2004;

Rourke \& Fuerst, 1991; Silver, 1984; 1997; 1999; Spekman, Goldberg \& Herman, 1992).

Although the number of data driven studies appearing in the professional literature is increasing, for the most part, a search on postsecondary programming for students with learning disabilities turned up position papers on best practice. Appropriately, there has been a call in the professional literature for field study exploring the experience of this population within the postsecondary setting (Brinckerhoff, McGuire, \& Shaw, 2002; Mull, Sitlington \& Alper, 2001; 
Rath \& Royer, 2002; Skinner, 2004). Since entrance into higher education is a relatively new phenomenon for individuals who have been diagnosed with learning disabilities, exploratory study is appropriate to understand the needs of the population.

This research project qualitatively explored supports and barriers experienced by the postsecondary student with learning disabilities during the transition to and persistence in a four year liberal arts institution. Extending the empirical knowledge base, grounded in the reality of the student voice, to build a foundation for postsecondary program design for the grouping, was the project mission. The development of responsive programmatic support may transfer into higher rates of degree completion for this marginal but emergent postsecondary population.

The results of the inquiry will be of interest to postsecondary professionals who provide direct service to the population in question, to those who deliver transition services in the $\mathrm{K}$ thorough 12 setting, to college administrators who seek to manage and retain enrollments, and to parents of students, and the students, who plan to enroll in baccalaureate degree programs.

An exploratory study was conducted by the researcher to gain more information about the postsecondary transition experience of students with learning disabilities. Analysis of seven semi-structured one-on-one interviews revealed the following themes of significance for firsttime, full-time college students enrolled in the first semester:

1. establishing academic competence and confidence

2. acknowledging the need for a responsive support system

3. recognizing the impact of adequate or inadequate academic preparation

4. appreciating the link with family support and nurturing social connections

5. navigating the differences between high school and college

6. establishing internal self-disciplinary structures 
7. affirming the importance of a strong work ethic and the will to persist

8. seeking compatibility with the campus milieu, and

9. acknowledging concern over being accepted as normal.

In addition, the exploratory findings suggested that supportive conditions facilitating postsecondary adjus tment focused not only on the practical aspects of access to accommodations and services; specific attitudinal attributes of parents, faculty, and support service providers were significant for the students. Transparent investment in student success, empathy, and confidence in the student's ability on the part of these significant players was considered by the interviewees to be instrumental in achieving transition to the postsecondary environment. Noteworthy was the student response to the assistance provided by a professional mentor. One person to link the student to accommodations and services, to help with academic scheduling, to troubleshoot and to be a sounding board for psychosocial transitional concerns, was repeatedly acknowledged as advancing the transition process. The students in the study recognized the use of scaffolding techniques by parents, teachers, and support service providers as a method of helping that encouraged independence and confidence. (Kuba, 2003).

The current study was conducted to substantiate the pilot findings and to extend these findings by exploring supports and barriers encountered by a transitional cohort of students, students undergoing the transition during their second semester of enrollment, and a persistence cohort of students, students who have progressed at least halfway toward the baccalaureate degree.

The inquiry addressed the following areas of interest, reflected in the semi-structured interview protocols, subtopics of the primary research objective: the investigation of internal and 
external supports and barriers experienced by students with learning disabilities as they transition to, and persist in, the college setting:

- What characteristics of support does the student with learning disabilities find beneficial?

- From the student's retrospective point of view, what happened in high school and what has happened in the postsecondary environment to facilitate the process of transition and persistence?

- What internal and external challenges does the student with learning disabilities face in the postsecondary environment?

- What qualities are evident in the student with learning disabilities who succeeds in taking on the environment of higher education?

- What environmental factors characterize a successful transition to, and ultimately, persistence in, the postsecondary environment for the student with learning disabilities?

- What are the common themes of concern for students with learning disabilities?

Qualitative methodology is particularly suited to answer the research question, because through open-ended inquiry, we can learn about student experience: what the student does, knows, thinks, and feels (Marshall \& Rossman, 1999; Patton, 1990; Strauss \& Corbin, 1998). To learn about the phenomenon of postsecondary transition and persistence for the student who has been diagnosed with a learning disability, it is appropriate to talk with the student, an insider going through the process. The open-ended interview together with its follow-up questioning provided an appropriate design to penetrate the depth and detail of the student experience (Gay \& Airasian, 2000; Patton, 1990). The unit of analysis was the student undergoing the 
postsecondary experience, and the center of the investigation was the participant's perspective once the student entered and/or persisted in the college setting (Patton, 1990).

A semi-structured interview format uncovered student perception of the postsecondary experience, significant themes of transition and persistence, and revealed strategies and attitudes that promoted or inhibited success for this population. These phenomena are not easily observed. The student voice expressed the major themes that were analyzed and will be used to inform the construction of responsive program development.

To discover and to code broad themes linked with transitioning or persisting in the postsecondary environment, the content of the corresponding interviews was read multiple times. The coding process helped to connect fragment concepts in the data with common elements of the postsecondary transition and persistence experience of the students under study (Coffey \& Atkinson, 1996). A cross-case comparative analysis was utilized to uncover themes found within and among each the transition and persistence cohort. The data was reviewed, labeled, integrated, analyzed, interpreted, and synthesized several times by the researcher who is an expert in the field of leaning disabilities. Core categories that illustrated the experience described by the students were confirmed (Gay and Airasian, 2000; Strauss \& Corbin, 1998; Merriam, 2002; Patton, 1990). The study is defined as an instrumental multiple or collective case study because the researcher utilized the cases to discover and understand "a phenomenon, population, or general condition" (Stake, 2000, p. 437).

Thirty-four students attending a small liberal arts college located in the Appalachian Region of the United States volunteered to interview for the study over a three year period. All were enrolled in a special services program for students with learning disabilities. Altogether, 33 verbatim student transcripts were deconstructed for presentation in the findings. The transition 
cohort was initially composed of 24 students: 16 made up the positive collective case and seven formed the negative collective case. One transition student did not meet the qualifications for the study so his transcript was not used in the analysis. The persistence cohort was composed of 10 students. One of the students who interviewed as a member of the transition cohort also interviewed as a student who persisted toward graduation three semesters later. The number of interviews finally transcribed and analyzed for the study was 33 .

\section{CONCLUSIONS}

The first set of conclusions are based on the analysis of the transition cohort: a comparison of the student patterns of effective and ineffective postsecondary transition, common disability-related problems experienced by students undergoing the postsecondary transition, a retrospective student view of unsupportive K-12 special educational practices, and external factors that facilitate an effective postsecondary transition. The second set of conclusions are based on the analysis of the persistence cohort: a prototype of internal facilitation for successful postsecondary functioning for the student with learning disabilities, external factors that facilitate the postsecondary persistence of students with learning disabilities, internal factors that bar the postsecondary persistence of students with learning disabilities, and external factors that bar the postsecondary persistence of students with learning disabilities.

\section{Transition Cohort}

Examination of the transitional cohort transcripts support the following conclusions: patterns of effective and ineffective student functioning that influence academic performance, disability-related problems experienced by the effective functioning students, student perception of inappropriate prior special education experiences, and external facilitators that promote successful transition. These conclusions will be discussed in detail below. 


\section{Effective and Ineffective Transitional Approach Compared}

The positive and negative performing transition students contrasted in their behavior and outlook in seven areas of func tioning: application of preparative experiences, integration into the campus community, disability management, utilization of support structures, problem solving approach, transactions based in self- understanding, and goal directedness. The contrasting patterns of effective and ineffective transitional functioning for students with learning disabilities undergoing the transition to the postsecondary setting are summarized in Table 9.

According to the findings from this study, students with diagnosed learning disabilities are likely to perform toward their potential during the transition to the postsecondary setting if they incorporate the following patterns of outlook and behavior into their everyday functioning:

- apply the formal and informal preparative experiences designed to ready them for the college setting and for life;

- $\quad$ proactively join in the campus community;

- manage their disabling condition by utilizing their knowledge of strengths and limitations and by disclosing their disability to the appropriate persons;

- employ constructive support structures that enhance independent functioning;

- acknowledge and actively engage in solving problems;

- strategically approach the transition by managing thinking and adjusting expectations to adapt to the social and academic environment, using self-control strategies, and individual and social cognitive techniques to enhance academic transaction; and,

- carry the primary goal of learning and graduating into every context of the postsecondary setting, staying goal-directed but flexible as the situation warrants. 
Students with diagnosed learning disabilities are likely to operate below their potential during the transition to the postsecondary setting if they present the following circumstances, patterns of outlook, and behavior in their everyday functioning:

- Have not had adequate academic or social preparation for the complex postsecondary environment or do not apply the preparative experience to which they have been exposed;

- $\quad$ stay isolated within the community and depend on prior networks for their sole means of support and interaction;

- block appropriate acknowledgement of needs and the use of support services because of personal embarrassment related to the disabling condition;

- take a passive stance toward academic transactions and remain unresponsive to environmental support structures even as authority figures attempt to intervene;

- deny and become overwhelmed by the presence of surfacing problems and block the generation and trial of solutions to those problems;

- lack self- understanding toward supporting the social and academic transition and remain passive toward understanding the internal dynamics to control starting and sustaining effort and following through for academic task completion;

- remain vague regarding their personal goals for attending college, enroll due to real or constructed parental or societal pressures, and are inflexible regarding the idea of exploring alternative majors if the original plan of study fails. 
Table 9

Effective and Ineffective Postsecondary Transitional Management

Effective performance Ineffective performance

\section{Preparation}

Intentional social and academic preparation Inadequate academic and social readiness for independent functioning; recognized and preparation; did not apply preparative and applied preparative experiences experiences

Integration into the campus community

Proactively integrated into the campus Constricted social interaction; deficient community; sought involvement with assertiveness; stayed isolated within the campus organizations and activities community; depended on prior networks

for interaction

Disability management

Productively managed disability; utilized Disability related self-embarrassment personal academic history to navigate new blocked acknowledgement of needs, setting; awareness-based compensation of appropriate disclosure, and use of limitations; disclosed disability to accommodations and services appropriate persons

\section{Utilization of support structures}

Acknowledged importance of support Passive stance toward academic

services; actively utilized interdependence- transactions; unresponsive to

based help; offered suggestions for environmental support structures and the improved services attempted intervention of authority figures 


\section{Problem-solving approach}

Realized and engaged in solving disability- Inability to cope with everyday difficulties; related and other problems involving self- denied academic problems; blocked to development and environmental generating and trying solutions; easily adjustment; openly acknowledged and overwhelmed and shut down by developing corrected self-generated predicaments problems

Self-awareness based transactions

Strategically approached the transition

based on self-knowledge; managed thinking and adjusted expectations to adapt to the environment; used self-control strategies to handle arduous and uninteresting academic tasks; utilized intraand social cognitive techniques
Passive disposition and inadequate selfunderstanding toward supporting the social and academic transition; inability to start to work, to sustain effort, and to follow through on the acknowledgment of how to carry out academic task completion

Goal directness

Carried the primary goal of learning and graduating into social, emotional, and academic contexts; valued the educational process; stayed goal directed but flexible
Vague personal goals for college attendance; not disappointing parental figures was the primary stated goal; inflexible in exploring alternative plans when the original plan of study failed 


\section{Disability-Related Problems}

The literature abounds with descriptions of the psychosocial vulnerabilities experienced by individuals who have been diagnosed with learning disabilities (Price, 2002; Silver, 1984, 1997; Goldstein, 1997; Ramsay \& Rostain, 2004). An important implication of the Beirne-Smith and Deck (1989) study was the concern practicing professionals expressed for the nonacademic needs of their students. "The same problems that interfere with reading, writing, and arithmetic also interferes with emotional and social development or can cause emotional and social problems" (Silver, 1984, p. 55). Price (2002) summarized five broad categories of psychosocial issues, revealed in the professional literature, that are commonly experienced by individuals with learning disabilities: self-concept development, social skills deficits, dependency issues, stress and anxiety, and negative feelings and behaviors.

The findings from the current study support the idea of extending psychosocial support to all students with learning disabilities within the postsecondary setting, even the successful students. The effective performance students openly discussed disability related problems experienced in gemeral and during their transition. Not one of the 16 students from the effective performing transition grouping was problem free. The following disability-related problems impact the well-being of students with learning disabilities as they transition to the postsecondary setting:

- $\quad$ problems with social interaction caused by the misreading of social cues;

- controlling impulsivity which impacted peer and other relationships;

- personal embarrassment as the disabling condition becomes apparent;

- fragile self-confidence;

- deciding about the benefits and risks of taking psychoactive medication; and, 
- $\quad$ performance anxiety.

Issues concerning academic adjustment, handling the social freedom of the new setting, and learning to independently operate in the new environment may have been magnified because of the additional support and structure to which students with learning disabilities are accustomed. It is noteworthy that the students from the effective functioning grouping were not overwhelmed by their problems. They were willing to work through the obstacles by using support structures to explore internal and external dynamics that could be used to correct or ameliorate the problematic circumstance.

\section{Inappropriate Prior Educational Experiences Disclosed}

Students from both the negative and positive transition cohort retrospectively addressed several concerns regarding the way their education, accommodations, and services had been handled in settings prior to their college enrollment. Although not fundamental to the effective performance narrative, seven of the 16 positive performance students were critical of their earlier special educational experiences. Taken together with the description of inappropriate prior educational experiences that permeated the narrative of the students in the negative performance grouping, the concerns raise meaningful questions regarding specific areas of special education practice in the secondary setting. The type of help described, although well intended, missed the mark and possibly caused more harm than good.

The students expressed the following concerns pertaining to their prior special educational experiences. In the cases described, educators and administrators intervened inappropriately, were unaware of, or were unable to correct the following situations:

- underestimation of student ability;

- limiting the student from taking challenging curricula; 
- failing to remedy clear indicators of inadequate academic and organizational skill development;

- inappropriately grouping students who manifest significantly divergent academic potential and behavior patterns;

- implementing accommodations that enabled student dependence and irresponsibility;

- insufficient training of regular education teachers on the condition of learning disabilities;

- inadequate training for the implementation of testing accommodations; and,

- ineffective monitoring of the modification of extended assignment deadlines.

\section{External Facilitators for an Effective Transition}

Within their description of proactive adjustment to college, the positive performing transitional students referred to external events and experiences that promoted their successful functioning. These results corroborated several findings from the exploratory study for this project and were again corroborated by the findings that emerged from the persistence cohort in the current study.

The seven students interviewed in the pilot study for this project (Kuba, 2003) indicated that the practical aspects of easy access to accommodations and services provided by the special support program were important in helping the student make the transition to the postsecondary setting. In addition, the students observed that the posture taken by parents, faculty, and support service providers was critical. Transparent investment in student success and confidence in the student's ability were attitudes found to be instrumental in helping the student to make the transition. A mentor to link the student to accommodations and services, help with academic scheduling, troubleshoot as problems emerged, and to be a sounding board for psychosocial 
concerns promoted the transition to the postsecondary setting. The students in the pilot study and the successful students in the current project described the use of scaffolding techniques by parents, teachers, and support service providers as a method of helping that encouraged independence and confidence. The educational concept of instructional scaffolding may be compared to Nevitt Sandford's (1967) description of the appropriate context for college student development: the right combination of readiness, challenge, and support. The idea of optimal environmental challenge is important because students get overwhelmed and fail if they are presented with situations or tasks that are far above their current capacities. However, if there is no stress, there is little or no development.

The scaffolding principle provides the kind of support that is ideal for growth and development. Scaffolding incorporates an instructional relationship in which the expert teacher, mentor, or parent sets up a learning experience, intervenes, and withdraws as appropriate (Bukatko \& Daehler, 1995). Initially, strong support is given; however, guidance and instruction gradually tapers. The learner ideally operates within his or her "zone of proximal development" (Vygotsky, 1978), an area in which the student is capable of task participation and, at the same time, stretched to expand competence (Bukatko \& Daehler, 1995). The students from the exploratory study, the positive transition, and the persistence cohort described benefiting from the type of help and instruction that corresponds closely with the instructional principle of scaffolding.

The following external factors will likely support the transition to and successful functioning of students with diagnosed learning disabilities in the postsecondary environment: 
1. Preparation through the development of informal and formal relationships that impart the value of hard work, persistence, flexibility, self-sufficiency, education, mental acuity, and social relationships;

2. Preparation through explicit coaching to develop academic, social, organizational, and self-management skills required to function in an independently structured setting;

3. Participation in academically rigorous college preparatory curricula;

4. Guidance programming that provides instruction in the differences between the secondary and postsecondary environment;

5. A nurturing and diverse campus community which affirms student membership and in which faculty encourage and mentor the student;

6. The structured first year seminar which presents the opportunity to meet other new students and upper class peer advisors and to process the transition with an experienced staff or faculty member;

7. Diverse membership opportunities offered through campus organizations, sports and performing arts, and volunteer networks;

8. Strong support programming for students with diagnosed learning disabilities, backed by the college administration;

9. The opportunity to review or relearn basic academic skills needed for the complex level of college study;

10. Teaching faculty who invite disability disclosure in course syllabi;

11. Cooperation and communication between the teaching faculty and the office responsible for the provision of special support services for students with disabilities; 
12. Mentoring from faculty and professional staff who use a scaffolding approach to guide the student toward autonomous social, academic, and emotional functioning; and,

13. Faculty and professional staff who communicate confidence in the student's ability to succeed and concern for the student's well-being.

Additional external supports for successful functioning that were specified by the students from the persistence cohort will follow.

\section{Persistence Cohort}

Analysis of the interviews with the ten students who made up the persistence cohort (students who earned 60 or more credits toward graduation) supported the findings of the effective functioning transitional cohort - especially the students' internal pattern of behavior and outlook for successful performance. The students from the persistence cohort revealed a prototype or example of internal facilitation that promoted successful performance for students with learning disabilities in the postsecondary setting. In addition, internal and external factors that facilitated and barred student transition to and persistence in the postsecondary setting have been extracted from the narrative of this cohort. The findings from both the transition and persistence cohorts provide the basis for developing programming for individuals with learning disabilities in the postsecondary setting.

The results of Maurice Miller's (2002) qualitative study on the resiliency of individuals with learning disabilities are supported by these findings. Using data from open-ended interviews with 10 individuals, Miller discovered thematic differences between the resilient and nonresilient college student with learning disabilities. Themes in how resilient "individuals saw, in their own histories, the elements which led to their resilience" (p. 293) were: identifiable success experiences, acknowledgement of particular areas of strength, self-determination, distinctive 
turning points, special friendships, encouraging teachers, and acknowledgement of the learning disability. Several of the themes Miller described are evident in the persistence cohort's description of internal and external facilitation of successful postsecondary performance.

\section{Process of Internal Facilitation for Successful College Performance}

The students from the persistence cohort revealed a prototype of internal facilitation that promoted the successful performance of students with learning disabilities in the postsecondary setting. The pattern revealed by these students corroborated the findings on effective transition management extracted from the positive performing transitional cohort. The prototype involves self-awareness-based practice to promote well-being. The knowledge of personal goals and strivings, limitations, strengths, and a mindset supported by self- understanding form the stage for individual and interactive practice to promote academic, social, and emotional well-being. Selfawareness leads to the development of an outlook or approach which facilitates student management of the environment through individual or interactive practice.

Self-knowledge of personal goals and strivings, strengths, limitations, and one's unique approach to navigating the college environment promote productive everyday functioning. Vigilance in staying goal-directed and the realization of inner strengths, personal transformations, and success lead to stable performance. Unguarded and reasonable honesty with self and others regarding personal limitations is the starting point for compensating barriers met in the academic setting. An attitude of determination can overcome the frustration inherent in the academic process for this population.

Personal goals and strivings energize the will to succeed and should be kept at the forefront of all aspects of the college experience. Recognition and awareness of past accomplishments, of current growth and success, and of past and ongoing personal 
transformation will arm the student with confidence. Compensation for personal limitations becomes possible with this self-understanding. The development of a mind-set based on selfawareness facilitates success. Important elements of this mindset are realism, optimism, academic diligence, determination, persistence, and self-reliance balanced with activation for appropriate assistance.

Specific individual and interactive practices generated by the students facilitated academic success and sustained their social and emotional well being. Individual study practices for effective performance included learning by repetition, practicing problems, self-testing, utilizing several sensory channels to learn course material, strategic organizational planning, and the application of procedures taught through study skills instruction and tutoring.

Interactive practices to promote effective academic functioning included intentional communication with professors, paying attention to the cues given by the professor in the classroom environment, studying with class peers, using professor feedback via returned tests and papers, and utilizing special services for students with learning disabilities.

The students practiced the following individual strategies to maintain social and emotional well-being: they worked to manage their thinking and changed outcome expectations to lessen performance anxiety. They were able to change a misguided course of action to mitigate developing problems. The utilization of self-talk controlled the self-reaction to stressful conditions brought on by academic work load or social and emotional concerns. Staying power for the completion of lengthy and taxing academic work came about by shifting focus, taking breaks, and using "prime" internal concentration time to take a "fresh perspective" on challenging tasks. 
Interactive practices that promoted the social and emotional well-being of the students included participating in extracurricular activities for release and relaxation, seeking the social and emotional support of others, and utilizing campus counseling resources to increase personal stability as difficulties are encountered.

The students in this study used a compensation approach much like what was termed learned creativity by Reiff, Ginsberg, and Gerber (1995): "specialized and individual methods for coping and succeeding with the very circumstances previously deemed overtaxing” ( $p$ 34). In addition, the students established social ecologies. They described surrounding themselves with supportive and helpful people but tried to not become overly dependent on them, much like the successful adults who were interviewed by Reiff et al. See Table 10 for a summary of the process of internal facilitation for successful postsecondary performance. 
Table 10

Process of Internal Facilitation for Successful College Performance

Self-knowledge

Vigilance in staying goal-directed

Develop personal goals and keep them at the forefront of every aspect of the college experience

Energize the will to succeed, in the face of limitation and frustration, through personal strivings

Identification of inner strengths to promote stable performance

Identify personal transformations

Realize growth and success

Anchor the self in positive experience

Carry personal history of accomplishment into the college setting

Unguarded acceptance of personal limitations and challenges

Recognize and understand limitations to allow for compensation

Meet limitations and work through them with self and others

Mindset that activates overcoming hardship

Develop realistic and optimistic vision of the self as it relates to the future

Maintain diligence in surmounting academic, social, and emotional barriers

Function with self-reliance balanced with activation for appropriate assistance 
Individual and interactive practice for academic well being Intracognitive practice

Start early, over-learn, practice retrieval and utilize multiple sensory channels to encode to-be-learned material, strategically plan, apply strategies introduced through study skills instruction

Social cognitive practice

Interact with professors and academic peers, pay attention to the academic cues in the classroom environment, respond to feedback via returned tests and papers, utilize special services for students with diagnosed disabilities Individual and interactive practice for social and emotional well being:

Individual practice

Manage thinking to increase self-confidence

Manage outcome expectations to lower performance anxiety

Shift, break, and use optimum concentration time to complete challenging academic tasks

Recognize and shift unproductive outlook and behavior

Use self-talk to cope with stressful conditions

Interactive practice

Participate in constructive nonacademic activities to relieve stress

Seek social and emotional support from others

Utilize campus counseling and other resources to cope with difficulties 


\section{External Facilitators of Successful Postsecondary Performance}

The foundations of external support for the persistence students came from two areas: environmental and individual systemic qualities and defined and informal support structures. Environmental systemic qualities that promoted student success resided in the character of the campus. An institutional tone of acceptance of and connection with the student from the beginning of the student partnership with the college generated a milieu of affiliation. The institution created the opportunity for the student to establish a sense of belonging by sponsoring student involvement on campus and in the surrounding community. Allowing for the opportunity to individually communicate with significant campus figures personalized the student experience and led to successful academic performance.

Individual systemic qualities that promoted success were defined by the character of faculty and professional staff on campus and other significant helpers in the students' lives. The effective helping relationship required student self-reflection and the development of interdependence. The following personal characteristics facilitated the growth of students: authenticity, availability, acceptance, kindness, patience, encouragement, honesty, and optimism balanced with realism. Exemplary helpers recognized student accomplishments, trusted in student potential, questioned to generate personal and academic development, and interacted in ways that facilitated student independence.

Specific support structures or systems that enhanced student functioning included the academic department and teaching faculty, the support system for students with disabilities, structured to fit the individual needs of the student, the mentor who specialized in working with students with learning disabilities, the student's family, and the student's peer support network. 
Teaching faculty played a significant role in facilitating student commitment. Professors enriched the student's personal and pre-professional development through inviting the student into academic discourse. The offering of constructive positive and critical feedback and the use of a scaffolding instructional approach enabled the student to respond to academic rigor that stimulated complex cognitive development. The utilization of teaching practices that supported diverse learning abilities and styles facilitated the performance of students with learning disabilities. Finally, departmental programs that provided students the opportunity to apply academic knowledge to practice facilitated an understanding of how the degree could be played out in the workforce. This enhanced student motivation

The support system for students with learning disabilities provided a safety net for the student. It responded to the student by offering an individually structured program to meet individual needs. The provision of remedial tutoring opportunities allowed for the student to remedy academic skill gaps. The communication of clear guidelines on how to use the support service enabled the student and faculty member to trust the consistency of the support system. A reliable support system developed a cooperative practice among the support system, student, and faculty at the institution.

The mentor facilitated successful postsecondary functioning by supporting the student in the following ways: the construction of a realistic academic schedule, the development of academic and organizational strategies, the processing of student priorities and motivational outlook, assessing the accommodation and support service needs of the student, coaching the student through the disability disclosure process, helping the student link to accommodation services, supporting the student to join campus organizations and activities, assisting the student 
to connect with other campus offices for referral and support, and anchoring the student by processing the college experience.

Parental understanding of the child's unique needs for successful transition to and persistence in the college setting facilitated student functioning. Parental allowance of extra time to complete the degree mitigated student stress that might be caused by carrying too heavy a course load. The parent who intentionally held back "advice giving" and explicitly encouraged the student to transfer the support function to designated campus helpers promoted student adaptation to the new environment. Parental communication of reasonable but high expectations for effort and outcome instilled confidence in the student. The parent who offered support when things went amiss communicated a tone of acceptance that encouraged the student to continue in the face of failure if continuation was realistic.

The informal peer network supported the student with a learning disability in the following ways: Students enrolled in the same major supported one another to understand the inner workings of a particular program of study and unique faculty requirements. Student affiliation with campus organizations and sports teams enhanced a sense of belonging to the campus. Finally, informal friendships impart a sense of social stability. See Table 11 for a summary of external facilitators for successful postsecondary performance for the student with a learning disability. 
Table 11

External Facilitation of Successful Postsecondary Performance

Qualitative Factors Supporting Success

Qualities of the college environment

A milieu of acceptance and connection

Sponsorship of student involvement on campus and in the surrounding

community

Opportunity for individual communication with significant campus figures

(faculty and staff)

Individual qualities of exemplary helpers

Trust in student potential

Balance optimism with realism

Recognize student accomplishments

Question to generate self-reflection about personal and academic development

Teach and interact in ways that facilitate student interdependence

Generate constructive positive and critical feedback

Exhibit authenticity, availability, acceptance, kindness, patience, encouragement, and honesty

Defined and informal support structures

Teaching faculty and academic department

Understand and utilize the primary role of student/faculty interaction as a path for personal and pre-professional enrichment of the student 
Invitation to academic discourse

Delivery of constructive positive and critical feedback for student formation

Scaffold student to develop the ability to respond to academic rigor

Utilization of teaching practices that support diverse learning abilities and styles

Provision of the opportunity to apply academic knowledge to practice in the field

Support system for students with disabilities

Design to provide a proactive safety net

Respond to the student by structuring program to meet individual needs

Provide tutoring opportunity to remedy academic skill gaps

Communicate clear guidelines for the utilization of support service facilities to students and faculty

Develop cooperative practice among support system, student, and faculty

Special support mentor

Advise student to balance a realistic academic load

Assist student to develop academic, organizational, and motivational strategies

Process the college experience in general, especially student priorities

Process accommodation and support service needs of the student

Coach the disability disclosure process

Facilitate connection with services for students with disabilities

Sponsor student connection with organizational membership

Encourage student to link with other campus offices for referral and support 
Parental structure

Communication of parental understanding of the student's unique needs for successful postsecondary performance to the student

Parental encouragement of the student to transfer the support function to designated helpers on campus

Parental communication of solid expectations to instill confidence in the student Parental support to make appropriate changes if the student fails and encouragement if continued matriculation is realistic

Peer support network

Support and guidance from students enrolled in the same major Affiliation with campus organizations to enhance a sense of belonging Support from peer mentors with learning disabilities Support from informal friendships impart a sense of social stability 


\section{Internal Barriers to Successful Postsecondary Performance}

Internal barriers to successful postsecondary performance were twofold: the disabling condition itself and how the students viewed themselves, including inadequate selfunderstanding and insufficient self- management. Technical difficulties caused by learning disabilities continuously impacted student functioning. They included:

- difficulty focusing and sustaining academic effort;

- sustaining effort during the lengthy process of test taking;

- staying with, while spending inordinate amounts of time, on assignment completion and learning information for classes;

- shifting among the multiple and varied types of academic tasks; and,

- skill deficiency that comes to the fore when combined with certain academic requirements.

Not only do students experience the negative impact of the technical aspects of their learning disabilities, they are vulnerable to developing secondary internal problems associated with the disabling condition. One can imagine how the view of the self might be inadequately developed in the individual who has experienced the sense that something about oneself is not right over a lifetime. Dr. Larry Silver (1984), a renowned expert psychiatrist in the field of learning disabilities, explained the faulty development of the self- view in the child with a learning disability as the multiplication of negative social and academic experiences:

They try just as hard [as other children] to learn. Why don't they succeed? Their experiences confuse and frustrate them. ... Their failures, their inadequacies, and their poor interactions with peers and significant adults leave the child feeling angry 
and devalued. ... No one can talk these children out of their self-assessments because the self-image results from a collection of real experiences (p. 58-62).

According to the students from the persistence cohort, the following self-related issues or limitations posed by self- view, self-understanding, and self- management impact the postsecondary functioning of students with learning disabilities:

- the inability to manage frustration over processing limitations;

- depleted self-confidence;

- the need to prove oneself;

- performance anxiety;

- apprehension over exposing cognitive vulnerabilities;

- intellectual defensiveness;

- ambition to achieve perfection;

- easy defeat by failure;

- absence of internal motivation; and,

- inadequate regulation of constructive academic behaviors.

See Table 12 for a summary of the internal barriers to successful postsecondary performance experienced by the student with a learning disability. 
Table 12

Internal Barriers to Successful Postsecondary Performance

Limitations posed by the disabling condition

General difficulty in focusing and sustaining academic effort

Sustaining effort during the lengthy process of test taking

Staying with learning and assignment completion for inordinate amounts of time

Shifting among the multiple and varied types of academic tasks

Skill deficiency combined with certain academic requirements

Limitations posed by self- view, self-understanding, and self- management

Inability to manage frustration over processing limitations

Depleted self-confidence

Needing to prove the self

Performance anxiety

Apprehension over exposing cognitive vulnerabilities

Intellectual defensiveness

Ambition to achieve perfection

Easy defeat by failure

Insufficient motivation based on absence of specific personal goals

Inadequate regulation for the development of constructive academic behaviors 


\section{External Barriers to Successful Postsecondary Performance}

External barriers to successful postsecondary performance for the persistence students were general time constraints, the limitation of professor understanding of unique student needs, meeting certain requirements of the college curriculum and the demands of coursework, and adverse familial and social factors.

Even though the students were eligible for and used appropriate need based accommodations such as extended time for testing, they described the external time pressure of juggling the collective demands of the academic course load with involvement in extracurricular activities. The fact that there is only 24 hours in a day posed a challenge for the students who spent an inordinate amount of time to complete academic tasks. Sleep deprivation often resulted from trying to manage all of the activities involved in full participation in the postsecondary environment.

The students experienced difficulty when their professors made impromptu changes to course assignments and deadlines and were not well organized in the presentation of class. The students struggled when the professor announced an assignment at the last minute. It was almost impossible to follow the lecture of a professor who, because of expertise and style, skips around within the course content and various time and conceptual frames, without making the transitions transparent. In addition, navigating a personal response when the professor misunderstood or forgot to take into account the unique needs of the individual with a disabling condition, after student disclosure, posed a considerable challenge. Finally, a flippant or inpatient response on the part of a professor demonstrated a lack of understanding and respect, especially for the student whose self-confidence is easily eroded. 
There is a range of factors connected with completing the academic requirements of the Liberal Arts degree which present a challenge for the postsecondary student who has learning disabilities. Managing disinterest in various general studies requisite classes, comprehending thick, detailed, and highly technical text, coping with the cumulative impact of a taxing course load, handling large amounts of reading and writing fundamental to postsecondary coursework, and dealing with complex testing formats threatened successful performance.

Social and familial factors can bar the successful postsecondary functioning of the student with learning disabilities. It is possible the learning disability may impede student facility to manage problematic circumstances or may intensify the perception of the personal impact of the difficult conditions. The students experienced difficulty negotiating the social opportunities available in the college setting. On the other hand, social isolation was a problem for the student whose perception problems impacted the development of social skills. Major family transitions such as divorce and death presented the students with a heavy burden. It was extremely difficult dealing with sadness and grief such circumstances posed away from the family and a familiar support network. See Table 13 for a summary of the external barriers to successful postsecondary performance experienced by the student with a learning disability. 
Table 13

External Barriers to Successful Postsecondary Performance

General time constraints

External pressure of meeting combined academic and extracurricular demands

Not enough hours in the day

Sleep deprivation in response to external time limitations

Limitations in professor understanding of student needs

Impromptu/frequent changes to course requirements

Absence of the provision of a lecture or discussion format or framework

Misunderstanding learning needs/forgetting to accommodate the student's disabling

condition

Flippant or impatient response to the student

Meeting certain requirements of the college curriculum

Managing personal disinterest in required general studies classes

Comprehending dense, detailed, and highly technical text

Handling large amounts of reading and writing essential to coursework

Coping with the cumulative impact of a taxing course load

Managing complex and lengthy testing formats

Adverse familial and social factors magnified by the disabling condition

Coping with major family transitions away from the familiar support network

Navigating multiple invitations in the context of the college social environment

Managing isolation in the context of the college social environment 


\section{DISCUSSION AND RECOMMENDATIONS}

Prior qualitative research exploring the experience of the individual with learning disabilities contributes to a contextual backdrop for facilitating the potential of this postsecondary grouping. One form of assistance is to instruct these students on how they can develop internal frameworks to promote their success and resilience, and how to come to terms with their disabling condition.

Personal reconciliation with the learning disability is a factor that strongly influences the student's success or failure in college. Higgins et al. (2002), who reported the stages of coming to terms with the condition of learning disabilities, provide a context to promote selfunderstanding. In a qualitative longitudinal project tracking the lives of 41 individuals with learning disabilities, these researchers discovered five common stages of "coming to terms" with the learning disability diagnosis and uncovered "a shared set of understandings concerning distinct stages" (p. 3) of accepting the diagnostic label.

In the first stage, awareness of a difference, the student observes a personal difference from others in the academic, social, emotional, behavioral, and physical arena, even before the diagnosis is made. In addition to this pre-diagnostic awareness, the individual describes a negative self-judgment in relation to others. The labeling event stage includes all of the events leading to the diagnosis or the labeling event. At this stage, individuals begin to accept the labels that reflect their difficulties, and to reject those that do not. The next stage, understanding/negotiating the label involves making sense out of the label by determining how it will impact school/life functioning for both the student and significant others. In the compartmentalization phase, the individual puts the limiting conditions into perspective: "the task of this stage is to minimize weaknesses and maximize strengths, both inside and outside the 
classroom, and contain the disability to classroom situations" (p.12). The individual sees the learning disability as one aspect of the self, "rather than being defined entirely by it" (p. 6). During the compartmentalization stage, individuals begin to discover or realize strengths and talents and to actively participate in remedial opportunities.

In the final stage of disability acceptance, transformation, the individual is able to view the disability in a positive light. Because the person is able to see the disability "as a positive force" (p. 13) in one's life, Higgins, et al. labeled this stage transformation. This phase relates closely to what Gerber and Ginsberg (1990) and Reiff, Gerber, and Ginsberg (1995), who studied successful attributes of highly successful adults with learning disabilities, defined as reframing of the learning disability: "appreciating that the key problem is not the disability itself, but rather the capacity to confront the various challenges one faces in living with it and overcoming it" (Gerber \& Ginsberg, 1990, p. 8). The effective functioning students from the transition cohort and the students from the persistence cohort openly discussed their disability related problems and their approach to solving them.

The effective functioning students from the transition cohort and the students from the persistence cohort in this study manifested the internal and external characteristics exhibited by the successful adults studied by Reiff, Gerber, and Ginsberg (1995). The students took control and managed themselves in order to have a successful college experience. Like the successful adults, the students showed the internal characteristics of exhibiting a desire to succeed, staying goal directed, and accepting and managing their disabling condition. The students demonstrated the externally manifested characteristics, found in the successful adults of the Reiff et al. study, of persistence, goodness of fit, by choosing to function in external environments that would bring 
about successful results, learned creativity, and the development of social ecologies, by developing individual and interactive practices that promoted their achievement.

Goldberg et al. (2003) expanded upon the Higgins et al. longitudinal project tracking the lives of 41 individuals with learning disabilities by exploring success attributes of the same individuals though the analysis of in-depth intervie ws of the informants. The findings demonstrated that successful functioning of the participants was attributed to the following characteristics: self-awareness, proactivity, perseverance, appropriate goal setting, effective use of social support systems, and emotional stability/emotional coping strategies. The characteristics described were "more predictive of success than ... academic skills" (Goldberg, et al., 2003).

Snow, Jackson \& Corno (1996) theorized that "many important student aptitude and achievement differences are not strictly cognitive; many are affective or conative" (p. 243). Conation defined is "that aspect of mental process or behavior by which it [the organism] tends to develop into something else. . purposive striving [characterized by] an intrinsic unrest of the organism" (English \& English, 1958, p. 104). Daniel Goleman (1995) coined the term "emotional intelligence" and described it as "being able to motivate oneself and persist in the face of frustrations; to control impulse and delay gratification; to regulate one's moods and keep distress from swamping the ability to think; to empathize and to hope" (p. 34).

The findings from this study demonstrate, yet again, the important role conative factors play in successful functioning and performance, specifically in the postsecondary transition and persistence of students with learning disabilities. Although the average of the number of disabling conditions and the average of the full-scale intelligence quotients were similar for both the negative and the positive transition groupings, in addition to the obvious grade point average 
difference, a marked divergence in qualitative patterns of student outlook and behavior manifest for the negative and positive transition performance groupings. It was the students' individual patterns of outlook and behavior that seemed to make the difference in their academic performance. The students from the persistence cohort rendered a blueprint of internal facilitation for successful postsecondary performance. Both the effective functioning transition and the persistence student cohorts demonstrated several if not all of the conative features described by the informants in the Goldberg, et. al (2003) and Reiff, Gerber, and Ginsberg (1995) studies. Goldberg et al. strongly suggested that we intervene in the lives of individuals with learning disabilities by helping them "learn to develop 'strategies of success' across the life span, and in multiple contexts" (p. 234).

The results of the current study echo this call. The project fulfilled its mission: extending the empirical knowledge base, grounded in the reality of the student voice, to assist in building a foundation for postsecondary program design for individuals with learning disabilities. The students were forthcoming about the personal features that facilitated and barred successful functioning; in addition, they offered their perspective on external supports and barriers they experienced as they transitioned to and persisted in the college environment. In light of the current findings, the following practical frameworks and theoretical tools are offered to promote the successful functioning of and the development of responsive programmatic support for the postsecondary student with learning disabilities. 


\section{Practical Frameworks for Effective Postsecondary Functioning}

The grounded theory research strategy was utilized in this project to "derive inductively from data a theory that is "grounded" in the data - hence, grounded theory" (Merriam, 2002, p. 7). Substantive theory building is founded upon the practical, everyday, locally situated concern of professional practice (Meriam, 2002), concern similar to that of this study: discovering and understanding supports and barriers experienced by students with learning disabilities in the environment of higher education. The goal of this project was to contribute to substantive educational theory via conceptual ordering to promote the success of students with learning disabilities in the postsecondary environment. Strauss and Corbin (1998) maintained that highlevel description and conceptual ordering are "important to the generation of knowledge and can make a valuable contribution to a discipline" (p. x). The findings of this project implicate the following commonsense practices of preparation, environmental support, and student adaptation to promote the effective functioning of the postsecondary student with learning disabilities.

\section{Preparation}

Postsecondary preparation for the student with learning disabilities may be developed by the implementation of the following recommendations carried out within familial and/or K-12 educational contexts:

1. Explicit academic and organizational skill instruction;

2. Formal/informal instruction in the development of help-seeking behaviors to prepare for operation in complex social and academic environments;

3. Participation in academically rigorous college preparatory curricula;

4. Instructional experience to promote an understanding of multiple career opportunities related to curricula in higher education; 
5. Instructional experience to promote an understanding of the underlying purpose of the liberal arts education weighed against technical or vocational training;

6. Participation in multiple types of extra-curricular, special interest, and recreational activities to develop life interests, socialization, mental and physical fitness, and characteristics of adaptability, flexibility, diligence, and persistence;

7. Formal and informal mentoring through familial, academic, social, and recreational contexts to develop awareness of personal values, goals, and strivings;

8. Tutoring/therapy/mentoring to address the following issues:

- increase self-understanding and self-management;

- encourage and practice interpersonal and intrapersonal processing;

- learn about the disabling condition and how it impacts everyday functioning; and,

- the understanding of cognitive, executive, and social strengths and weaknesses and how strengths can be used to compensate for the disabling condition.

9. Parental and instructional scaffolding for independent social and academic functioning to allow for the internalization of social and academic self-discipline.

\section{Environmental Support}

The following environmental constructions will assist the student with learning disabilities to transition to and persist in the postsecondary setting:

1. Administrative Support:

The development of clear and well communicated guidelines for direct and centralized access to services and accommodations for the student with disabilities; 
Proactive outreach on the part of the campus community leaders to facilitate student participation in diverse activities, clubs, intramural or varsity sports, and organizations as a means of interpersonal and leadership development; Approachable campus community support via residence life, the campus counseling center, special support groups, and areas of special academic interest; Professional staff interaction that conveys availability, authenticity, balances realism with optimism, trusts in student potential, offers constructive feedback, and promotes student self- reflection and interdependence.

2. Academic Departmental Support:

Faculty who are informed about learning and other disorders that impact the cognitive, social, and executive functioning of the student; Faculty who are approachable and committed to the academic, social, and emotional development of the student; Faculty mentoring that conveys availability, authenticity, realism balanced with optimism, trust in student potential, offers constructive feedback, and promotes student self-reflection and interdependence;

Departmental programs that engage the student in both the academic discourse and the practical experience of the discipline.

Special Programmatic Support for the Student:

Professional staff that have post-graduate training in the diagnosis and characteristics of disabling conditions that impact the cognitive, social, and executive functioning of students, human development, human relationships, and individual cognition; 
Specialized mentoring that includes academic advising, guidance in the development of academic, organizational, and social strategies, and verbal processing of the student experience to navigate the academic, social, and emotional barriers to effective functioning;

Professional staff that conveys availability, authenticity, realism balanced with optimism, trust in student potential, offers constructive feedback, and promotes student self-reflection and interdependence;

Remedial tutoring opportunities to fill in academic background and skill gaps for reading, writing, mathematical, and organizational processing;

Support group opportunities to allow students to process the transition with peers who have learning disabilities, to exchange strategies for transition, and to offset feelings of isolation.

\section{Consultative Function of Programmatic Support:}

Family education to encourage parental support that communicates solid academic expectation, promotes student linkage with helpers in the college environment, and sponsors realistic continuation as barriers are met;

Family education to promote parental support that can adapt to and advocate for a different or extended academic plan if the student's progress is not compatible with the expected major or time frame;

Communication of the institutional accommodation and support processes to faculty and students and their families; 
Individualized and small group education and consultation for faculty and administrative staff to promote knowledge and understanding of diverse disabling conditions and their impact on student functioning.

\section{Personal Adaptation}

The following proactive practices will optimize the potential of the student with learning disabilities within the postsecondary setting:

1. Join the campus community:

Establish membership in campus organizations and/or special interest groups;

Participate in organized campus events, ongoing activities, and intramural sports; Seek informal friendships.

2. Strategically participate in the environment:

Seek out an academic major of personal interest;

Apply current repertoire of academic, social, and self- management strategies learned in prior settings to the new environment;

Prioritize academic work and effort over free time;

Develop a plan for constructive relaxation and the management of stress; Stay goal-directed but flexible;

Discover and implement new best personal practices for managing the selfreaction to lengthy, arduous, or uninteresting academic projects;

Develop a contingency plan for adjusting to expected and unexpected barriers.

3. Manage the disability:

Acknowledge and manage cognitive and social processing limitations;

Recognize and utilize personal strengths and accomplishments; 
Discern appropriate use of accommodations and services;

Disclose the disabling condition in appropriate circumstances;

Seek out an academic and social support network;

Utilize assistance that promotes interdependent functioning in the areas of academic, social, emotional, and organizational development.

4. Adapt to the environment:

Develop goals for full participation in the postsecondary environment;

Respond to the new environment by developing or adapting current repertoire of academic, social, and self- management strategies;

Acknowledge and actively engage presenting problems;

Adjust expectations to adapt to challenging circumstances, stay optimistic, and energize effort and assistance instead of focusing on desired or predicted outcomes;

Explore different areas of study if the initial plan falls through.

The Mentoring Relationship and Existing Theoretical Tools

Salient findings of this project relate to how self-understanding or its absence corresponds to effective or ineffective patterns of functioning. The emphasis on self-knowledge and its components of goaldirectedness, identification of inner strengths, acceptance of personal limitations, and the development of a proactive mindset calls for the utilization of theory-based practical frameworks to help students increase self-awareness to activate personal strengths and strivings in order to overcome adversity. The mentoring relationship supports the selfunderstanding of the student with learning disabilities through the postsecondary transition, and is an important resource, albeit not as intense, for student continuation throughout the 
postsecondary experience. This section contains a discussion of how certain existing theoretical tools can be utilized within a supportive relational context as a means of promoting healthy student development and effective functioning within the postsecondary environment.

The postsecondary student with learning disabilities will benefit from engagement in a relationship with a professional mentor who has been trained, on the post-graduate level, in several areas: human development, human relations, individual cognition, and diverse disabling conditions which impact cognition, for example. The research on successful adults with learning disabilities emphasizes the successful individual's development of "social ecologies" of support (Gerber \& Ginsberg, 1990). The goal of the mentoring relationship is to enable the student to function independently while developing a sense of how and when to get the right kind of help; help that promotes the student's autonomy, confidence, and personal integrity. Although complex and serious problems should be referred to appropriate campus or community resources, the relations hip with the professional mentor can provide an anchor for the student to transition to and persist in the postsecondary environment.

To help move the postsecondary student with learning disabilities forward, the mentor should be equipped with a working knowledge of the following existing theoretical frameworks: the stages of psychosocial (Chickering \& Reisser,1993) and cognitive (Perry, 1981) development of college-aged students; models of self-determination (Field \& Hoffman,1994) and selfregulated learning (Zimmerman, 2002); cognitive behavioral techniques (Beck, 1976; Ellis \& Harper, 1975; Hackney \& Cormier, 2005; Maultsby, 1984) and the model of emotional intelligence (Bar-On \& Handley, 1999; Goleman, 1995; Parker \& Bond, 2002). The prudent application of these theories may promote the student's effective performance by helping the student develop self-knowledge, self- management, social and academic proactivity, constructive 
help-seeking behaviors, strategic thinking, realistic goal setting, and constructive management of the disabling condition. The integration of cognitive behavioral and emotional intelligence theory and technique into the relational framework should facilitate the student's formation of constructive, flexible, and resilient thinking. The following discussion will describe how these theoretical constructs may contribute to increased awareness and effective functioning of the postsecondary student with learning disabilities.

\section{Psychosocial Perspective}

College students move from simple, less formed adolescents to more complex and effective functioning young adults by the time of graduation. Theories of college student development provide descriptions and explanations of how students grow during and because of their exposure to institutions of higher education (Evans, Forney \& DiBrito, 1998). Particularly useful for understanding traditionally aged college students are Arthur Chickering and Linda Reisser's (1993) revised theory of identity development and William Perry's (1981) description of cognitive structural positions.

Chickering (1969) and Chickering \& Reisser (1993) developed a theory of college student development describing psychosocial growth that characterized traditionally aged college students as they move through the postsecondary experience. Psychosocial theories help describe developmental concerns individuals face at various points in their lives (Evans et al., 1998). According to psychosocial theorists, development occurs throughout the lifespan in a series of stages that are connected to the age of the individual. Each stage presents with a new "developmental task" as physical and emotional changes intersect with social expectations to create a developmental crisis or turning point. The "developmental task" or crisis places the individual off balance and creates the need for the person to act to adjust to new situational 
demands. At each juncture, the person can choose to move forward or regress developmentally (Erikson, 1982). According to Erikson (1982), a person's life, in large part, is a result of the choices made at each stage (1982). Going to college represents a turning point linked with the stages of adolescence and early adulthood.

Drawing on Erik Erikson's psychosocial theory of life span development $(1968,1982)$ Chickering (1969) and Chickering and Reisser (1993) expanded upon tasks laid out for adolescents and young adults: the establishment of identity and intimacy. Chickering \& Reisser's theory encompassed intrapersonal, emotional, interpersonal, intellectual, and moral dimensions of college student development. Movement through each phase of development varies in terms of timing and pace because of individual differences. "Chickering's theory provides a comprehensive picture of the developmental tasks college students face. [The] work not only helps explain the issues and concerns with which students are dealing but also suggests steps that student development educators can take to foster student growth. . . [the] theory is easy to understand and use" (Evans et al., 1998, pp. 51-52).

A psychosocial theoretical perspective is particularly helpful as a context for understanding the postsecondary student with learning disabilities given their risk for developing psychosocial vulnerabilities, especially during the transition away from familiar supports and resources and into the environment of higher education. As the results of this study indicate, even the effective functioning students experienced multiple psychosocial challenges.

The following aspects of student development may be addressed through the utilization of Chickering and Reisser's (1993) model: developing competence, managing emotions, moving through autonomy toward interdependence, developing mature interpersonal relationships, establishing identity, developing purpose, and developing integrity. Several developmental 
features of this theory were expressed as major elements that facilitated or barred effective functioning for both the transition and persistence students in this project.

Developing competence includes movement toward "greater confidence and acceptance of the self as a respectable work in progress" (Reisser, 1995, p. 507) in the areas of intellectual, physical, and interpersonal development. Visual, auditory or kinesthetic processing deficits inherent in learning disabilities often undermine the development of self-confidence. An understanding of how the individual views personal abilities/disabilities will facilitate the exploration of the development of competence and the student's adjustment to the college environment. The effective performing students from this project were able to acknowledge their limitations as well as their strengths and to view these as part of the human condition rather than to focus on their deficiencies.

Managing emotions involves the ability to label a range of positive and negative feelings, to recognize their differing intensities, and to make sound decisions about their communication. It also incorporates the task of "increasing awareness and acceptance of ne gative emotions as vital sources of information [and] more flexible control of impulses" (Reisser, 1993, p. 507). This is an important area to monitor since the student with learning disabilities is prone to experience feelings of stress, anxiety, and depression than other students (Goldstein, 1997; Price, 2002; Silver, 1984; 1997). The successful students who were interviewed for this project acknowledged both positive and negative experiences. They were able to use emotional information to correct their problems.

Moving through autonomy toward interdependence describes developing "freedom from continual and pressing needs for reassurance, affection, or approval from others" (Chickering \& Reisser, 1993). The individual with learning disabilities is at risk for becoming dependent on 
parents and teachers (Price, 2002; Spekman, Goldberg, \& Herman, 1992). The student ideally develops self-direction and a healthy need for others; interdependence is a key objective. The student should be able to internalize the personal support that has been given by significant others throughout the years. The participants from this study who performed well described utilizing the type of help that promoted their independent/interdependent functioning.

Developing mature interpersonal relationships involves developing partnerships and friendships "that are consistently rewarding and that last through time, despite crises, distance, or separation" (Reisser, 1995, p. 509) and the ability to acknowledge and accept personal differences. History of educational difficulty may cause the student to over focus on the academic aspects of college at the expense of developing social connections (Kuba, 2003). The student should be encouraged to participate in college sponsored activities to increase the opportunity for interpersonal growth. The students interviewed for this project had better outcomes when they actively joined the campus community.

Establishing identity entails learning and affirming oneself. "Any experience that helps students define "who I am" and "who I am not" can help solidify a sense of self" (Reisser, 1993, p. 509). Ideally, an understanding of personal strengths and weaknesses contributes to a healthy sense of personal awareness, which in turn, contributes to optimal everyday functioning. The student should be helped to acknowledge strengths and weaknesses and to gain an understanding of how these interface with academic, social, and emotional management in the college environment. Higgins, Raskind, Goldberg \& Herman (2002) discovered five common stages of coming to terms with the disability diagnosis. One of the last two stages, compartmentalization, involved putting the disability into perspective: "The task of this stage is to minimize weaknesses 
and maximize strengths, both inside and outside the classroom" (p.12). The individual sees the learning disability as one aspect of the self, "rather than being defined entirely by it" (p. 6).

Developing purpose involves making and staying with intrapersonal, interpersonal, and vocational commitments, in spite of obstacles. Developing purpose can be examined in light of Gerber and Ginsberg's (1990) findings linking the quality of persistence to successful adults who have learning disabilities. Persistence is defined as doing whatever is necessary to accomplish or achieve a goal; this may mean working harder than others. Seeking environments that have a goodness of fit and nurturing social ecologies involves situating oneself to adapt and set up responsive structures for further personal development. Making and staying with commitments involves continual academic, social, and emotional learning; developing a personal system of learning based on knowledge of strengths and weaknesses or learned creativity should facilitate the student's ability to develop purpose (Gerber \& Ginsberg, 1990). The successful students in this study had developed personal reasons for being in school and were able to keep these goals at the forefront of their college experience.

Developing integrity includes descriptions of processes similar to the latter stages of college student cognitive development discussed by William Perry (1981), commitment in relativism. Students develop "humanizing values" when they move away from a dualistic (blackor-white/all-or-nothing) cognitive position toward a more relativistic form of thinking that takes the other and/or many points of view into account. The student is able to acknowledge personal values while understanding another perspective. "Students develop congruence by aligning their behavior with. . . personal values in socially responsible ways" (Reisser, 1995, p. 510). In addition, moving from away from a dualistic perspective can help repair one's view of self. Just as the student can affirm differences in others, he or she is ready to accept the learning disability 
as an individual difference that is okay. The student has moved past the "all or nothing" thinking that erodes self-acceptance and no longer believes "I am wrong" because of the learning disability. In this stage, the student can transform the disabling condition into a positive force (Higgins et al., 2002). For a complete discussion of the theory of identity development, see Chickering and Reisser's (1993) Education and Identity.

\section{Cognitive Perspective}

Cognitive theories help explain transformations in the way a person thinks. William Perry is a cognitive theorist who wrote about the intellectual development of young adults (Perry, 1981). Rooted in the work of Jean Piaget (Chickering \& Reisser, 1993; Eva ns, 2003), cognitivestructural theorists believe the mind has structures that Piaget labeled "schemas" (Walls, 1999) and Perry called "positions" (Perry, 1981). These structures are sets of assumptions by which persons "adapt to and organize the environme nt" (Walls, p. 285, 1999). The different positions in Perry's theory act as a formative lens for the perception and judgment of experiences and events (Evans et al., 1998). These structures gradually change, become larger and more complex as the person develops. New information that cannot be taken in by the cognitive structure as it exists creates conflict. When this is experienced, the resulting disequilibrium forces either the inclusion of the new information into the existing cognitive structure (assimilation) or the development of a new cognitive structure (accommodation) (Chickering \& Reisser, 1993; Walls, 1999). Personal readiness as well as environmental stimulation cause cognitive growth (Chickeing \& Reisser, 1993).

The cognitive theory developed by William Perry describes changes in how college aged students think. "Perry's scheme still has saliency today because the basic underlying structure movement from right-wrong mentality, to one in which multiple viewpoints are experienced as 
valid, and finally to one in which evaluations of evidence are made in a relativistic world remains viable" (Love \& Guthrie, 1999, p. 13). Although Perry (1981) observed students at nine levels of cognitive growth, four basic concepts are identified in his theory: dualism, multiplicity, relativism, and commitment in relativism. Movement along each of the nine positions represents development of more complicated thought processes; the positions are viewed as "resting points" along a continuum of cognitive growth, ending in a place of personal acceptance and commitment to an intentional life path, commitment in relativism. Perry's theory promotes an understanding of the variations in the way students interpret their experiences (Evans et al., 1998). Understanding the student's current cognitive developmental level may help the postsecondary service provider support the student's self-acceptance through discussion which sponsors the development of more complex levels of cognitive functioning.

The following description of the four basic concepts in Perry's scheme is developed from the work of Perry (1981), Evans et al. (1998), Chickering and Reisser (1993), and Love and Guthrie (1999). When a student is thinking from the position of dualism, he or she believes an authority (parent, teacher, or book) holds the right answer for everything. There is an all or nothing, right or wrong, good or bad (dichotomous) view of the world. Learning, from this position, involves taking in the right answers. Since the world is viewed from this dualistic or dichotomous perspective, the student who has a learning disability may be thinking, not always consciously, that his or her processing abilities are wrong because of the disabling condition. Disequilibrium or cognitive conflict occurs when the expectation or the student's previous way of thinking is challenged by experience. When a student is exposed to multiple points of view and is able to see that the experts often disagree, a space for transition to the next position, multiplicity, can take place. 
In the stage of multiplicity, the student is able to accept diverse viewpoints when the right answers are not yet known. "As individuals move through multiplicity, they tend to shift their idea of the role of student from that of one who learns how to learn and works hard to one who learns to think more independently" (Evans et al., 1998, p. 131). The student with a learning disability begins to understand that there is not one right way to process information, that there are multiple ways of learning and understanding. "Rightness vanishes as a standard of evaluation" (Love \& Guthrie, 1999, p. 9) in this stage and all opinions are thought to have equal merit. The transition to relativism can be seen when the student understands there is a need to support a point of view.

When a student is thinking from the position of relativism, he or she is able to discern the difference between a well thought out, substantiated opinion and one that is not and to critically analyze information to form a personal conclusion. All knowledge has a contextual backdrop. Love and Guthrie (1999) describe the transition to this position as a "radical reperception of all knowledge and values as contextual and relativistic" (p. 12). Mental processing from the position of relativism also requires "the capacity to think about one's own thinking” (Love \& Guthrie, p. 12). At this stage, the student with learning disabilities is able to reevaluate one's perception of personal abilities and disabilities. The final stage of cognitive development discussed by Perry, commitment in relativism, is not "different in terms of cognitive complexity" (Evans et al., 1998 p. 133).

Commitment in relativism involves knowing that personal choices need to be made in order to find one's "bearings in a relativistic world" (Love \& Guthrie, 1999, p. 12). An individual makes life-forming decisions regarding vocation, relationships, political beliefs, religious commitments and life style, from a contextual and relativistic framework. If knowledge 
is relativistic and contextual, then there is not one right way of knowing, not one right way of learning. Having a learning disability is not flawed or wrong, it is a variance. Once a student has reached this position on Perry's scheme, having a learning disability "involves appreciating that the key problem is not the disability itself, but rather the capacity (and commitment) to confront the various challenges one faces in living with it and overcoming it" (Gerber \& Ginsberg, 1990, p. 8) just as one commits to other life tasks.

\section{Self-Determination and Self-Regulated Learning}

Field and Hoffman have (1994) developed an educational model describing the construct that has come to be known in the disability literature as self-determination (Brinckerhoff, McGuire \& Shaw, 2002; Field \& Hoffman, 1994; Field, Sarver \& Shaw, 2003; Ryan \& Deci, 2000). The authors of the model described self-determination as "the ability to define and achieve goals based on a foundation of knowing and valuing oneself. It is promoted, or discouraged, by factors within the individual's control (e.g., values, knowledge, skills) and variables that are environmental in nature (e.g., opportunities for choice making, attitudes of others)" (Field \& Hoffman, 1994, p. 164).

Although the model of self-determination considers "factors which can be mediated by the individual" which "compromise and promote" self-determined behavior, the authors do not describe specific features that impact self-determination, "such as opportunities and supports available in the environment" (p. 164). However, Field and Hoffman do not overlook the importance of the setting: "This model is concerned with the way individuals can achieve and maintain self-determination in environments of varying levels of receptivity and support" (p. 164). 
Field and Hoffman (1994) hypothesized five basic steps that describe the path to increased levels of self-determination. Based on a foundation of knowing and valuing oneself, persons with disabilities can then plan and act to experience outcomes and learn. The last phase described in the cyclical process leads back to the developing foundation of knowing and valuing oneself, etc. ... The model is "reciprocally causal" in that it assumes actions that generate "selfdetermination are also expressions of self-determination" (p. 164).

The model of self-determination promotes healthy decision-making and is compatible with psychosocial theory. It provides a framework for moving individuals with disabilities toward healthy and autonomous functioning. Field, Sarver, and Shaw (2003) promote the use of this model with individuals who have been diagnosed with learning disabilities in the postsecondary environment: "Self-determination is an emerging concept in postsecondary services that holds tremendous promise for increased success for students with learning disabilities in postsecondary settings. With further research and broader implementation of selfdetermination practices, this promising concept could become a key program feature that promotes success for students with learning disabilities in postsecondary educational settings" ( $\mathrm{p}$. $348)$.

Although the fleshing out of the model and the development of supporting curricula have primarily focused on preparing students to transition out of the public school system, it is reasonable to extend the construct to guide post-secondary service provision. Once more, Field, Sarver and Shaw (2003) comment on the value of using the model as a resource for increasing the success and retention of college students with learning disabilities:

To be successful, college students with learning disabilities need to have a sense of themselves as individuals who make decisions about important matters in their lives. 
They need to understand and value themselves, and they need to take actions according to responsible plans in order to achieve their academic goals. Finally, they need to exhibit behaviors indicative of reflective thinking and self-awareness consistent with an accurate evaluation of outcomes (p. 343).

Self-knowledge and self-appreciation are the starting points of the self-determination model; they provide a platform for working through the psychosocial vulnerabilities that are often experienced by students with learning disabilities. Field and Hoffman (1994) discuss the importance of the need to know oneself to be able to act in one's self-interest, to establish goals that are reflective of that self-knowledge, and to know about available opportunities in order to set appropriate goals. A practical understanding of personal strengths, limitations, goals and strivings is fundamental to coming to terms with one's learning disability and to effectively function in any environment. The opportunity to verbalize these personal understandings within a supportive relational context may increase the student's self-knowledge and confidence, tools needed for judging and making appropriate self-disclosure.

Self-knowledge and self-acceptance provide the foundation for forming plans and acting upon those plans (Field \& Hoffmann, 1994). The pattern revealed by the students from the persistence cohort in this project involved self-awareness-based practice to promote well-being. The knowledge of personal goals and strivings, limitations, strengths, and a mindset supported by self- understanding set the stage for individual and interactive practice to promote academic, social, and emotional well-being. Self-awareness led to the development of an outlook or approach which facilitated student management of the environment.

Another construct that may be useful in facilitating the effective performance of the postsecondary student with learning disabilities is Zimmerman's model of self-regulated learning 
(2002). Although the model is cumbersome, Zimmerman and his colleagues have been researching various motivational, affective, and behavioral subprocesses and outcomes related to self-regulated learning since 1986 (Zimmerman, 1989, 1998, 2002; Zimmerman, Bandura \& Martinez-Pons, 1992; Zimmerman, Bonner \& Kovach, 1996; Zimmerman \& Martinez-Pons, 1986, 1988; 1990; Zimmermnan \& Schunk, 1989, 2001).

In its simplest form, the self-regulatory process has been described by Zimmerman (2002) as a three phase cyclical progression including forethought which consists of the mental processing that paves the way for action; performance which involves action to secure intended outcomes; and self-reflection which refers to the analysis of and personal reaction to the results of the action phase; the self-reflection phase influences the subsequent forethought phase. In a recent description of the process (2002), Zimmerman categorized and defined several nebulous self-regulatory motivational, affective, and behavioral concepts while positioning them in the appropriate phase of the self-regulation cycle.

The benefit of including self-regulated learning theory in the discussion of service provision for the postsecondary student with learning disabilities is based in the model's characterization of many elusive motivational, affective, and behavioral subprocesses that impact academic performance. A student may muse: "I'm not motivated to do my work." The mentor can respond by asking questions to understand if the student is interested or values the task (Forethought/intrinsic interest/value), or if the student is overwhelmed because specific or reachable goals are not set (Forethought/task analysis/goal setting), for example. Perhaps the student does not feel capable (Forethought/self-motivation beliefs/self-efficacy) in a skill area and is not starting for that reason. Maybe the student needs to develop strategies for starting to work (Forethought/strategic planning) or to develop specific study skills relevant to a particular 
content area (Performance/task strategies). The mentor's response will vary according to the challenge expressed by the student. Zimmerman's model provides a bank of subprocesses the mentor can draw from when confronted with such general statement.

Self-determination (Field \& Hoffman, 1994) and self-regulation (Zimmermann, 2002) may be thought of as complementary constructs that can be used together to promote the effective functioning of the postsecondary student with learning disabilities. Table 1 summarizes and compares phases and subprocesses of the models of self-determination and self-regulation. For a summary of the self-regulated learning model and definitions of self-regulatory subprocesses as they relate to academic performance, refer to Barry Zimmerman's article "Becoming a self-regulated learner" in volume 41 of the journal Theory into Practice (2002).

\section{Cognitive Management}

Rational thinking leads to healthy emotions and productive behavior. Cognitive intervention methods (Beck, 1976; Ellis \& Harper, 1975; Ellis \& Grieger, 1977; Maultsby, 1984, 1986) have been effective with students who have developed a negative self-belief system caused by long-standing self-disappointment and frustration (Cohn, 1998; Ramsay \& Rostain, 2004). Cognitive restructuring techniques can be used within the student-mentor relationship as a tool to assist the student to rethink incorrect ideas about self-potential. If the student has developed trust in the mentor, the mentor is in a position to help the student recognize thoughts or self-beliefs that interfere with effective daily operation. Incorrect or correct thinking can be reflected back to the student through the process of active listening; the student can be helped to link seemingly isolated thoughts into patterns of thinking that produce effective or ineffective functioning. 
Ramsay and Rostain (2004) discuss two examples of incorrect automatic thought patterns that often plague young adults with ADHD. It can be argued these beliefs are applicable to students with all types of learning disabilities given what is known about the psychosocial vulnerabilities of individuals with learning disabilities (Silver 1997; Price, 2002; Cohn, 1998). The first is the tendency to take setbacks personally; the second is to base one's self-worth on the standard of others. In addition, other types of incorrect thinking common to students with learning disabilities stem from the belief that the self is "wrong" or inadequate. We have learned for Gerber and Ginsberg's (1990) research that the ability to reframe or rethink the disability is common to highly successful adults who have learning disabilities. Higgins et al. (2002) emphasize the importance of transforming or rethinking the learning disability into a positive force as the individual moves from the stage of disability acknowledgment to self-acceptance. Direct examination of thinking processes or cognitive intervention, within the context of a reliable relationship, can help the student increase self-understanding and self-appreciation.

Several methods can be used to counter ineffective thinking (Ellis \& Harper, 1975; Hackney \& Cormier, 2005; Maultsby, 1984; McMullin, 1986; Padesky \& Greenberger, 1995). Basic cognitive intervention skills described by Hackney and Cormier (2005) are consistent with the idea of helping the student develop self-determination and self-regulation. They include helping the student "differentiate between thoughts and feelings and to express opinions, beliefs, [and] self-rules" and to "to change thought patterns when it is deemed appropriate" (p. 182). A brief example of how cognitive intervention may be applied follows.

The A-B-C analysis facilitates the separation of events, thoughts, feelings and reactions (Ellis \& Harper, 1975; McMullin, 1986; Powell, 1992). Once these are separated out, cognitive restructuring or countering techniques may be used to erode the person's irrational beliefs. "A" is 
the trigger event. " $\mathrm{B}$ " is how the event is perceived and evaluated by the individual. " $\mathrm{C}$ " is the individual's response or reaction to "B", not "A" (the trigger event) (McMullin, 1986). The A-B$\mathrm{C}$ analysis is premised on the idea that individuals react ("C") to what they think about the triggering event (“B”) as opposed to the trigger event itself (“A”).

For example, two students receive a low grade on a paper, the trigger event ("A"). The first student may think the following ("B"): "I was never a good writer; maybe I should withdraw from the class; the teacher doesn't like me, she will never help me if I ask for assistance; there is nothing I can do to change my grade or to become a better writer; I spent more time on the assignment than my roommate who got an A, this is not fair." Another student who is evaluating the same situation more constructively might think: "This is just one grade out of several; I will talk with the professor to find out how to perform better on the next assignment or to find out if I can rework the paper; I should have gone to the writing center or I will go for help on the next assignment; I will ask the professor to review a rough draft of the paper for the next assignment; maybe I should start the next assignment sooner so I can give myself the chance to perform better." The second student will be more likely to take constructive action because he or she is thinking differently. Challenging the student's automatic thought about the event presents the student with the opportunity to develop a more constructive way of thinking about the failure. Cognitive behavioral theory predicts that constructive thinking leads to constructive behavior. The second student does not personalize the failure and the thinking process shows the student is taking responsibility and control. Control, according to Gerber and Ginsberg (1990), is a major factor in the success of adults who have learning disabilities. The cognitive viewpoint predicts both students will respond ("C") in line with their thinking about the trigger event ("B"). For, if it were the trigger event itself ("A") that caused the response, both students would have the same 
reaction to it. The idea behind the cognitive analysis is that a shift in thinking will influence a shift in action. There is great hope in this approach for students who maintain self-defeating belief systems.

Unearthing automatic thoughts and replacing them with neutral or positive credible statements is at the heart of cognitive intervention. Although it has surfaced as a counseling technique, cognitive restructuring may be used at a commonsense level in many different settings. Unproductive cognitions about life situations such as having a learning disability, academic, or social disappointments can be neutralized by using cognitive restructuring methods. For a practical discussion of methods that can be utilized to dispute and neutralize faulty or irrational thinking, see works by Maultsy (1986) or Ellis (1975).

\section{Emotional Management}

Conation is defined as "That aspect of mental process or behavior by which it [the organism] tends to develop into something else. . purposive striving [characterized by] an intrinsic unrest of the organism" (English \& English, 1958, p. 104). Snow, Jackson \& Corno (1996) theorized that..."Many important student aptitude and achievement differences are not strictly cognitive; many are affective or conative" (Snow, et al., 1996, p. 243). Daniel Goleman (1995) coined the term "emotional intelligence" and defined it as "being able to motivate oneself and persist in the face of frustrations; to control impulse and delay gratification; to regulate one's moods and keep distress from swamping the ability to think; to empathize and to hope" (p. 34).

The Bar-On Model of Emotional Intelligence is a tool that may be used to help students develop emotional and social competence (EQ). Emotional intelligence, sometimes referred to as "noncognitive intelligence," encompasses the "emotional, personal, social, and survival dimensions of intelligence. . . [and] is concerned with understanding oneself and others, relating to people, and 
adapting and coping with the immediate surroundings, which increases one's ability to be more successful in dealing with daily demands" (Bar-On \& Handley, 1999 p. viii). Emotional intelligence is observed when a person shows he or she is competent in areas of self-awareness, self-management, social awareness, and social skills at high stakes times (Boyatzis, Goleman, \& Rhee, 2000). Because students with learning disabilities may develop secondary psychosocial vulnerabilities, the application of this model may be a useful tool in the mentor-student relationship. The construct of emotional intelligence is compatible with the models of self-determination and self-regulation, which are founded upon personal resilience, in that it "represents an important factor in determining one's ability to succeed in life" (Bar-On \& Handley, 1999, p. 2) and because a person's emotional intelligence is not fixed at birth, it represents a cluster of personal characteristics, all of which can be strengthened (Goleman, 1995).

The EQ-i (Bar-On, 1997) is a self-report inventory developed to measure emotional intelligence; it focuses on five components of emotional intelligence: intrapersonal skills, interpersonal skills, stress management, adaptability, and general mood control. The test can be read at the sixth grade level and is geared for those aged 17 and above (Bar-On \& Handley, 1999). There have been several studies correlating high EQ-i scores with emotional and social competence in various conditions (Handley, 1999; Reker \& Parker, 2002; Parker \& Bond, 2002; Parker, 2002). In a series of studies conducted at a small Canadian liberal arts college, successful academic functioning of first year students was linked to the emotional intelligence factors of intrapersonal skills, adaptability, and stress management, as measured by the EQ-i (Parker \& Bond, 2002). In addition, persistence study results indicating high and low emotional intelligence factors of intra- and interpersonal skills, adaptability, and stress management, predicted the majority of university students who would persist or withdraw, respectively (Parker, 2002). Given the results of EQ-i research and 
the psychosocial vulnerabilities of students with learning disabilities, instruction in dimensions of emotional and social intelligence are offered as a tool for promoting the effective functioning of the student with learning disabilities, especially in light of the findings of the current research project. Even though there is similarity and overlap among the constructs of self-determination, selfregulation, and emotional intelligence, all three models are presented for what each uniquely contributes to the facilitation of the effective functioning of students with learning disabilities.

Although addressed to the corporate audience, Optimizing People: A practical guide for applying EQ (Bar-On \& Handley, 1999) is an excellent source that lists several resource options and specific suggestions for helping students modify emotional intelligence subprocesses. In addition, Emotional Intelligence: Why it can matter more than IQ (Goleman, 1995) contains ideas for developing emotional intelligence in the individual.

The components of effective functioning for individuals with learning disabilities are numerous and complex. However, the likelihood of success for this emerging postsecondary population may be increased by the building of supportive relational environments to instruct students in cognitive, conative, and behavioral processes that impact academic performance, the benchmark of postsecondary success.

\section{Limitations and Future Research Directions}

This research utilized the methodologies of the phenomenological approach, the collective case study, and grounded theory. A small number of participants were engaged at a meaningful level for the purpose of understanding their subjective experience in order to explore the essence of the phenomenon under study (Creswell, 1994; Merriam, 2002; Patton, 1990). The project mission was to explore through phenomenological means the perceptions of multiple participants to arrive inductively at the construction of substantive theory. Substantive theory 
building is supported by the practical concerns of professional practice within specified contexts (Meriam, 2002). In this case it was the exploration of internal and external supports and barriers experienced by the student with learning disabilities in postsecondary setting.

Even though the collective case study approach inherently contains a small number of participants, the homogeneous nature of the participants within the special population examined presents a concern for the transferability of the project results. There was an even split between the male and female participants; however, there were two African-American participants and all of the students were from middle, upper-middle, and upper socioeconomic backgrounds. Transferability implies that the findings of the study will be useful to others who have like "questions of practice" (Marshall \& Rossman, 1999, p. 193). Caution should be used in applying the knowledge gained from this project to the student who comes from a more diverse ethnic and socioeconomic background. That said, exploratory projects investigating like concerns in a more diverse, larger sized university environment will contribute to the developing field of postsecondary service provision for this population.

Similarly, only $30 \%$ of the transitional students who volunteered to participate in the project were ineffective performers. This concern was initially addressed after the completion of the exploratory study for the project; at that time, it was found that all of the students who volunteered were successful. To correct this problem, the letter of invitation sent to potential interviewees, during the three years that followed, was written to target both effective and ineffective performing students. Although the number of ineffective functioning students who interviewed increased, additional research needs to substantiate or to add to this project's findings with regards to this grouping. 
Finally, a case analysis of the students who have transformed from ineffective to effective functioning may reveal a model for overcoming ineffective patterns. Two students from the negative performance transition cohort have persisted. Since the interview, one of these students joined a varsity sport, participated in a campus play, and decided about an alternate field of study as her original major did not materialize. In addition, we were able to observe through the interview, the transformation of the persistence student who made the decision to cut down on his alcohol consumption as a result of being voted to a position of responsibility in his fraternity. After making that decision, the student became interested in finding out more about his disabling condition. This student described an informal mentoring relationship with his supervisor from summer employment. The mentor intermittently asked him "Are you pleased with your academic performance?" to help the student develop an internal measure of success. Follow-up interviewing to track these important "in-between" points may uncover a model of change that could be used to facilitate the ineffective students toward more effective functioning.

\section{A Final Word}

I gratefully acknowledge the students who volunteered their time and vulnerabilities to this project. The students were earnest in describing their struggles and accomplishments. Energized by the hope of creating more responsive learning environments, they allowed me to participate in and to uncover their experience. Their candidness will likely serve the cohorts who follow them, both in the postsecondary setting and in life contexts beyond the college environment. 


\section{References}

Adelizzi, J. U. (1995). The relationship between psychological trauma \& learning disabilities: A look at classroom trauma. In June Utley Adelizzi \& Diane Goss (Eds.), A closer look: Perspectives and reflections on college students with learning disabilities (pp. 85-100). Milton, MA: Currey College.

American Psychiatric Association. (2000). Diagnostic and statistical manual of mental disorders. (4 ${ }^{\text {th }}$ ed.). Washington, DC: Author.

Bar-On, R. (1997). EQ-I Bar-On emotional quotient inventory. North Tonawanda, NY: MultiHealth Systems Inc.

Bar-On, R., \& Handley, R. (1999). Optimizing people: A practical guide for applying EQ (emotional intelligence) to improve personal and organizational effectiveness. New Braunfels, TX: Pro-Philes.

Beck, A. T. (1976). Cognitive therapy and the emotional disorders. New York: International Universities Press.

Beirne-Smith, M., \& Deck, M. D. (1989). A survey of postsecondary programs for students with learning disabilities. Journal of Learning Disabilities, 22(7), 456-457.

Boyatzis, R. E., Goleman, D., \& Rhee, K. S. (2000). Clustering competence in emotional intelligence: Insights from emotional competence inventory. In R. Bar-On \& J. D. Parker (Eds.), The handbook of emotional intelligence (pp. 343-362). San Francisco: JosseyBass.

Brincherhoff, L. C., McGuire, J. M., \& Shaw, S. F. (2002). Postsecondary education and transition for students with learning disabilities (2nd ed.). Austin TX: PRO-ED. 
Brinckerhoff, L. C., Shaw, S. F., \& McGuire, J. M. (1993). Promoting postsecondary education for students with learning disabilities: A handbook for practitioners. Austin TX: PROED.

Bukatko, D., \& Daehler, M. W. (1995). Learning and perception. In Child development: A thematic approach (pp. 212-213). Boston: Houghton Mifflin.

Chickering, A. W. (1969). Education and identity. San Francisco: Jossey-Bass Publishers.

Chickering, A. W., \& Reisser, L. (1993). Education and identity (2nd ed.). San Francisco: Jossey-Bass Publishers.

Coffey, A. J., \& Atkinson, P. A. (1996). Concepts and coding. In Making sense of qualitative data (pp. 26-53). Thousand Oaks, CA: Sage Publications.

Cohn, P. (1998). Why does my stomach hurt? How individuals with learning disabilities can use cognitive strategies to reduce anxiety and stress at the college level. Journal of Learning Disabilities, 31, 514-516.

Cosden, M. (2001). Risk and resilience for substance abuse among adolescents and adults with LD. Journal of Learning Disabilities, 34(4), 352-358.

Council for Disability Rights. (1990, August). ADA fact sheet. [CDR Reports]. Chicago, IL: Author.

Creswell, John W. (1994). Research design: Qualitative \& quantitative approaches. Thousands Oaks, CA: Sage Publications.

Dalke, C., \& Schmitt, S. (1987). Meeting the transition needs of college-bound students with learning disabilities. Journal of Learning Disabilities, 20(3), 176-180.

Denzin, N. K. (1989). The research act: A theoretical introduction to sociological methods (3rd ed). Englewood Cliffs, NJ: Prentice Hall. 
Denzin, N. K., \& Lincoln, Y. S. (Eds.). (2000). Handbook of qualitative research. Thousand Oaks, CA: Sage Publications.

Dexter, B. L. (1982). Helping learning disabled students prepare for college. Journal of Learning Disabilities, 15(6), 344-346

Eaton, H. (1996). Self-Advocacy: How students with learning disabilities can make the transition from high school to college. Santa Barbara, CA: Excel.

Ellis, A., \& Harper, R. (1975). A new guide to rational living. Hollywood, CA: Wolshire Books.

Erikson, E. (1982). The life cycle completed. New York: Longman's Green.

Erikson, E. (1968). Identity: Youth and crisis. New York: Norton.

Evans, N. J. (2003). Psychosocial, cognitive, and typological perspectives on student development. In S. R. Komives, D. B. Woodard, Jr., \& Associates (Eds.), Student services: A handbook for the profession (pp. 179-202). San Francisco: Jossey-Bass Publishers.

Evans, N. J., Forney, D. S., \& Guido-DiBrito, F. (1998). Student development in college: Theory, research, and practice. San Francisco: Jossey-Bass Publishers.

Field, S., \& Hoffman, A. (1994). Development of a model for self-determination. Career Development for Exceptional Individuals, 17, 159-169.

Field, S., Sarver, M. D., \& Shaw, S. F. (2003). Self-determination: A key to success in postsecondary education for student with learning disabilities. Remedial and Special Education, 24, 339-349.

Finn, L. L. (1999). Learning disabilities programs at community colleges and four-year colleges and universities. Community College Journal of Research \& Practice, 23(17), 629-639. 
Fisher, E. L. (1985, September). Educator examines myths, realities of LD students at college level. Hill Top Spectrum, 3(1), 1-5, 8.

Garcia, T. (1995). The role of motivational strategies in self-regulated learning. In New Directions in Teaching and Learning, 63, 29-42.

Gay, L. R., \& Airasian, P. (2003). Educational research: Competencies for analysis and application (7th ed.). Upper Saddle River, NJ: Prentice-Hall.

Gerber, P. J., \& Ginsberg, R. J. (1990). Identifying alterable patterns of success in highly successful adults with learning disabilities. Richmond, VA: Commonwealth University, School of Education.

Gergen, M. M., \& Gergen, K. J. (2000). Handbook of qualitative research. In Norman K. Denzin \& Yvonna S. Lincoln (Eds.), Qualitative inquiry: Tensions and transformations (2nd ed., pp. 1025-1046). Thousand Oaks, CA: Sage Publications

Goldberg, R. J., Higgins, E. L., Raskind, M. H., \& Herman, K. L. (2003). Predictors for success in individuals with learning disabilities: A qualitative analysis of a 20-year longitudinal study. Learning Disabilities Research \& Practice, 18(4), 222-236.

Goldstein, S. (1997). Psychosocial treatments. Managing attention and learning disorders in late adolescence \& adulthood: A guide for practitioners (pp. 236-265). New York: John Wiley \& Sons, Inc.

Goleman, D. (1995). Emotional intelligence: Why it can matter more than IQ. New York: Bantam Books.

Greenbaum, B., Graham, S., \& W. Scales. (1995). Adults with learning disabilities: Educational and social experiences during college. Exceptional Children, 61 (5), 460-471. 
Gregg, N. \& Ferri, B. A. (1998). Hearing voices, witnessing pain: In response to "Why does my stomach hurt?" Journal of Learning Disabilities, 31, 517-519

Hackney, H., \& Cormier, S. (2005). The professional counselor: A process guide to helping $\left(5^{\text {th }}\right.$ ed.). Boston: Pearson.

Hall, C. W., Spruill, K. L., \& Webster, R. E. (2002). Motivational and attitudinal factors in college students with and without learning disabilities. Learning Disability Quarterly, 25, 79-86.

Harris, R., \& Robertson, J. (2001). Successful strategies for college-bound students with learning disabilities [Electronic Version]. Preventing School Failure, 45(3), 125-131.

HEATH Resource Center. (1999). A biennial statistical profile of college freshmen with disabilities. Washington, DC: The American Council on Education.

Henderson, K. (2001). An overview of ADA, IDEA, and section 504: Update 2001. LD Online. http://www.ldonline.org/ld_indepth/legal_legislative/update_504_2001.html

Heyward, S. (1998). Disability and higher education: Guidance for section 504 and ADA compliance. Horsham, PA: LRP Publications.

Hicks-Coolick, A., \& Kurtz, P. D. (1996). An exploratory study of postsecondary services for students with learning disabilities. Social Work in Education, 18(2), 104-111.

Hicks-Coolick, A, \& Kurtz, P. D. (1997). Preparing students with learning disabilities for success ... Social Work in Education, 19(1), 31-43.

Higgins, E. L., Raskind, M. H., Goldberg, R. J., Herman, K. L. (2002). Stages of acceptance of a learning disability: The impact of labeling. Learning Disability Quarterly, 25, 3-18.

Hildreth, B. L., Candler-Lotven, A., \& Macke, R. A. (1994). College as a transition option for students with learning disabilities. In Diane Montgomery (Ed.), Rural partnerships: 
Working together. Proceedings of the Annual National Conference of the American Council on Rural Special Education (ACRES). Austin TX: American Council on Rural Special Education. (ERIC Document Reproduction Service No. ED369637)

Horn, L., \& Berktold, J. (1999). Students with disabilities in postsecondary education: A profile of preparation, participation, and outcomes. Washington, DC: U.S. Department of Education, National Center for Education Statistics.

Hoy, C., Gregg, N., Wisenbaker, J., Manglitz, E., King, M., \& Moreland, C. (1997). Depression and anxiety in two groups of adults with learning disabilities. Learning Disability Quarterly, 20, 278-292.

Janiga, S. J., \& Costenbader, V. (2002). The transition from high school to postsecondary education for students with learning disabilities: A survey of college service coordinators [Electronic Version]. Journal of Learning Disabilities, 35(5), 462-469.

Kincaid, J. M. (1994). The americans with disabilities act (ADA) and section 504 as applied to colleges \& universities: An overview of the rights and responsibilities of students. [Fact Sheet] Center Barnstead, NH: Author.

Kuba, S. (2003). "They can't tell I'm not normal unless I tell them...": First year college students with learning disabilities voice themes of transition. Unpublished Manuscript, West Virginia University, Morgantown.

Latham, P. H. (1996). Learning disabilities and the law: After high school. LD Online. http://www.ldonline.org/ld_indepth/legal_legislative/latham_ld.html

Latham, P. H., \& Latham, P. S. (1997). Legal rights. In Managing attention and learning disorders in late adolescence \& adulthood: A guide for practitioners (pp. 315-326). New York: John Wiley \& Sons. 
Learning Disabilities Association (LDA). (1997, July/August). A new IDEA signed into law. LDA Newsbriefs, 32(4), 1, 4.

Lerner, J. (2000). Learning disabilities: Theories, diagnosis, and teaching strategies (8th ed.). Boston: Houghton Mifflin.

Lock, R. H., \& Layton, C. A. (2001). Succeeding in postsecondary ed through self-advocacy. Teaching Exceptional Children, 34(2), 66-71.

Love, P. G., \& Guthrie, V. L. (1999). Understanding and applying cognitive development theory. San Francisco: Jossey- Bass Publishers.

Mangrum, C. T., \& Strichart, S. S. (Eds.). (1997). Peterson's colleges with programs for students with learning disabilities or attention deficit disorders (5th ed.). Princeton, NJ: Peterson's.

Marshall, C., \& Rossman, G. B. (1999). Designing qualitative research (3rd ed.). Thousand Oaks, CA: Sage Publications.

Maultsby, M. C., Jr. (1984). Rational behavior therapy. New Jersey: Prentice-Hall, Inc.

Maultsby, M. C., Jr. (1986). Coping better...anytime, anywhere: The handbook of rational selfcounseling. New York: Prentice Hall Press.

McGuire, J. M., Hall, D., Litt, A. V. (1991). A field-based study of the direct service needs of college students with learning disabilities. Journal of College Student Development, 32, 101-108.

McMullin, R. E. (1986). Handbook of cognitive therapy techniques. New York: W. W. Norton \& Company.

Merriam, S. B. (2001). Qualitative research and case study applications in education (Rev. ed.). San Francisco: Jossey- Bass Publishers. 
Merrian, S. B. (2002). Qualitative research in practice: Examples for discussion and analysis. San Franciso: Jossey-Bass Publishers.

Michaels, C. (1997). Preparing for employment: Counseling practices or promoting personal competency. In P. J. Gerber \& D. S. Brown (Eds.), Learning disabilities and employment (pp. 187-215). Austin, TX: PRO-ED.

Miles, M. B., \& Huberman, A. M. (1994) Qualitative data analysis: An expanded source book (2nd ed.). Thousand Oaks, CA: Sage Publications.

Miller, M. (2002). Resilience elements in students with learning disabilities. Journal of Clinical Psychology, 58(3), 291-298.

Mull, C., Sitlington, P. L., \& Alper, S. (2001). Postsecondary education for students with learning disabilities: A synthesis of the literature. Exceptional Children, 68(1), 97-118.

National Joint Committee on Learning Disabilities (NJCLD). (1995). Important definitions of learning disabilities. LD Online. http://ldoline.org/ld_indepth/general_info/definitions.html

National Joint Committee on Learning Disabilities (NJCLD). (1999). Learning disabilities: Issues in higher education. Learning Disability Quarterly, 22, 263-266.

Navicky, J. (1998, Winter). A match made by design not accident. (Reprinted from The PostSecondary LD Report. LD Online. http://www.ldonline.org/ld_indepth/postsecondary/navicky_match.html)

Nielsen, J. A. (2001). Successful university students with learning disabilities. Journal of College Student Psychotherapy, 15(4), 37-48.

Osman, B. (1986). Learning disabilities in adolescents generate socialization disorders. Hill Top Spectrum, 3(3), 1, 6, 7-8. 
Osman, B. (1996). No one to play with. Novato, CA: Academic Therapy Publications.

Ostrander, R., Goldstein S., Silver, L., \& Griffin, M. (1998, March). The secondary emotional problems experienced by individuals with learning disabilities. Paper presented at the meeting of LDA International Conference, Washington, DC.

Padesky, C. A., \& Greenberger, D. (1995). Clinician's guide to mind over mood. New York: The Guilford Press.

Pagels, C. F. (1998, April). Transitioning high school students with learning disabilities to the college environment: Avoiding common pitfalls. Paper presented at the Annual Convention of the National Association of School Psychologists, Orlando FL. (ERIC Document Reproduction Service No. ED423481)

Parker, J. D. (2002, November). Emotional intelligence and academic success: Examining the transition from high school to university. Paper presented at the meeting of the West Virginia Counselors Association, Morgantown, WV.

Parker, J. D., \& Bond, J. B. (2002, November). Emotional intelligence and behavioral problems in children and adolescents. Paper presented at the meeting of the West Virginia Counselors Association, Morgantown, WV.

Patton, M. Q. (1987). Creative evaluation. Newbury Park, CA: Sage Publications

Patton, M. Q. (1990). Qualitative evaluation and research methods (2nd ed.). Thousand Oaks, CA: Sage Publications.

Perry, W. G., Jr. (1981). Cognitive and ethical growth: The making of meaning. In Arthur W. Chickering and Associates (Eds.), The modern American college: Responding to the new realities of diverse students and a changing society (pp. 76-116). San Francisco: JosseyBass Publishers. 
Powell, T. (1992). The mental health handbook. Bicester, Oxon: Winslow Press Limited.

Pressley, M., \& McCormick, C. (1997). How motivation and achievement can be undermined. In Educational Psychology: Learning, instruction and assessment (pp. 30-38). New York: Longman-Addison Wesley.

Price, L. (2002). The connections among psychosocial issues, adult development, and selfdetermination Postsecondary education and transition for students with learning disabilities (2nd ed., pp. 131-155). Austin TX: PRO-ED.

Ramsay, J. R., \& Rostain, A. L. (2004). Cognitive therapy: A psychosocial treatment for ADHD in adults. ADHD Report, 12, 1-16.

Rath, K. A., \& Royer, J. M. (2002). The nature and effectiveness of learning disability services for college students. Educational Psychology Review, 14(4), 353-381.

Reiff, H. B., Ginsberg, R., \& Gerber, P. J. (1995). New perspectives on teaching from successful adults with learning disabilities. Remedial and Special Education, 16, 29-37.

Reis, S. M., McGuire, J. M., \& Neu, T. W. (2000). Compensation strategies used by high-ability students with learning disabilities who succeed in college. Gifted Child Quarterly, 44, 123-134.

Reisser, L. (1995). Revisiting the seven vectors. Journal of College Student Development, 36, $505-511$.

Reker, D. L., \& Parker, J. D. (2002, November), Emotional intelligence in children and adolescents: Relationships with internalizing and externalizing behaviors. Paper presented at the meeting of the West Virginia Counselors Association, Morgantown, WV.

Rourke, B. P. \& Fuerst, D. R. (1991). Learning Disabilities and psychosocial functioning: A neurobiological perspective. New York: Guilford. 
Ryan, R. M., \& Deci, E. L. (2000). Self-Determination theory and the facilitation of intrinsic motivation, social development, and well being. American Psychologist, 55, 68-78.

Sanford, N. (1966). Self and society. New York: Atherton Press.

Sanford, N. (1967). Education for individual development. Washington DC: U.S. Department of Health, Education, and Welfare. (ERIC Document Reproduction Service No. ED013353)

Satcher, J. F. (1989). Learning disabled students: Making the transition to college life. Mississippi State: University, Department of Counselor Education.

Schackner, B. (2004, September 5). 'Invisible' disability now visible on campus. Pittsburgh Post-Gazette. pp. A1, A16-A17.

Schlossberg, N. K., Waters, E. B., \& Goodman, J. (1995). Counseling adults in transition (2nd ed.). New York: Springer.

Schumaker, J. B., \& Deshler, D. D. (1995, March/April). Social skills and learning disabilities. LDA Newsbriefs, 12-13.

Silver, L. B. (1984). The misunderstood child: A guide for parents of learning disabled children. New York: McGraw-Hill Book Company.

Silver, L. B. (1997, February). Learning disabilities: Comorbidity with other emotional and neurological disorders. Paper presented at the meeting of the Learning Disabilities Association of America, Chicago, IL.

Silver, L. B. (1999). Attention deficit/hyperactivity disorder (2nd ed.). Washington DC: American Psychiatric Press, Inc.

Skinner, M. E. (2004). College students with learning disabilities speak out: What it takes to be successful in postsecondary education. Journal of Postsecondary Education and Disability, 17(2), 91-104. 
Snow, R., Jackson, D, \& Corno, L. (1996). Individual differences in affective and conative functions. In D. Berliner, \& R. Calfee (Eds.), Handbook of educational psychology. (pp. 243-310). New York: Simon and Schuster MacMillan.

Spekman, J. J., Goldberg, R. L., \& Herman, K. L. (1992). Learning disabled children grow up: A search for factors related to success in the young adult years. Learning Disabilities Research and Practice, 7, 161-170.

Stake, R. E. (1981). Case study methodology: An epistemological advocacy. In W. W. Welsh (Ed.), Case study methodology in educational evaluation (pp. 31-39). Proceedings of the Minnesota Evaluation Conference. Minneapolis: Research and Evaluation Center.

Stake, R. E. (1995). Triangulation. In The art of case study research (pp. 107-120). Thousand Oaks: Sage Publications.

Stake, R. E. (2000). Handbook of qualitative research. In Norman K. Denzin \& Yvonna S. Lincoln (Eds.), Case studies (pp. 435-454). Thousand Oaks, CA: Sage Publications.

Strasburger, R., Turner, M., \& Walls, R. T. (1998). Factors relating to the postsecondary success of students with learning disabilities. Journal of the First-Year Experience, 11(1), 63-76.

Strauss, A., \& Corbin J. (1998). Ground theory methodology: An overview. In Norman K.

Denzin \& Yvonna S. Lincoln (Eds.), Strategies of qualitative inquiry (pp. 158-183). Thousand Oaks, CA: Sage Publications.

U.S. Department of Education Office for Civil Rights. (2002). Transition: Students with disabilities preparing for postsecondary education. Available:http://www.ed.gov/about/offices/list/ocr/transition.html Vogel, S. A. (1982). On developing LD college programs. Journal of Learning Disabilities, 15, $518-528$. 
Vogel, S. A., Hruby, P. J., Adelman, P. B. (1993). Educational and psychological factors in successful and unsuccessful college students with learning disabilities. Learning Disabilities Research \& Practice, 8(1), 35-43.

Vogel, S. A., Leonard, F., Scales, W., Hayeslip, P., Hermansen, J., \& Donnells, L. (1998). The national learning disabilities postsecondary data bank: An overview. Journal of Learning Disabilities, 31(3), 234-247.

Vygotsky, L. S. (1978). Mind in society: The development of higher psychological processes. Cambridge: Harvard University Press.

Walls, R. T. (1999). Psychological foundations of learning. Washington DC: Library of Congress.

Wax, I. F., \& Kravets, M. (2003). The K\&W Guide to colleges for students with learning disabilities or attention deficit disorder (7th ed.). New York: Random House.

Wolanin, T. R., \& Steele, P. E. (2004). Higher education opportunities for students with disabilities: A primer for policymakers. Washington, DC: The Institute for Higher Education Policy (IHEP).

Wren, C., \& Segal, L. (1985). College students with learning disabilities: A student's perspective. Chicago, IL: DePaul University.

Zimmerman, B. (1989). A social cognitive view of self-regulated academic learning. Journal of Educational Psychology, 81, 329-339.

Zimmerman, B. (1998). Academic studying and the development of personal skill: A selfregulatory perspective. Educational Psychologist, 33, 73-86.

Zimmerman, B. (2002). Becoming a self-regulated learner: An overview. Theory Into Practice, 41, 64-70. 
Zimmerman, B., Bandura, A., \& Martinez-Pons, M. (1992). Self-Motivation for academic attainment: The role of self-efficacy beliefs and personal goal setting. American Educational Research Journal, 29, 663-677.

Zimmerman, B., Bonner, S., \& Kovach, R. (1996). Developing self-regulated learners: Beyond achievement to self-efficacy. Washington DC: American Psychological Association.

Zimmerman, B., \& Martinez Pons, M. (1986). Development of a structured interview for assessing student use of self-regulated learning strategies. American Educational Research Journal, 23, 614-628.

Zimmerman, B., \& Martinez-Pons., M. (1988). Construct validation of a strategy model of student self-regulated learning. Journal of Educational Psychology, 80, 284-290.

Zimmerman, B., \& Martinez-Pons, M. (1990). Student differences in self-regulated learning: Relating grade, sex, and giftedness to self-efficacy and strategy use. Journal of Educational Psychology, 82, 51-59.

Zimmerman, B., \& Schunk, D. H. (1989). Self-Regulated learning and academic achievement: Theory, research, and practice. New York: Springer-Verlag.

Zimmerman, B., \& Schunk, D. H. (2001). Self-Regulated learning and academic achievement (2nd ed.). Mahwah, NJ: Lawrence Erlbaum Associates. 


\section{APPENDIX A:}

Persistence Interview Protocol 


\section{PERSISTENCE SCRIPT}

Good morning (afternoon). Thank you for agreeing to participate in my study. The goal of my research is to understand, from an upper class student perspective, supports and barriers experienced by students with learning dis abilities while they are enrolled in college. The information gathered from my study will be used to complete a research project that is in partial fulfillment of the requirements of my doctoral program at West Virginia University.

I would like to point our a few things before we start:

1. Your responses will remain anonymous and confidentiality of your answers will be maintained at all times;

2. Your participation is entirely voluntary and you do not have to respond to every item or question;

3. Neither your enrollment in our program, athletic status, or grades will be affected by refusing to participate or by withdrawing from this study;

4. Audiotapes will be stored in locked files while I am not using them and will be destroyed after completion of this study.

Thank you for agreeing to participate in this interview.

1. What individual goals have you achieved since you enrolled in college?

2. What additional goals would you like to reach before graduation? What other things would you like to accomplish before your graduate?

3. Does this campus environment meet your expectations for college? How or how not?

4. Tell me about the most rewarding/satisfying aspects of your college experience?

5. Tell me about the most frustrating/difficult/challenging aspects of your college experience?

6. What strategies have you developed to help you succeed in the college environment? 
7. What personal (internal) mindset or attitudes have facilitated (promoted) your success in the college environment?

8. What personal (internal) mindset or attitudes have undermined (or have been a stumbling block) to your success in the college environment?

9. Tell me about your most significant or important external supports during your college experience?

10. Describe the characteristics/type of external support or help you have found to be most beneficial?

11. What external barriers or obstacles have you experienced as a college student?

12. As you look back on your college experience, do you believe you have experienced anything like a turning point? If so, could you tell me about this experience?

13. Is there anything else you can tell me that you think would help me to better understand the experience or programming needs of college students who have learning disabilities?

Thank you for your help with this project! 


\section{APPENDIX B:}

Transition Interview Protocol 


\section{TRANSITION SCRIPT}

Good morning (afternoon). Thank you for agreeing to participate in this study. The goal of my research is to understand the transitional needs of first year college students who have learning disabilities and to understand if our current support structure is meeting the needs of students enrolled in the Student Academic Support Services Program. The information gathered here will be used to fulfill part of my research requirement as a doctoral student at West Virginia University and to help me make program changes as needed.

I would like to point our a few things before we start:

1. Your participation is entirely voluntary and you do not have to respond to every item or question;

2. Your responses will remain anonymous and confidentiality of your answers will be maintained at all times;

3. Neither your enrollment in our program, athletic status, or grades will be affected by refusing to participate or by withdrawing from this study.

Thank you for agreeing to participate in this study.

First I will ask you some general questions about the transition to college, then I will ask you for your opinion about some of the supports we have set up to assist the students enrolled in our program.

- [1] What led you to attend Wesleyan?

- [2] How is college different than high school?

- [3] Who or what best helped you to prepare for the transition to college?

- [4] Is there something you wish you knew at the beginning of the year that would have helped you make the transition? 
- [5] What [programs, classes, campus events, or offices have] have been helpful to you in making the transition to college?

- [6] How would you characterize your transition:

Explain.

- What is going well?

- What is not going well?

The next few questions I ask will center on the way the Student Academic Support Services program is set up to help incoming students.

- [7] What do you know about how to go about receiving support, services, and accommodations from the Student Academic Support Services office (this center)?

- [8] Are you able to tell me about the kinds of things you cover in the meetings with your Comprehensive Advisor?

- [9] Show the student each of the handbooks.... Then ask...

- What kinds of information have you found in the handbook?

- What other kinds of information would be helpful to put in this handbook?

- [10] Show the blank letter of disability verification...Can you tell me what you think of showing this letter to your professors? What is your opinion about the accommodation process as we have structured it here? Did you feel prepared to talk with your professors about your accommodation needs?

- [11] Tell me about the strategies you use to understand and learn the material for your courses.

- [12] Is there anything else you can tell me that would help me understand the needs of first year college students who have learning disabilities as they make the transition to college?

Thank you for your help in understanding how we can better serve first year students coming into our program! 
APPENDIX C:

Letter to Potential Persistence Participants 
Student Academic Support Services

November 15, 2004

Dear

You may already know that I am a doctoral student at West Virginia University. The next step in my program of study is to gather information for my dissertation research project.

My area of interest is in building college environments of support for students with diagnosed le arning disabilities. I have already interviewed several students about their transition to college. Now I am trying to understand the supports and barriers students experience as they continue through the college setting.

I believe the best way to understand this is by talking with students about their experience. Since you have achieved success in the college setting and have earned at least 60 credit hours toward graduation, I am inviting you to participate in this study.

I would like to ask you to talk with me about your experience as a college student no matter how trouble-free or difficult your experience has been; this will help me understand the whole picture.

Please let me know if you are willing to participate in a one-on-one interview that will last less than one hour. You are not required to complete this interview; it is voluntary and confidential if you choose to participate. I will also ask you if I may audiotape your interview. Tapes will be kept in locked files and destroyed after completion of the study.

Fill out the form below if you would like me to contact you. You may call or e-mail me at extension 8499/ kuba_s@wvwc.edu to arrange a time to meet.

Thank you for your help with this project. It is important that you know I have received permission from the Research Review Boards at West Virginia Wesleyan and West Virginia University to work on this study.

Sincerely,

Shawn Kuba, M.S., M.A., L.P.C.

Director of Student Academic Support Services

$* * * * * * * * * * * * * * * * * * * * * * * * * * * * * * * * * * * * * * * * * * * * * * * * * * * * * * * * * * * * * * * * * * * * * * * * *$

I would like to interview.

Name__ Campus phone number E-mail

Best times to meet with you Thank you. 


\section{APPENDIX D:}

Letter to Potential Transition Participants 


\section{Student Academic Support Services}

February 27, 2003

Dear

You may already know that I am a doctoral student at West Virginia University. The next step in my program is to design and gather information for a research project that may lead to my dissertation (the final step).

My area of interest is in how students with diagnosed learning disabilities experience the transition to college. I believe the best way to understand this is by talking with students about their experience during the first year.

I would like to invite you to talk with me about how you think your transition to college is going. Some of you have had an "easy" transition and for others, it has been more difficult. I would like to talk with you no matter how easy or difficult your transition has been; this will help me understand the whole picture. Also, the information you report will help me understand how we can improve our program for students with learning disabilities.

Please let me know if you are willing to participate in a one-on-one interview that will last about 30 to 45 minutes. You are not required to complete this interview; it is voluntary and confidential if you choose to participate.

Fill out the form below if you would like me to contact you. You may call or e-mail me at extension 8499/ kuba_s@wvwc.edu to arrange a time to meet.

Thank you for your help with this project. It is important that you know I have received permission from Wesleyan's Research Review Board to work on this study.

Sincerely,

Shawn Kuba, M.S., M.A., L.P.C.

Director of Student Academic Support Services

I would like to interview.

Name Campus phone number E-mail

Best times to meet with you Thank you. 
APPENDIX E:

West Virginia Wesleyan RRB Approval of the Persistence Study 
WEST VIRGINIA

WESLEYAN COUEGE

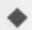

Department of Athletic Training

Re: RRB approval

Congratulations. Your study entitled "Exploration of the Transition and Retention of Students with Diagnosed Learning Disabilities in the College Setting" has been reviewed and approved by the WVWC RRB. Good luck with your research.

Should you make any changes to your study, please notify the RRB as soon as possible. Thank you.

Dr. Jeremy Sibold

Chair- WVWC RRB

304-473-8022

sibold@wvwc.edu
(304) $473-8002$

(304) $473-8056$ F

Rockestliar Center

-

59 Colege Averuse

Surckhamxn

What Whingia $2 \times 291$ 


\section{APPENDIX F:}

West Virginia University IRB Approval of Transition Interview Extension 
W. West VirginiaUniversity

College of Human Resources and Education

April 14, 2003

Ms. Shawn Kuba

21 College Avenue

Buckhannon, WV 26201

Dear Shawn,

The purpose of this correspondence is to approve your request to continue your research project entitled "Exploration of the Transitional Needs of First Year College Students Who Have Diagnosed Learning Disabilities and Have Enrolled in a Special Services Program." The approval is made with the assumption that the interview protocol and procedures that were specified in the original request will be followed.

Good luck with your research project and I look forward to hearing from you if you have any questions in the future. As per our phone conversation today, I apologize for the length of time that it has taken to get approval, but $I$ have a note that indicates that initial approval was given on February 23, 2003.

Sincerely.

Lym R. Cartwright, Interim Associate Dean

College of Human Resources \& Education 
APPENDIX G:

West Virginia Wesleyan College RRB Approval of Transition Interview Extension 


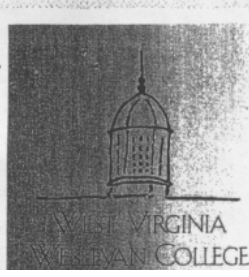

February 14, 2003

Shawn Kuba

21 College Avenue

Buckhannon, WV 26201

Dear Ms. Kuba:

I am pleased to inform you that the Research Review Board has approved your request for continuing use of human subjects in research titled "Exploration of the transitional needs of first year college students who have diagnosed learning disabilities and have enrolled in a special services program." This approval is based upon your interview protocol and procedures as outlined in your submission to the RRB. If you make any changes to your procedures or other elements of the study, please contact us immediately.

Best wishes for a successful research experience. If you have any questions, please feel free to contact me at (304) 473-8044 or johnson_d@wvwc.edu.

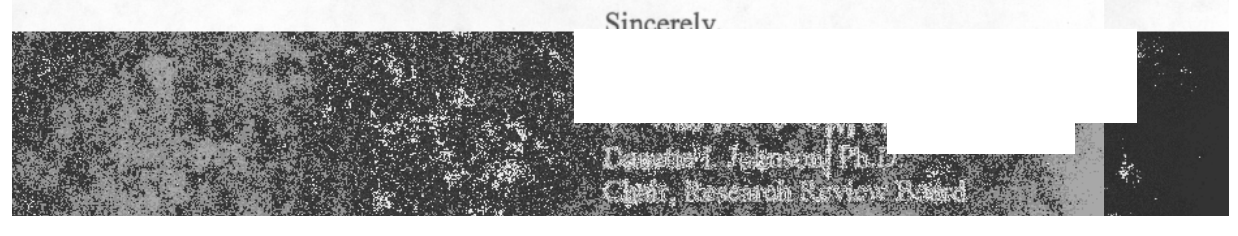


APPENDIX H:

West Virginia University IRB Approval of Exploratory Transition Study 


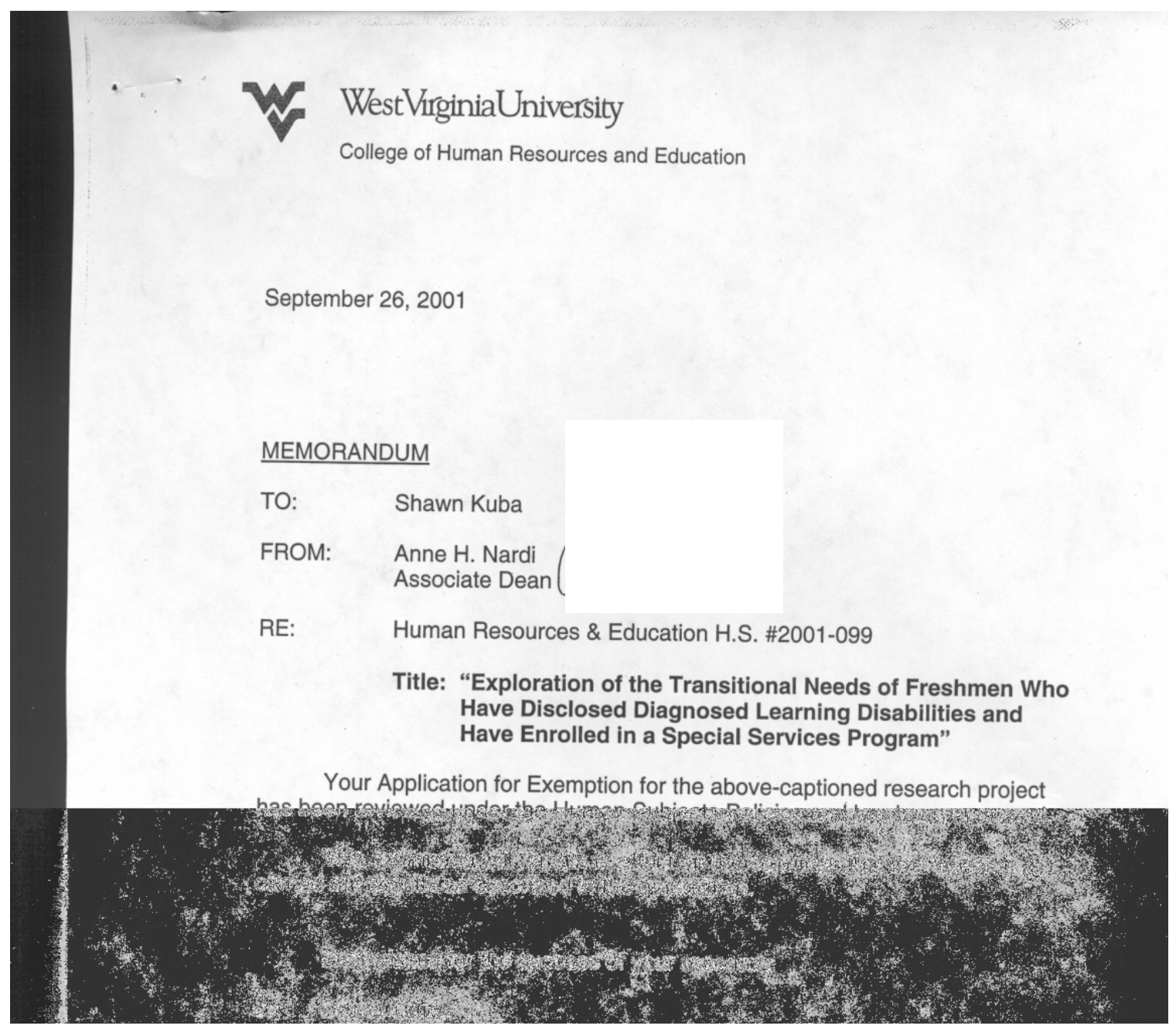


Appendix I

West Virginia Wesleyan College RRB Approval of Exploratory Transition Study 


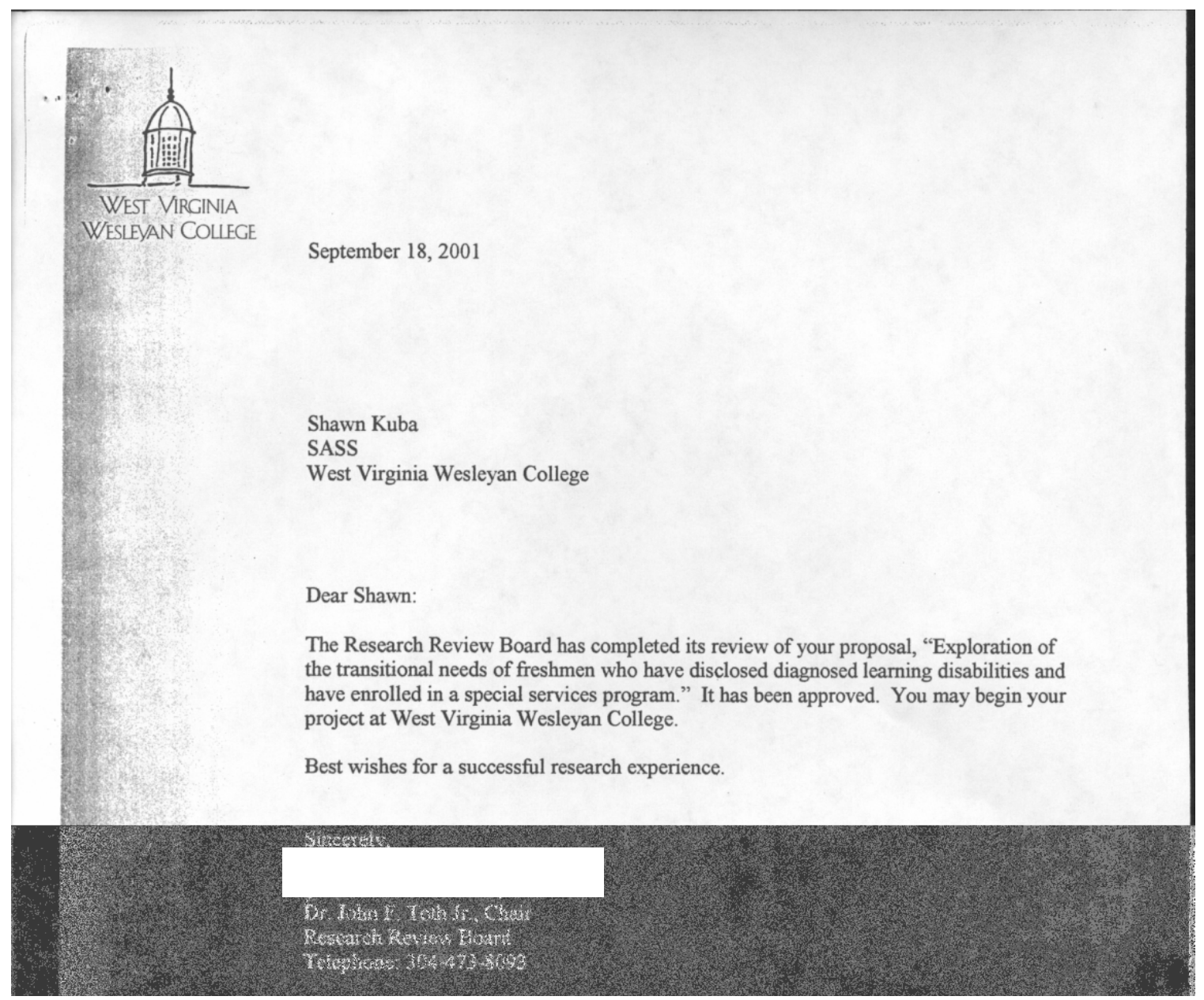




\section{Appendix $\mathbf{J}$}

West Virginia University IRB Approval of Dissertation Study 


\section{West VirginiaUniversity}

College of Human Resources and Education

November 17, 2004

\section{MEMORANDUM}

TO:

Shawn Kuba

FROM: Lynn Cartwright

Interim Associate Dean

RE: Human Resources \& Education H.S. \#2004-083

Title: "Exploration of the Transition and Retention of Students with Diagnosed Learning Disabilities in the College Setting"

Your Application for Exemption for the above-captioned research project has been reviewed under the Human Subjects Policies and has been approved.

This exemption will remain in effect on the condition that the research is carried out exactly as described in the application.

Best wishes for the success of your research.

cc: Deans Office

Student Advising and Records

Neal Shambaugh 
Appendix K:

Sample of Initial 25 Transitional Themes and

\section{Coding Process}


Came because of program

Running transition themes

Difference between H.S. and College

Preparation for college

Social isolation and social acceptance

Freedom, flexibility within the environment

Learning more about how to handle the LD and dealing with the LD

Proactivity to gain control (see Frostig study, 2004)

Anxiety about college (express need for emotional support of some type)

Stress relief

Help for transition other and program/services for students with LD

Problems in transition

Good stuff in transition positive/favorable/beneficial

External complaints about the environment

Academic help/Accommodations

Help with stuff besides academic accommodations and strategies

Mentor

Accommodation request process/ self-disclosure

Basic strategies for success

Suggestions to improve services

Parents role in experience

Self regulation

Painful experience

Resilience/determination

Academic self-concept

Miscellaneous 


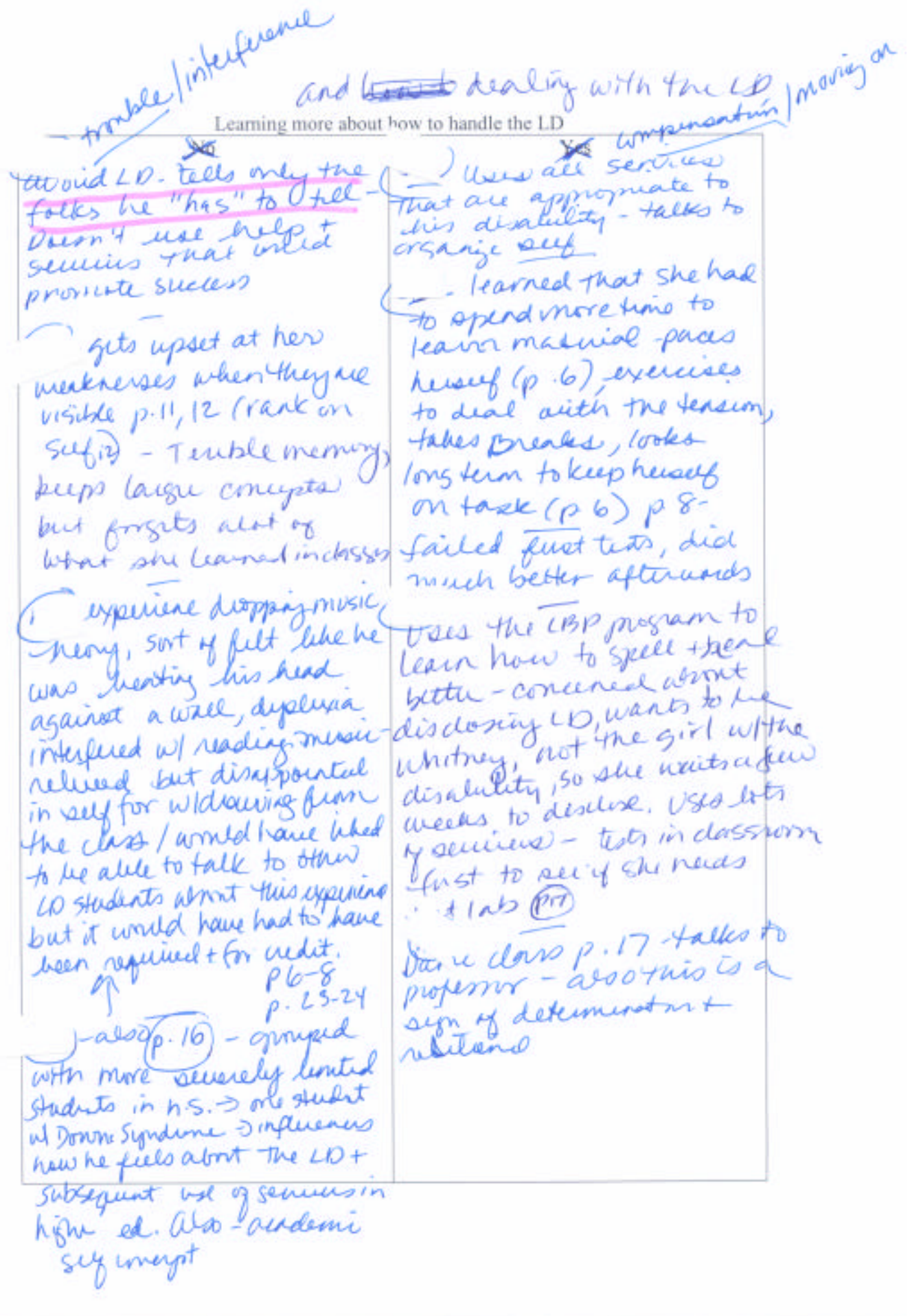


Learning more about how to handle the LD/Dealing with the LD

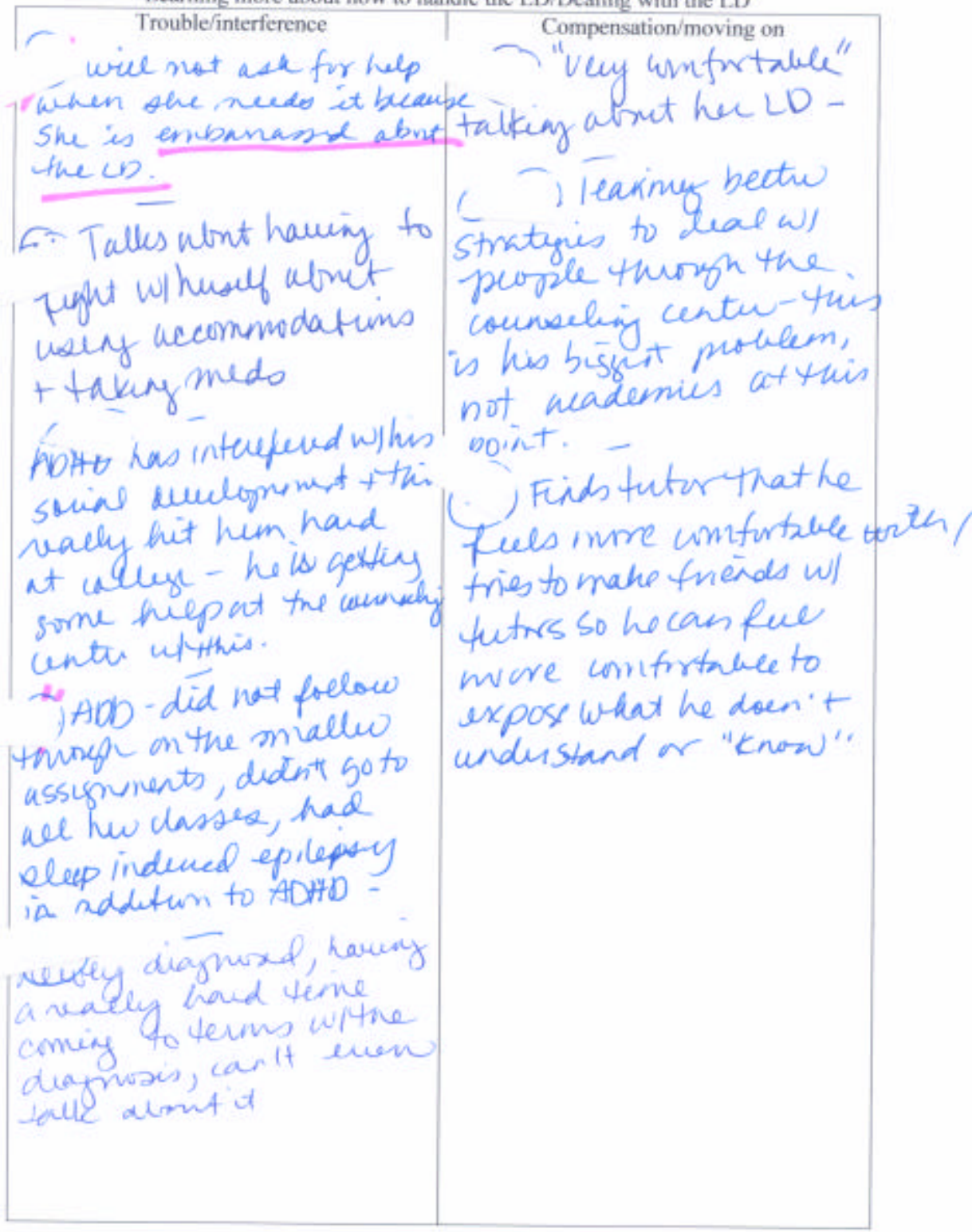




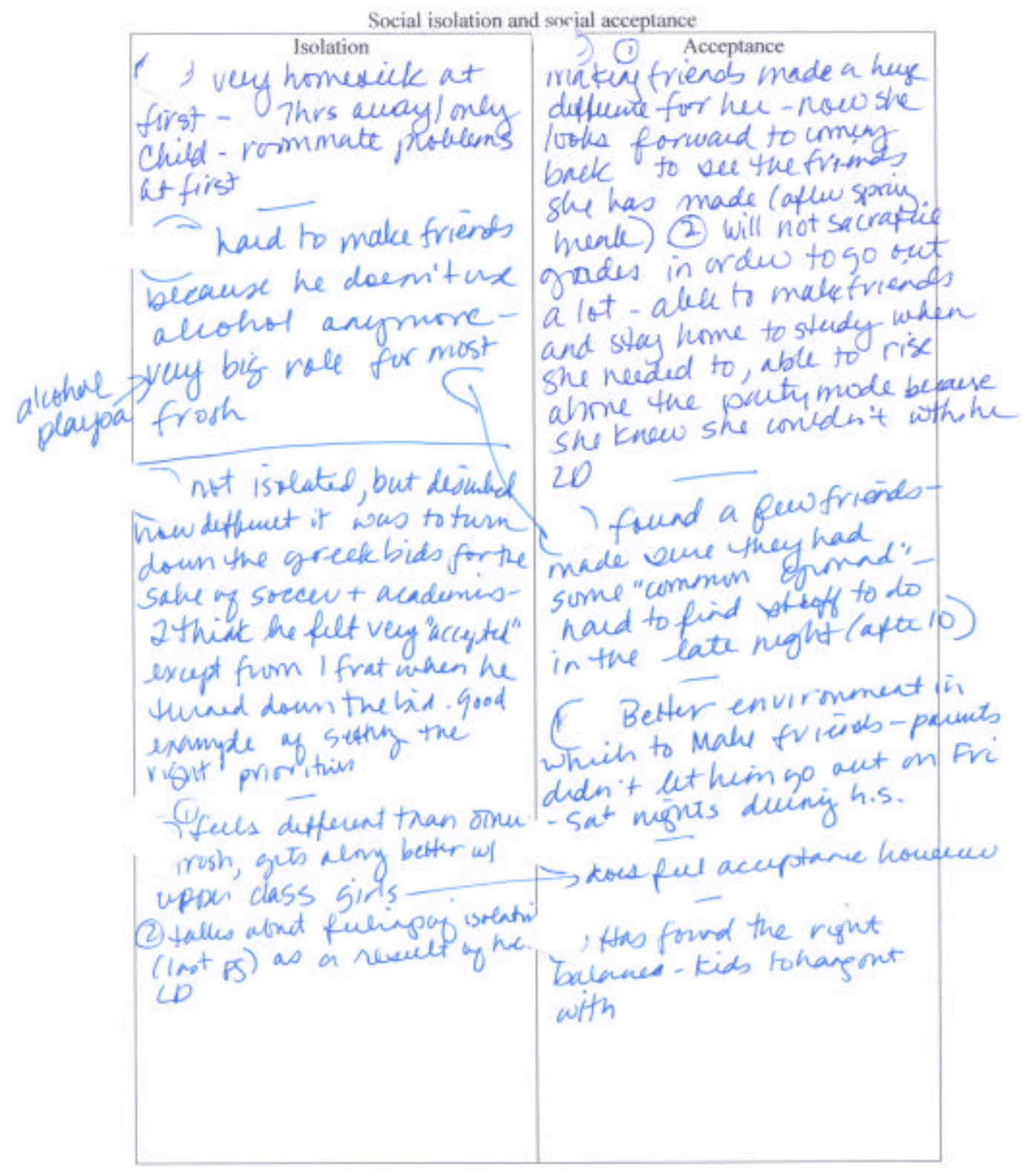


Leaming more about how to handle the LD/Dealing with the LD

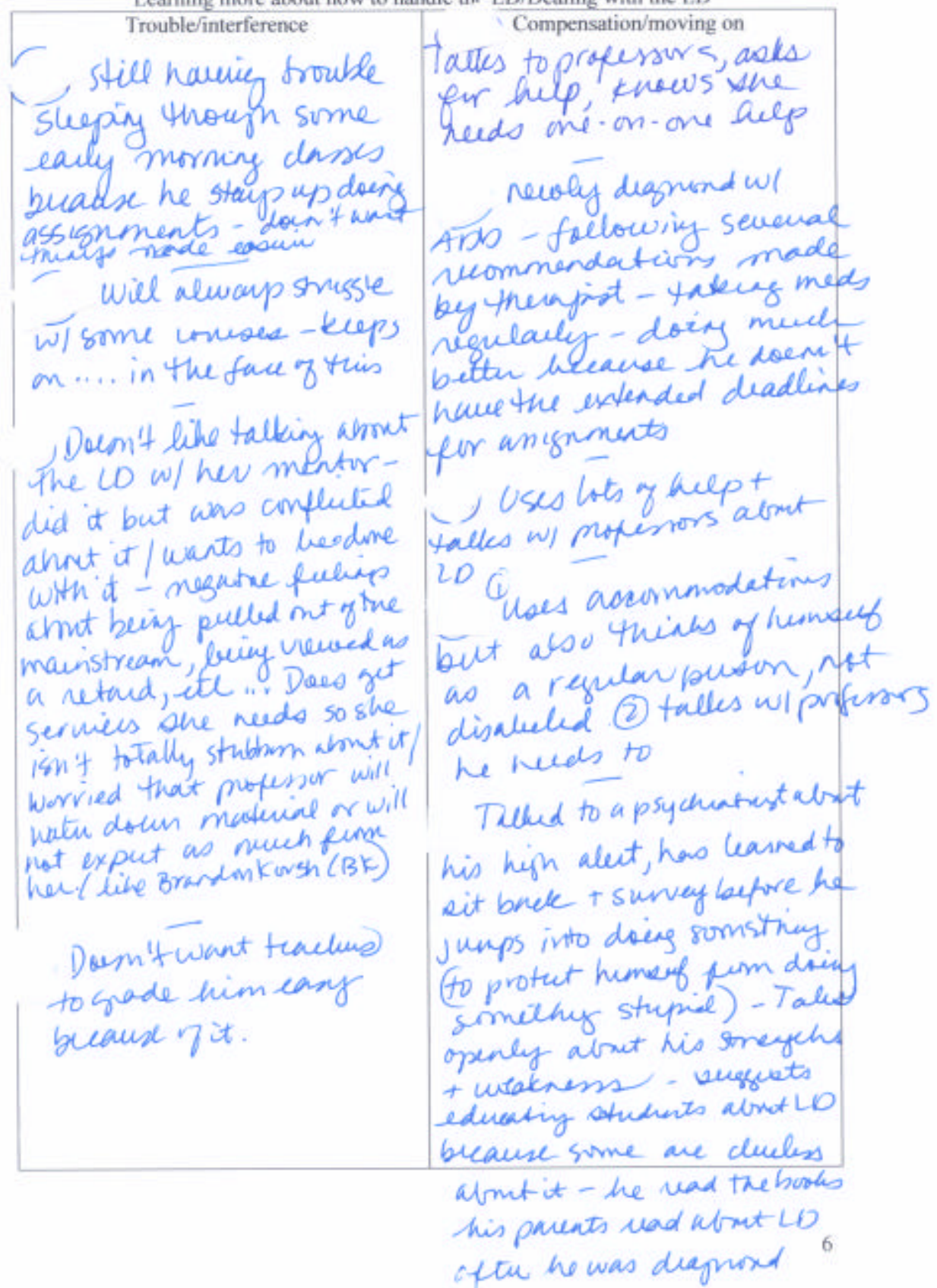




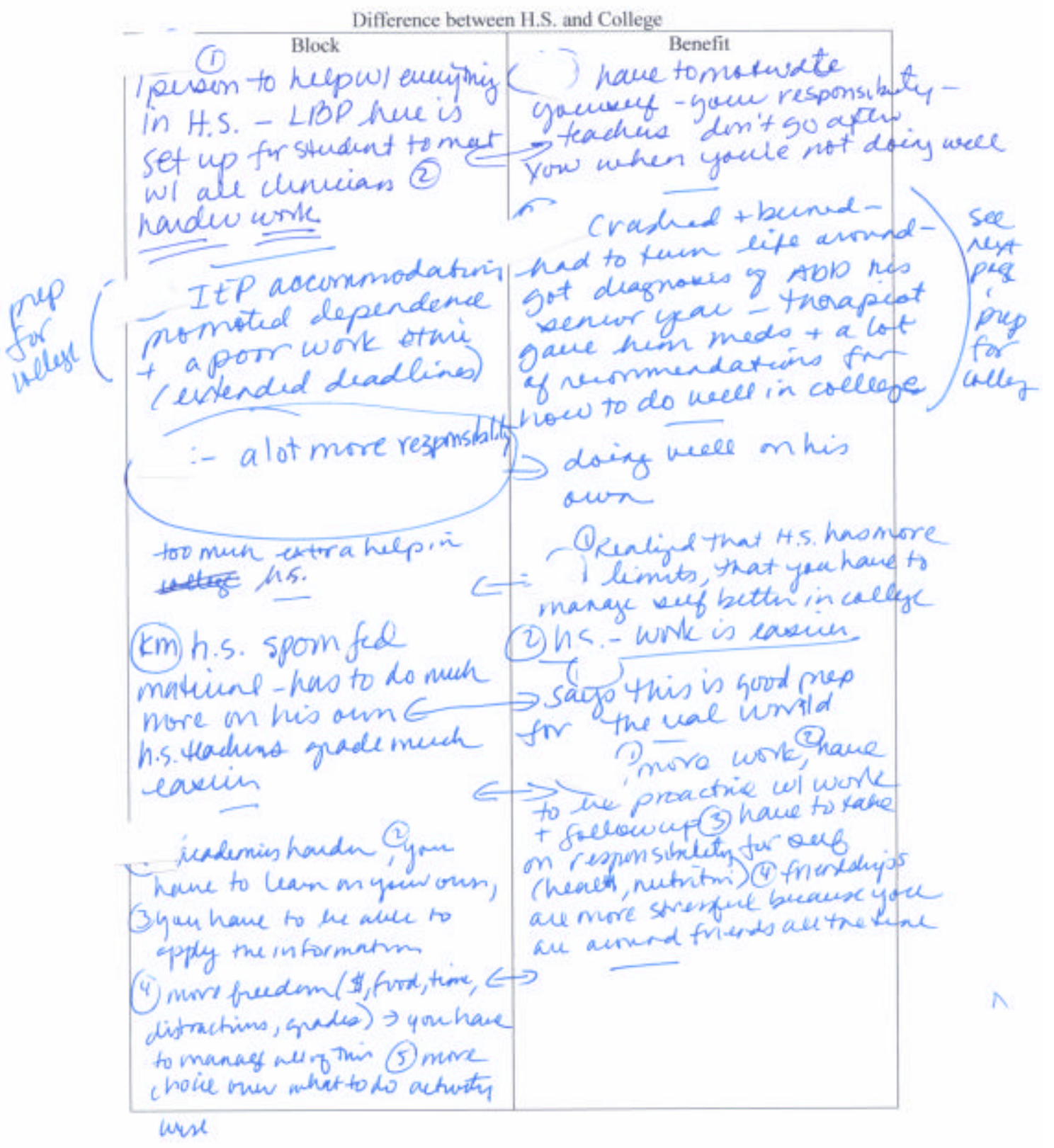


Appendix L:

Sample of Persistence Coding Process: Running themes to internal facilitation 


\section{Running Analysis of persistence cohort}

Goals

Take on a leadership position in the frat

Wants to find a career goal

Good GPA to get into frat

General goal to finish college

Academic good GPA

Figuring out a major:

Made friends in college:

Figure out the future/becoming independent

Succeeding in college

Good grades in adversity, friends, communicating with professors

Employment

Grades, getting though classes successfully

To continue with school even though her dad died

Academic and career goals

Academic goals related to major

graduation, varsity swim, sorority

good grades, graduating in 4 years/keeping up with sib

grad school/jobs

graduate and learn from my classes

Senior project, learn more

Function with OCD away from home

Wean self away from services before graduation

Dropping accommodations last semester senior year

academic success

independence and able to apply major in the real world

Strategies

Negative case (JP) figure out what needs to be done on finals

Social strategy to stay neutral:

Strategic to cut down on drinking

Being responsible with his time and work/social networking

staying in touch with the professor

Be organized first and everything else follows

Pace yourself

Reading the teacher

Constant review to learn general studies information

Turning points

Decision not to drink as much

positive outlook on life, job, likes learning

feeling at home with the College

sense of brotherhood in the fraternity

the accomplishment of finishing each year

improving communication skills

Understanding her learning disability and working to overcome it

Diagnosis/understanding there was a problem

Following through with her career dream

Academic success

High GPA caused her to think about grad school

Reinforcement of transitional findings

Small community atmosphere helped him (JP)

Small community atmosphere

Social growth and integration

Sense of community: 
Small community is less intimidating

Socially integrated, open to help, pos:

Open about problems

Sense of being in place in academic department, team and sorority

small community

Motivational problems

Negative case - (JP) stayed away form using services and mentor

small community

Emerging findings

Evolution of life style

Maturation over the experience

Grow out of fraternity

Decis ion to cut down on drinking

Likes who he's become

Relates problems or personal preferences with the way he reacts in his life (JP doesn't come to see mentor because he doesn't respond well to nagging parents)

Notices change as a result of college:

Social growth:

Improvement, more thoughtful/growth over the experience

realization of growth

How she has grown as a result of being in college

personal transformation

Satisfying experiences

Dean's list/finding the right major:

Recognition for good art wo rk:

Frustrating experiences

Realizing she couldn't finish the major and switching over:

Problems keeping roommates:

Adversity turned around/Hard class helped her be successful

figuring out a major

changed majors because of a professor

changing majors

External facilitators

Faculty interest in the students (Rupp, come see me after first test)

parents - work on not pushing too much

mentor - helped him develop an internal measure of success...

family -sister encouragement

Language processing program:

Not critical and encouraging but firm support:

Love and acceptance/type of support suggested

fraternity support

fraternity brothers who model academic success

Professor challenged him to stay or leave the major

Reflection on the professor's challenge (could be internal)

Parental expectations

Accessibility of Test Lab

patient, constructive help and feedback

cooperation between support system and faculty/clear guidelines on how to use the support system

Services and accommodations/helpful faculty

Professors are helpful

Professor encouragement/helped her navigate her response to a bad grade

Structured program

Mentor help

Friends:

Characteristics in a helper/patience

Train faculty 
Accommodations and services

Challenging classes

Campus involvement with the community helped her feel involved

Help from upper-class students in the major

Language tutoring

Student support within the majors

Helpers who care about the whole person, not only academics

Helpers who are empathic and have had similar experiences

Continued peer mentoring for first year students

Language tutoring

Summarizing services into a one page document for first year students

Emotional support

Supportive environment of the LD program

Supportive feedback from professor

Sorority

Support from family and friends at home

People who care

understanding, patience, know about the disability

first year students need someone to talk to/LD mentor

the structure of a varsity sport

High school helped prepare her for college

friends act as helpers

support service

Language tutoring/application to coursework

mentor from the LD Program

Parents support

LD support/family support

Raise awareness of learning disabilities

department faculty are smart and engaging

Structured practice in the major

Supportive parents and to prove he can do it

department facilitates career opportunities after graduation

Use of accommodations

Working with mentor from support program to resolve problems

Characteristic of a good helper/available and leads the student to the answer:

extra time to graduate if needed

careful introduction to individualized services by the mentor

Accommodation friendly academic department

Faculty advisor had high expectations

Helper had confidence in her

mentor helps adjustment

Parents encourage transition of help to college mentor

Helper teaches independence

independent internship experience

help students think positively about being able to handle college

Internal facilitators

Stay in school so he can get a better job, wants the degree

Thought about a better job/the future

Stubbornness to combat the negative predictions and worry about finding and keeping a job

Get help/go to class/talk to teachers

Determination:

Wean self from services that facilitated success:

Thoughts of future employment

Learning to speak her mind

Attitude that I can do well in college/effort

Takes what comes and goes with it 
Learning the professors' teaching style

Aware of how she learns/Talking with professors/Not taking notes

Going to all classes

Making use of accommodations and services

Expectation of lower grades

Working out the issue of grade performance

Finding a adoptive family while away at college

Intrinsic interest/values what she was learning

Constructive breaks/other interests

Being okay with getting help

Getting emotional support shifted her life

Thoughts of her dad as a teacher inspire her to continue

Working through her father's death/bearing up/continuing

Use of academic strategies and medicine

Pushing through the uninteresting/difficult classes

taking the lead in getting diagnosed/accepting the disability

talking herself through the stress

Self-talk to handle problems

pretending not to care

defensive pessimism

thoughts of father to stay motivated

knowing how your LD affects you

participation in a varsity sport as a stress reliever and a place of full

competence:

persistence:

asking for help

self-advocacy

Anchoring successful experiences

growth in academic confidence, self-talk to neutralize public speaking fears

managed time by studying ahead and long hours

test preparation

study on weekends

self talk to increase confidence

Finding a social life at a small school without joining a fraternity

persistent study strategies

persistent effort

Handling worry and stress

Handling worry and stress

using the support program

deciding not to move to the next class in a sequential curriculum for lack of background:

Balance and relax to work better

assuming that you can through thinking and self-talk

taking action to adjust to college

\section{Internal barriers}

Self talk - I'm not smart; school isn't for me

Motivation - start off well, lose motivation after test grade is lower than expected

Perseveration/holding on without good sense

Trying to prove herself:

Self-management problems

Lack of effort:

Lack of effort in courses outside of his major interest:

Putting off assignments when he is overloaded

Guilt over the cost of her education and special support

performance concerns

not talking about problems

First years students need support even though they don't want it 
not being able to stay with a task on a test:

processing time/extra time for testing

Limitations of the LD

frustration over the limitations of the $\mathrm{LD} /$ comparison to sibs and parents

Low confidence

general studies classes

disability impacts performance on general studies tests

Difficulty memorizing compared to other students

worry about performance and the future

having to be perfect

External barriers

Friends - time away fromacademics

Fraternity/organizations - time away from academics

Very difficult textbook

Doubting the student's potential/adversity turned around

Solving the external barriers of uncooperative professors and time on the Kurzweil reader and the time crunch for proofreading a paper that was assigned at the last minute

Difficult classes become rewarding

General studies' requirements

Family problems

Poorly scheduled study sessions

Time constraints

Her father's recent death

Heavier workload

Dealing with courses that she finds uninteresting and difficult

Dealing with academics prior to diagnosis

feeling sad about the death of her father

Personality conflict with instructor

Not enough time to complete assignments

not enough time to do everything

professors who don't understand the experience of being LD

testing format

Challenge of being on a varsity team

The press to socialize

General studies classes - okay in the end, worked through them

determination of referral for evaluating LD in public school system

getting used to the academic environment and using help

faculty baulking at testing in the Test Lab

uns tructured teaching 


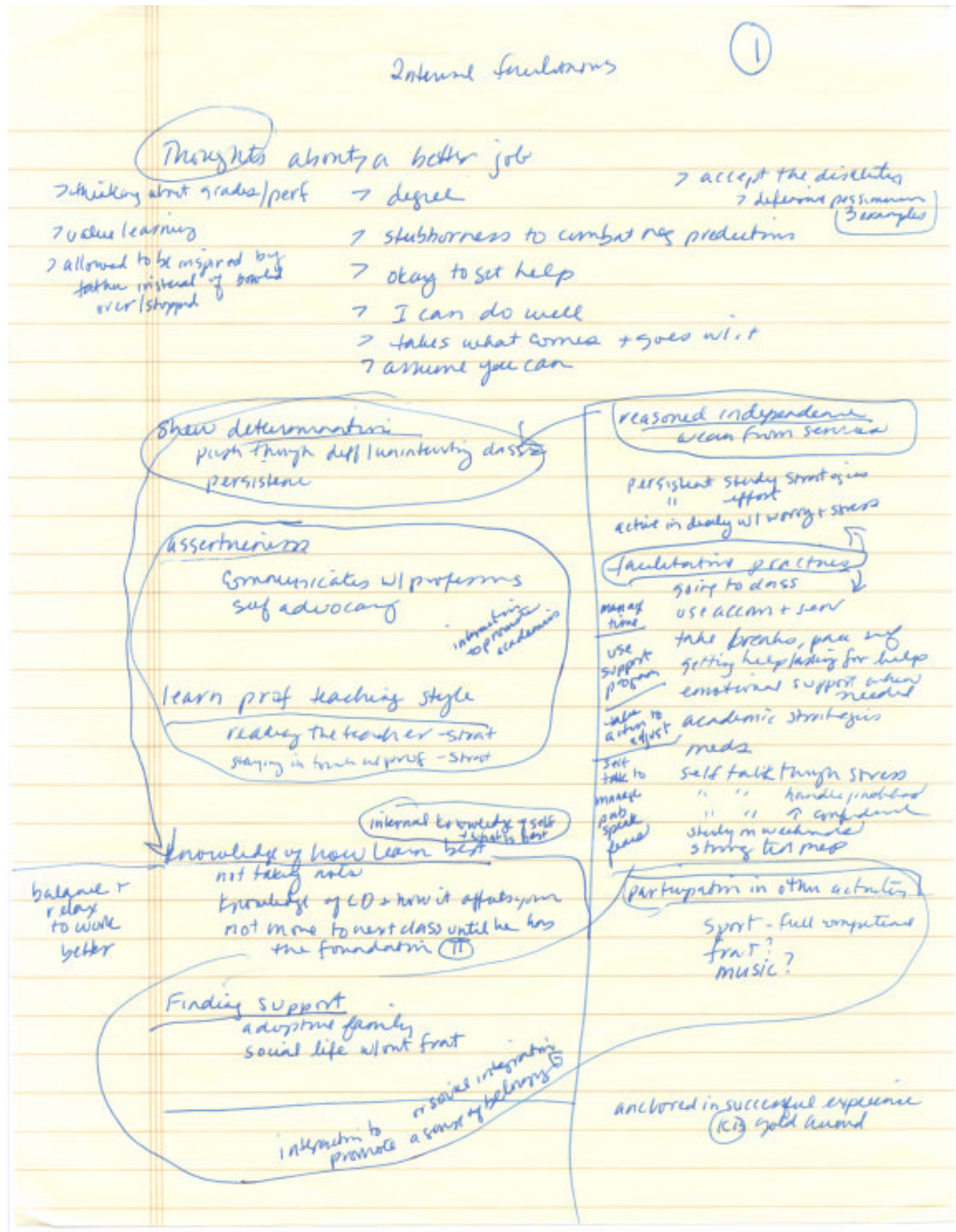




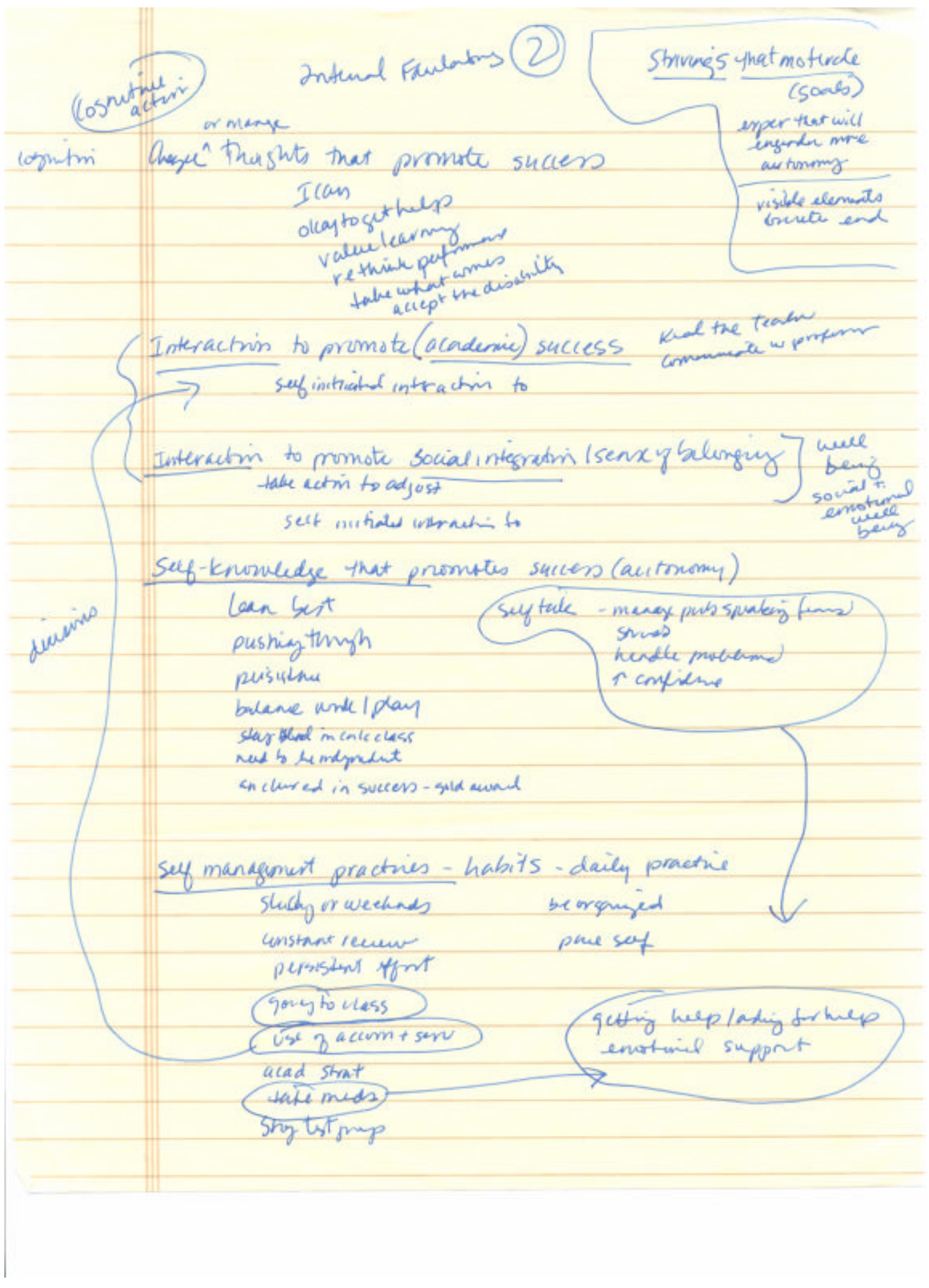




\section{Internal fouletatios}
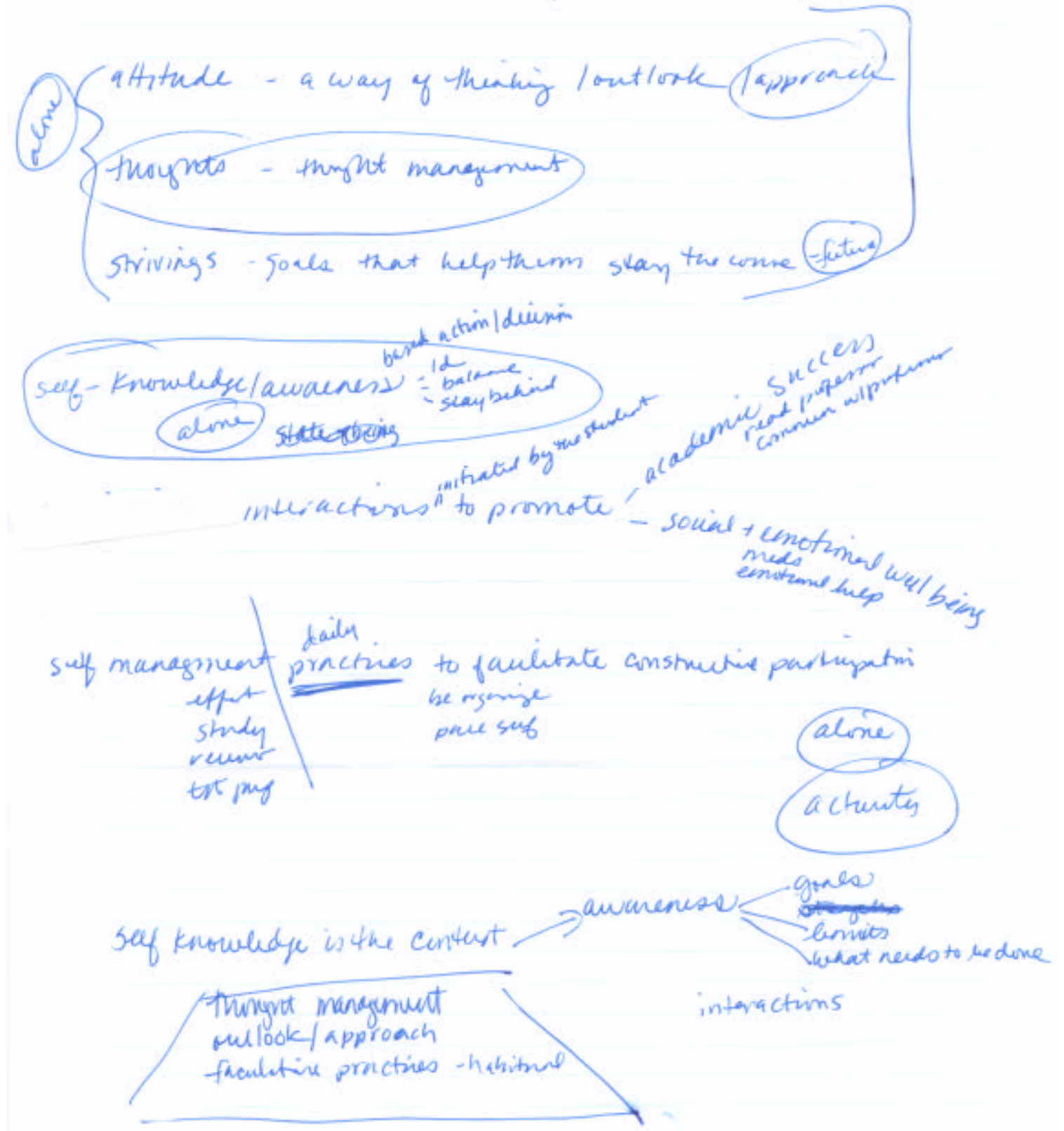

interactions 

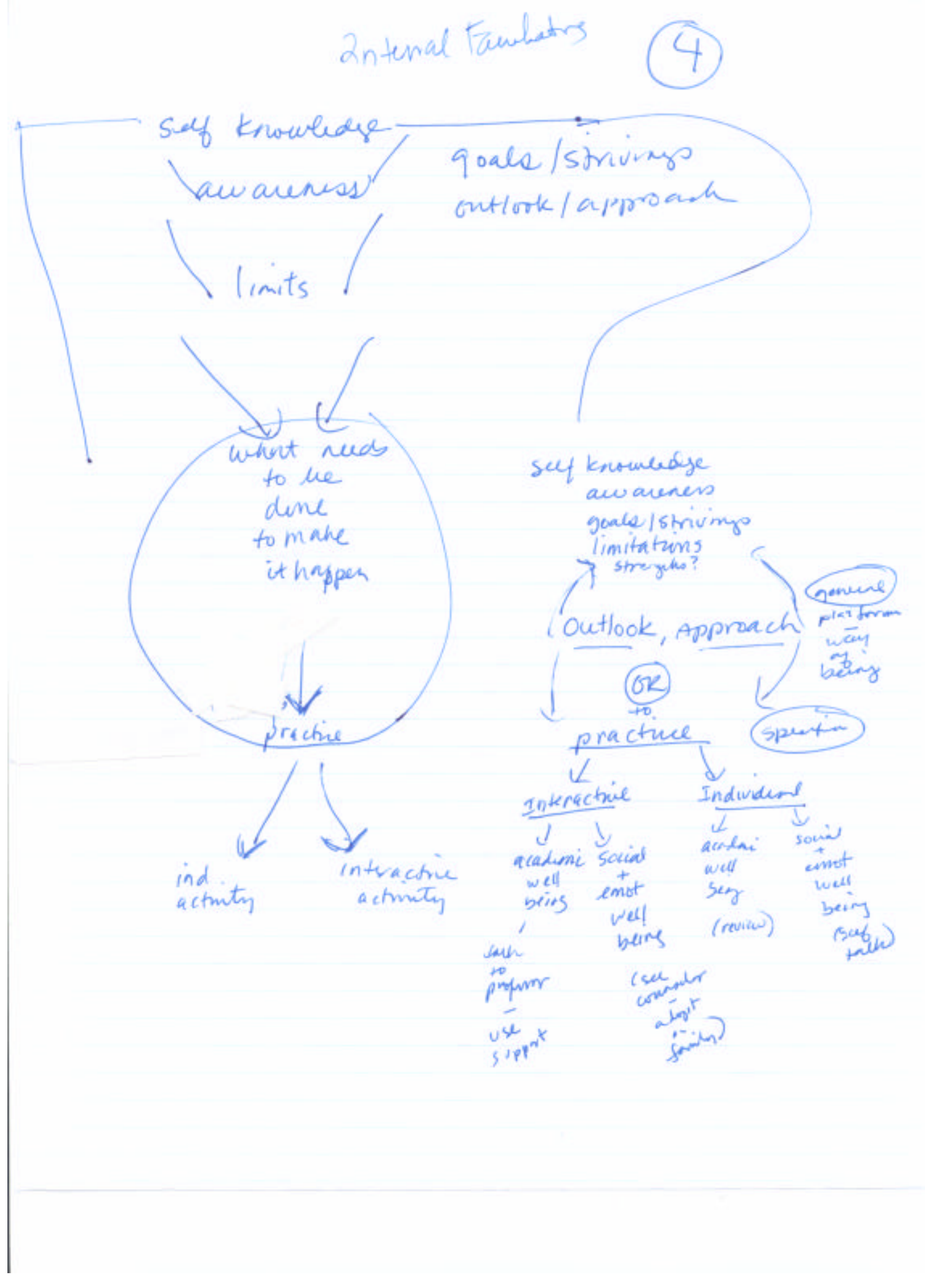
Appendix M:

Samples of Audit Trail 


$$
\text { (audit) procers } 4 \text { analysis }
$$

$0^{5}$ tork hots on the areas wheyen $L 0$ intersects

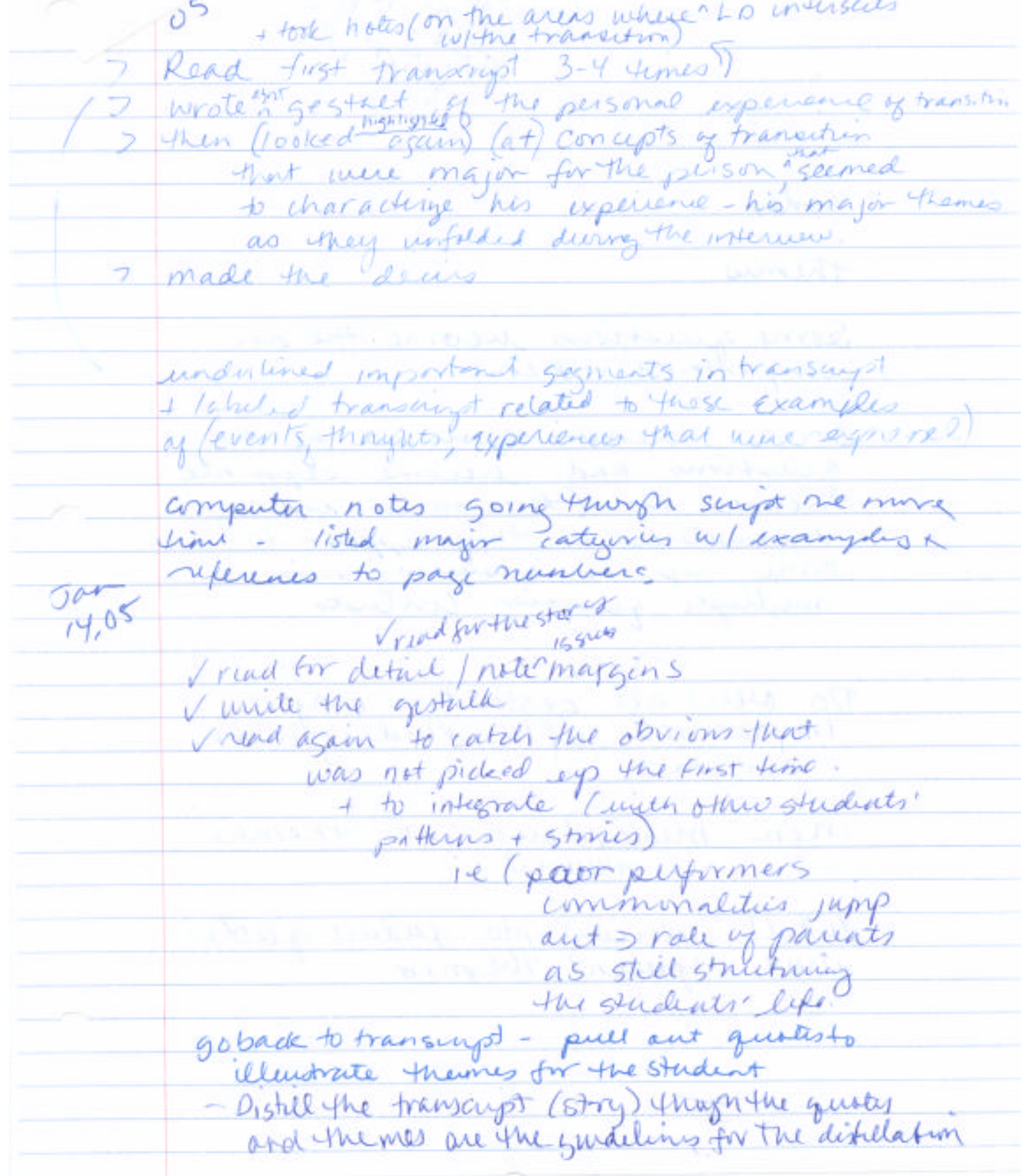


Notes on the proass

$$
\begin{aligned}
\text { oweall wing of basic content categories } \\
\text { preparation } \\
\text { diff betman } h s+\text { collese } \\
\text { handling the } \angle D \\
\text { solial noceptene } r \text { isolation } \\
\text { etc... }
\end{aligned}
$$

loded ael traneition tranaciysts according to the anmee main calegries-condensed each stadent's trasciupt according to these caterris Then-2 follound mey hanch that students w/ hish + low LPS umed falt devilue ditheunt inin expiniens diffently - there sumed to the some ratical differemes in thiw appoach to navgating the envirmment

Then - 2 decired to track the GPAs mew the Remestus inulled and devided the students by acdemic succes:

(4) Iow punctuniz $(1 \operatorname{sem}<2.0$, cum GPA hovering around $a 2.0,<2.3$ )

(B) high effetunating (cum WPA 73.0 aftu The most veent eem of enrollmut

(C) middle etfecture functiony (cum G.PA $>2.5,<2.99$ aptu the most revent semestur of

Then 2 took the LF Condense transciupts and looked for themes asain for this guryping alone (there mere 6) and I came out w/ oeverae commonalitis in their expeniene:

$>$ not acceping the $C D$

2 wanting to he independent of heep

2 lots of talk ahme authoity figins

then I intessated ill astrations of these themes wi the thenes 
Analytic Prows

splat up the grins lay gPA (kid if) kish furctimy case (6) middle of the road (10?)

GL explain how he is ananomoly ${ }^{(24)}$

did themes for negative cases by renewing cases caufully

categorized examples of themes, wrote up the finding and reurnkid themes as appromate

wrote up neg care funding

Went to 6 high functioning Students revered them caufully started to sinuate multiple thanes gimped their theirs into conceptual categories

contrast il them w/regcase conceptual categories

review the middle of the road sip. still successful - see if there are major differences -reurdid additional themes

531 